\title{
Time, temperature and frequency viscoelastic behavior of commercial polymers
}

\author{
Michael John Julius
}

West Virginia University

Follow this and additional works at: https://researchrepository.wvu.edu/etd

\section{Recommended Citation}

Julius, Michael John, "Time, temperature and frequency viscoelastic behavior of commercial polymers" (2003). Graduate Theses, Dissertations, and Problem Reports. 1324.

https://researchrepository.wvu.edu/etd/1324

This Thesis is protected by copyright and/or related rights. It has been brought to you by the The Research Repository @WVU with permission from the rights-holder(s). You are free to use this Thesis in any way that is permitted by the copyright and related rights legislation that applies to your use. For other uses you must obtain permission from the rights-holder(s) directly, unless additional rights are indicated by a Creative Commons license in the record and/ or on the work itself. This Thesis has been accepted for inclusion in WVU Graduate Theses, Dissertations, and Problem Reports collection by an authorized administrator of The Research Repository @ WVU. For more information, please contact researchrepository@mail.wvu.edu. 


\title{
Time, Temperature and Frequency Viscoelastic Behavior of Commercial Polymers
}

\author{
Michael J. Julius \\ Thesis submitted to the \\ College of Engineering and Mineral Resources \\ at West Virginia University \\ in partial fulfillment of the requirements \\ for the degree of \\ Master of Science \\ in \\ Mechanical Engineering \\ Ever J. Barbero, Ph.D., Chairman \\ Jacky C. Prucz, Ph.D., Associate Chairman \\ Victor H. Mucino, Ph.D., Professor
}

Department of Mechanical and Aerospace Engineering

\author{
Morgantown, West Virginia \\ 2003
}

Keywords: creep, time-temperature superposition, frequency-temperature superposition, polymers, aging 


\section{ABSTRACT}

Time, Temperature and Frequency Viscoelastic Behavior of Commercial

\section{Polymers}

\section{Michael J. Julius}

This work involves an experimental investigation of creep behavior of commercial polymers with emphasis on characterizing the effects of physical aging, temperature, and frequency. The test specimens are cut from polymer samples that are used as encased liners in deteriorated sewer pipelines. The procedure for finding the shift rate, $\mu$, is based on Struik's protocol. Time- temperature superposition (TTSP) of shortterm data, at different temperatures, was done. The master curve obtained is shifted to the desired test temperature and desired initial age. Effective Time Theory (ETT) is used to find the effective time, $\lambda$, as a function of real time, $t$, from the master curve obtained by TTSP. This gives the long-term behavior of the polymer samples at the desired temperature. A mechanical conditioning procedure was introduced to obtain repetitive results.

Dynamic Mechanical Analysis (DMA) tests were done to get complex relaxation modulus, $E^{*}(\omega)$, as a function of frequency. Frequency Temperature Superposition (FTSP) was done to extend the frequency range. Mathematical transformations from the frequency domain to the time domain were done using a proposed empirical equation and data was compared to the TTSP data. The analytical relationship is given in the form of $0 \sim$ infinity. However, it is very difficult to get either very small or very large time during testing, thus providing justification for performing TTSP and FTSP. 


\section{DEDICATION}

This thesis is dedicated to my parents Mrs and Mrr. C. K. Julius and my sister Zelma

Julius, without whom's support and prayers this wouldn't have been possible. Thanks. 


\section{ACKNOWLEDGEMENT}

I would first like to thank God for helping me in every difficult situation and being there every time I needed him.

I would like to thank Dr.Ever J. Barbero, whom I have always admired for his intellectual skills, for giving me the opportunity to work under him as a Graduate Research Assistant and finish my thesis under his guidance. I would also like to thank Dr. Jacky C. Prucz and Dr. Victor H. Mucino for serving on my committee. Thanks to Dr.Rakesh Gupta for allowing me to use his test equipments. Thanks to the National Science Foundation and the Pipe Rehabilitation Council for funding this project.

Thanks to Shalini Rangarajan, Kevin Ford, and Ziheng Yao for being of constant help during the project. I would like to thank Edward Wen, for helping me in the initial stages of the project.

I would also like to thank all my friends for being there when I needed them and for all the fun that we had during our study away from home. Special thanks to my roommates for enduring me and making me feel at home away from home. Thanks a million.

Finally I would like to thank the Government of India and the United States for giving several others and me the opportunity to pursue our higher studies and widen our knowledge. 


\section{TABLE OF CONTENTS}

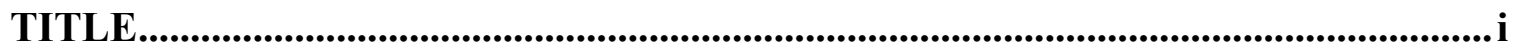

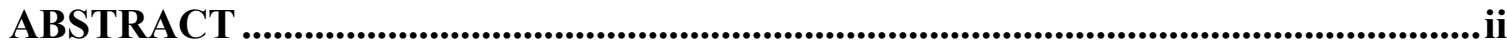

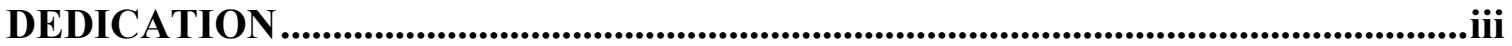

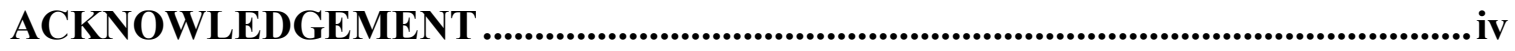

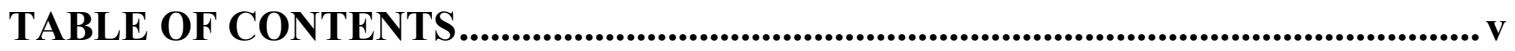

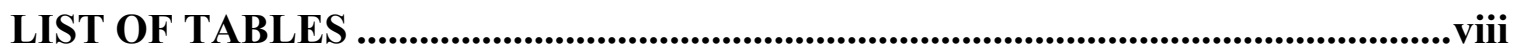

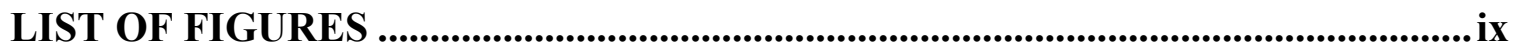

CHAPTER 1: INTRODUCTION AND LITERATURE REVIEW .......................... 1

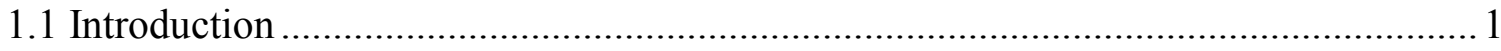

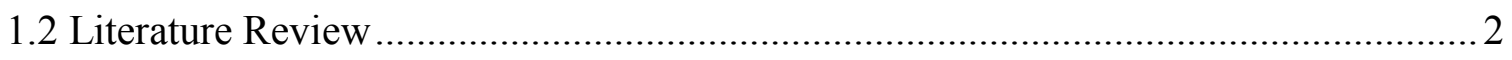

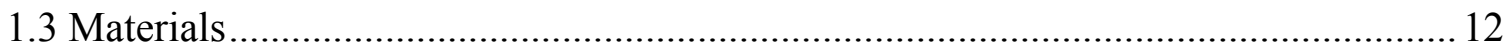

CHAPTER 2: AGING STUDY ....................................................................................... 14

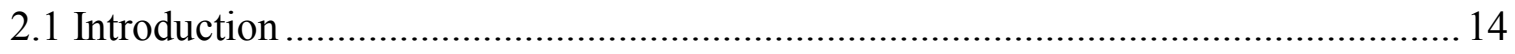

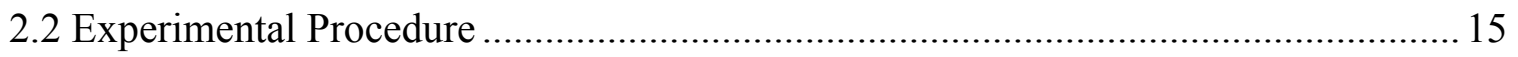

2.2.1 Apparatus And Testing Machine............................................................. 15

2.2.2 Test Environmental Conditions............................................................ 15

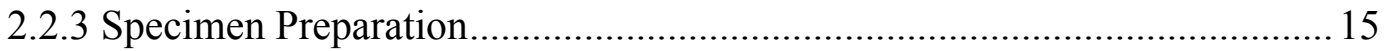

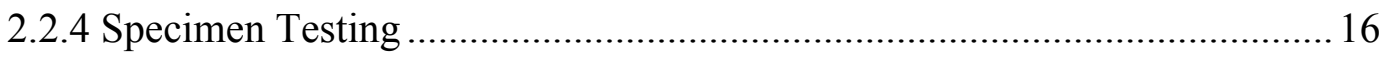

2.3 Experimental Results And Data Interpretation ................................................. 17

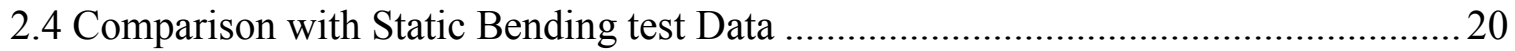




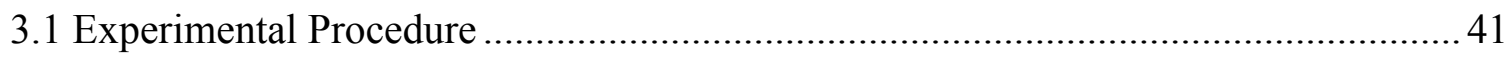

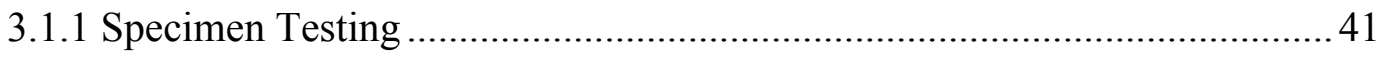

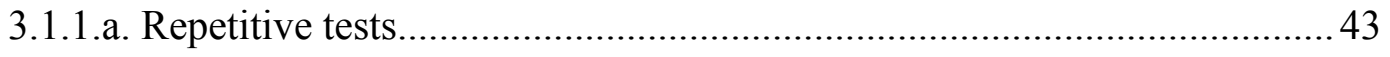

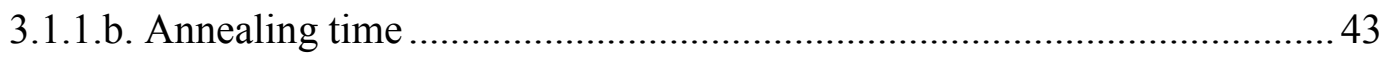

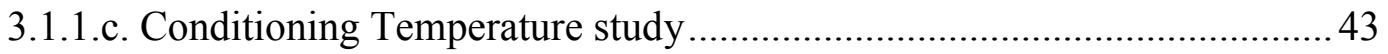

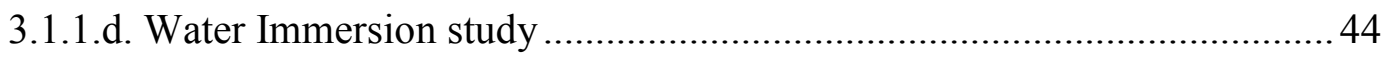

3.2 Experimental Results And Data Interpretation ...................................................... 44

3.3 Comparison with Long term bending data and temperature effects .....................46

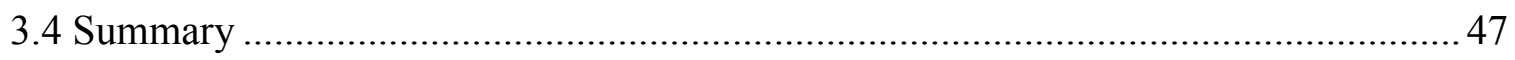

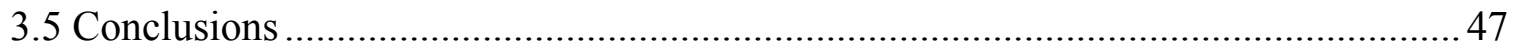

\section{Chapter 4: PREDICTION OF FULL-SCALE RESULTS USING SHORT TERM}

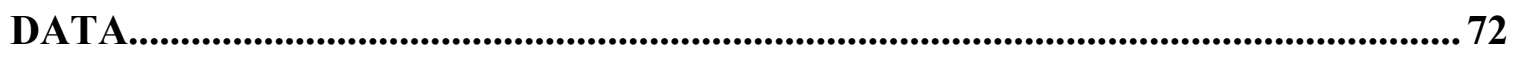

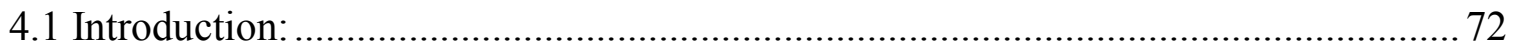

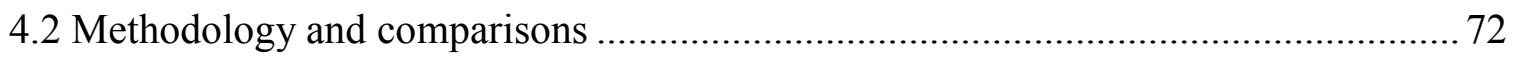

4.2.1 Shifting for Temperature and initial age ................................................. 72

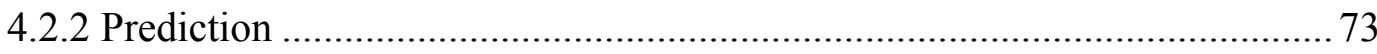

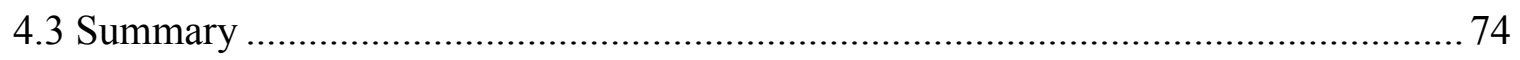

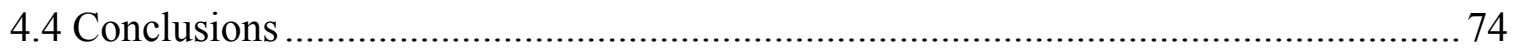




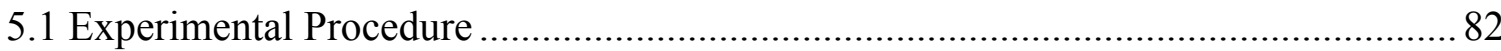

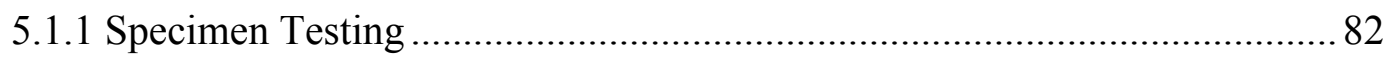

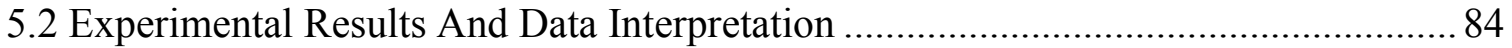

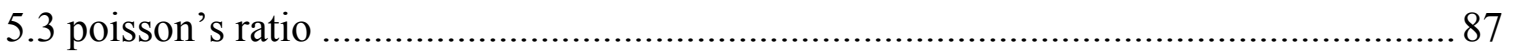

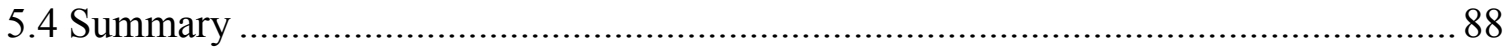

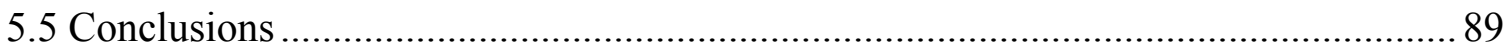

Chapter 6 SUMMARY AND RECOMMENDATIONS ........................................110

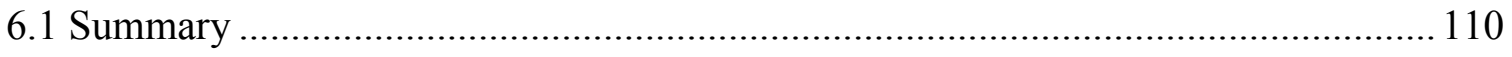

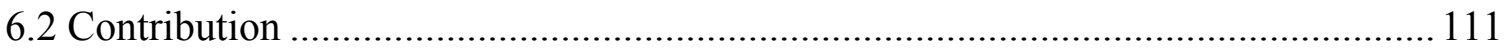

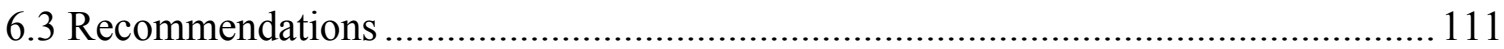

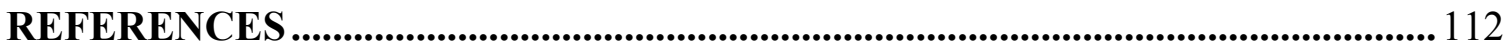

Approval of Examining Committee........................................................................ 115 


\section{LIST OF TABLES}

Table 2.1 Value's Of Shift Rate, $\mu$, for every material ............................................... 23

Table 2.2 Glass Transition Temperature $\left(\mathrm{T}_{\mathrm{g}}\right)$ and Annealing Temperature $\left(\mathrm{T}_{\mathrm{a}}\right)$ for every

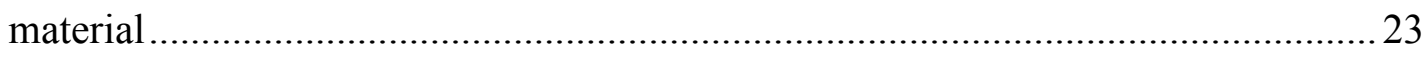

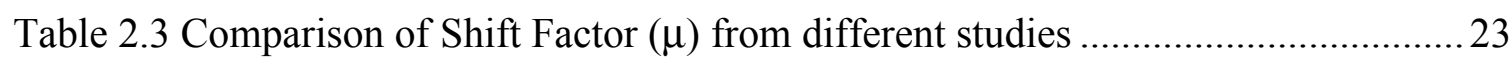

Table 3.1 Change of weight of specimen after immersing in water (Material A) ...........49

Table 3.2 Change of weight of specimen after immersing in water (Material B)............ 49

Table 3.3 Change of weight of specimen after immersing in water (Material C)............ 49

Table 3.4 Change of weight of specimen after immersing in water (Material D) ...........50

Table 3.5 Change of weight of specimen after immersing in water (Material E)............ 50

Table 4.1. Initial physical age of the full-scale samples and their corresponding shift

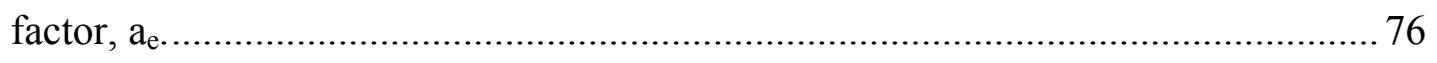




\section{LIST OF FIGURES}

Fig 2.1 Momentary creep curve without discarding initial points (Material A) ..............24

Fig 2.2 Momentary creep curve after discarding initial points (Material A) ................... 24

Fig 2.3 Momentary creep curves (Material A) .......................................................... 25

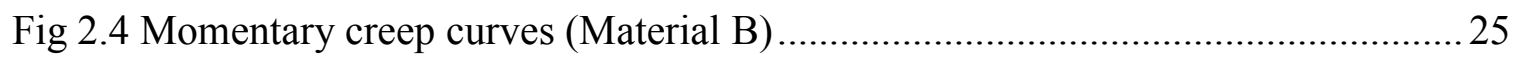

Fig 2.5 Momentary creep curves (Material C) ...................................................... 26

Fig 2.6 Momentary creep curves (Material D)......................................................... 26

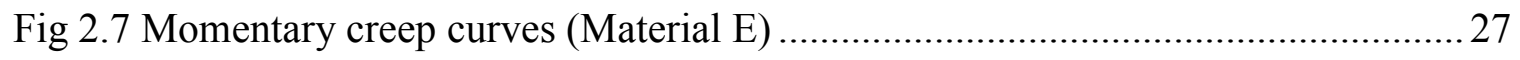

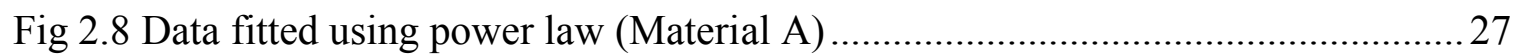

Fig 2.9 Data fitted using power law (Material B) ....................................................28

Fig 2.10 Data fitted using power law (Material C) ................................................. 28

Fig 2.11 Data fitted using power law (Material D) .................................................29

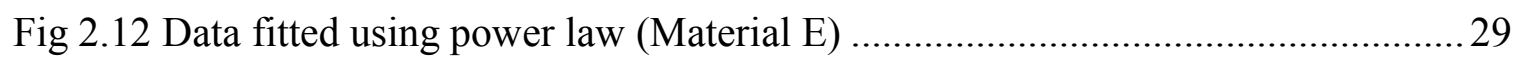

Fig 2.13 Master momentary curve at $\mathrm{t}_{\mathrm{e}-\mathrm{ref}}=5562 \mathrm{~min}($ Material A) ............................ 30

Fig 2.14 Master momentary curve at $\mathrm{t}_{\mathrm{e}-\mathrm{ref}}=6300 \mathrm{~min}($ Material B) .............................. 30

Fig 2.15 Master momentary curve at $\mathrm{t}_{\mathrm{e}-\mathrm{ref}}=8060 \mathrm{~min}($ Material C) ............................... 31

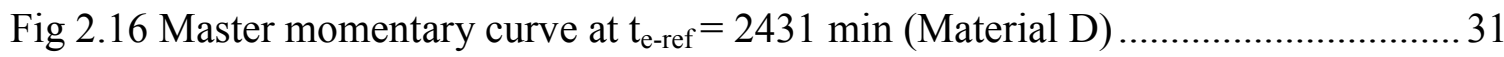

Fig 2.17 Master momentary curve at $\mathrm{t}_{\mathrm{e}-\mathrm{ref}}=2810 \mathrm{~min}($ Material E) ............................. 32

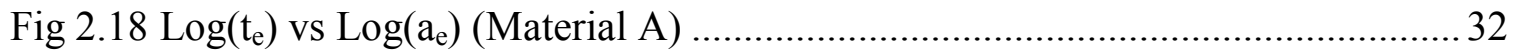

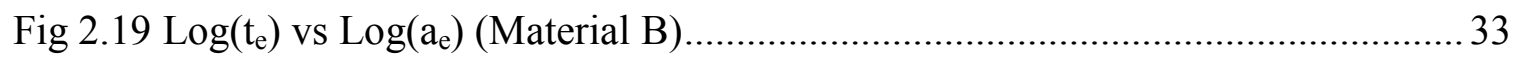

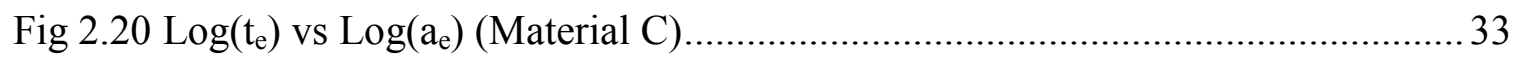

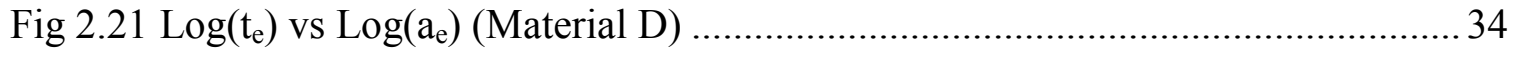

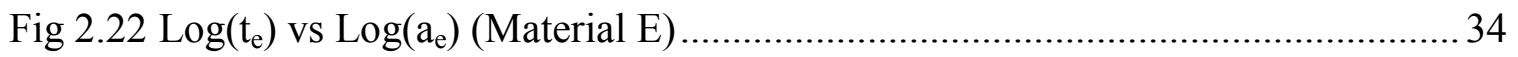


Fig 2.23 Comparison with long-term bending data (Material A) ................................. 35

Fig 2.24 Comparison with long-term bending data (Material B) .................................. 35

Fig 2.25 Comparison with long-term bending data (Material C)................................. 36

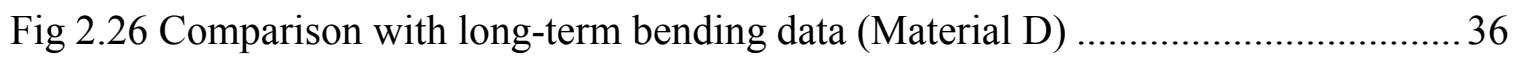

Fig 2.27 Comparison with long-term bending data (Material E) .................................. 37

Fig 2.28 Comparison with long-term bending data after shifting (Material A) ............... 37

Fig 2.29 Comparison with long-term bending data after shifting (Material B) ............... 38

Fig 2.30 Comparison with long-term bending data after shifting (Material C) ................ 38

Fig 2.31 Comparison with long-term bending data after shifting (Material D) ............... 39

Fig 2.32 Comparison with long-term bending data after shifting (Material E) ............... 39

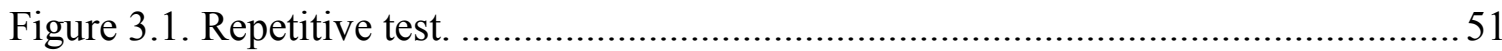

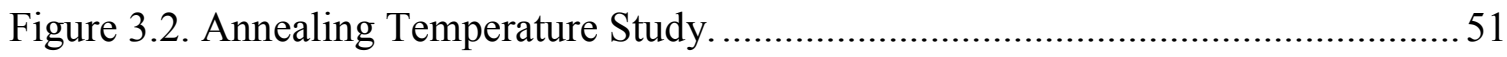

Figure 3.3. Conditioning Temperature Study....................................................... 52

Figure 3.4. TTSP graphs and master curve shifted to $40^{\circ} \mathrm{C}$ (Material A) ......................52

Figure 3.5. TTSP graphs and master curve shifted to $40^{\circ} \mathrm{C}$ (Material B) .......................53

Figure 3.6. TTSP graphs and master curve shifted to $40^{\circ} \mathrm{C}$ (Material C)......................53

Figure 3.7. TTSP graphs and master curve shifted to $40^{\circ} \mathrm{C}$ (Material D)......................54

Figure 3.8. TTSP graphs and master curve shifted to $40^{\circ} \mathrm{C}$ (Material E). ...................... 54

Figure 3.9. Theoretical and experimental values of the TTSP shift factors at $40{ }^{\circ} \mathrm{C}$

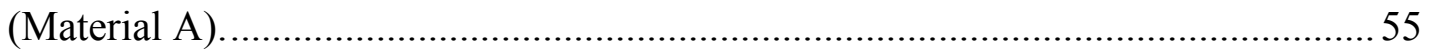

Figure 3.10. Theoretical and experimental values of the TTSP shift factors at $40{ }^{\circ} \mathrm{C}$

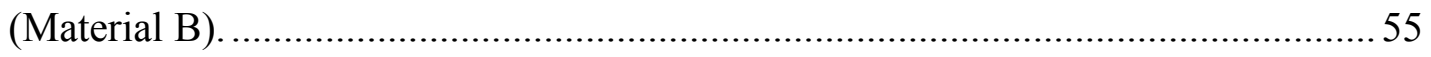


Figure 3.11. Theoretical and experimental values of the TTSP shift factors at $40{ }^{\circ} \mathrm{C}$ (Material C). 56

Figure 3.12. Theoretical and experimental values of the TTSP shift factors at $40{ }^{\circ} \mathrm{C}$ (Material D) 56

Figure 3.13. Theoretical and experimental values of the TTSP shift factors at $40{ }^{\circ} \mathrm{C}$

(Material E). 57

Fig 3.14 Un-shifted momentary curves of 5 specimens............................................ 57

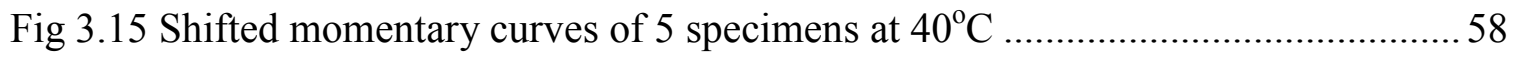

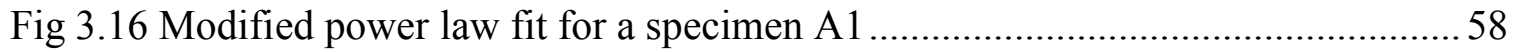

Fig 3.17 Final representation of the momentary curves of 5 specimens at $40^{\circ} \mathrm{C}$ (Material

A).. 59

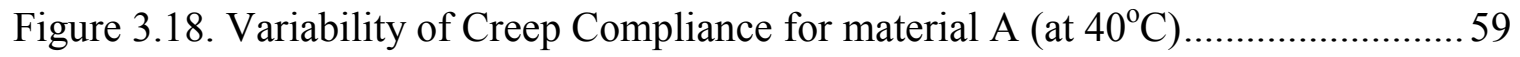

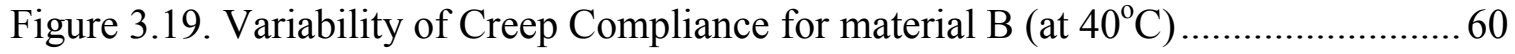

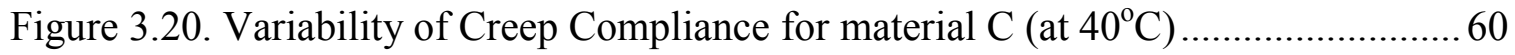

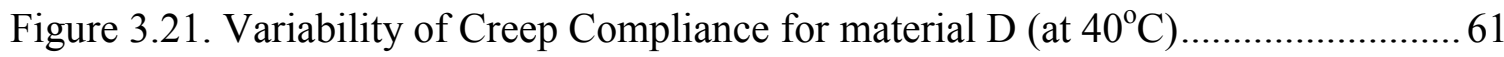

Figure 3.22. Variability of Creep Compliance for material E (at $40^{\circ} \mathrm{C}$ ) ............................ 61

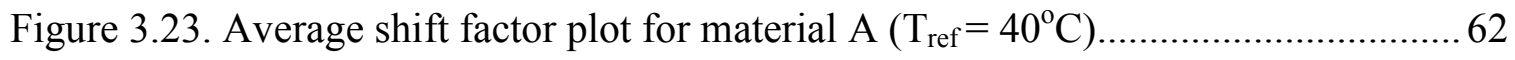

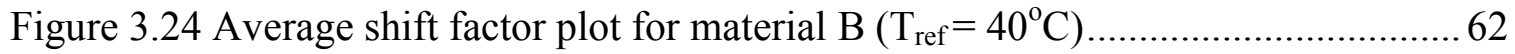

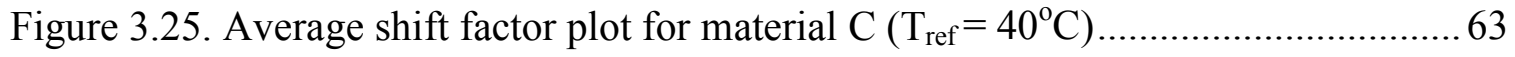

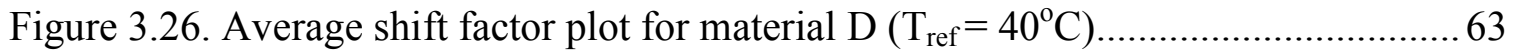

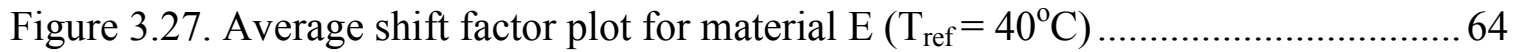

Figure 3.28. Specimen master curves of material A shifted for temperature $\left(t_{\mathrm{e}}=60 \mathrm{~min}\right)$ 
Figure 3.29. Specimen master curves of material B shifted for temperature $\left(t_{e}=60\right.$ min $)$

Figure 3.30. Specimen master curves of material C shifted for temperature $\left(t_{e}=60\right.$ min $)$

Figure 3.31. Specimen master curves of material D shifted for temperature $\left(t_{e}=60 \mathrm{~min}\right)$

Figure 3.32. Specimen master curves of material E shifted for temperature $\left(t_{e}=60\right.$ min $)$

Fig 3.33 Comparison with long-term bending data at $21.1^{\circ} \mathrm{C}$ (Material A).................... 67

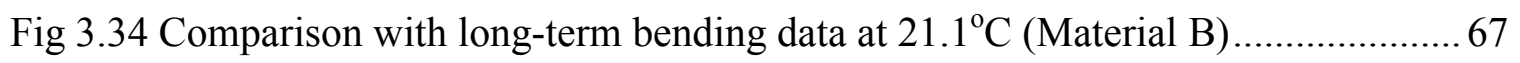

Fig 3.35 Comparison with long-term bending data at $21.1^{\circ} \mathrm{C}$ (Material C) ..................... 68

Fig 3.36 Comparison with long-term bending data at $21.1^{\circ} \mathrm{C}$ (Material D)....................68

Fig 3.37 Comparison with long-term bending data at $21.1^{\circ} \mathrm{C}$ (Material E) .................... 69

Fig 3.38 Comparison with long-term bending data at $21.1^{\circ} \mathrm{C}$ after shifting (Material A) 69

Fig 3.39 Comparison with long-term bending data at $21.1^{\circ} \mathrm{C}$ after shifting (Material B) 70

Fig 3.40 Comparison with long-term bending data at $21.1^{\circ} \mathrm{C}$ after shifting (Material C) 70

Fig 3.41 Comparison with long-term bending data at $21.1^{\circ} \mathrm{C}$ after shifting (Material D) 71

Fig 3.42 Comparison with long-term bending data at $21.1^{\circ} \mathrm{C}$ after shifting (Material E) 71

Fig 4.1 Prediction using 5 specimens compared to data of 3 encased liners (Material A)77

Fig 4.2 Prediction using 5 specimens compared to data of 3 encased liners (Material B) 77

Fig 4.3 Prediction using 5 specimens compared to data of 3 encased liners (Material C) 78

Fig 4.4 Prediction using 3 specimens compared to data of 3 encased liners (Material D) 78

Fig 4.5 Prediction using 3 specimens compared to data of 3 encased liners (Material E) 79 
Fig 4.6 Prediction using the average of the 5 specimens compared to encased liner data (Material A)

Fig 4.7 Prediction using the average of the 5 specimens compared to encased liner data (Material B) 80

Fig 4.8 Prediction using the average of the 5 specimens compared to encased liner data (Material C) 80

Fig 4.9 Prediction using the average of the 3 specimens compared to encased liner data

(Material D) 81

Fig 4.10 Prediction using the average of the 3 specimens compared to encased liner data (Material E) 81

Figure 5.1. FTSP graphs and master at $40^{\circ} \mathrm{C}$ (Material A) ......................................... 90

Figure 5.2. FTSP graphs and master curve at $40^{\circ} \mathrm{C}$ (Material B)................................ 90

Figure 5.3. FTSP graphs and master curve at $40^{\circ} \mathrm{C}$ (Material C) ............................... 91

Figure 5.4. FTSP graphs and master curve at $40^{\circ} \mathrm{C}$ (Material D) ................................ 91

Figure 5.5. Storage Modulus vs log frequency (Material E)........................................ 92

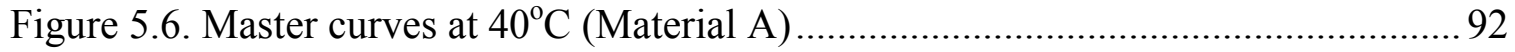

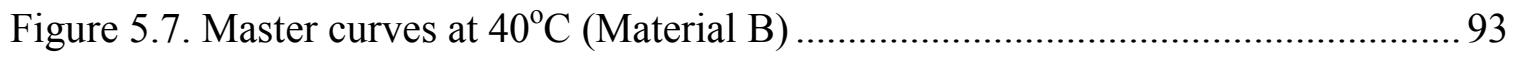

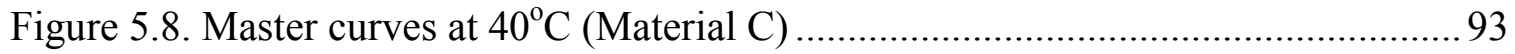

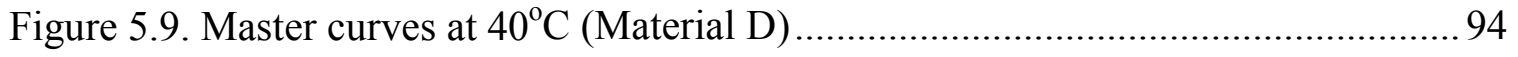

Figure 5.10. Linear fit for shift factor $\left(\mathrm{a}_{\mathrm{T}}\right) \mathrm{Vs}$ Temperature (Material A) ....................... 94

Figure 5.11. Linear fit for shift factor $\left(\mathrm{a}_{\mathrm{T}}\right)$ Vs Temperature (Material B) ...................... 95

Figure 5.12. Linear fit for shift factor $\left(\mathrm{a}_{\mathrm{T}}\right)$ Vs Temperature (Material C) ......................95

Figure 5.13. Linear fit for shift factor $\left(\mathrm{a}_{\mathrm{T}}\right) \mathrm{Vs}$ Temperature (Material D) ..................... 96 
Figure 5.14. Fit for the un-shifted momentary curve at $40^{\circ} \mathrm{C}$ (Material B) 96

Figure 5.15. Final representation of the shifted momentary curves at $40^{\circ} \mathrm{C}$ (Material B) 97

Figure 5.16. Final master curve at $40^{\circ} \mathrm{C}$ (Material A)............................................... 97

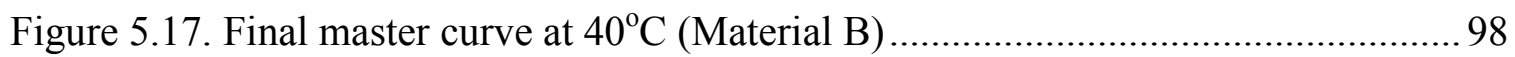

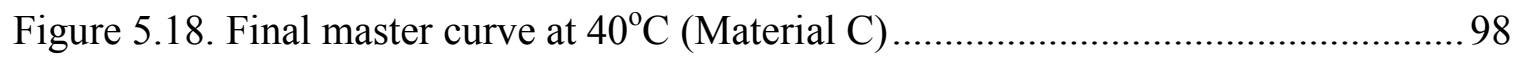

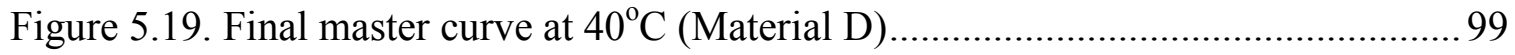

Figure 5.20. Average Shift Factor plot for Material A............................................... 99

Figure 5.21. Average Shift Factor plot for Material B............................................. 100

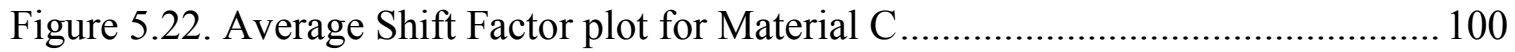

Figure 5.23. Average Shift Factor plot for Material D.......................................... 101

Figure 5.24. Polynomial Fit for the Master Curve at $13^{\circ} \mathrm{C}$ (Material A) ....................... 101

Figure 5.25. Linear Fit for the Master Curve at $13{ }^{\circ} \mathrm{C}$ (Material B) .............................. 102

Figure 5.26. Linear Fit for the Master Curve at $13^{\circ} \mathrm{C}$ (Material C) .............................. 102

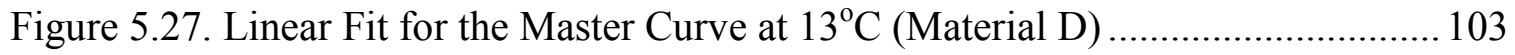

Figure 5.28. Power law fit for Relaxation modulus of Material B............................... 103

Figure 5.29. Power law fit for Relaxation modulus of Material C................................. 104

Figure 5.30. Power law fit for Relaxation modulus of Material D ............................... 104

Figure 5.31. Comparison of master curves from TTSP and FTSP at $13^{\circ} \mathrm{C}$ (Material B) 105

Figure 5.32. Comparison of master curves from TTSP and FTSP at $13^{\circ} \mathrm{C}$ (Material C) 105

Figure 5.33. Comparison of master curves from TTSP and FTSP at $13^{\circ} \mathrm{C}$ (Material D) 106

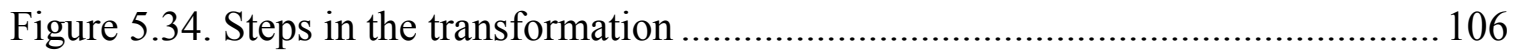

Figure 5.35. Comparison of master curves from TTSP and FTSP at $13^{\circ} \mathrm{C}$ (Material A) 107

Figure 5.36. Variation of Poisson's ratio with frequency for material A. 107 
Figure 5.37. Shear Loss and Storage modulus for material A ................................... 108

Figure 5.38. Bending Loss and Storage modulus for material A............................... 108

Figure 5.39. Variation of Poisson's ratio with frequency for material A...................... 109 


\section{CHAPTER 1: INTRODUCTION AND LITERATURE REVIEW}

\subsection{INTRODUCTION}

Polymers or reinforced polymers are increasingly used for trenchless liners for rehabilitation of deteriorated sewer pipes. Rehabilitation of existing sewer lines is done using the "trenchless" and "no-dig" technology [12]. Long-term Viscoelastic behavior of the polymer is one the most important aspects for its durability and dimensional stability. Several studies have been done to understand the viscoelastic properties of the polymer. However, enhanced understanding of physical aging and its effects on long-term creep of the polymer is necessary.

"When a polymeric material is cooled below its glass transition temperature $\left(\mathrm{T}_{\mathrm{g}}\right)$, it does not immediately achieve thermodynamic equilibrium; rather, the material evolves towards this state. During this period, physical properties such as compliance and modulus change continuously. This phenomenon is known as physical aging"[2]. Physical aging is accompanied by increase in stiffness, yield stress, density and viscosity. Also there is a decrease in creep and stress relaxation rates. Further, Struik [1] in his study showed that aging caused embrittlement of polymeric material.

The objective of this thesis was to develop a short term testing procedure to conduct short-term tests on small-size (15mm length $\mathrm{X} 1 \mathrm{~mm}$ thick $\mathrm{X} 10 \mathrm{~mm}$ width) specimens of different liner materials and predict the long-term creep of the liner, as produced in standard industrial conditions. The results of the short-term tests done using the DMA were also compared to tests done using static bending test (SBT) fixtures. 
Dynamic testing of the samples was also done and the results, which were in frequency domain, were transformed into the time domain. This was then used to predict the long-term creep compliance of the liner material. The results of all the three tests were compared and studied.

\subsection{LITERATURE REVIEW}

Over the years, extensive research has been done on the effect of aging on a variety of mechanical properties of polymers. Various short-term and medium-term tests have been conducted previously on polymers and encased liners samples in order to predict the long term behavior of the liners and the effect of aging on its properties. A brief review is shown here.

Between 1962 and 1972, Struik [1] did a systematic study of the aging phenomenon and its effects on a variety of mechanical properties of more than 40 materials, most of which were synthetic polymers. He concluded that the temperature range in which the aging occurs generally is not restricted to a narrow band below $\mathrm{T}_{\mathrm{g}}$, but it usually falls between the primary transition $\left(T_{g}\right)$ and the secondary transition $\left(T_{\beta}\right)$. The secondary transition $\left(T_{\beta}\right)$ is the temperature below which the state of the material is truly glassy. Below this temperature the free volume is so small that the motion of the segments is strongly hindered. Several properties of glassy polymers undergo marked changes and strongly depend on aging time. He also found that for temperatures in the aging range, the time dependence of the small-strain mechanical properties of a glassy material are independent of the specific chemical structure of the material. 
In 1997, Beckmann and McKenna [2] performed creep experiments on semicrystalline syndiotatic polystyrene (sPS) in order to explore the difference in kinetics of the physical aging process on sPS having two different processing histories. The evolution of the viscoelastic response with increasing aging time after quenching, was represented by Time-Aging Time Superposition. Creep behavior at each aging time was represented using Kohlrausch-Williams-Watts (KWW) function:

$$
D(t)=D_{o} \exp \left[t / \tau_{o}\right]^{\beta}
$$

Where $\mathrm{D}(\mathrm{t})=\varepsilon / \sigma$ is the creep compliance, $\varepsilon$ is the measured strain $\sigma$ is the applied stress, $\tau_{0}$ is a characteristic retardation time, $\beta$ a shape parameter for each creep curve, and $\mathrm{D}_{\mathrm{o}}$ is the initial compliance. The aging shift factor $\mathrm{a}_{\mathrm{te}}$ used for shifting the data horizontally along the time axis is derived from the KWW function as:

$$
\log \left[\mathrm{a}_{\mathrm{te}}\right]=\log \left[\tau_{o}\left(t_{e}\right) / \tau_{o}\left(t_{r e f}\right)\right]
$$

Where $\tau_{\mathrm{o}}\left(\mathrm{t}_{\mathrm{e}}\right)$ is the value of $\tau_{\mathrm{o}}$ at aging time $\mathrm{t}_{\mathrm{e}}$ and $\tau_{\mathrm{o}}\left(\mathrm{t}_{\mathrm{ref}}\right)$ its value at the reference aging time. The shift rate, $\mu$, is found by making a double logarithmic plot of $\log \left(a_{e}\right)$ vs $\log \left(t_{\mathrm{e}}\right)$ and finding its gradient, which is defined by Struik as

$$
\mu=\frac{d \log \left(a_{e}\right)}{d \log \left(t_{e}\right)}
$$

Four samples of syndiotactic polystyrene in the form of dumbbell-shaped specimens were produced by injection molding. Two of the samples were used in physical aging experiments. One sample was injected into a hot mold $\left(300^{\circ} \mathrm{F} ; 149^{\circ} \mathrm{C}\right)$ and contained a nucleating agent, while the other was injected into a mold held at $140^{\circ} \mathrm{F}$ $\left(60^{\circ} \mathrm{C}\right)$ and contained a nucleating agent. 
The aging experiments were carried out by first annealing the specimens at $160^{\circ} \mathrm{C}$ for $1 \mathrm{Hr}$ and then were placed in the test machine at test temperature, and sequence of aging "probe" stresses in creep was applied. Experiments were performed at different aging test temperatures from $60^{\circ} \mathrm{C}$ to $120^{\circ} \mathrm{C}$. After quenching the samples to the aging test temperature, the creep tests were started sequentially at increasing aging times, $t_{\mathrm{e}}$. The ratio $t_{1} / t_{e}$, where $t_{1}$ was duration of the load application, was kept constant at $1 / 10$. The zero aging time was chosen to be the time at which the samples attained the testing temperature.

The viscoelastic response of sPS could be represented by a time aging time superposition similar to those observed for amorphous polymers and the double logarithmic shift rate $\mu$ is near to unity well below $T_{g}$ and decreases to zero as temperature increases to and above $T_{\mathrm{g}}$. Near $\mathrm{T}_{\mathrm{g}}$ the creep behavior does not change as aging time increases. In this range time-aging time superposition could not be applied to the result. The observed behavior was different from that in other semi crystalline polymers. Above $\mathrm{T}_{\mathrm{g}}$ the creep compliance response changed upon aging, but there was no apparent change in the characteristic viscoelastic retardation time. All the changes could be expressed as a simple increase in material stiffness, which was different from either that of the amorphous material or other semi crystalline material. Finally the two different materials under investigation exhibited somewhat different aging behaviors. The material that was molded at $140^{\circ} \mathrm{F}$ showed a more rapid change in the viscoelatsic response with increasing aging time in the vicinity of $\mathrm{T}_{\mathrm{g}}$.

In 1994, Wang et.al [3] investigated the effect of physical aging on the viscoelastic creep property of a thermoplastic- toughened cyanate ester resin (Fiberite 
954-2) and its IM8/954-2 composites, and semi-crystalline thermoplastic (Fiberite ITX) and its IM8/ITX composite. Dynamic mechanical analysis (DMA) and tensile creep tests were carried out for this study. The fiberite $954-2$ resin was cured at $177^{\circ} \mathrm{C}$ for $4 \mathrm{Hrs}$ followed by a post cure at $232^{\circ} \mathrm{C}$ for $2 \mathrm{Hrs}$. The composite specimens were vacuum bagged using the same curing cycle. The IM8/ITX specimens were molded at $393-404^{\circ} \mathrm{C}$ for $10-30 \mathrm{~min}$ and cooled to a temperature below $150^{\circ} \mathrm{C}$ at a rate between 14 and $28^{\circ} \mathrm{C} / \mathrm{min}$

Creep tests were conducted on $954-2$ plain resin specimens, $\left[90^{\circ}\right]_{4 \mathrm{~s}}$ IM8/954-2, and $\left[90^{\circ}\right]_{4 \mathrm{~s}}$ IM8/ITX composite specimens using DuPont 983 dynamic mechanical analyzer. The dimensions for the plain resin specimens were $40 \mathrm{~mm}$ X $10 \mathrm{~mm}$ X $2.7 \mathrm{~mm}$ and the dimensions for the composite specimens were $40 \mathrm{~mm} \mathrm{X} 10 \mathrm{~mm} \mathrm{X} 1.2 \mathrm{~mm}$. Aging time of $0.67,2.0,6.0,18.0$ and $54.0 \mathrm{hrs}$ were used for all creep tests while the creep times for each loading cycle were $0.083,0.25,0.75,2.25$ and $6.75 \mathrm{hrs}$ so as to keep the ratio between the aging time and the test time to be 8 . This was done to ensure that the creep was momentary and the aging effect during creep was negligible. The 954-2 based specimens and IM8/ITX specimens were tested at $140,150,160,180,190$ and $200^{\circ} \mathrm{C}$ using the above mentioned loading scheme. In order to investigate the physical aging effects on the shear creep behavior $\left[ \pm 45^{\circ} \mathrm{C}\right]_{2 s}$ IM8/954-2 and IM8/ITX specimens having dimensions $200 \mathrm{~mm}$ X $25 \mathrm{~mm}$ X $1.1 \mathrm{~mm}$ were tested. The shear creep compliance of $\pm 45^{\circ}$ specimen was given by

$$
S_{66}=\frac{2 A(e x-e y)}{P}
$$


Where, $\mathrm{S}_{66}$ is the shear compliance, $\mathrm{P}$ is the axial load applied on the specimen, $\mathrm{A}$ is the cross-sectional area of the specimen, and ex and ey are the strain along the loading and transverse direction respectively.

Creep compliance curves of neat resin specimen and $90^{\circ}$ and $\pm 45^{\circ}$ composite specimen at $160^{\circ} \mathrm{C}$ showed that the creep curves strongly depend on the aging times. The creep levels at the same temperature decreases as the aging time increases. All the creep curves were shifted to $54 \mathrm{Hrs}$ of aging time using a shift factor. The shift factor versus the logarithmic aging time was plotted and the result was a straight line. The slope of this line was called the aging shift rate, $\mu$. Since the creep behavior of the polymer was significantly influenced by changes in temperature a comparison was made between the effect of aging and temperature. From this comparison it was seen that an increase in a decade of aging time was approximately equal to a reduction of $4-5^{\circ} \mathrm{C}$. Creep tests were conducted at other temperatures in order to determine the effects of temperature on the aging kinetics. The specimens used were $954-2$ plain resin specimens, and $90^{\circ}$ and $\pm 45^{\circ}$ composite specimen. The results were an average from three different tests having a typical scatter of the order of $\pm 10 \%$. The results showed significant variation in the shift rate with lamina orientation. It indicated that the dependency of the shift rate on temperature is quite different from that obtained on the single-phase polymeric glass.

For the long-term creep prediction, the creep behavior could not be modeled using ETT as suggested by Struik [1] because the material, cynate ester sample, was not able to rejuvenate. An alternate method described by Dean [4] was sought in order to predict long-term creep response with physical aging. 
Dean used long-term data in which creep and physical aging take place concurrently in contrast to the momentary data used in TTSP. For two-component polymer systems, Dean represented the creep deformation over time as a superposition of two independent transition mechanism, referred to as $\alpha$ and $\beta$ :

$$
D(t)=D_{\alpha}(t)+D_{\beta}(t)+D_{\alpha \beta}(t)
$$

where $D_{\alpha}(t)$ is the creep compliance of the region below $T_{g}$ of both components, $D_{\beta}(t)$ is the creep compliance of the region greater than the lower $T_{g}$ but lower than the upper $T_{g}$, and $D_{\alpha \beta}(t)$ is the compliance of the transition between the two regions. The shorter creep compliance, ie., $1<\mathrm{t}<3475 \mathrm{~s}$, was represented by Struik's relationship for tensile creep compliance:

$$
D_{\alpha}(t)=D_{\alpha o} e^{\left(t / t_{0}\right)^{m}}
$$

while the longer times, ie., $\mathrm{t}>26000 \mathrm{sec}$ was represented as

$$
D_{\beta}(t)=D_{\beta o}+m_{1} t^{n}
$$

It was noted that in the $\beta$ region the experimental data was linear over a period of two decades. It was assumed that the data would remain linear for a longer period and was used to predict the creep compliance of the material system over a period of 120,000 hrs. No experimental validation of this assumption exists.

Results from the DMA creep tests on the as-received $90^{\circ}$ IM8/ITX composite and $\pm 45^{\circ} \mathrm{IM} 8 / \mathrm{ITX}$ composite in tensile creep showed that as aging time increased, the creep compliance reduced consistently, revealing the physical aging effect on the creep behavior of the material. Aging shift rates of $90^{\circ}$ and $\pm 45^{\circ}$ composite at different temperatures were plotted and were found to range from $0.9-1.3$, with values above 1.0 
been theoretically impossible [Struik]. From the test results it was observed that the physical aging phenomenon persist at temperature above $T_{\mathrm{g}}$. This behavior was explained by the role of the crystalline phase as an 'inert' filler. A comparison was made between the aging time and temperature equivalency curve. From this comparison it was seen that an increase in a decade of aging time was approximately equal to a reduction of $7-8^{\circ} \mathrm{C}$. Vertical shift rates of $\pm 45^{\circ}$ IM8/ITX composites were plotted as a function of aging temperature and were found to be quite significant. The shifting appeared to be downward and negative. The vertical shifts were attributed to the change in crystallinilty in the semi-crystalline polymer at higher temperatures and also due to accelerated chemical degradation. For the long term prediction, TTSP master creep compliance curves were formed by shifting the momentary curves obtained at different temperatures having an aging time $t_{e}$ of 2 hrs. The master curve was obtained for a reference temperature of $150^{\circ} \mathrm{C}$. The master curve was fitted using a power law. The coefficients of the creep compliance power curves could be represented as a function of temperature and was represented as

$$
D(t, T)=(A+B T)+(C+D T) t^{n}
$$

The long-term compliance associated with the real time axis was obtained by the following equation:

$$
D(t, T)=D_{o}(T)+K(T) t^{n}
$$

Results obtained from the long-term TTSP prediction and ETT prediction were compared to the experimental data. Since the value of shift rate, $\mu$, was found to be greater that unity the absolute value of the ETT parameter, $\alpha$, was used. For shorter creep times the the analytical model over estimated the data. Around 1000s of creep time, the 
analytical model and experimental data converged, after which they diverged. It was concluded that the reason for this discrepancy was possibly due to having data obtained from different specimens and error in the shift rate.

In 1991, McCrum [5], proposed Sequential Aging theory in order to make explain the shift of retardation time observed during physical aging of a viscoelastic polymer. According to Struik [1] in his aging study, following a quench, isothermal shifts of creep curves are observed, which are often identified with shifts of the viscoelastic spectra as large as $10^{4}$ or $10^{5}$ decades. This was contradictory to the interpretation of DMTA and DETA data, which suggests that the temperature of a loss peak depends on the frequency of measurement, but not appreciably on the thermal history of the specimen. Cooper and McCrum observed that quenching of linear polyethylene clearly increased the magnitudes of the $\beta$ and $\gamma$ relaxations but the temperature of the $\gamma$ shift is barely shifted by quenching. The spectra produced by quenching were not large ie., several decades, as suggested by Struik. Similarly, in polyoxymethylene, aging in the region of $\beta$ relaxation at room temperature alters the magnitude of the $\beta$ relaxation, but the shift was also found to be small.

McCrum [5] did a computer modeling of physical aging using Sequential Aging theory. In a sequential aging mechanism, elements having same retardation spectrum move towards their equilibrium values appropriate to the quench temperature T. Elements with shorter retardation times have already reached equilibrium, while the elements with larger retardation time have not begun their move towards equilibrium. In simple terms, the elements age in a sequence. In Struik mechanism of physical aging, it was assumed that the retardation spectra was superposable and the relationship between the shift factor 
of the $i$ th element, $\log \mathrm{a}_{i}(\mathrm{te})$, and its retardation time, $\tau_{i}(0)$, was given by a single relaxation time:

$$
\log a_{i}\left(t_{e}\right)=\log a(\infty)\left[1-\exp \left(-t_{e} / p \tau_{i}(0)\right]\right.
$$

where, $\mathrm{p}$ is a positive number. McCrum didn't find this equation in agreement with experimental results. Good agreement was found using a distributed model, whose equation is given as:

$$
\log a_{i}\left(t_{e}\right)=\log a_{i}(\infty)\left\{\frac{\sum_{j=1}^{16} x_{j}\left[1-\exp \left(-t_{e} / p_{j} \tau_{i}(0)\right]\right.}{\sum_{j=1}^{16} x_{j}}\right\}
$$

This lead to the conclusion that retardation times shift were only slight (X10). The double-logarithmic shift rate, vertical and horizontal shifts, took value $\mu=1$ for an equilibrium retardation spectrum of zero slope. It was also concluded that the best approach to obtain an equilibrium data either by Dynamic Mechanical Analysis (DMTA) or creep would be to use slow cooling following annealing.

In 1987, Janas and McCullough [6] studied the effect of physical aging on the viscoelastic behavior of thermoset polyester. Two types of mechanical tests, tensile creep and dynamic mechanical analysis, were used to characterize the polyester resin. Tensile tests were performed in a controlled temperature and humidity environment. Strains at a constant load for each specimen was recorded from $10 \mathrm{~s}$ to $1.5 \times 10^{5} \mathrm{~s}$ after loading. Loads applied varied from $3.45 \times 10^{5}$ to $2.76 \times 10^{6} \mathrm{Nm}^{-2}$. Samples aged at $1,3.3$ and 10 days were creep tested at $80^{\circ} \mathrm{C}$. The creep compliance curves were plotted against time and were shifted in order to find the shift rate. The aging study was done at 60,80 and $100^{\circ} \mathrm{C}$ 
and a plot were drawn between the shift rate $\mu$ and temperature. It was found that the shift rate $\mu$ rises rapidly from 0.4 to 1.0 between 60 and $100^{\circ} \mathrm{C}$ and was found to be constant over a large range of temperatures just below $\mathrm{T}_{\mathrm{g}}$.

Dynamic Mechanical Analysis (DMA) testing was performed by Janas and McCullough [6] using Rheometrics Model 800 Spectrometer. The storage compliance, J', and loss compliance, J", were determined for isothermal frequency sweeps. A plot of the storage compliance versus frequency at various temperatures was drawn. Another plot of the loss compliance versus frequency at various temperatures was drawn. The storage and loss compliance data were shifted to a reference temperature, using the method of reduced variables, to form a master curve. The resulting master curve is a master curve over a wider range of frequencies, ranging over 22 decades. The plot showed that the compliance decreased as the frequency increased, indicating that as frequency increases, the behavior of polyester moves slowly from high compliance rubbery-like value to low compliance glassy-like values.

The Ninomiya and Ferry equation (1.12) was used by Janas and McCullogh [6] to estimate the time dependent shear creep compliance from the DMA data. The equation is given by

$$
J(t)=J^{\prime}(\omega)+0.40 J^{\prime \prime}(0.40 \omega)-\left.0.014 J^{\prime \prime}(10 \omega)\right|_{\omega=1 / t}
$$

where $\mathrm{J}$ ' and $\mathrm{J}$ ' are the shear storage and loss compliances measured at the appropriate frequencies. The shear creep compliance was then converted to tensile creep compliance by using 


$$
D(t)=\frac{J(t)}{2(1+v)}
$$

where $v$ is the Poisson's ratio, considered to be a constant, 0.34 .

To get long-term predictions from short-term tests, Effective Time Theory (ETT) was used by Janas and McCullough [6]. The relationship is given by:

$$
t=t_{e}\left(e^{\lambda / t_{e}}-1\right) \text { for } \mu=1
$$

and

$$
t=t_{e}\left[\left(1-\frac{\lambda \alpha}{t_{e}}\right)^{1 / \alpha}-1\right] \text { for } \quad \mu<1
$$

where $\quad 0<1-\mu<1$

The long-term predictions were then compared to the experimentally measured long-term creep behavior and were found to be in good agreement.

Though the experimental method had good agreement, there were some approximations made, namely, assuming the Poisson's ratio to be constant at every frequency. This according to Progelhof and Throne [7] was incorrect. According to them, the Poisson's ratio of a viscoelastic material depends on frequency.

\subsection{MATERIALS}

Materials referred in this thesis as material A, B and C are three commercial Poly Vinyl Chloride (PVC) types. Material D is commercial high-density polyethylene (HDPE). Material E is a polyester resin reinforced with polyester felt. Since this is a

thermoset, the samples were fabricated flat. These materials are based upon work 
supported by the National Science Foundation under Grant No. 9978634 and Pipe Rehabilitation Council contract OSP\#99-261. 


\section{CHAPTER 2: AGING STUDY}

\subsection{INTRODUCTION}

When a polymeric material is taken below its glass transition temperature $\left(T_{g}\right)$, it does not immediately achieve thermodynamic equilibrium; rather, the material evolves slowly towards equilibrium. During this period, physical properties such as compliance and modulus change continuously. This phenomenon is known as physical aging. According to Sullivan [8], aging of a polymer is the most important aspect controlling the long-term predictions of creep.

In this work, the aging testing followed the protocol developed by Struik. Aging experiments were carried out by first annealing the specimens at a temperature $15^{\circ} \mathrm{C}$ above its $T_{\mathrm{g}}$. The sample is then quenched from above the glass-transition temperature, $\mathrm{T}_{\mathrm{g}}$, to the testing temperature and maintained at that temperature for the aging time, $\mathrm{t}_{\mathrm{e}}$. Tests are then performed for a short time interval: one-tenth the age, $t_{e}$, of the specimen. Creep tests are performed at ages 10,12,30,90,270,810 and 2430min.

The creep curves were shifted to a reference age (curves having the longest age), using a shift factor $a_{e}$. The slope of the double logarithmic plot of $\log \left(a_{e}\right) v s \log \left(t_{e}\right)$ gave the shift rate, $\mu$, defined as

$$
\mu=\frac{d \log \left(a_{e}\right)}{d \log \left(t_{e}\right)}
$$

Three samples each of materials A, B, C, D, and E were tested. 


\subsection{EXPERIMENTAL PROCEDURE}

Creep tests were performed in a configuration similar to ASTM D-790.

\subsubsection{APPARATUS AND TESTING MACHINE}

The tests were conducted using Perkin Elmer's Dynamic Mechanical Analyzer (DMA 7e). The fixture used one loading point at one half of the support span of $15 \mathrm{~mm}$ (0.59 in). The load points had sharp edges.

\subsubsection{TEST ENVIRONMENTAL CONDITIONS}

All tests were conducted at $40^{\circ} \mathrm{C}$ temperature. The temperatures were recorded during the tests from a thermocouple placed along side the specimen. The tolerances were held to $+/-0.5^{\circ} \mathrm{C}$. Helium was used as a purge gas with a flow rate of $30 \mathrm{ml} / \mathrm{min}$.

\subsubsection{SPECIMEN PREPARATION}

Round pipe liner samples of each material were produced at the vendor facility by lining a $305 \mathrm{~mm}$ ID (12'ID) steel pipe. All liner samples were cut perpendicular to the direction of extrusion and had a minimum length of $305 \mathrm{~mm}$ (12" ID). The samples were then cleaned using a mild soap and water solution. These samples were further cut into four pieces (with longitudinal cuts) into four equal quadrants. A strip of thickness 1.5 - 2 $\mathrm{mm}$ was cut along the thickness and these were then cut into several pieces of length 18 $\mathrm{mm}$.

Three specimens of A, B, C, and D were cut from the liner sample. Specimens for material $\mathrm{E}$ were cut from the flat liner sample provided by the manufacturer. The specimens had a minimum aspect ratio of 16 to 1 . They had an approximate height, width 
and depth of $1.5 \mathrm{~mm}, 15 \mathrm{~mm}$ and $10 \mathrm{~mm}$ respectively. In no case was the depth of the specimen allowed to exceed the width.

\subsubsection{SPECIMEN TESTING}

Each specimen is tested one at a time for the determination of its change in compliance due to aging.

a. The thickness and width of each specimen is measured at both ends and at the mid-span using a micrometer. The values measured are averaged for calculations. All measurements are made in SI units.

b. The specimen is placed in the three point bending fixture of the DMA. The DMA is attached to a computer, which controlled the operations of the DMA using "PYRIS" software (version 3.80). The height and depth of the specimen are entered along with the initial state of the specimen, i.e., the initial temperature. The width remained constant at $15 \mathrm{~mm}$, as it was the span of the three point bending fixture.

c. After making sure that the specimen is properly seated into the fixture, the furnace is closed and the temperature is set to the annealing temperature. There is a time lag of 3-4 min for the temperature to equilibrate.

d. The specimen is kept at the annealing temperature for $10 \mathrm{~min}$ after which the furnace is opened in order to air-quench the specimen at room temperature. The time at which the furnace is opened is considered to be age zero $\left(t_{\mathrm{e}}=0\right)$ of the specimen. 
e. In the meantime the furnace is set to test temperature. After $5 \mathrm{~min}$ the furnace (having reached test temperature) is closed. The sample is allowed to stabilize in the test temperature for another $5 \mathrm{~min}$.

f. Creep tests are performed at ages of 10,12,30,90,270,810,2430 min. Duration of each test is such that $\mathrm{t} / \mathrm{t}_{\mathrm{e}} \leq 10$, as suggested by Struik.

The load and the corresponding deflection data for the specimen is automatically recorded and then saved into a file. The load is kept between $1000 \mathrm{mN}$ and $1750 \mathrm{mN}$ depending on the sample thickness and deflection. The deflection is not allowed to exceed $10 \%$ of the support span.

After testing, the specimen is removed from the fixture and a new specimen is tested.

\subsection{EXPERIMENTAL RESULTS AND DATA INTERPRETATION}

Load and the corresponding deflection data of every creep test are obtained from the files mentioned earlier. The initial portion, first 12 seconds, of the curve for each specimen is discarded (Fig. 2.1-2.2). This is due to the allowance given for the specimen not being snugly fit in the fixture and for the damping of the probe, which applies the load gradually and not instantaneously. Double logarithmic plot of creep compliance vs time for each specimens after discarding the initial portion of data, are plotted. The

constant flexural stress and changing flexural strain are calculated using equations (3) and (4) of the ASTM D790-99 standard

$$
\sigma_{f}=\frac{3 P l}{2 b d^{2}}
$$


where $\sigma_{\mathrm{f}}$ is the stress in the outer fibers at the midpoint, and $P$ is the load at the given point in the load-deflection curve in $\mathrm{mN}$

$$
\varepsilon_{f}=\frac{6 \Delta d}{L^{2}}
$$

where $\varepsilon_{\mathrm{f}}$ is the strain in the outer fiber in $\mathrm{mm} / \mathrm{mm}$, and $\Delta \mathrm{d}$ is the maximum deflection of the center of the beam in $\mathrm{mm}$.

The compliance for every point in the test is found by diving the strain by the constant stress. A point to be remembered is that the compliance measured is a function of time. The double logarithmic plot of compliance vs time at every age of the sample is plotted (Fig 2.3-2.7). The curves are fitted with an exponential curve

$$
D(t)=D_{o}+D_{1} t^{n}
$$

where $D_{0}$ is the initial compliance, $D_{1}$ is the linear coefficient, and $t$ is the time, and $n$ is the power exponent. The momentary creep curves of sample D (Fig 2.6) could not be fit with the Eq. 2.4 as their initial compliance was zero. This is probably due to the fact that the $\mathrm{T}_{\mathrm{g}}$ of the amorphous phase is below $0^{\circ} \mathrm{C}$ (Table 2.2) and thus aging of the sample is controlled by the crystalline phase in the sample. Hence $D_{0}$ was fixed at zero and Eq. 2.4 was fit. Another problem faced by sample D was that the curves tended to creep at longer test time. Hence only the data till $10 \mathrm{~min}$ of the momentary curves were used.

These curves are then rotated [13] in order to make all tests into parallel straight lines (Fig. 2.8-2.12). A reference curve was chosen and other curves at different ages were shifted horizontally by using shift factors, $a_{\mathrm{e}}$. The shift factor moves the curve in the 
horizontal direction in the time scale and thus a master curve is obtained (Fig 2.13-2.17).

It was found that the first two tests on every sample are unpredictable, as the data is not aligned with the rest (Fig 2.18-2.22). It was concluded that this is due to the sample not being seated properly after quenching. Hence, the first two tests are regarded as mechanical conditioning tests and the corresponding data is discarded.

The shift rate, $\mu$, is found by making a double logarithmic plot of $\log \left(a_{e}\right)$ vs $\log \left(t_{e}\right)$ and finding its slope (Table 2.1). Using this slope, the shift factor $\left(\mathrm{a}_{\mathrm{e}}\right)$ at any given aging time $\left(t_{\mathrm{e}}\right)$ can be found out by using

$$
a_{e}=10^{\left(\log \left(t_{e}\right)^{*} \mu\right)}
$$

The same procedure is repeated by using three specimens of each sample. The average of the three values of $\mu$ 's is taken as the shift rate of the sample. The shift rate, $\mu$, found using the DMA was also compared to the shift rate found using the long-term bending fixture (Table 2.3) and the values were found to be close.

\subsubsection{MECHANICAL CONDITIONING:}

This work shows for the first time the need for mechanical conditioning. This phenomenon has been independently verified in [13]. It was found that the first two tests done on the specimen gave wrong results due to the specimen not being seated properly after it was annealed and air quenched. This could be clearly seen from Fig.2.18-2.22. The first two tests done at age's $10 \mathrm{~min}$ and $30 \mathrm{~min}$ had to be discarded, as it did not follow the trend made by the following tests. The first two tests immediately after quenching were thus treated as mechanical conditioning tests. 


\subsection{COMPARISON WITH STATIC BENDING TEST DATA}

Using the Time Temperature Superposition (Fig 3.18-3.22) and aging parameters found in Table 2.1, as well as Eq. 4.3, the long-term compliance was predicted at $40^{\circ} \mathrm{C}$ (Fig 2.23-2.27) and compared with data from the static-bending test (SBT) study [13]. Six-day test data from the DMA are also compared to the predicted long-term compliance.

Due to uncertainty in the initial position of the displacement transducer, the data shows correct creep response but not correct initial compliance. Therefore the curves were vertically shifted to coincide at time 1 min with the average TTSP (Fig 2.29-2.32).

\subsection{SUMMARY}

A summary of the procedure is as follows:

1. The specimen to be tested is cut, measured and placed in the DMA 7e.

2. The specimen is annealed at a temperature $15^{\circ} \mathrm{C}$ above its glass transition temperature $\left(\mathrm{T}_{\mathrm{g}}\right)$ in the oven for $10 \mathrm{~min}$.

3. The specimen is then air quenched for $5 \mathrm{~min}$ and then enclosed inside the DMA at test temperature.

4. Creep tests of length $1 / 10^{\text {th }}$ of the aging time of the specimen are done at ages 10 , $30,90,270,810,2430$. and so on.

5. A momentary curve is chosen as the reference curve and all the other curves are shifted to this curve using a shift factor $\mathrm{a}_{\mathrm{e}}$.

6. A plot is drawn between $\log \left(\mathrm{t}_{\mathrm{e}}\right)$ vs $\log \left(\mathrm{a}_{\mathrm{e}}\right)$ and their slope is found. This slope is the shift rate, $\mu$, of the specimen at that temperature. 


\subsection{CONCLUSIONS}

The following are the conclusions drawn from the aging study done on the polymer liner specimens:

1. The measurements of width and depth of the specimen has to be taken accurately to obtain the right result.

2. The initial portion of the curve of log compliance vs log time was not correct and so the curves from time $12 \mathrm{sec}$ was chosen to be the start point of the test.

3. The first two tests after quenching had to be disregarded, as they did not follow the trend the other tests were following and so were considered as mechanical conditioning tests.

4. The momentary creep curves of sample D could not be fit with the modified power law and so $D_{0}$ was fixed at zero and then it was refitted. Also the data after 10 min of test time is discarded, as it tends to creep.

5. Due to uncertainty in the initial position of the displacement transducer, the data for sample A, D and C shows correct creep response but not initial compliance. Therefore the curves were vertically shifted to coincide at time $1 \mathrm{~min}$ with the average TTSP. Sample C follows the TTSP and not the prediction as the sample yields on testing.

6. For sample B, the residual stresses released while cutting small samples prevented us from obtaining a TTSP. It was seen that the 6-day test done using the DMA followed the long-term tests done using the long-term bending fixtures, when they were shifted vertically to compensate for the uncertainty in the initial position of the displacement transducer. 
7. Sample E, cracked when tested dynamically or repeatedly, so we could not obtain a TTSP. Similar to Sample B, long-term bending tests followed the 6-day test done using the DMA, when shifted vertically to correct for initial displacement.

8. The values of the shift rate, $\mu$, obtained using the DMA and the long-term bending fixtures were found to be close. The slight variance could be due to the difference in sample size and fixture. 


\begin{tabular}{|c|c|c|c|c|c|}
\hline Material & Sample 1 & Sample 2 & Sample 3 & Average & Standard Deviation \\
\hline A & 0.5047 & 0.458765 & 0.613352 & 0.52560567 & 0.07938558 \\
\hline B & 0.925505 & 0.938357 & 0.768258 & 0.87737333 & 0.09471489 \\
\hline C & 0.89218 & 0.853858 & 0.849898 & 0.865312 & 0.023352462 \\
\hline D & 0.15543035 & 0.1761609 & 0.2053408 & 0.17897735 & 0.02507414 \\
\hline E & 0.82741 & 0.774997 & 0.758206 & 0.786871 & 0.036097677 \\
\hline
\end{tabular}

Table 2.1 Value's Of Shift Rate, $\mu$, for every material

\begin{tabular}{|c|c|c|}
\hline Material & $\mathbf{T}_{\mathbf{g}}\left({ }^{\circ} \mathbf{C}\right)$ & $\mathbf{T}_{\mathbf{a}}\left({ }^{\circ} \mathbf{C}\right)$ \\
\hline A & 70 & 100 \\
\hline B & 90.2 & 110 \\
\hline C & 85.9 & 100 \\
\hline D & -30 & 100 \\
\hline E & 130.2 & 135 \\
\hline
\end{tabular}

Table 2.2 Glass Transition Temperature $\left(T_{g}\right)$ and Annealing Temperature $\left(T_{a}\right)$ for every material

\begin{tabular}{|c|c|c|c|}
\hline Material & $\mu$ using DMA & $\mu$ using CBT fixtures & \% Difference \\
\hline A & 0.525605667 & 0.481 & $8.49 \%$ \\
\hline B & 0.877369 & 0.72 & $17.94 \%$ \\
\hline C & 0.86533 & 0.718 & $17.03 \%$ \\
\hline D & 0.1789 & 0.177 & $1.06 \%$ \\
\hline E & 0.786871 & 0.602 & $23.49 \%$ \\
\hline
\end{tabular}

Table 2.3 Comparison of Shift Factor $(\mu)$ from different studies 


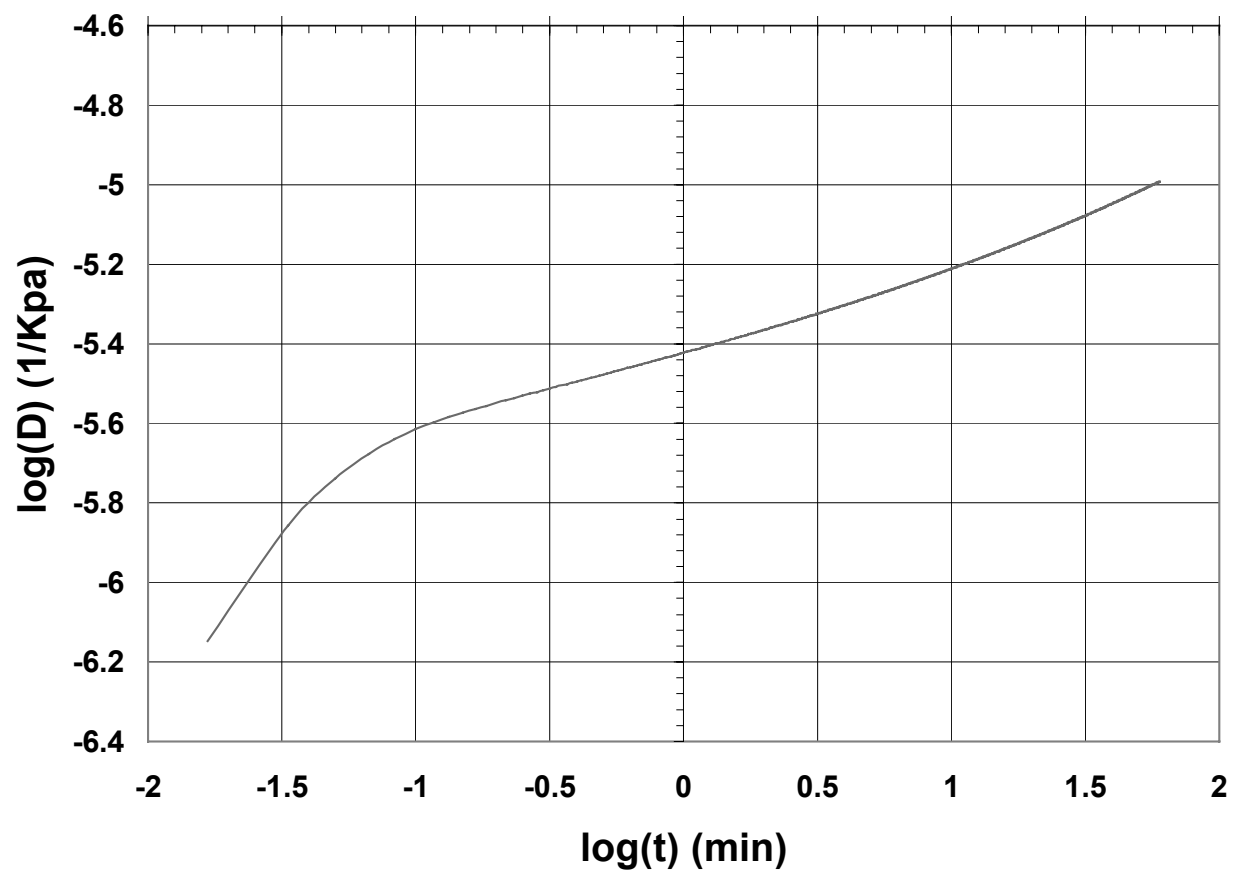

Fig 2.1 Momentary creep curve without discarding initial points (Material A)

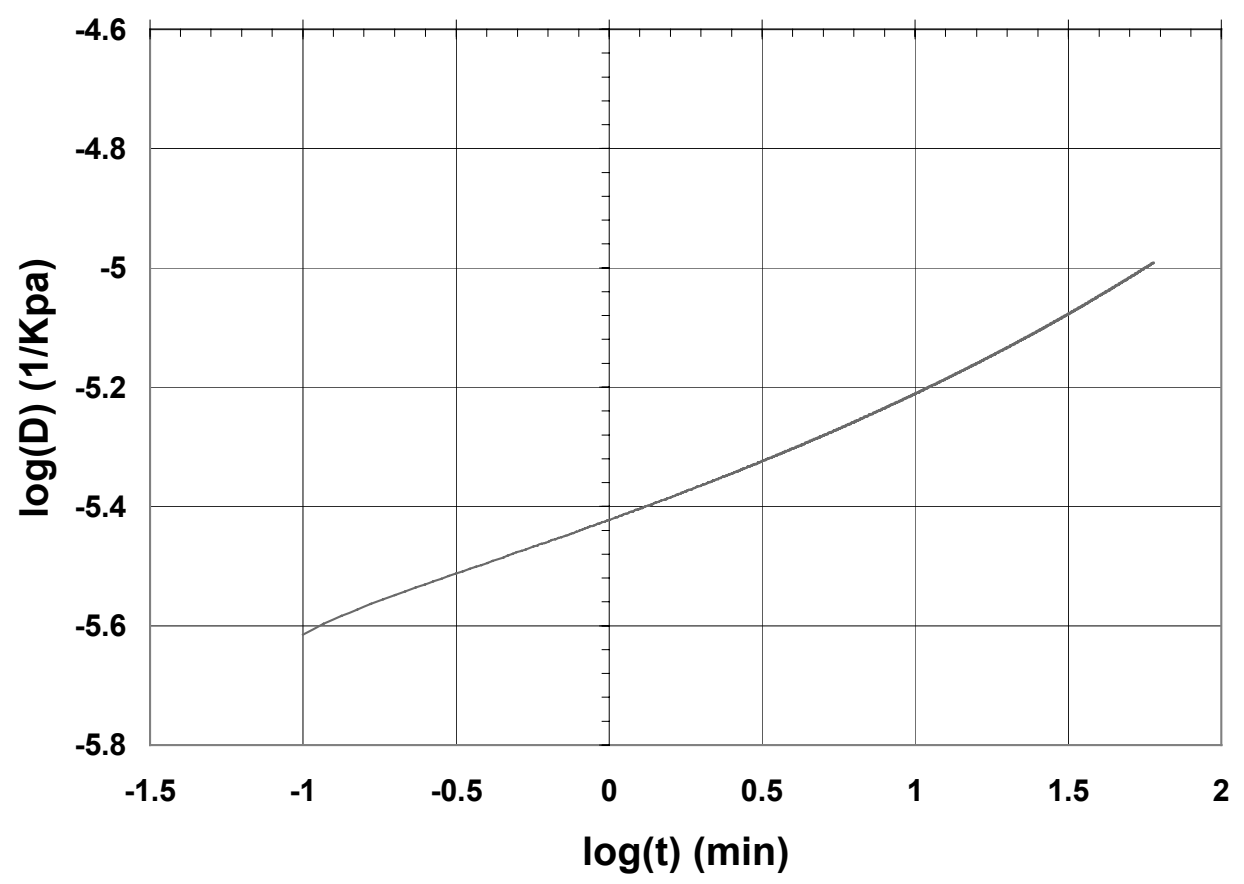

Fig 2.2 Momentary creep curve after discarding initial points (Material A) 


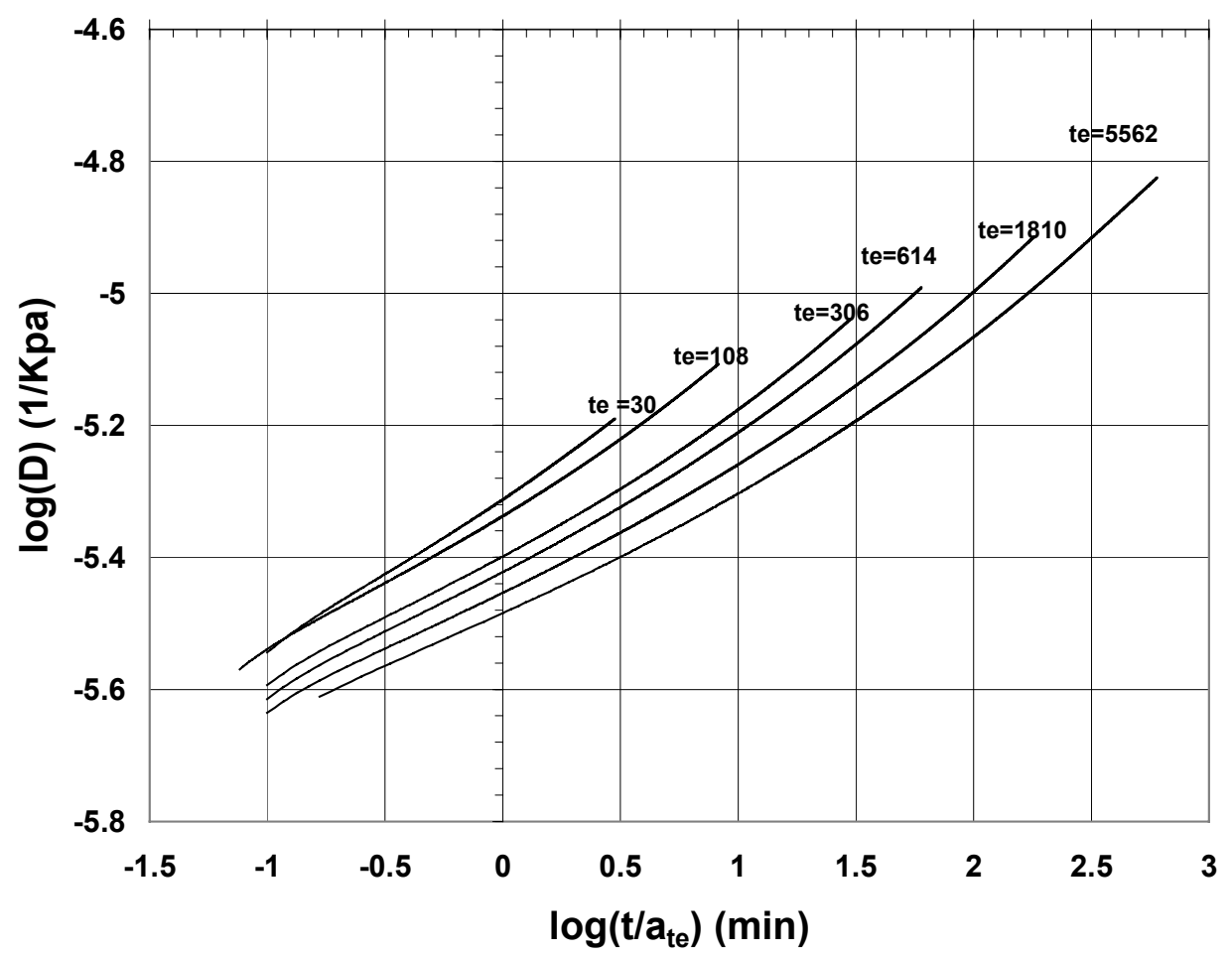

Fig 2.3 Momentary creep curves (Material A)

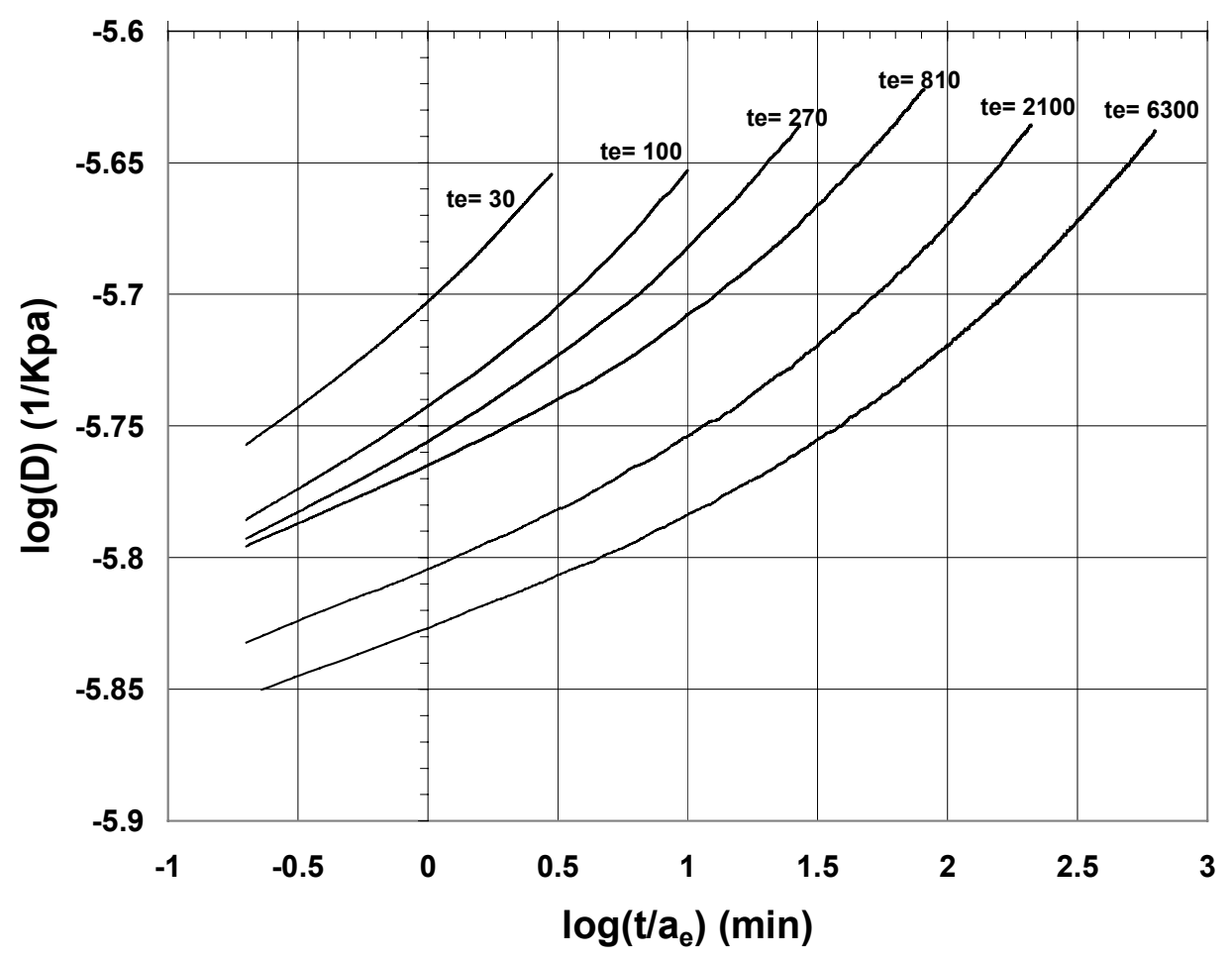

Fig 2.4 Momentary creep curves (Material B) 


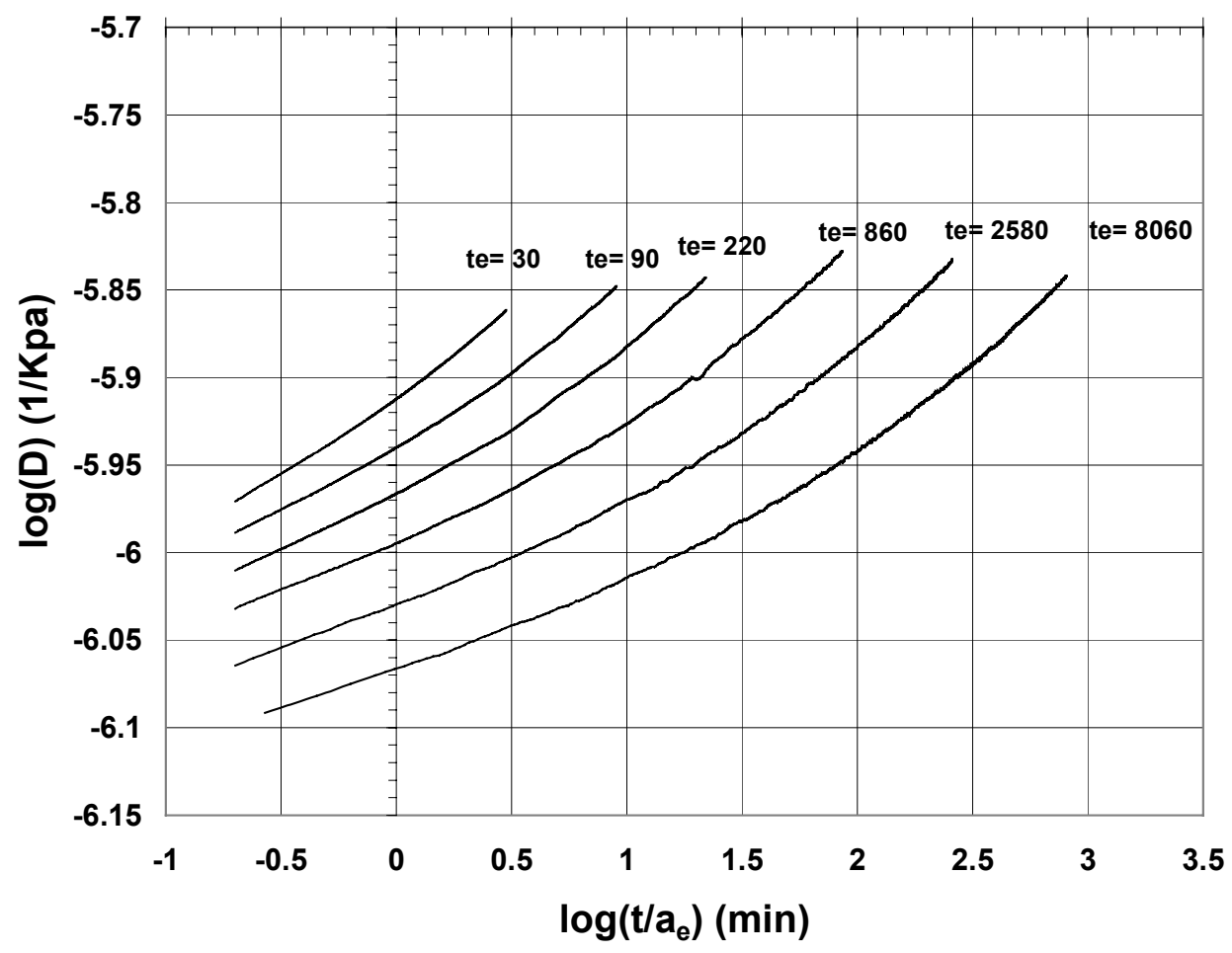

Fig 2.5 Momentary creep curves (Material C)

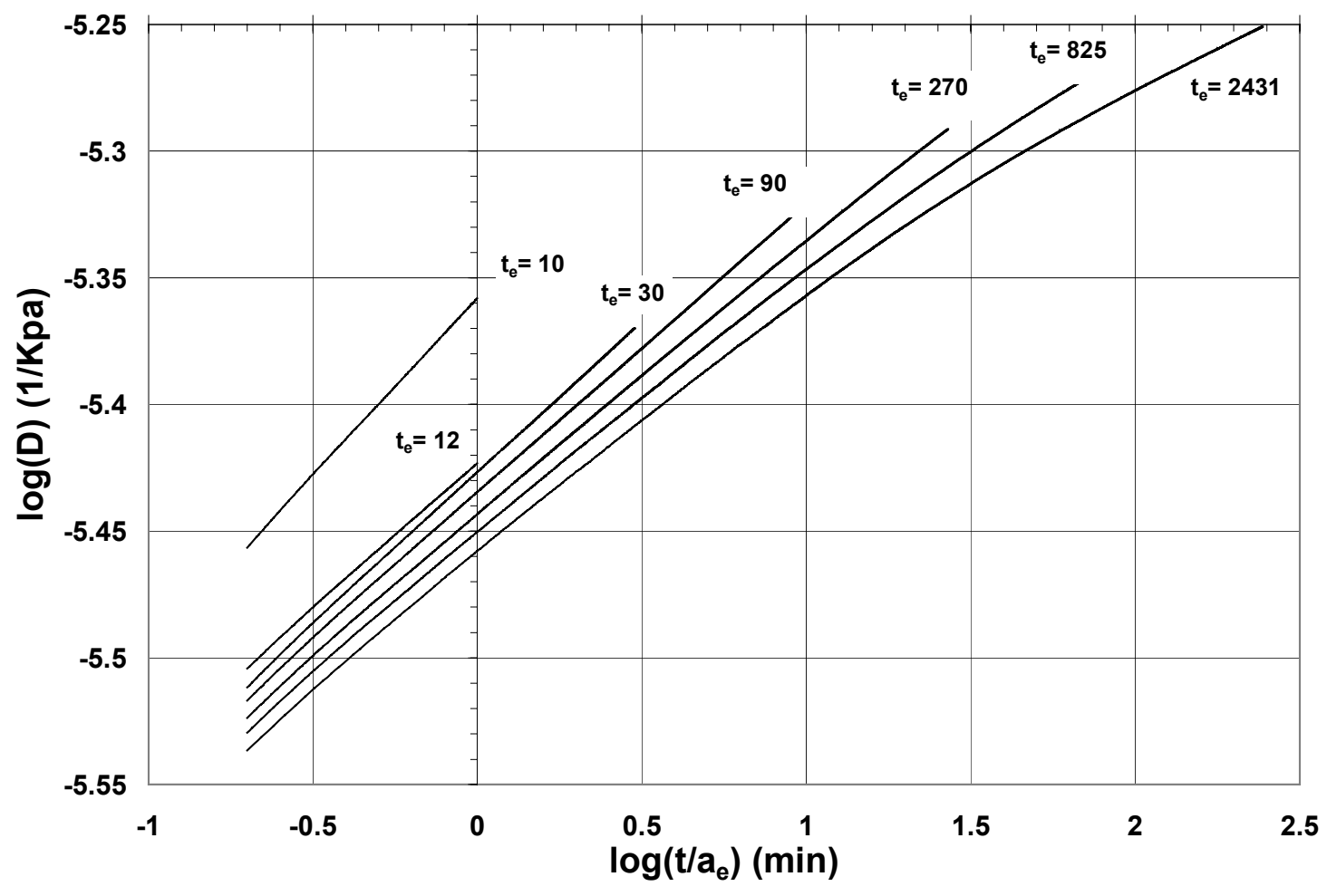

Fig 2.6 Momentary creep curves (Material D) 


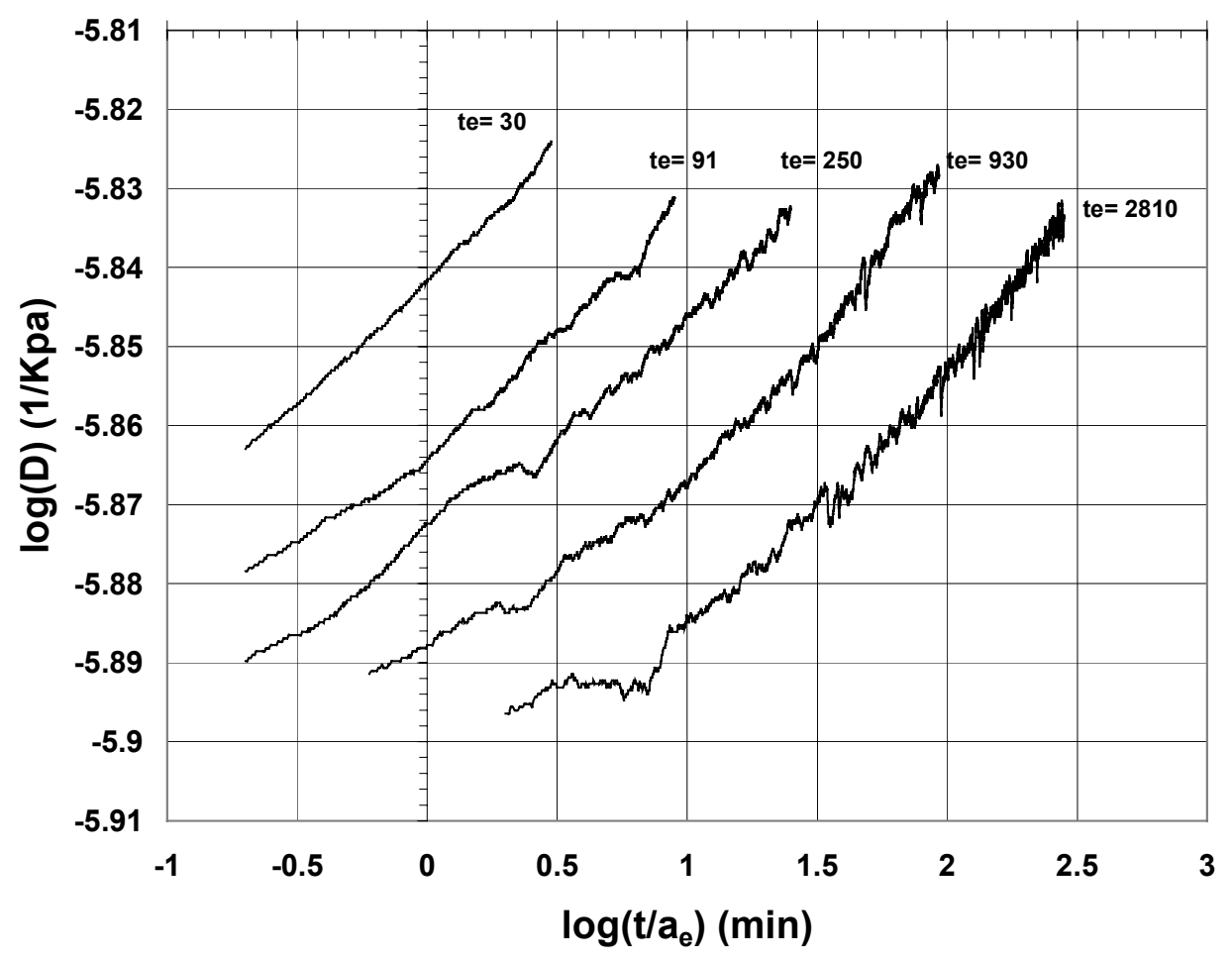

Fig 2.7 Momentary creep curves (Material E)

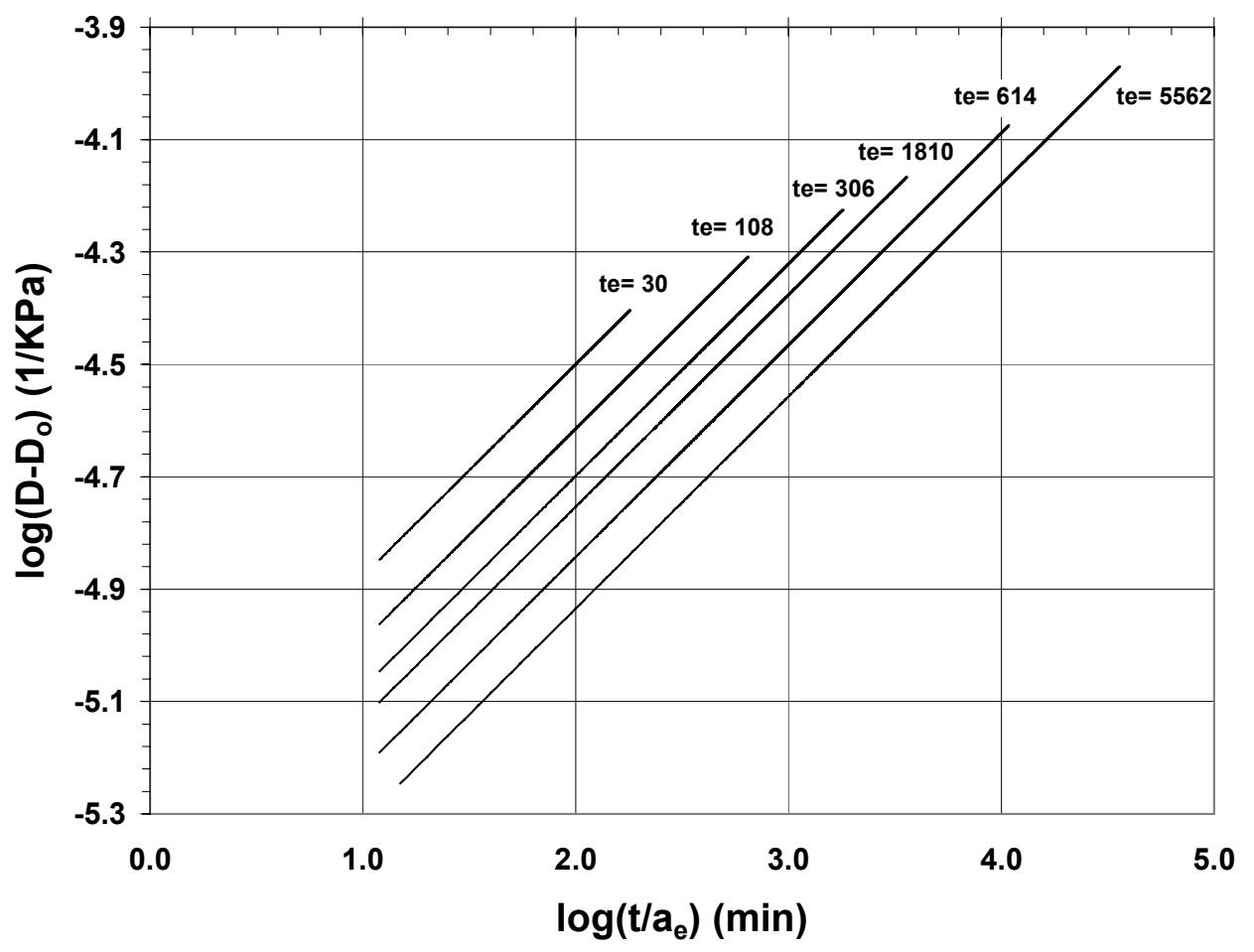

Fig 2.8 Data fitted using power law (Material A) 


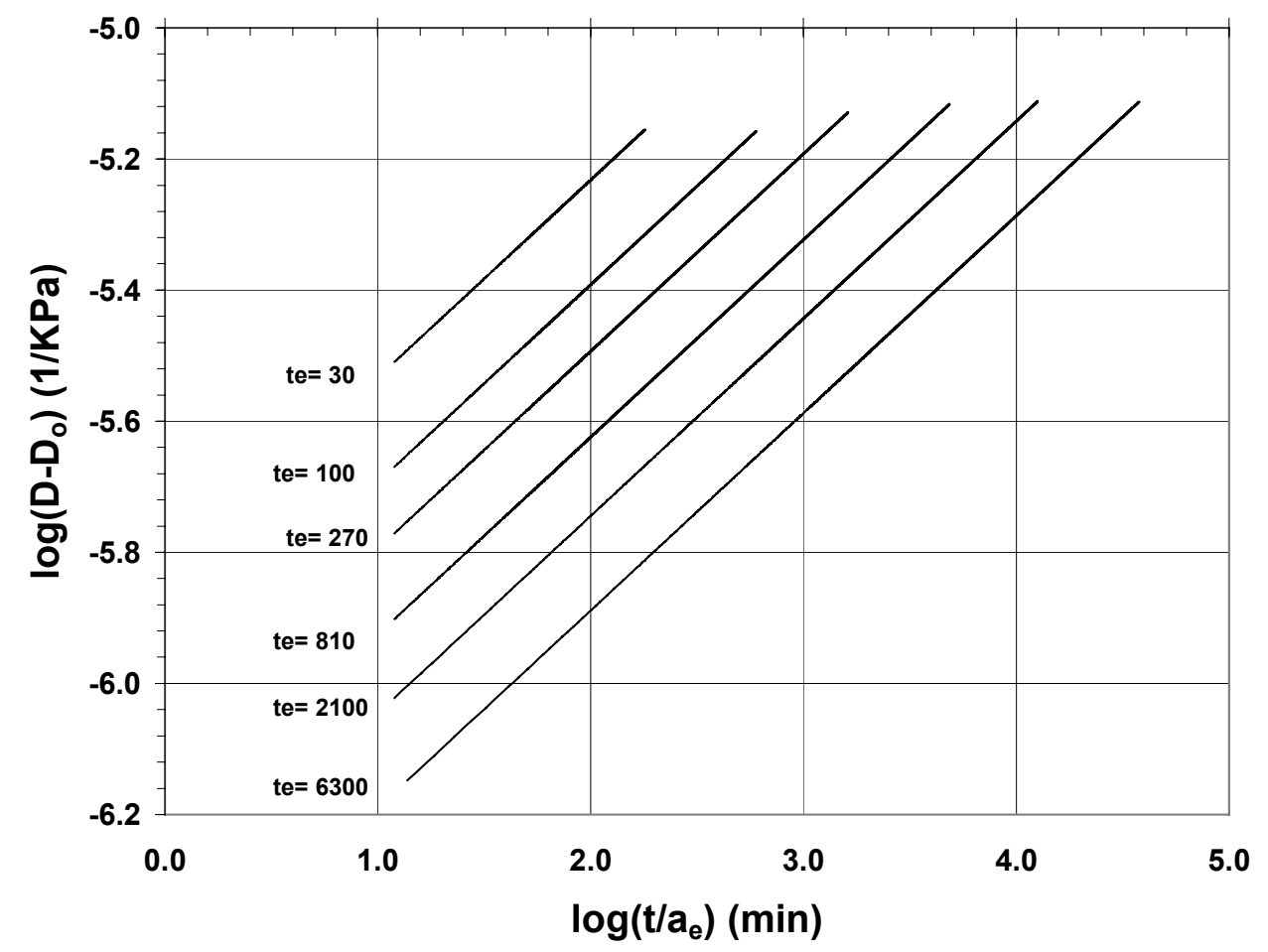

Fig 2.9 Data fitted using power law (Material B)

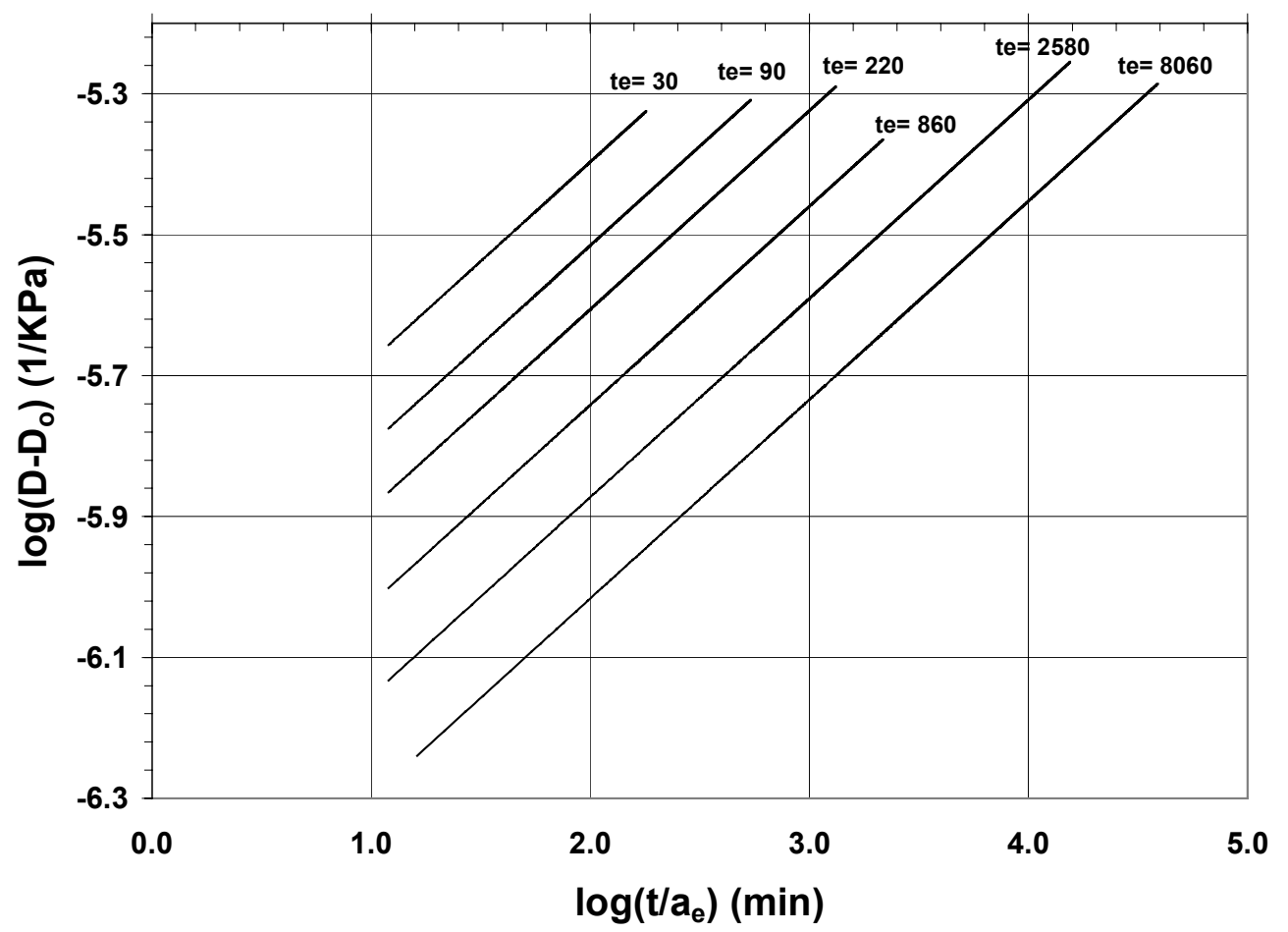

Fig 2.10 Data fitted using power law (Material C) 


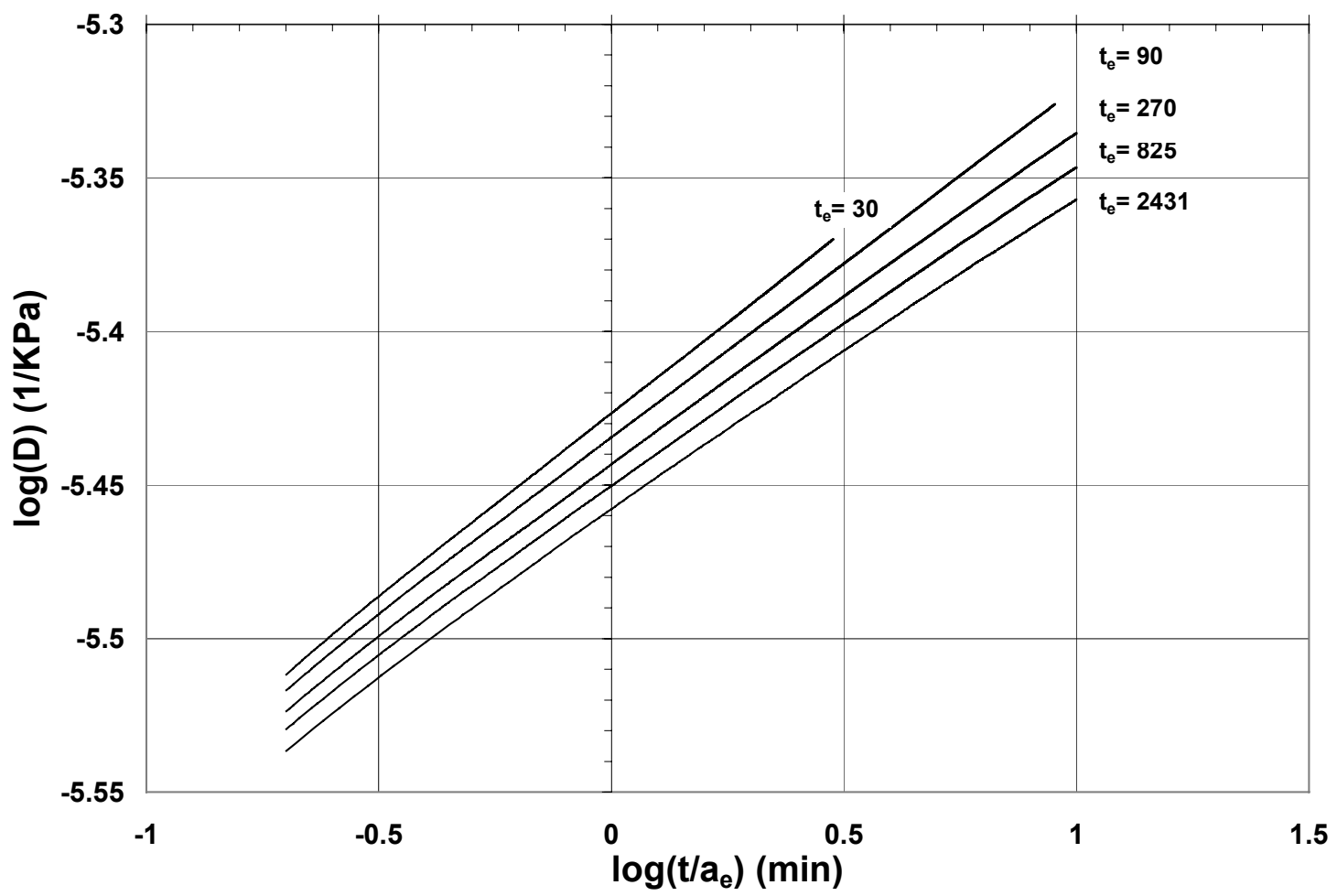

Fig 2.11 Data fitted using power law (Material D)

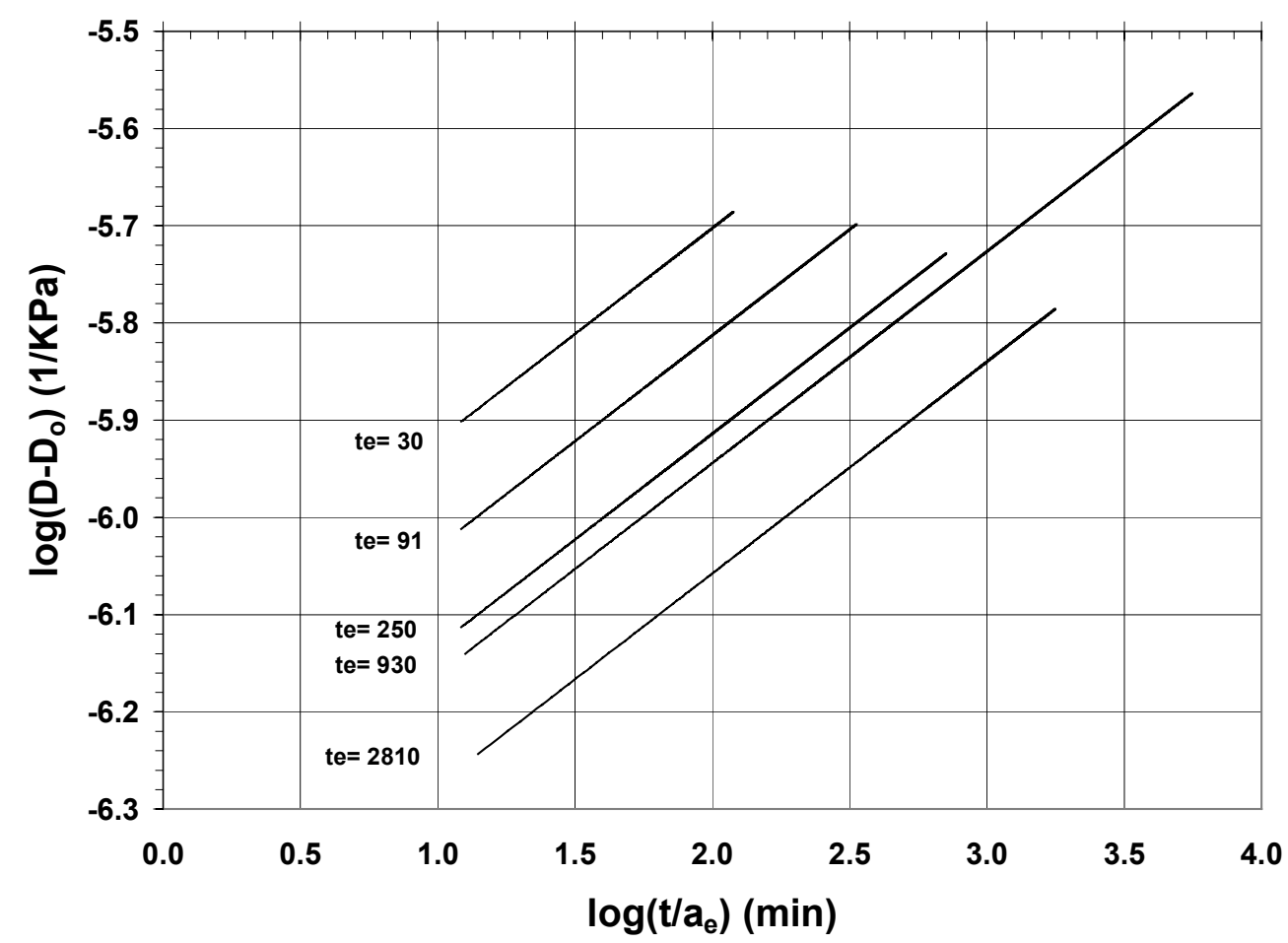

Fig 2.12 Data fitted using power law (Material E) 


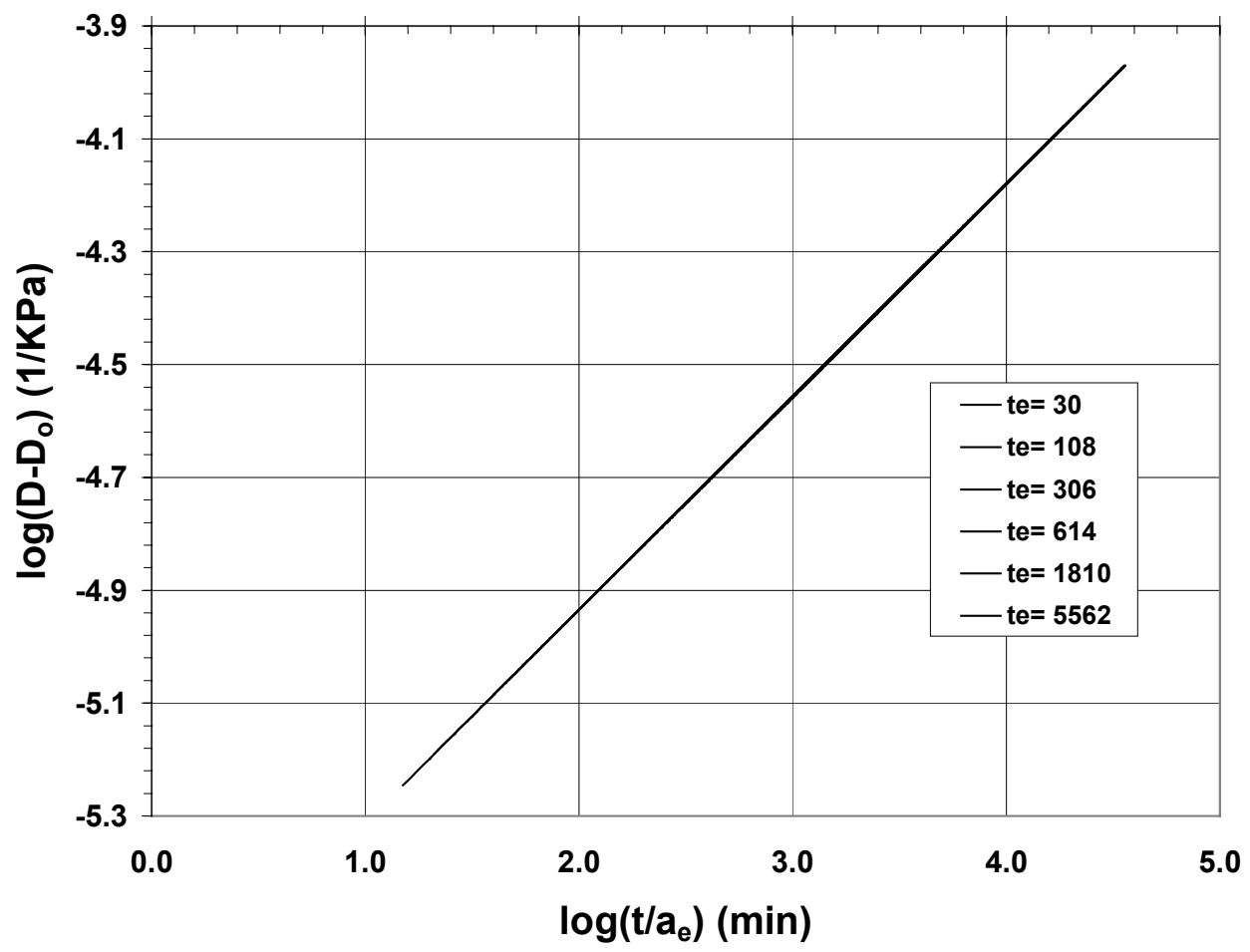

Fig 2.13 Master momentary curve at $t_{\text {e-ref }}=5562 \mathrm{~min}($ Material A)

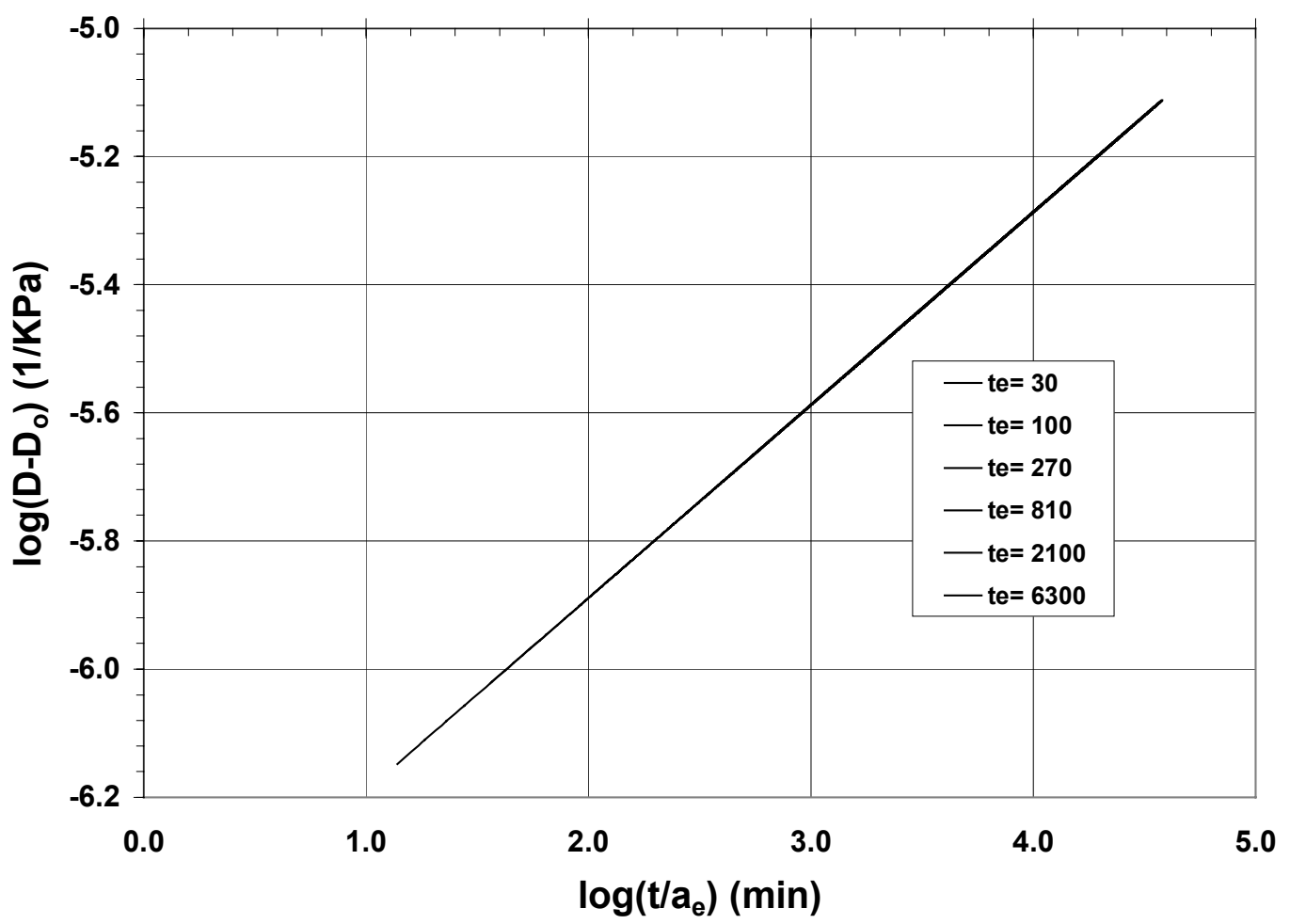

Fig 2.14 Master momentary curve at $t_{\text {e-ref }}=6300 \mathrm{~min}$ (Material $\mathrm{B}$ ) 


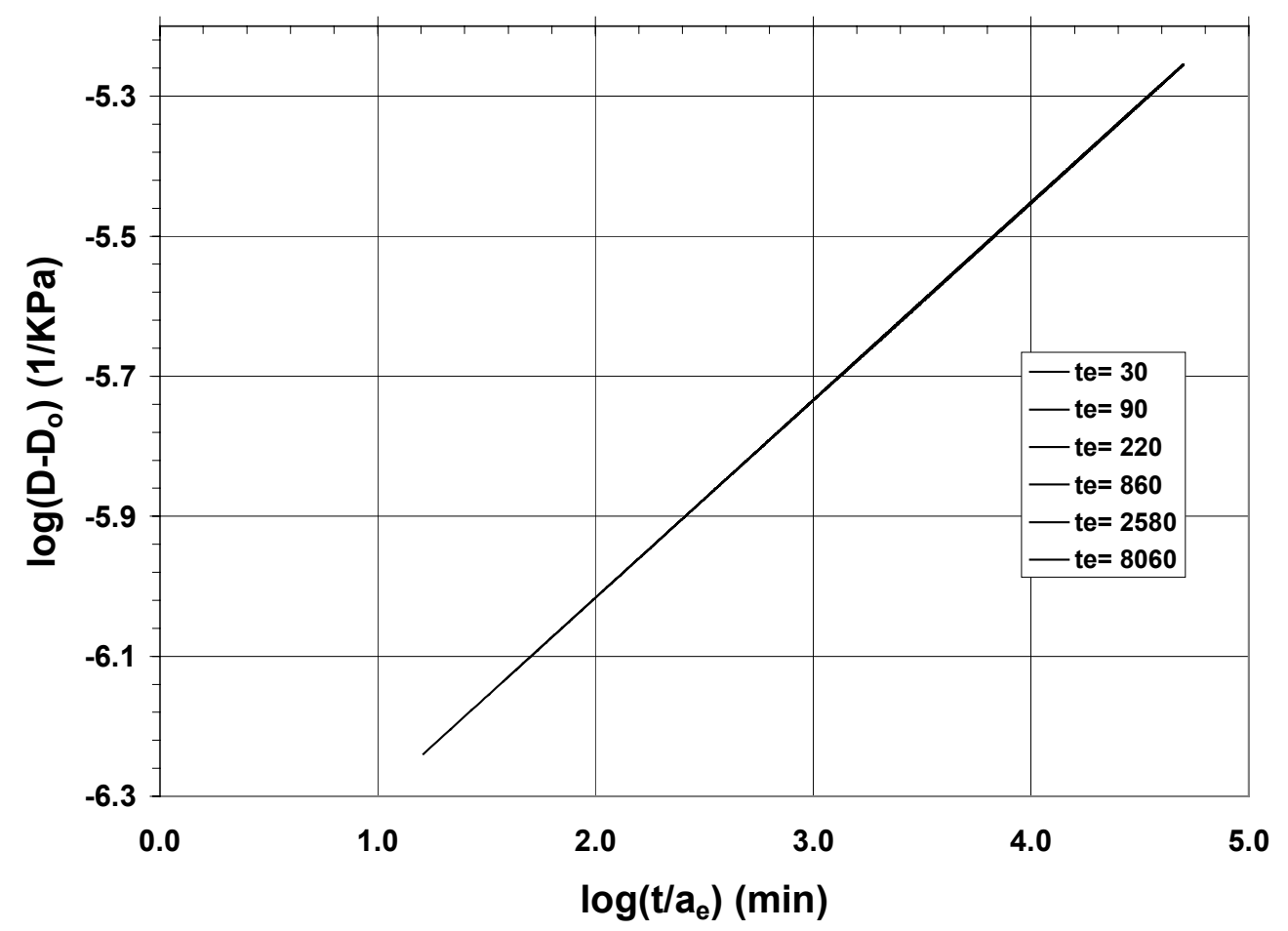

Fig 2.15 Master momentary curve at $t_{\text {e-ref }}=8060 \mathrm{~min}$ (Material C)

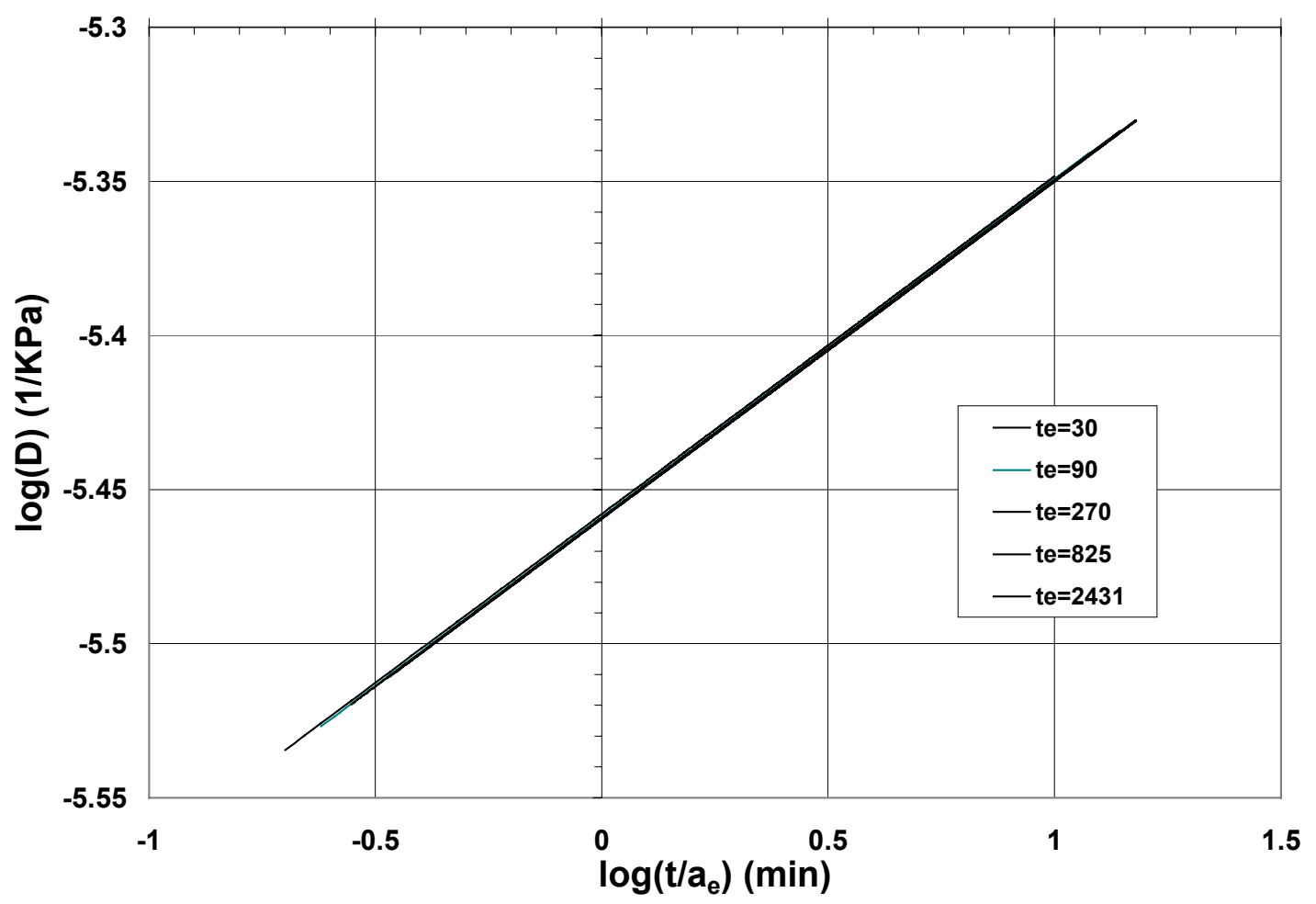

Fig 2.16 Master momentary curve at $t_{\text {e-ref }}=2431 \mathrm{~min}$ (Material D) 


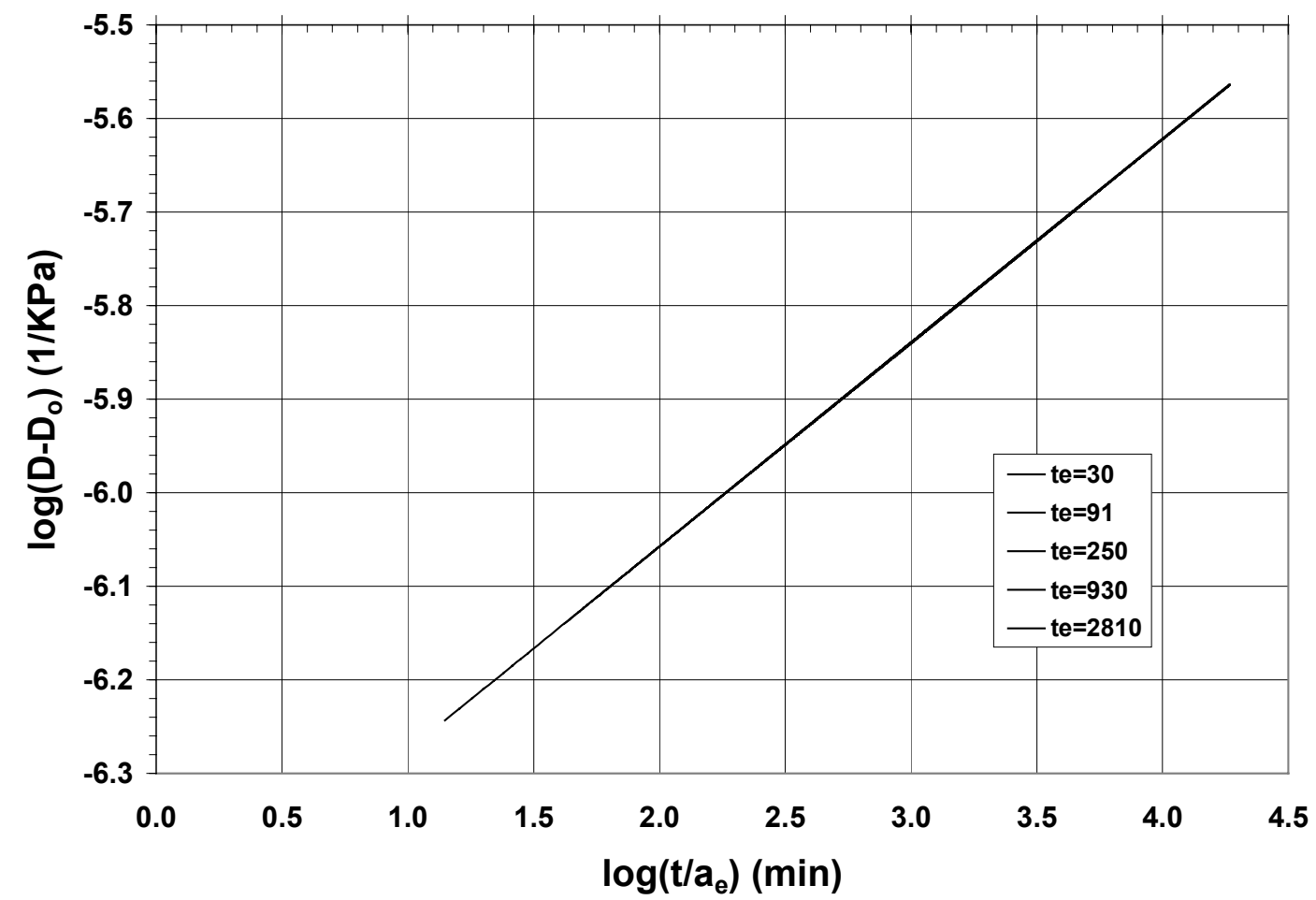

Fig 2.17 Master momentary curve at $t_{\text {e-ref }}=\mathbf{2 8 1 0}$ min (Material E)

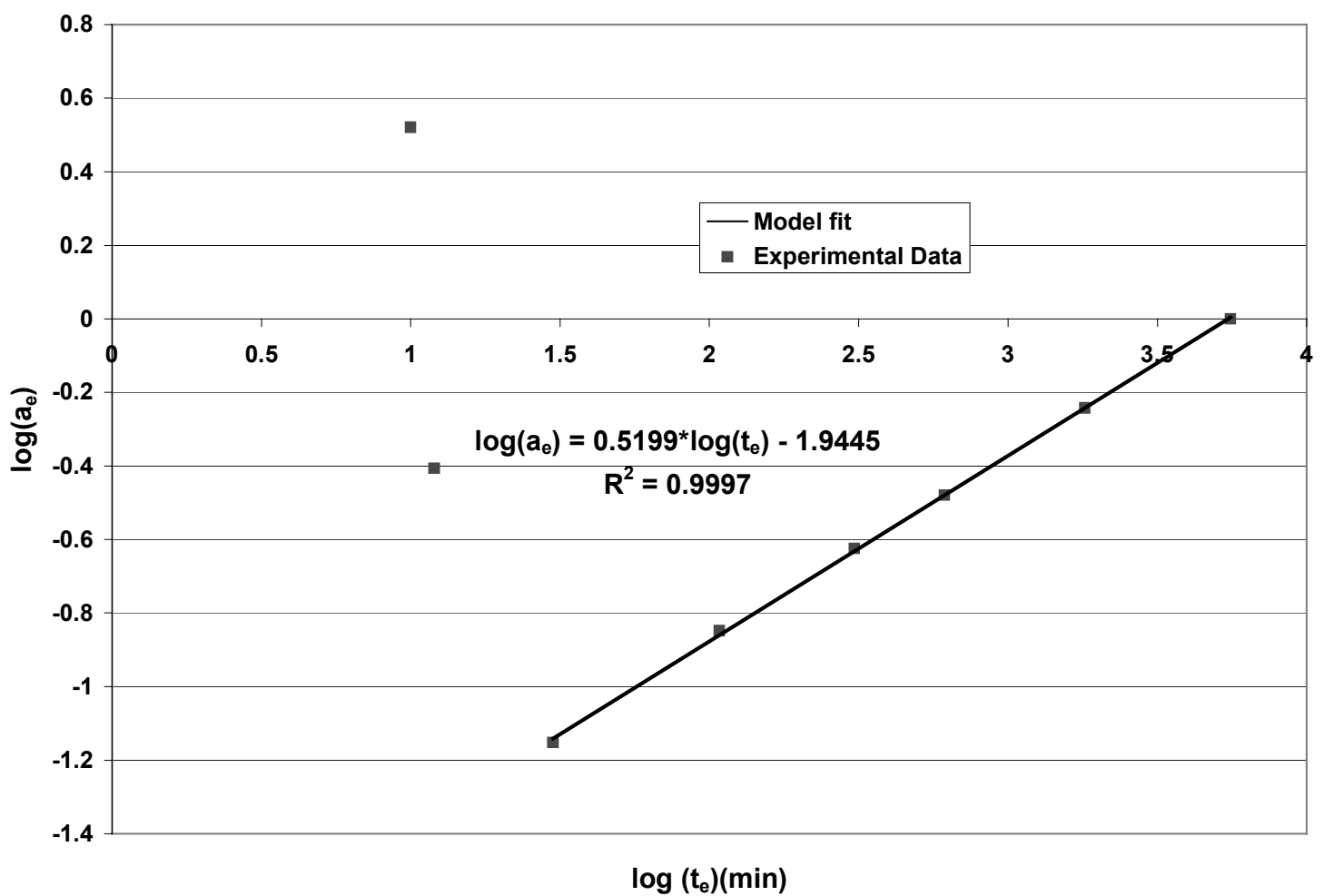

Fig $2.18 \log \left(t_{e}\right)$ vs $\log \left(a_{e}\right)($ Material $A)$ 


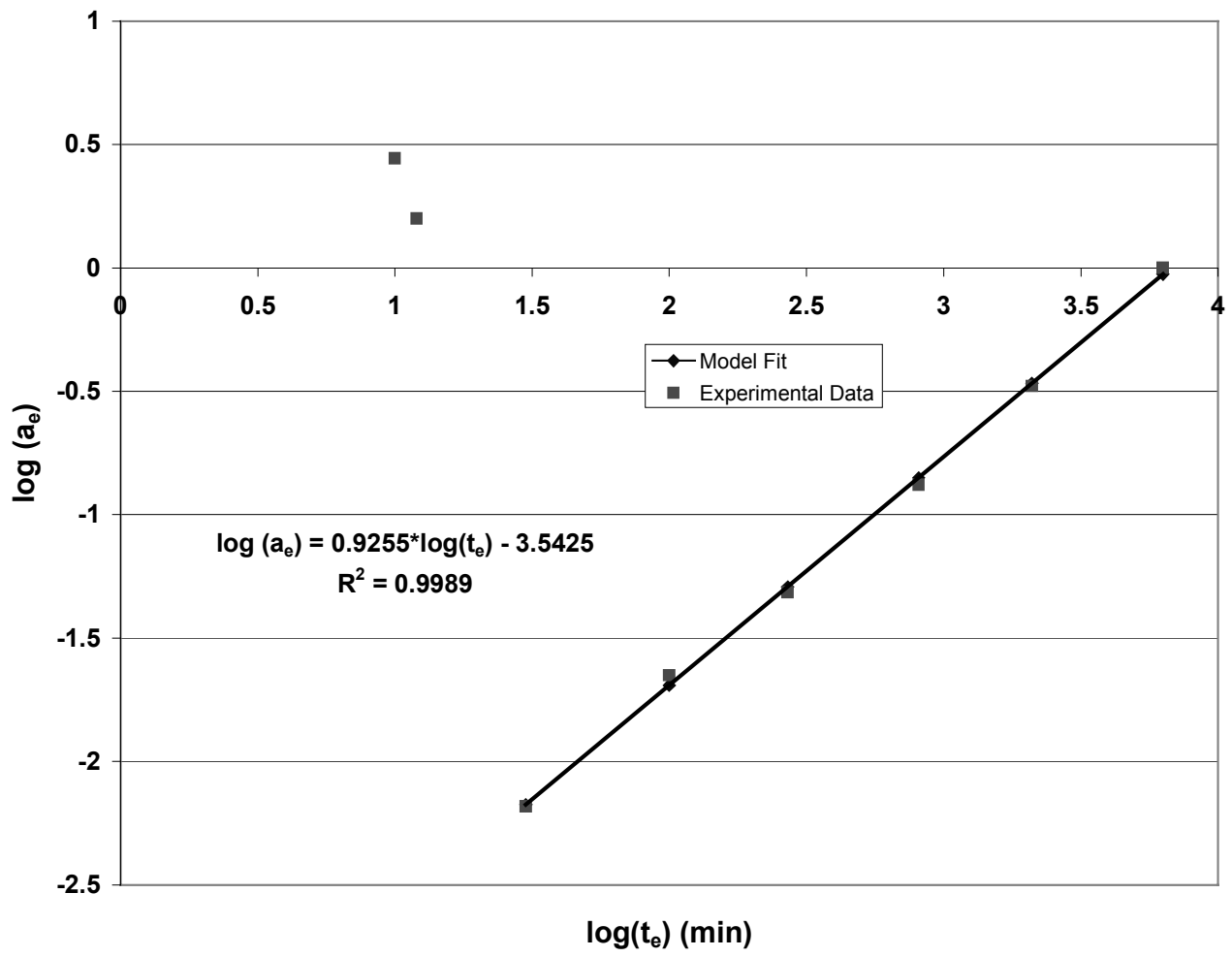

Fig $2.19 \log \left(t_{e}\right)$ vs $\log \left(a_{e}\right)($ Material $B)$

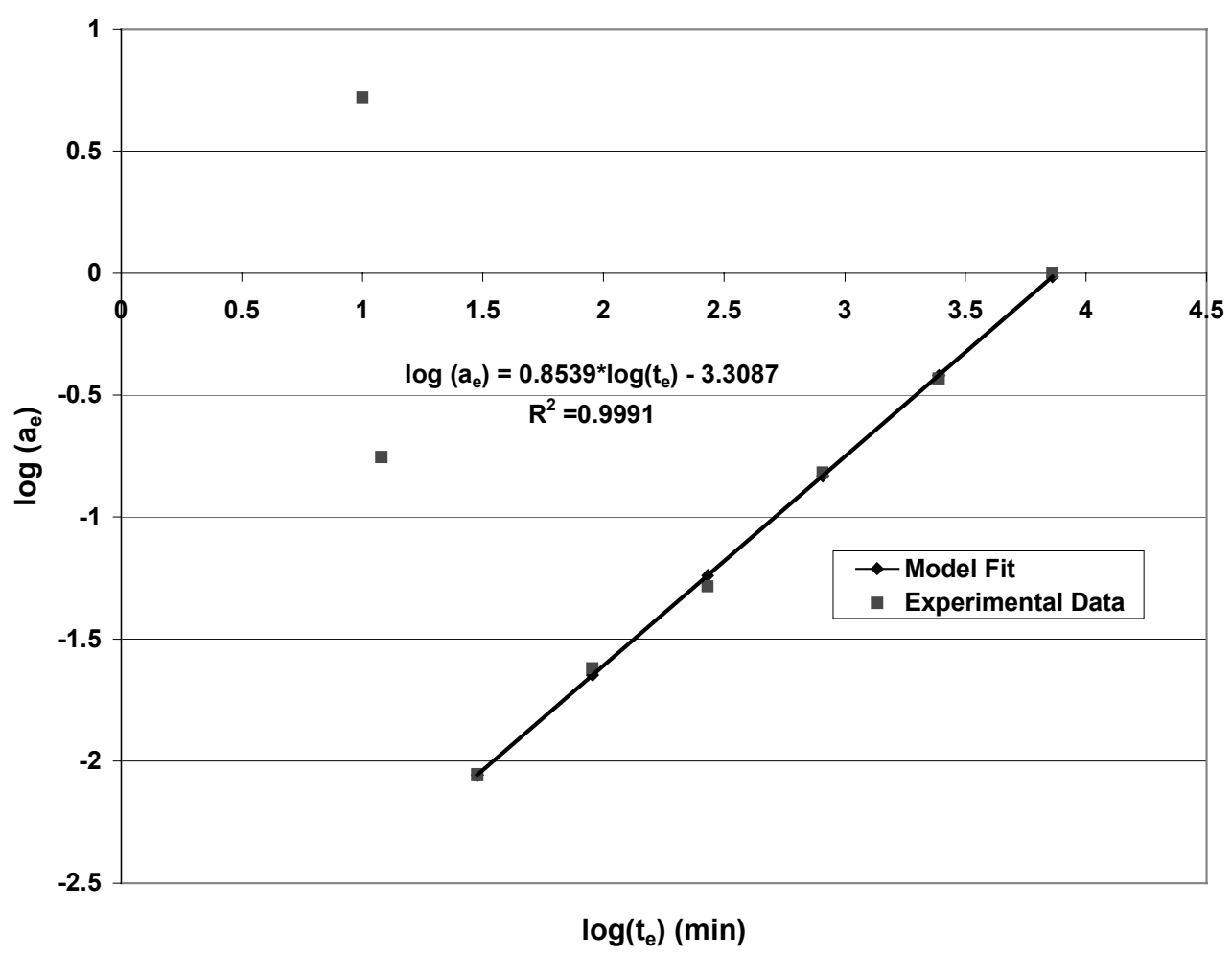

Fig $2.20 \log \left(t_{e}\right)$ vs $\log \left(a_{e}\right)($ Material $C)$ 


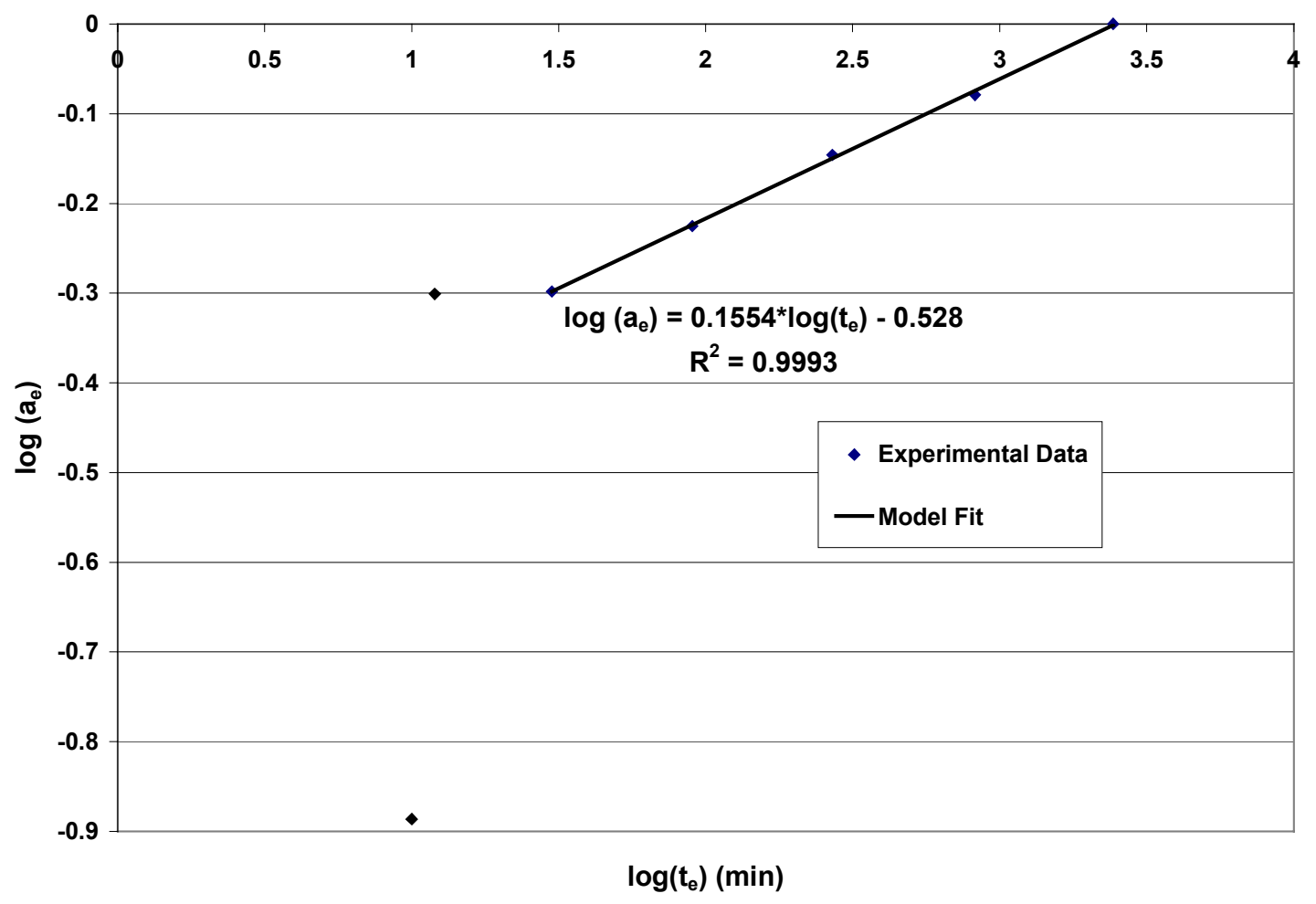

Fig 2.21 $\log \left(t_{e}\right)$ vs $\log \left(a_{e}\right)($ Material D)

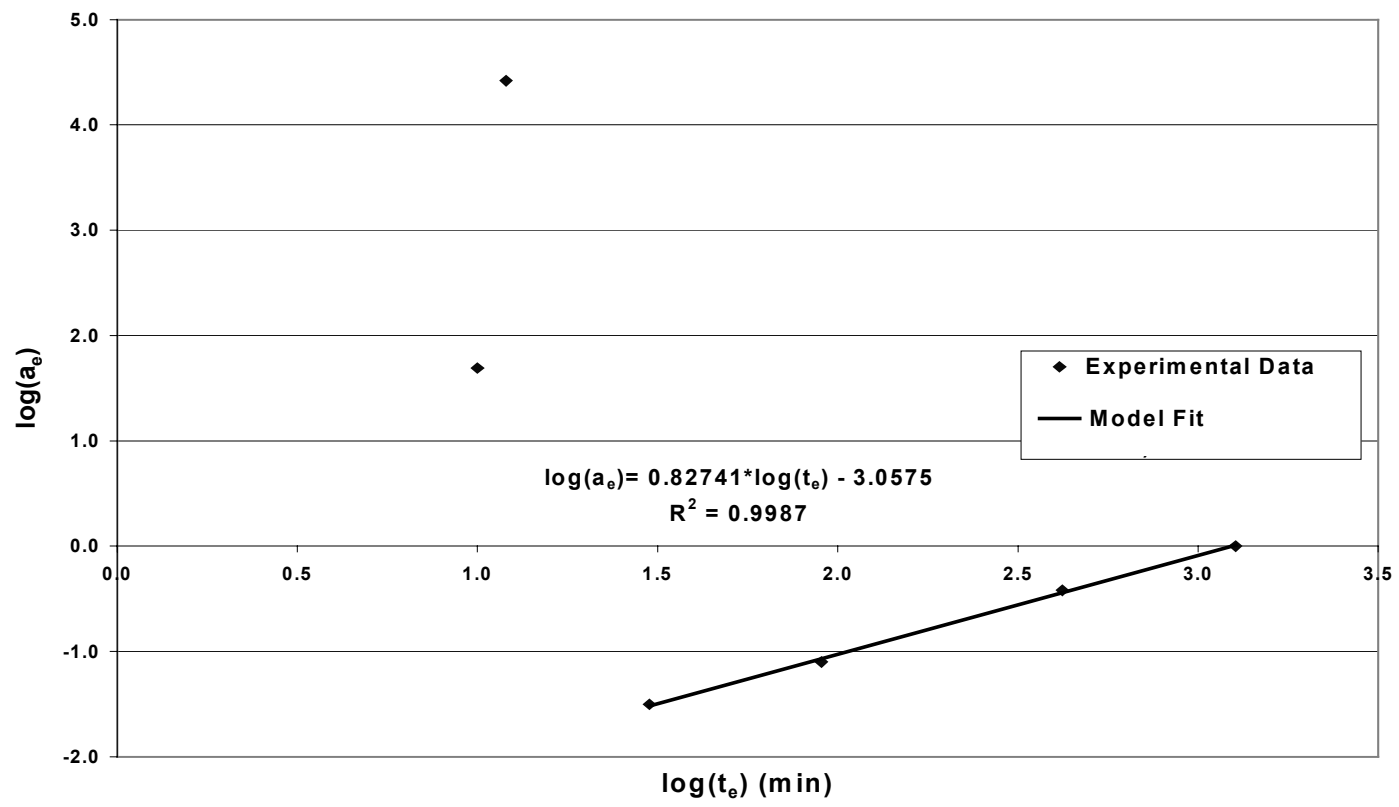

Fig 2.22 $\log \left(t_{e}\right)$ vs $\log \left(a_{e}\right)($ Material E) 


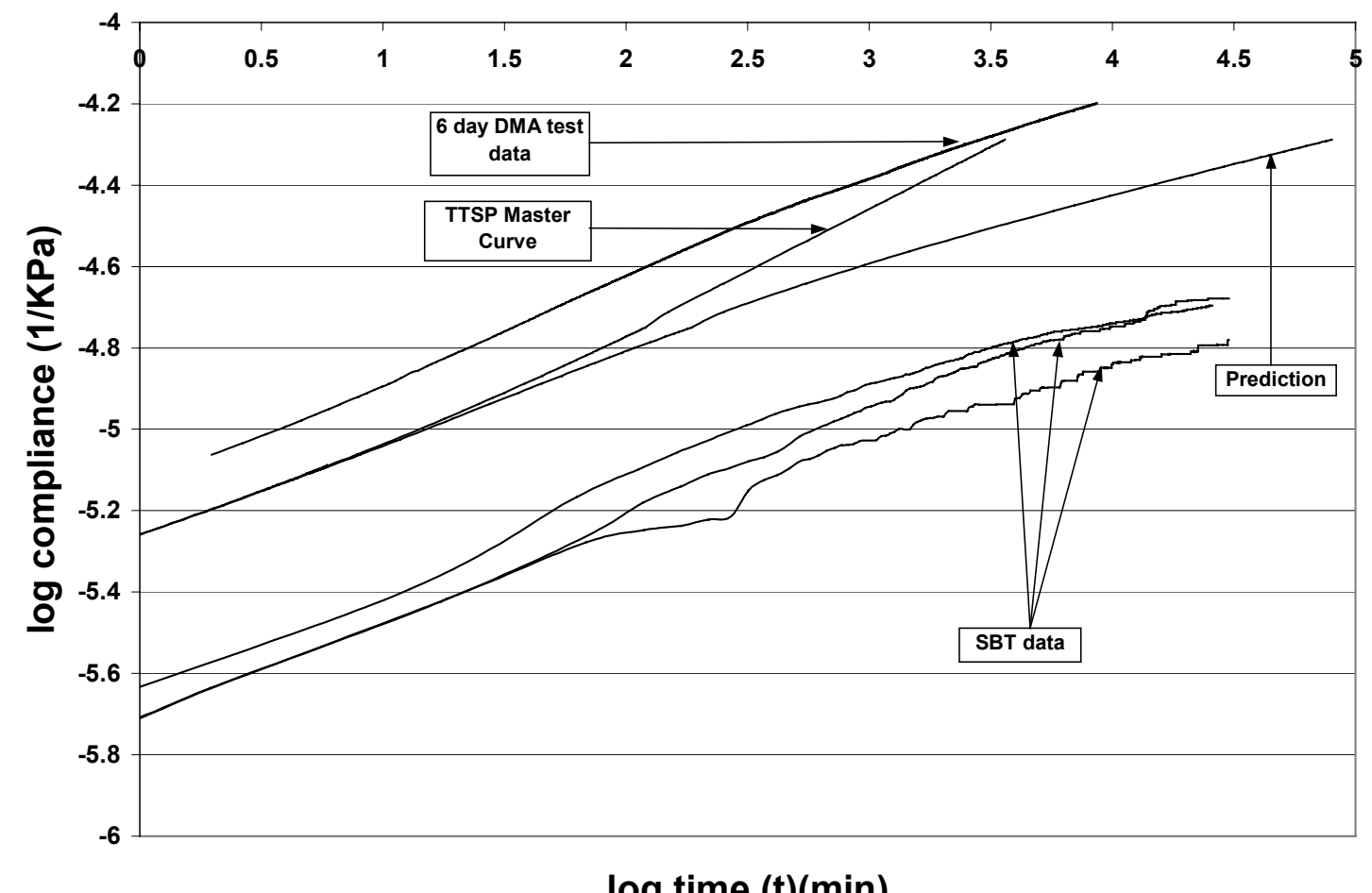

Fig 2.23 Comparison with long-term bending data (Material A)

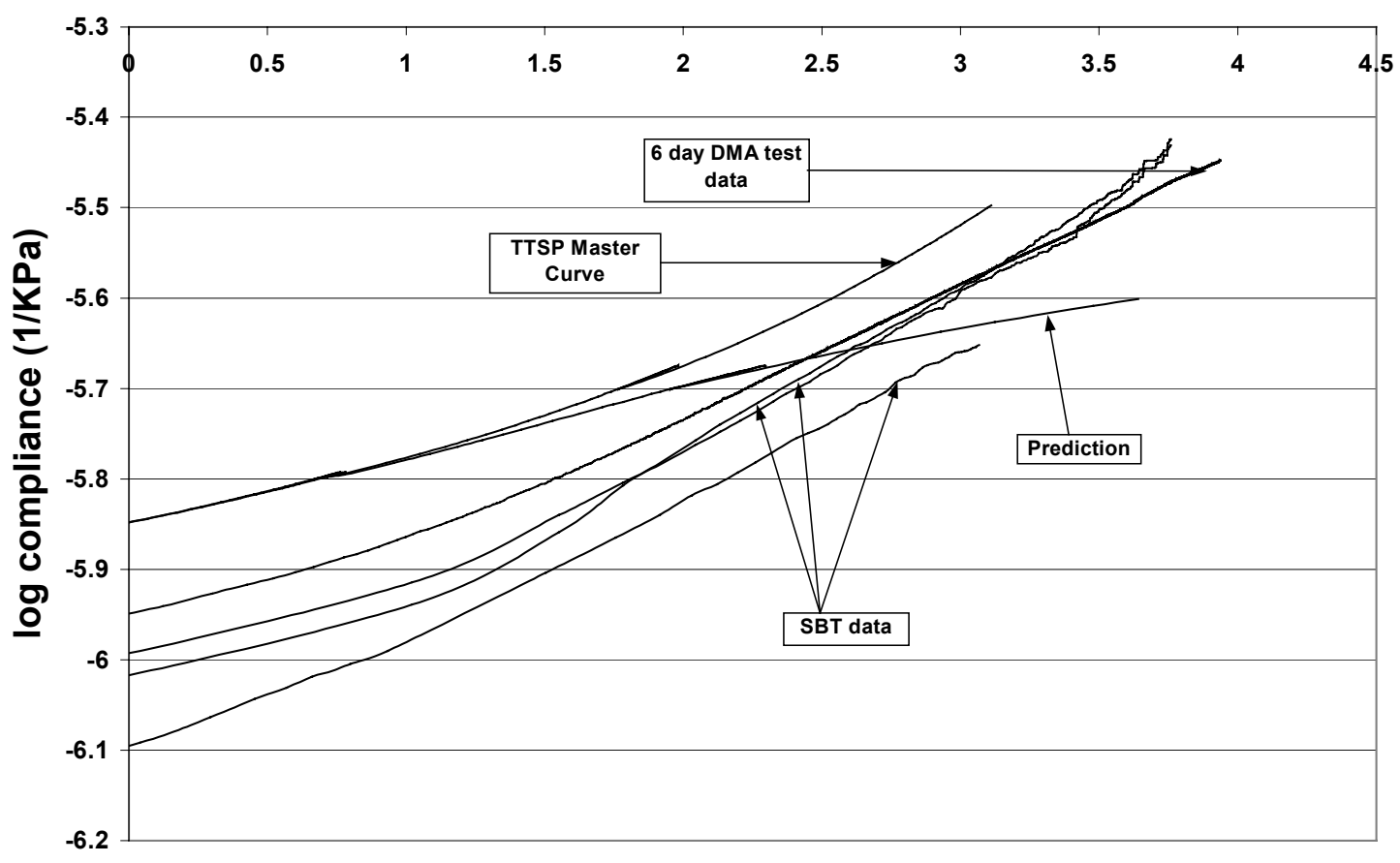

$\log$ time $(t)(\min )$

Fig 2.24 Comparison with long-term bending data (Material B) 


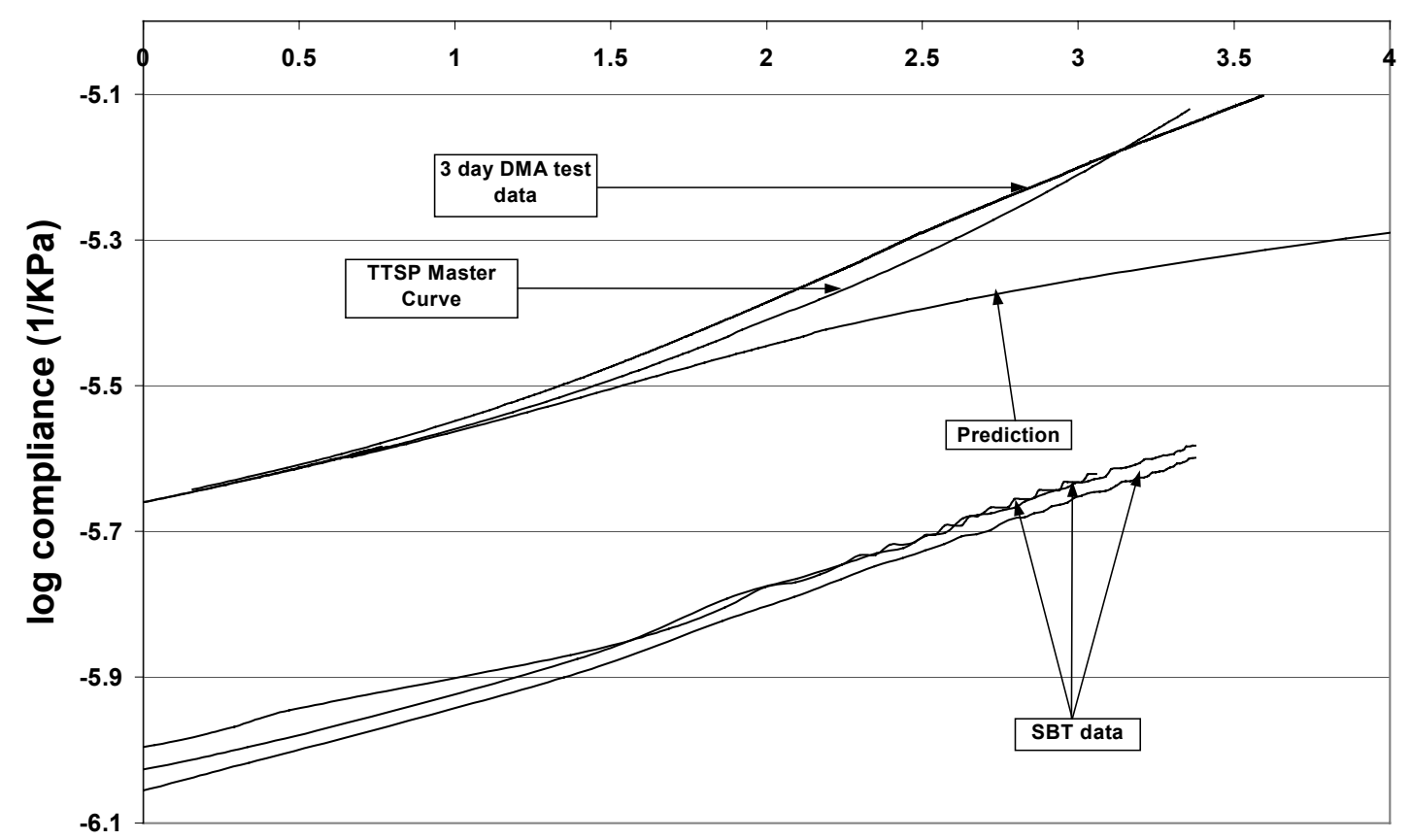

log time $(t)(\mathrm{min})$

Fig 2.25 Comparison with long-term bending data (Material C)

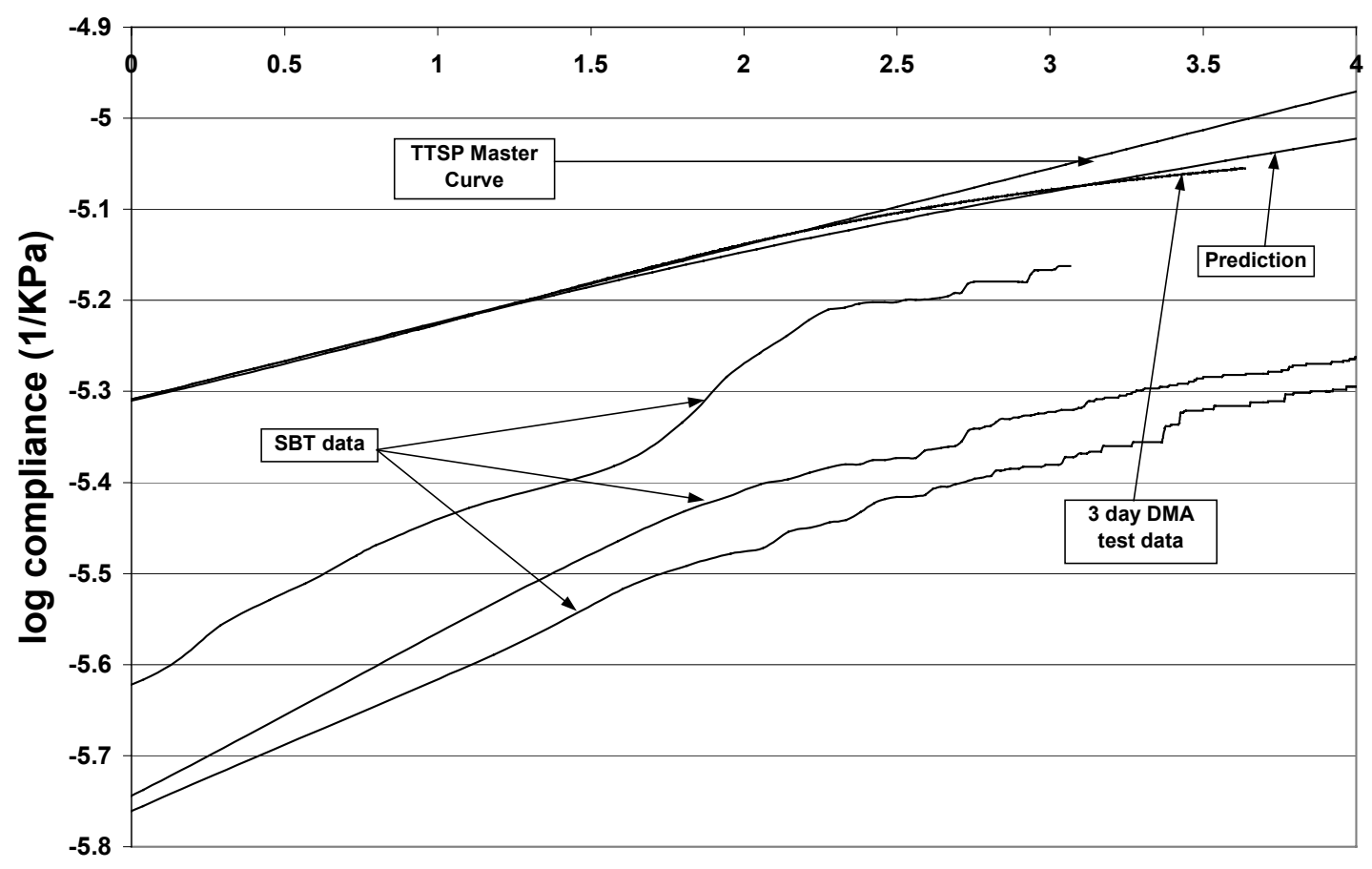

$\log$ time $(t)(\min )$

Fig 2.26 Comparison with long-term bending data (Material D) 


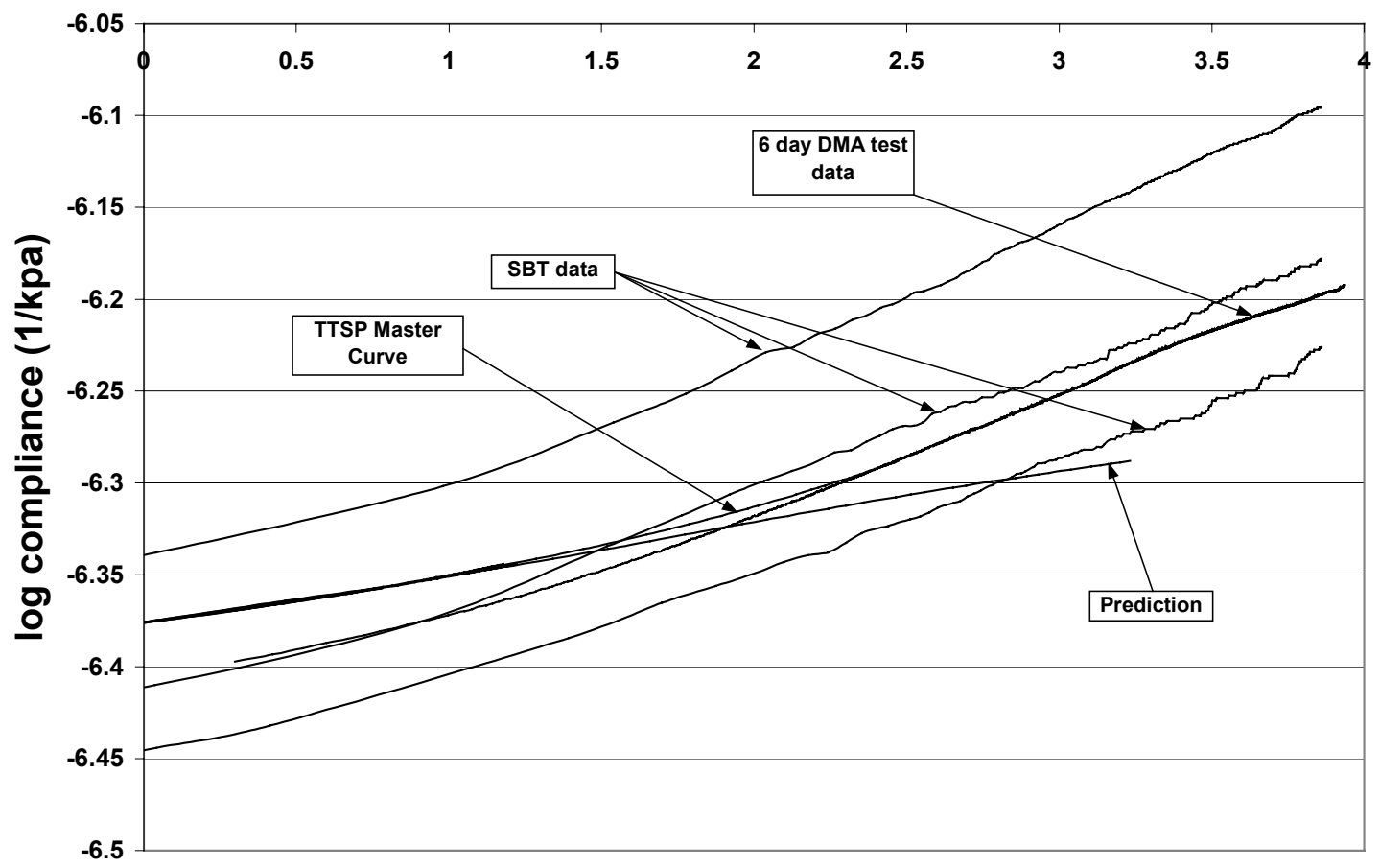

log time ( $\mathrm{min}$ )

Fig 2.27 Comparison with long-term bending data (Material E)

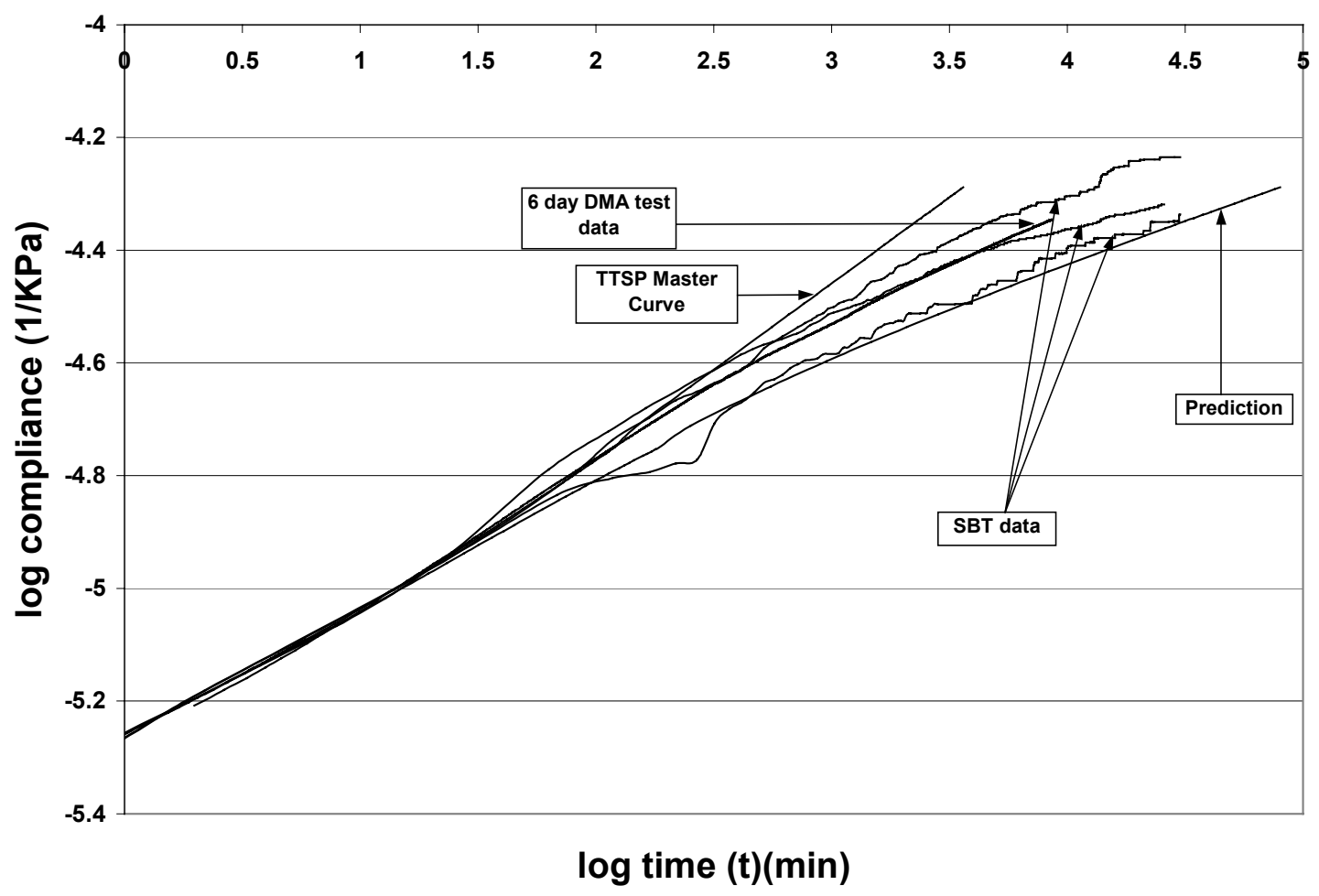

Fig 2.28 Comparison with long-term bending data after shifting (Material A) 


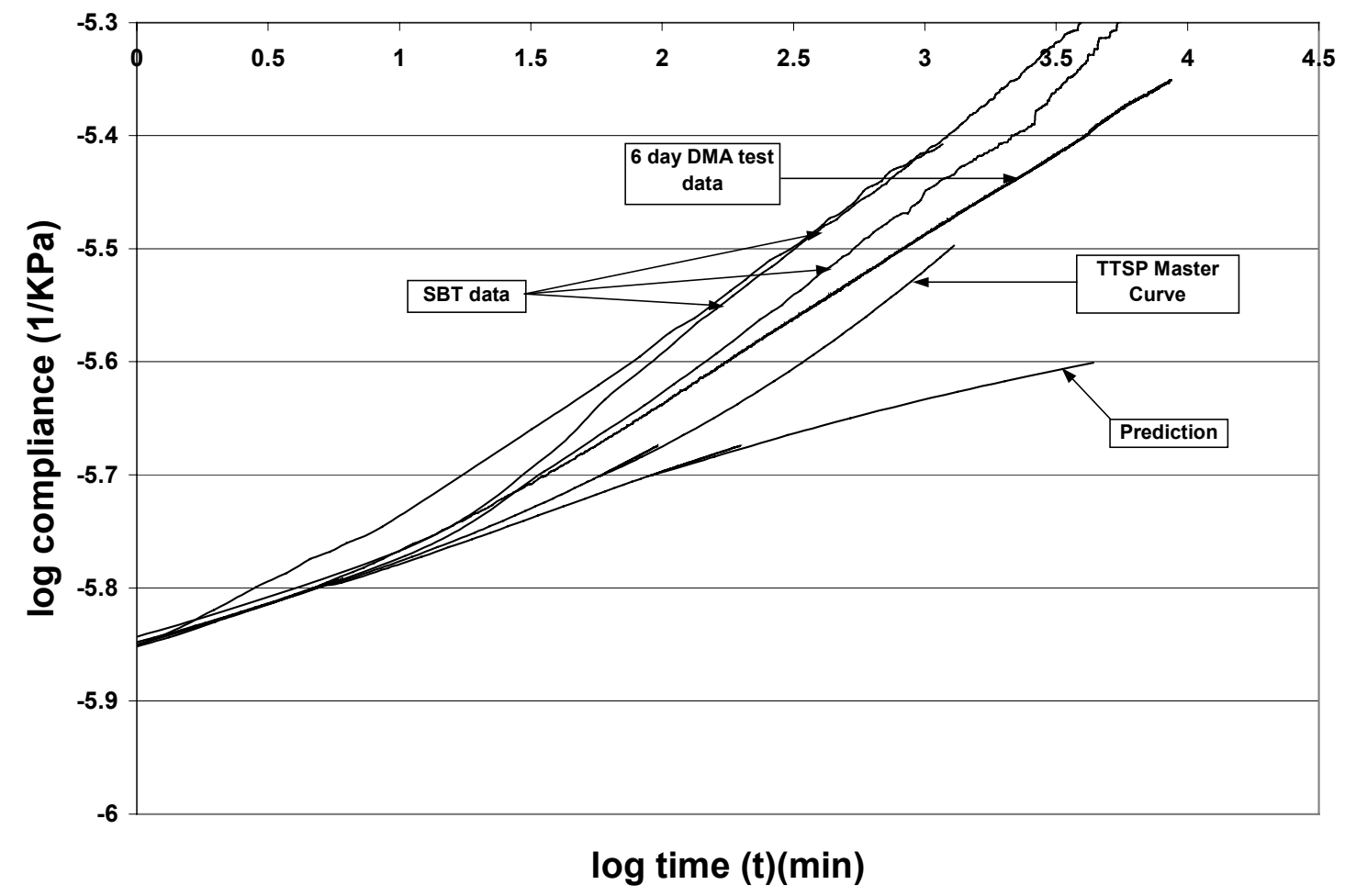

Fig 2.29 Comparison with long-term bending data after shifting (Material B)

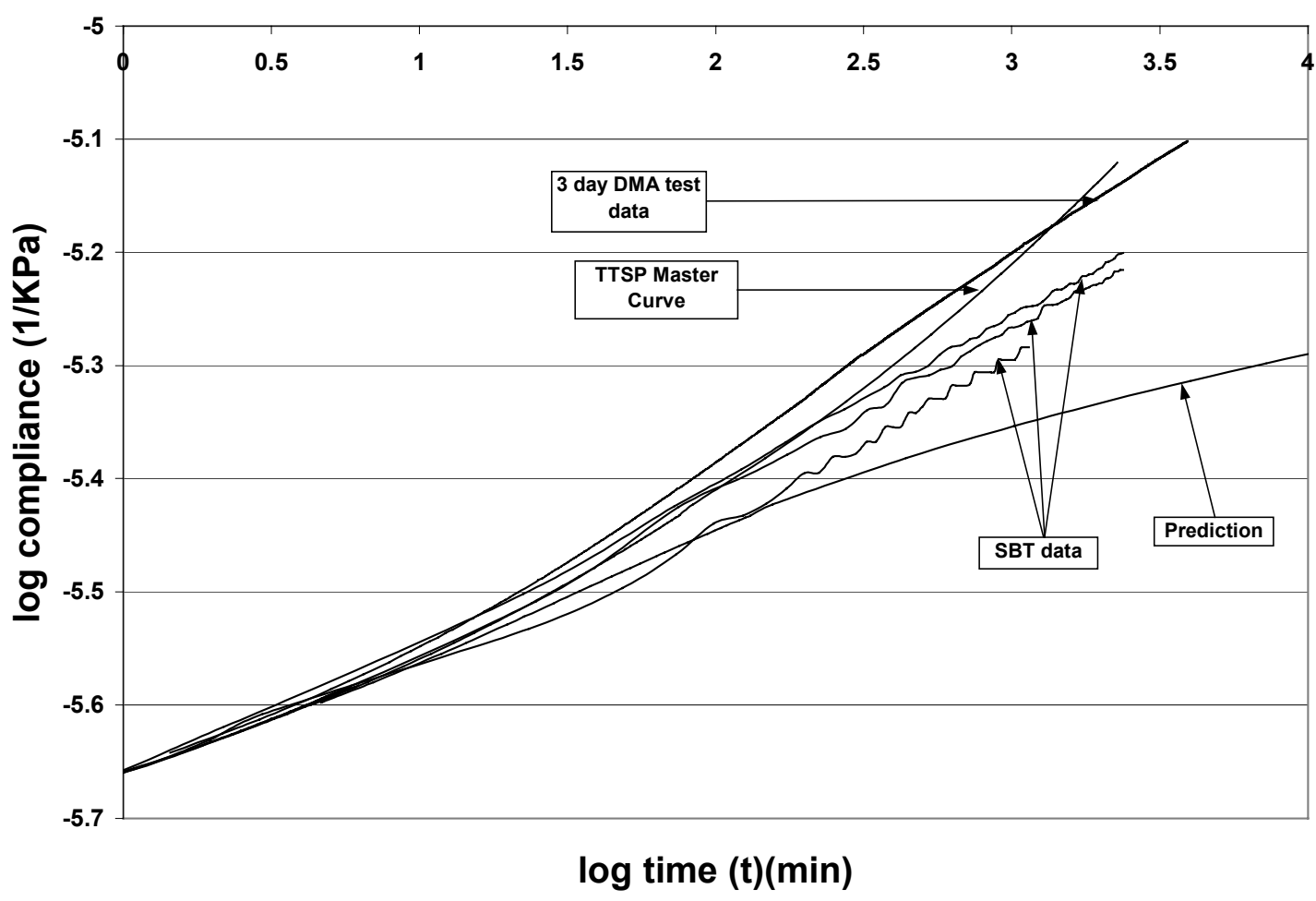

Fig 2.30 Comparison with long-term bending data after shifting (Material C) 


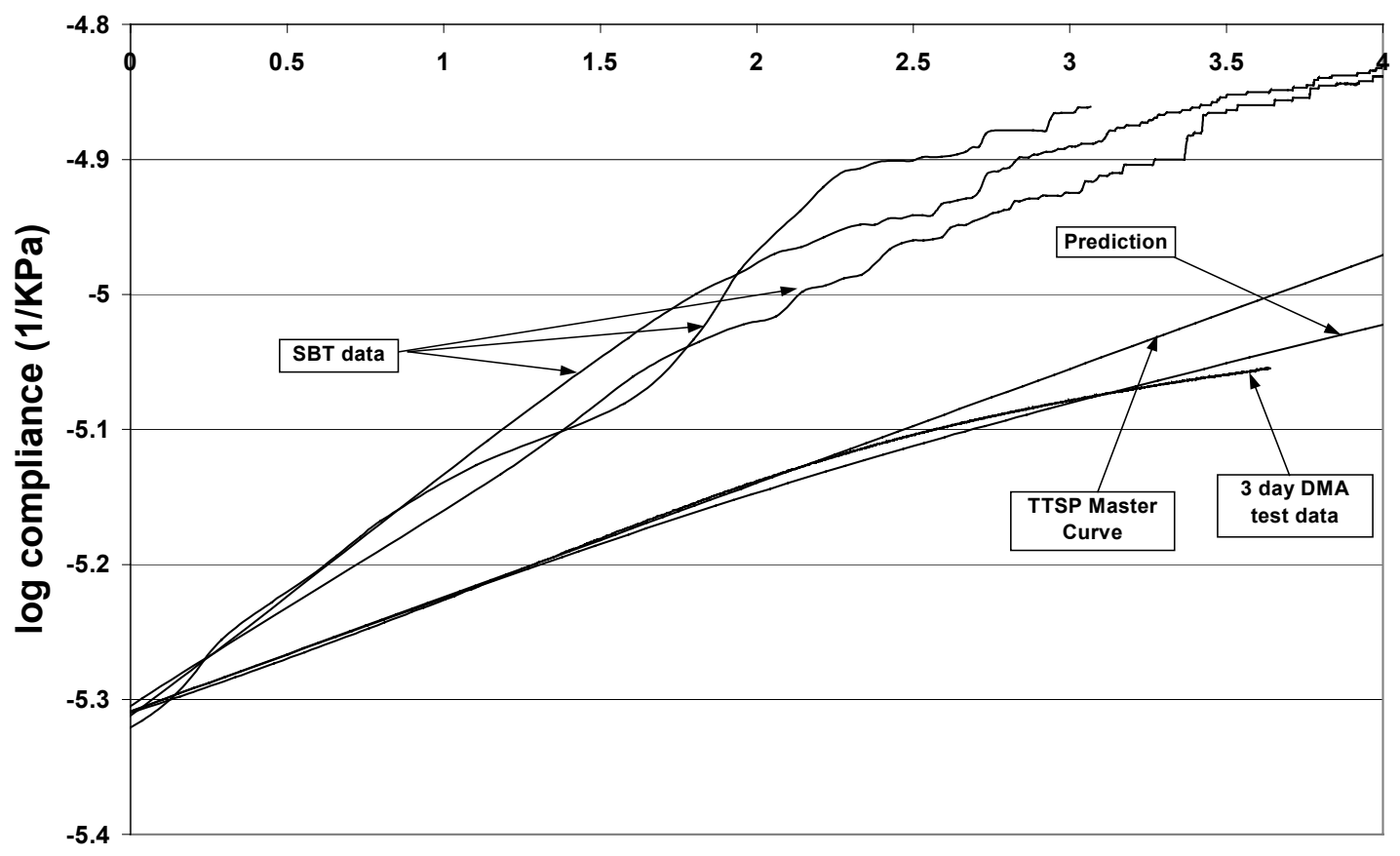

log time $(t)(\min )$

Fig 2.31 Comparison with long-term bending data after shifting (Material D)

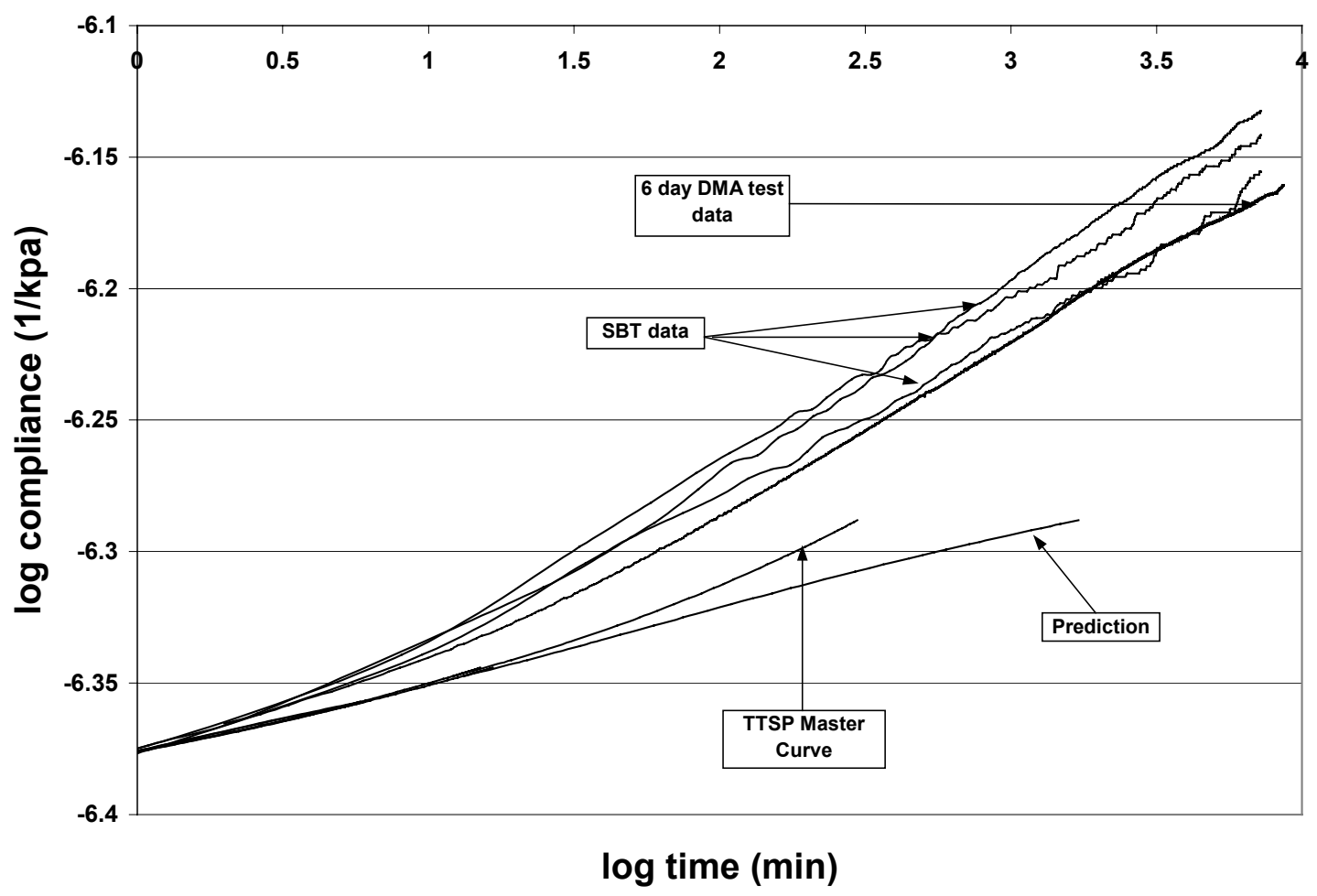

Fig 2.32 Comparison with long-term bending data after shifting (Material E) 


\section{CHAPTER 3: TIME TEMPERATURE SUPERPOSITION}

In order to predict the long-term creep behavior of encased liners, snapshot tests are conducted at different temperatures. The momentary creep curves thus obtained are superimposed on a reference curve to form a smooth master curve [18]. This is called Time Temperature Superposition (TTSP). In a snapshot test, the testing time remains small when compared to the physical aging time. In our case the physical aging time was $t_{\mathrm{e}}=60 \mathrm{~min}$ and the testing time was kept at $\mathrm{t}_{\max }=6 \mathrm{~min}$. During such a short test, aging does not affect the relaxation time of the viscoelastic model. The creep compliances determined by snapshot tests are called momentary curves [1]. Ref. [13] showed for the first time that if the individual tests at various temperatures are longer than $t_{e} / 10$, physical aging invalidates the time-temperature superposition principle as described in the literature.

The momentary creep curves obtained at different temperatures are superimposed onto a reference curve, in our case the momentary curve at $\mathrm{T}_{\text {ref }}=40^{\circ} \mathrm{C}$. The master curve represents the material property of a material physically aged for aging time $t_{e}$, in our case $t_{e}=60 \mathrm{~min}$. The range of time of a momentary master curve may be much longer than the aging time $t_{e}$ because many momentary curves at different temperatures are shifted and joined to form the master curve. Still the master curve represents the compliance vs time of a fictitious material that does not age [13]. 


\subsection{EXPERIMENTAL PROCEDURE}

The apparatus, test environment conditions and specimen preparation were the same as discussed in section 2.1. The tests were done at temperatures ranging from $7^{\circ} \mathrm{C}$ to $70^{\circ} \mathrm{C}$ at intervals chosen so that the curves would superpose.

\subsubsection{SPECIMEN TESTING}

Each specimen is tested at different temperatures to determine the compliance vs time at each temperature. The testing method remains the same as described in section 2.1.4 until the sample is air quenched. The complete procedure is given here:

a. The thickness and width of each specimen is measured at both ends and at the mid-span using a micrometer. The values measured are averaged for calculations. All measurements are made in SI units.

b. The specimen is placed in the three point bending fixture of the DMA. The DMA is attached to a computer, which controlled the operations of the DMA using "PYRIS" software (version 3.80). The height and depth of the specimen are entered along with the initial state of the specimen, i.e., the initial temperature. The width remained constant at $15 \mathrm{~mm}$, as it was the span of the three point bending fixture.

c. After making sure that the specimen is properly seated into the fixture, the furnace is closed and the temperature is set to the annealing temperature. There is a time lag of 3-4 min for the temperature to equilibrate.

d. The specimen is kept at the annealing temperature for $10 \mathrm{~min}$ after which the furnace is opened in order to air-quench the specimen at room temperature. The 
time at which the furnace is opened is considered to be age zero $\left(t_{e}=0\right)$ of the specimen.

e. After quenching for $10 \mathrm{~min}$, the furnace is closed and the temperature is set to $40^{\circ} \mathrm{C}$. The sample is allowed to stabilize at this temperature for $15 \mathrm{~min}$. Two creep tests, each of $1 \mathrm{~min}$ duration are performed. These tests are done in order to mechanically condition the sample.

f. After $45 \mathrm{~min}$ of aging time, the temperature of the furnace is set to the test temperature.

g. Then, when the physical age of the specimen reaches 60 min a creep test of 6 min duration is performed. The test is done such that it is a snapshot, $t / t_{e} \leq 10$, in order to keep the creep curve as a momentary creep curve.

The load and the corresponding deflection data for the specimen are automatically recorded and then saved into a file. The load is kept between $1000 \mathrm{mN}$ and $1750 \mathrm{mN}$ depending on the sample thickness, deflection and temperature. The deflection is not allowed to exceed $10 \%$ of the support span.

Momentary creep curves at different temperatures are obtained for the same specimen. The test temperature range is from $7^{\circ} \mathrm{C}$ to $70^{\circ} \mathrm{C}$. For highest accuracy, all momentary curves are obtained without removing it from the measuring system. After testing, the specimen is removed from the fixture and a new specimen is tested.

The following separate studies were done to check for the reliability of the data collected. 


\subsubsection{A. REPETITIVE TESTS}

In order to prove that the specimens did not undergo any change in properties due to chemical aging, the specimens were tested for repeatability. A number of tests were done at $40^{\circ} \mathrm{C}$, on the same specimen. The specimen was taken through the full testing process again and again. A total of 15 tests (Fig 3.1) were done on the specimens and the results showed that the data had very slight variation. It was concluded that the specimen could be rejuvenated by annealing and there was no chemical aging of the specimen.

\subsubsection{B. ANNEALING TIME}

Annealing time is the length of time that the specimen remains at the annealing temperature, which in this case is about $15^{\circ} \mathrm{C}$ above the glass transition temperature. Creep tests were done on a specimen annealed for different lengths of time $(10,30,60$ and $120 \mathrm{~min}$ ) and aged for the same period of time, i.e., $60 \mathrm{~min}$. There was no significant change in compliance due to annealing time (Fig 3.2).

\subsubsection{CONDITIONING TEMPERATURE STUDY}

Conditioning Temperature is the temperature at which the specimen ages after it has been taken through annealing and air quenching. Specimens, which were conditioned at the test temperature, were compared to specimens that were conditioned at $40^{\circ} \mathrm{C}$ and then taken to the test temperature $10 \mathrm{~min}$ before testing it. There was little change between the tests (Fig 3.3). Compliance is affected by the temperature at which the specimen is tested and not by the conditioning temperature. 


\subsection{1.d. WATER IMMERSION STUDY}

Three specimens of each sample were immersed in water and continuously monitored for any weight change. The percentage of weight change recorded (Table 3.13.5), was not found to be significant and hence was concluded that moisture does not play a significant role in the long-term creep behavior of the polymer, at least for the polymers used in this study.

\subsection{EXPERIMENTAL RESULTS AND DATA INTERPRETATION}

The compliance curve for every temperature is found as discussed in Section 2.3 and plotted against time in a double logarithmic plot. A reference temperature is chosen and all the other momentary creep curves at different temperatures are shifted horizontally along the time axis using a shift factor, $\mathrm{a}_{\mathrm{T}}$, to form a master curve (Fig 3.43.8). The horizontal shift factor, $\mathrm{a}_{\mathrm{T}}$, was determined by minimizing the time difference between pairs of curves for the range of compliance that they have in common. Bradshaw and Brinson [9-11] showed that including a vertical shift factor when determining the reference curve and shift factor did not significantly improve predictions of the given experimental data. Thus only a horizontal shift factor is used.

The data points of the master curve are reduced to fewer data points using a moving average program in MAT Lab [12]. A logarithmic plot of temperature (T) vs shift factor $\left(\mathrm{a}_{\mathrm{T}}\right)$ is plotted (Fig 3.9-3.13). This plot helps to determine the shift factor for any given temperature. A linear model,

$$
\log \left(a_{T}\right)=A(T)+B
$$


where, A and B are constants, is fitted to the experimental data. Using this, the shift factor for any given temperature can be found out by using

$$
a_{T}=10^{(A(T)+B)}
$$

The same procedure is repeated by using three specimens of each sample. Three master curves were obtained for samples D and E, while five master curves were obtained for samples A, B, and C.

A single specimen is used to construct each master curve. This is done by performing several momentary tests $\left(t<t_{e} / 10\right)$ at various temperatures, at constant age $t_{e}$. Therefore, every specimen has its own master curve, which vary from specimen to specimen. Also, the particular set of temperatures that make up a master curve vary from specimen to specimen.

To reduce the scatter, one would want to test several specimens simultaneously at the same temperature and average the compliances. Unfortunately the DMA holds only one specimen at a time and it is not convenient to remove a specimen from the fixture but rather perform all the tests at various temperatures on the same specimen, then switch to a new specimen, and so on. Although the nominal temperature set is the same for every specimen (say, $13,20,30,40,50,60^{\circ} \mathrm{C}$ ), the actual testing temperature varies slightly from specimen to specimen due to the temperature tolerance of the DMA furnace. Therefore, in trying to average the data, the first thing to do is to shift individual tests (Fig. 3.14) to a nominal temperature (say $40^{\circ} \mathrm{C}$ as in Fig. 3.15) using the shift factor plot (Fig. 3.9-3.13) of the same specimen.

Each shifted curve is fitted with (Fig 3.16) 


$$
D(t)=D_{o}+D_{1} t^{n}
$$

Next, take the average of $D_{0}$, average of $D_{1}$, and the average $n$ as representation of the material behavior at the nominal temperature (Fig. 3.17). Repeat this procedure for every nominal temperature and then shift the curves to the reference temperature, thus creating a master curve that represents all the data from multiple specimens, as shown in Fig 3.18-3.22. The corresponding shift factor plots are shown in Fig.3.23-3.26.

Next, using the average shift-factor plots to shift the raw data for every specimen results in Fig.3.18-3.22, which shows the actual scatter.

An alternative procedure could be to fit an equation to the individual specimen master curves shown in Fig. 3.28-3.32. But it would require assuming a model equation for the master curve. In addition, there would be no rational way to average the shift factor plots (Fig. 3.9-3.13). In contrast, the procedure proposed in this work results in the thick line in Fig. 3.18-3.22 where the master curve is a direct representation of data without assuming any model equation.

\subsection{COMPARISON WITH LONG TERM BENDING DATA AND TEMPERATURE EFFECTS}

Using the shift factors of Table 2.1, TTSP master curves (Fig. 3.18-3.22), TTSP average shift factor plots (Fig.3.9-3.13) and Equation 4.3, the Long-Term Bending compliance for every material was predicted (Fig.3.33-3.37) at $21.1^{\circ} \mathrm{C}$ and compared with $21.1^{\circ} \mathrm{C}$ data from the Static Bending Test Study [13]. Due to uncertainty in the initial position of the displacement transducer, the curves were vertically shifted to coincide at time 1 min with the average TTSP (Fig 3.38-3.42). 


\subsection{SUMMARY}

A summary of the our findings are given below:

1. The specimen to be tested is cut, measured and placed in the DMA 7e.

2. The specimen is annealed at a temperature $15^{\circ} \mathrm{C}$ above its glass transition temperature $\left(\mathrm{T}_{\mathrm{g}}\right)$ in the DMA for $10 \mathrm{~min}$.

3. The specimen is then air quenched for $10 \mathrm{~min}$ and then enclosed inside the DMA at $40^{\circ} \mathrm{C}$ temperature.

4. After stabilizing at $40^{\circ} \mathrm{C}$ for $15 \mathrm{~min}$, two mechanical conditioning tests are conducted and the corresponding data are discarded.

5. After 45 min of aging time the furnace is set to test temperature

6. Creep tests of $6 \mathrm{~min}$ duration are done at temperatures ranging from $7^{\circ} \mathrm{C}$ to $70^{\circ} \mathrm{C}$ when the specimen reaches a physical age of $t_{e}=60 \mathrm{~min}$.

7. A momentary curve is chosen as the reference curve and all the other curves are shifted to this curve using a shift factor $\mathrm{a}_{\mathrm{T}}$. This is the master curve.

8. A single logarithmic plot of temperature $(\mathrm{T})$ vs $\log \left(\mathrm{a}_{\mathrm{T}}\right)$ is plotted and a linear model is fitted to it. The linear model is used to predict the shift factor for the material at any given temperature.

\subsection{CONCLUSIONS}

The following are the conclusions drawn from the TTSP done on the polymer liner specimens:

1. Annealing above the $T_{g}$, rejuvenated the specimen. The compliance was nearly the same every time the specimens were annealed and tested.

2. Annealing time didn't affect the compliance of the material. 
3. The compliance depends on the test temperature and not on the temperature at which it was conditioned.

4. Water had no effect on the material.

5. A novel method to average the master curves of each sample was proposed.

6. From Fig.3.33 - Fig.3.37, it was observed that aging is barely noticeable at $21.1^{\circ} \mathrm{C}$ for the time-span of the data, but significant at $40^{\circ} \mathrm{C}$ (see Fig.2.22 Fig.2.26). 


\begin{tabular}{|c|c|c|c|}
\hline Time (min) & A1 & A2 & A3 \\
\hline $\mathbf{0}$ & 0.24417 & 0.21946 & 0.40665 \\
\hline $\mathbf{6 6}$ & 0.24444 & 0.21957 & 0.40704 \\
\hline $\mathbf{1 3 1}$ & 0.2442 & 0.2195 & 0.40673 \\
\hline $\mathbf{3 8 7}$ & 0.24436 & 0.21955 & 0.40708 \\
\hline $\mathbf{1 4 3 0}$ & 0.24443 & 0.21968 & 0.40693 \\
\hline $\mathbf{1 4 9 3}$ & 0.24441 & 0.21971 & 0.40705 \\
\hline $\mathbf{1 5 5 2}$ & 0.24442 & 0.21968 & 0.40709 \\
\hline & & & \\
\hline \% change in weight & $\mathbf{0 . 1 0 2 2 8 3}$ & $\mathbf{0 . 1 0 0 1 4 6}$ & $\mathbf{0 . 1 0 8 0 8 4}$ \\
\hline
\end{tabular}

all units in grams

Table 3.1 Change of weight of specimen after immersing in water (Material A)

\begin{tabular}{|c|c|c|c|}
\hline Time (min) & B1 & B2 & B3 \\
\hline $\mathbf{0}$ & 0.35498 & 0.33353 & 0.36204 \\
\hline $\mathbf{6 8}$ & 0.355513 & 0.3337 & 0.36206 \\
\hline $\mathbf{1 3 3}$ & 0.35508 & 0.33354 & 0.36213 \\
\hline $\mathbf{3 9 2}$ & 0.35532 & 0.3337 & 0.36224 \\
\hline $\mathbf{1 4 3 4}$ & 0.35552 & 0.33403 & 0.36266 \\
\hline $\mathbf{1 4 9 6}$ & 0.35555 & 0.33406 & 0.36254 \\
\hline $\mathbf{1 5 5 4}$ & 0.35562 & 0.33398 & 0.36258 \\
\hline & & & \\
\hline \% change in weight & $\mathbf{0 . 1 7 9 9 6 7}$ & $\mathbf{0 . 1 3 4 7 3 9}$ & $\mathbf{0 . 1 4 8 9 3 3}$ \\
\hline
\end{tabular}

all units in grams

Table 3.2 Change of weight of specimen after immersing in water (Material B)

\begin{tabular}{|c|c|c|c|}
\hline Time (min) & C1 & C2 & C3 \\
\hline $\mathbf{0}$ & 0.33353 & 0.40934 & 0.30792 \\
\hline $\mathbf{7 3}$ & 0.3337 & 0.40977 & 0.30804 \\
\hline $\mathbf{1 3 6}$ & 0.33354 & 0.40984 & 0.30804 \\
\hline $\mathbf{3 9 5}$ & 0.3337 & 0.4099 & 0.30815 \\
\hline $\mathbf{1 4 3 7}$ & 0.33403 & 0.4101 & 0.30841 \\
\hline $\mathbf{1 4 9 9}$ & 0.33406 & 0.41014 & 0.30844 \\
\hline $\mathbf{1 5 5 7}$ & 0.33398 & 0.4101 & 0.30842 \\
\hline & & & \\
\hline \% change in weight & $\mathbf{0 . 1 3 4 7 3 9}$ & $\mathbf{0 . 1 8 5 3 2 1}$ & $\mathbf{0 . 1 6 2 1 1 7}$ \\
\hline
\end{tabular}

all units in grams

Table 3.3 Change of weight of specimen after immersing in water (Material C) 


\begin{tabular}{|c|c|c|c|}
\hline Time (min) & D1 & D2 & D3 \\
\hline $\mathbf{0}$ & 0.19024 & 0.26269 & 0.26999 \\
\hline $\mathbf{7 5}$ & 0.19029 & 0.26293 & 0.27014 \\
\hline $\mathbf{1 4 1}$ & 0.19027 & 0.26268 & 0.26994 \\
\hline $\mathbf{3 9 9}$ & 0.19022 & 0.2628 & 0.27006 \\
\hline $\mathbf{1 4 3 9}$ & 0.19026 & 0.2628 & 0.26995 \\
\hline $\mathbf{1 5 0 1}$ & 0.19026 & 0.26273 & 0.27 \\
\hline $\mathbf{1 5 6 0}$ & 0.19027 & 0.262998 & 0.27002 \\
\hline & & & \\
\hline \% change in weight & $\mathbf{0 . 0 1 5 7 6 7}$ & $\mathbf{0 . 1 1 7 1 1 1}$ & $\mathbf{0 . 0 1 1 1 1}$ \\
\hline
\end{tabular}

all units in grams

Table 3.4 Change of weight of specimen after immersing in water (Material D)

\begin{tabular}{|c|c|c|c|}
\hline Time (min) & E1 & E2 & E3 \\
\hline $\mathbf{0}$ & 0.24097 & 0.33934 & 0.24916 \\
\hline $\mathbf{8 0}$ & 0.24136 & 0.33977 & 0.24934 \\
\hline $\mathbf{1 4 3}$ & 0.24158 & 0.33995 & 0.24943 \\
\hline $\mathbf{4 0 4}$ & 0.24178 & 0.34005 & 0.24953 \\
\hline $\mathbf{1 4 4 1}$ & 0.24192 & 0.3404 & 0.24994 \\
\hline $\mathbf{1 5 0 3}$ & 0.24218 & 0.34054 & 0.2501 \\
\hline $\mathbf{1 5 6 2}$ & 0.24166 & 0.34041 & 0.24992 \\
\hline & & & \\
\hline \% change in weight & $\mathbf{0 . 2 8 5 5 2 5}$ & $\mathbf{0 . 3 1 4 3 2 7}$ & $\mathbf{0 . 3 0 4 0 9 7}$ \\
\hline
\end{tabular}

all units in grams

Table 3.5 Change of weight of specimen after immersing in water (Material E) 


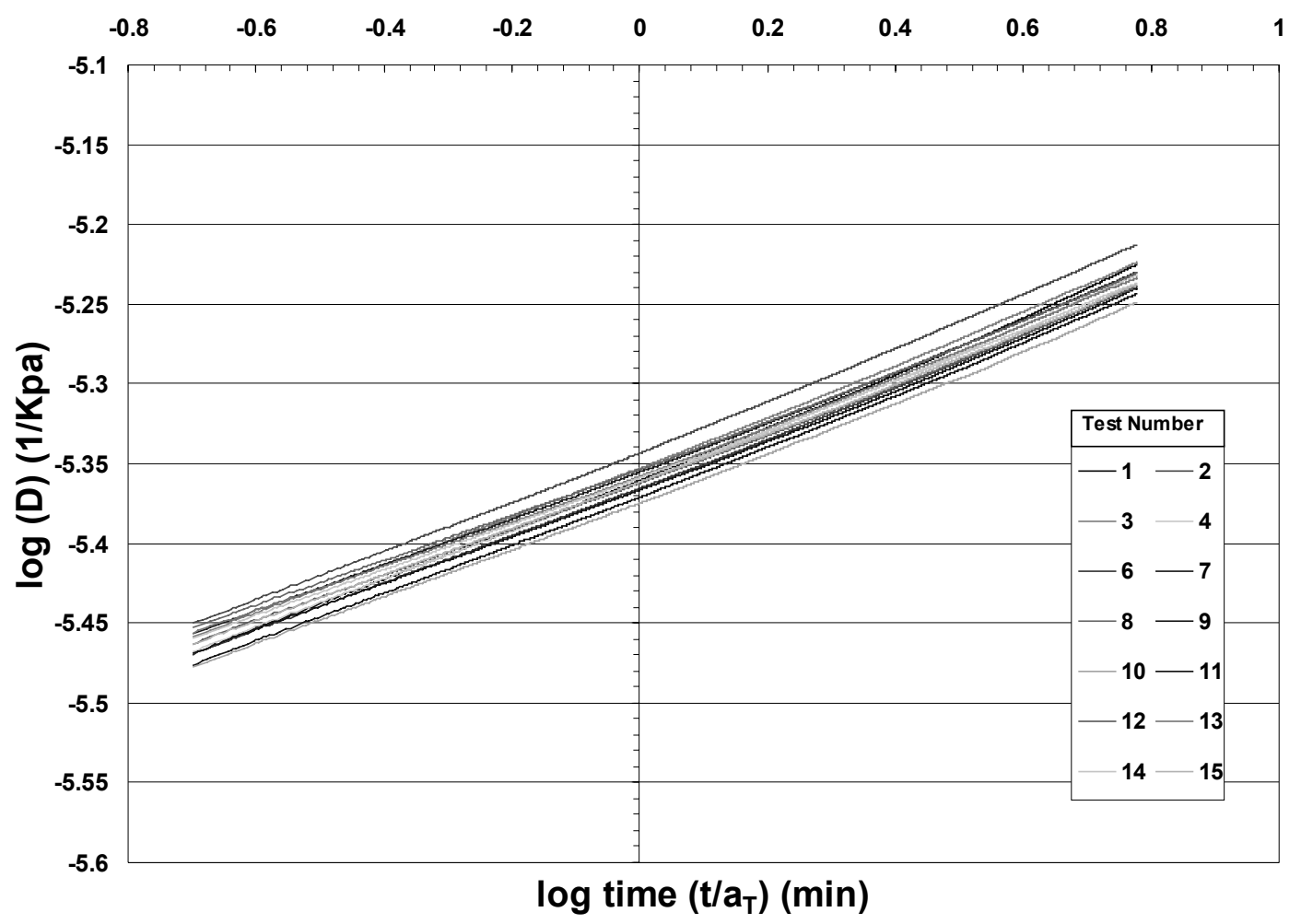

Figure 3.1. Repetitive test.

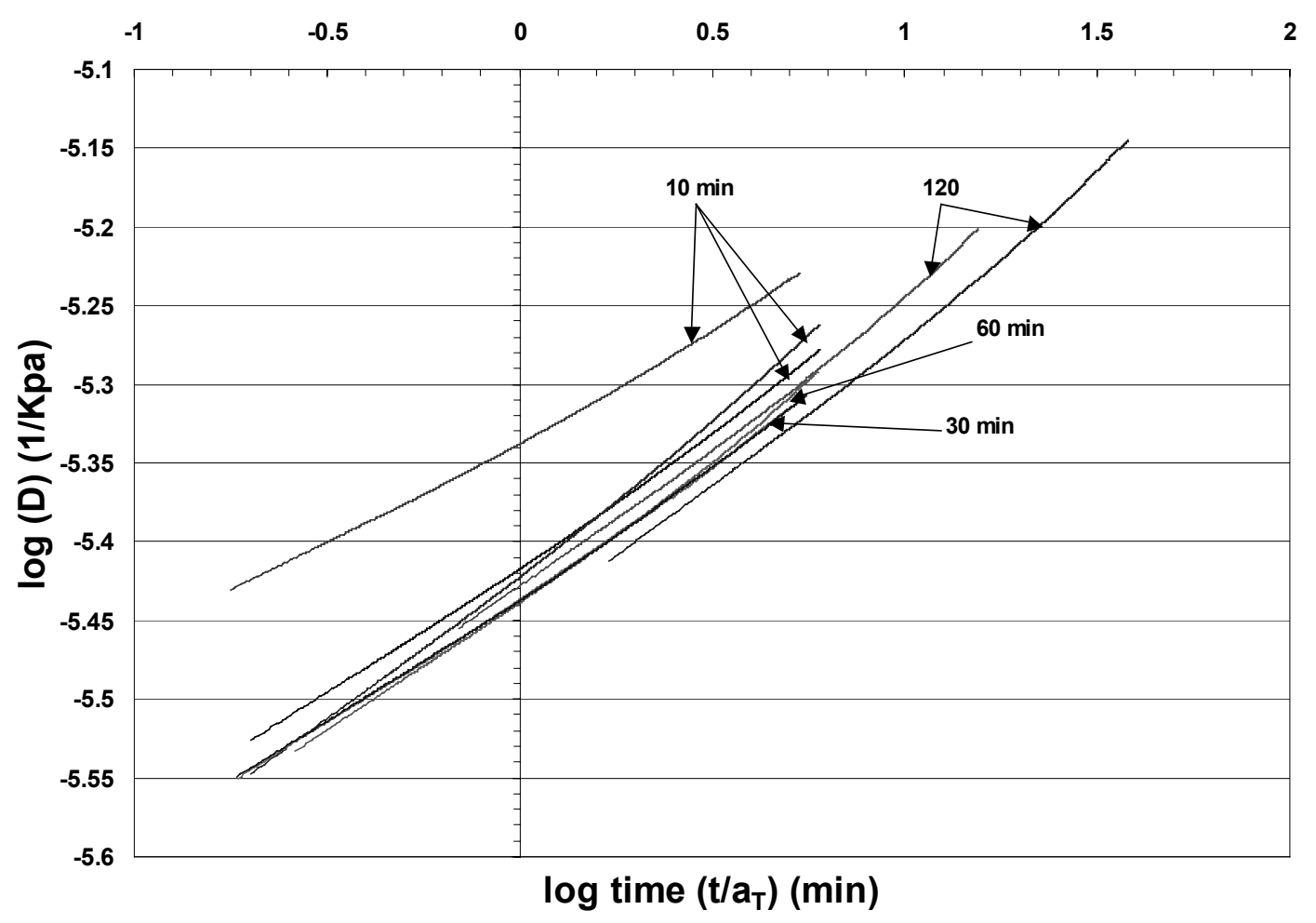

Figure 3.2. Annealing Temperature Study. 


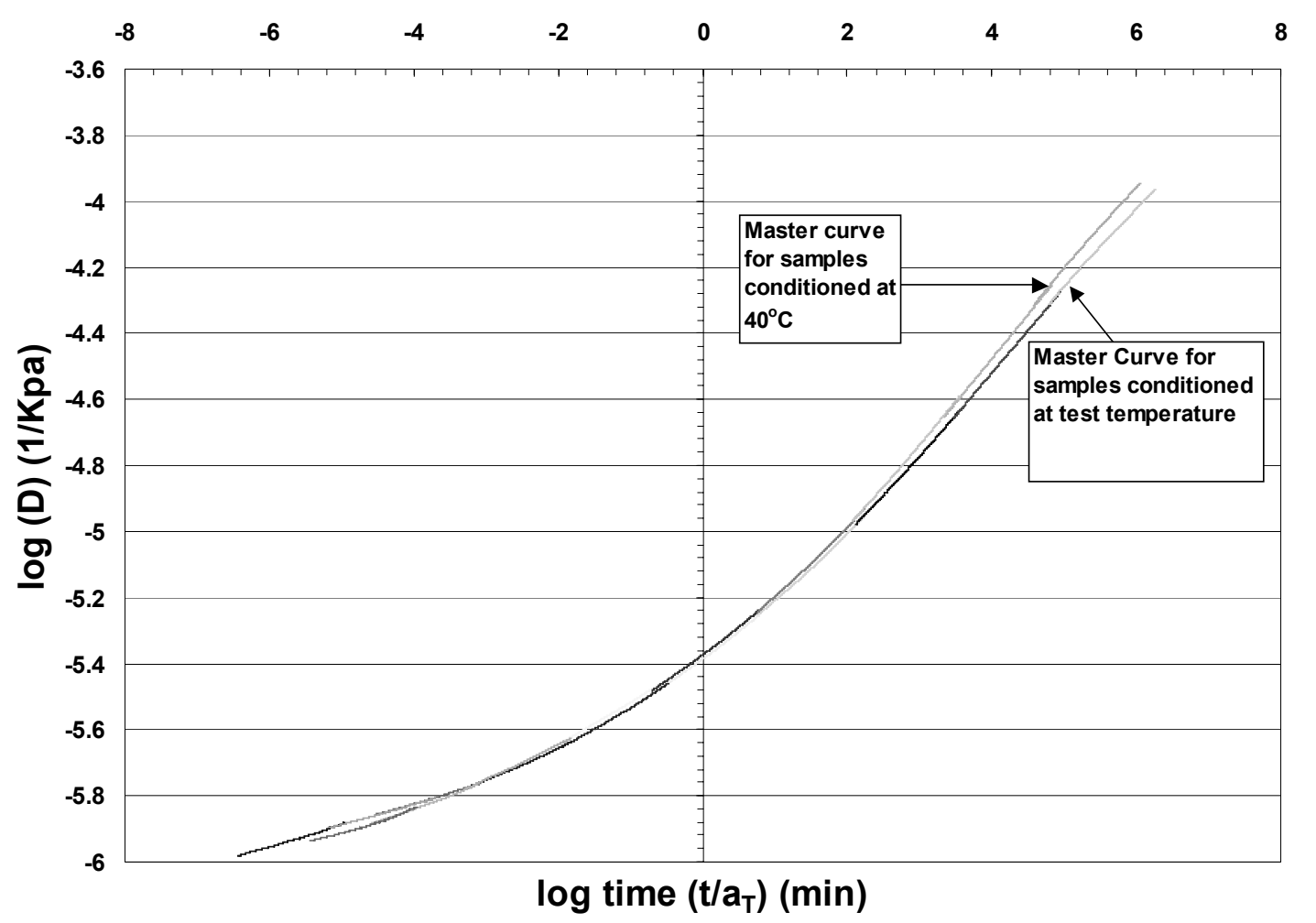

Figure 3.3. Conditioning Temperature Study.

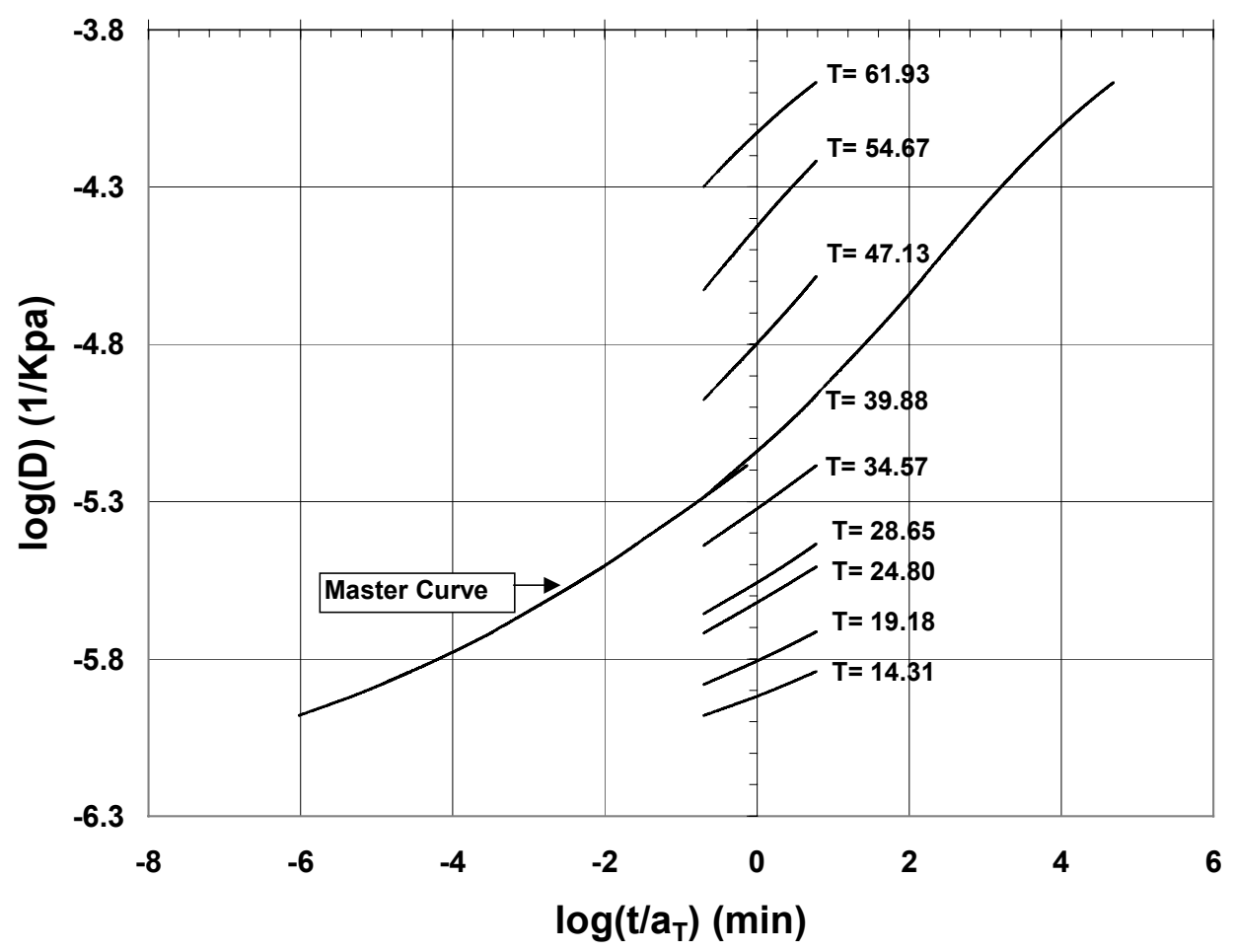

Figure 3.4. TTSP graphs and master curve shifted to $40^{\circ} \mathrm{C}$ (Material A) 


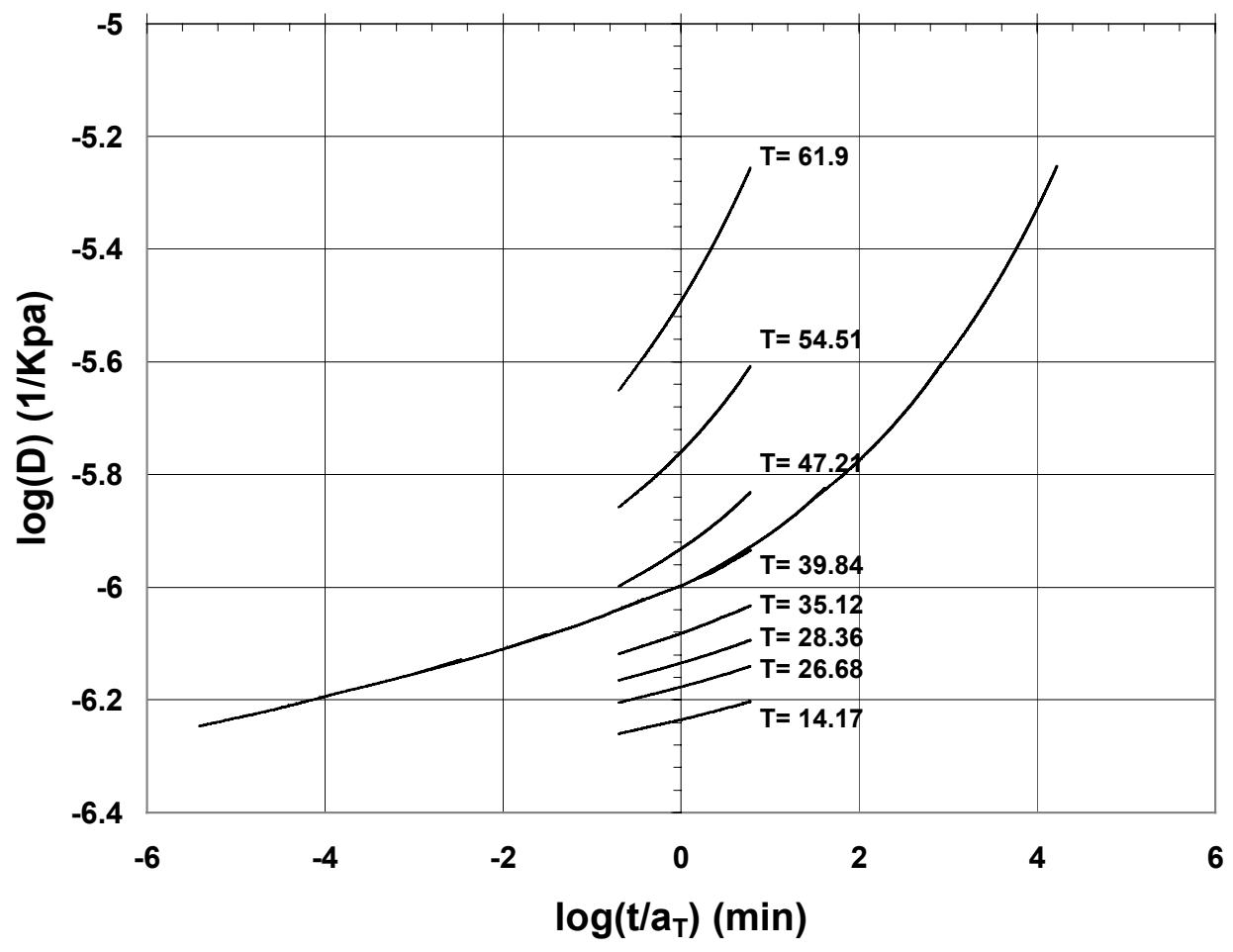

Figure 3.5. TTSP graphs and master curve shifted to $40^{\circ} \mathrm{C}$ (Material B)

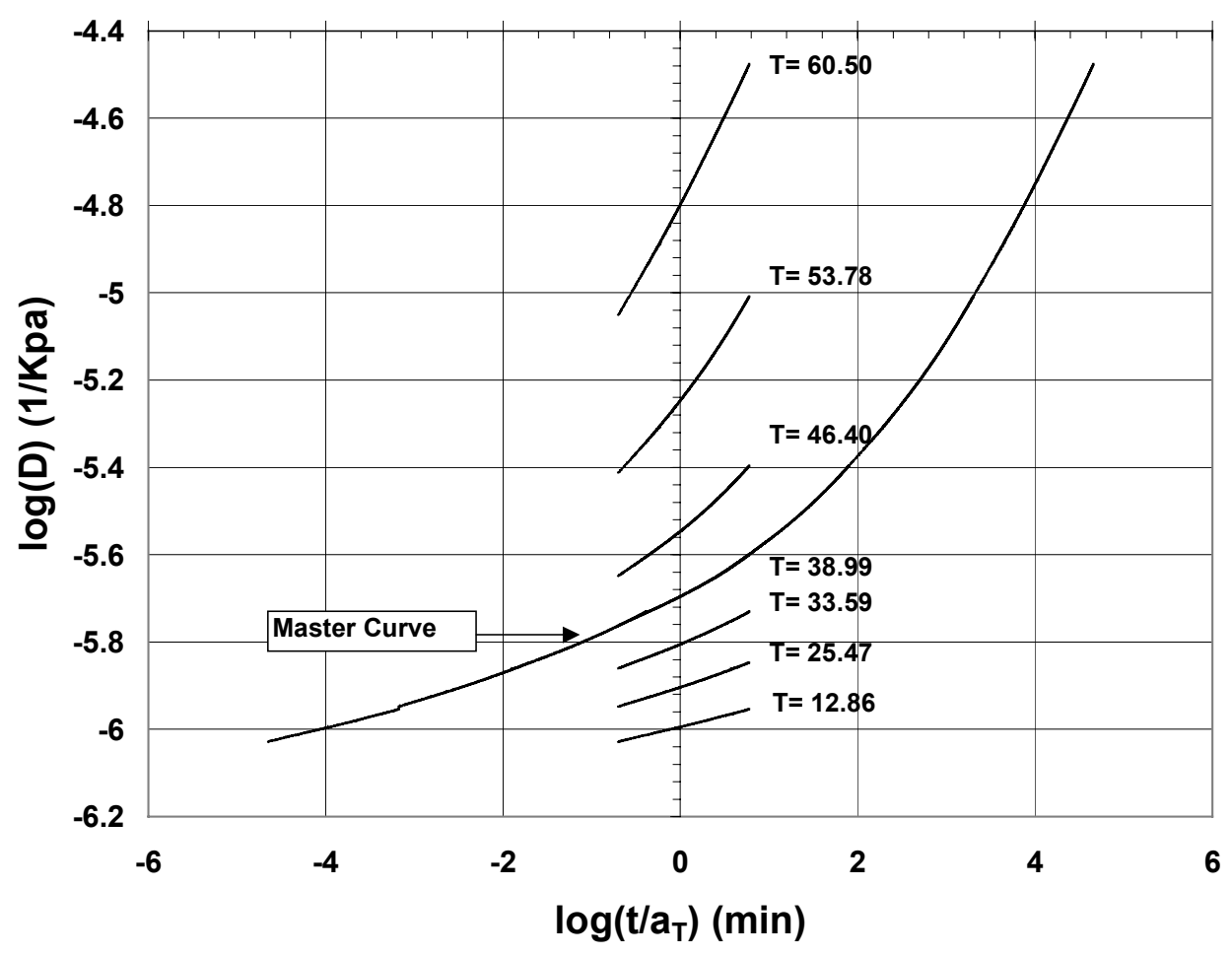

Figure 3.6. TTSP graphs and master curve shifted to $40^{\circ} \mathrm{C}$ (Material C). 


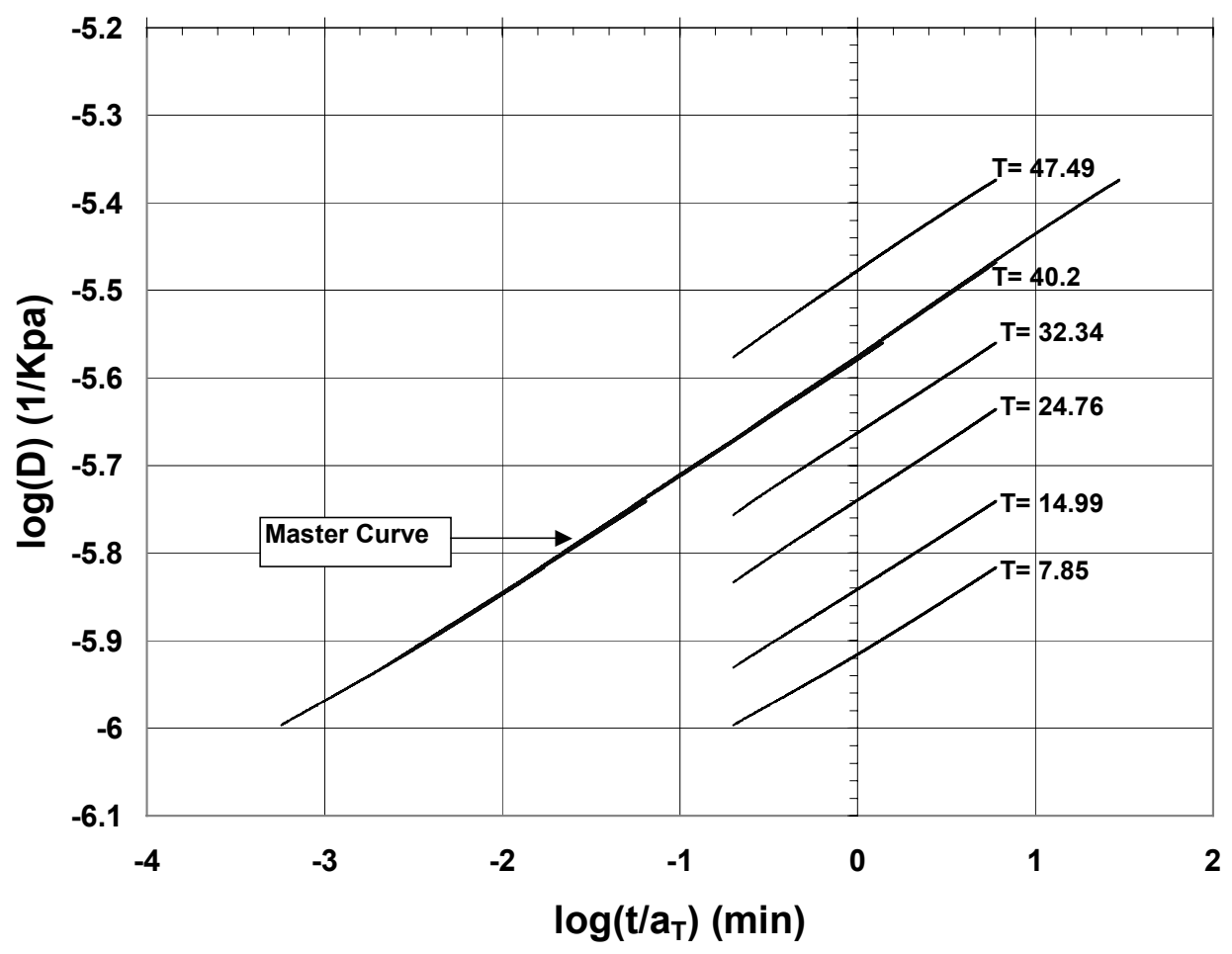

Figure 3.7. TTSP graphs and master curve shifted to $40^{\circ} \mathrm{C}$ (Material D).

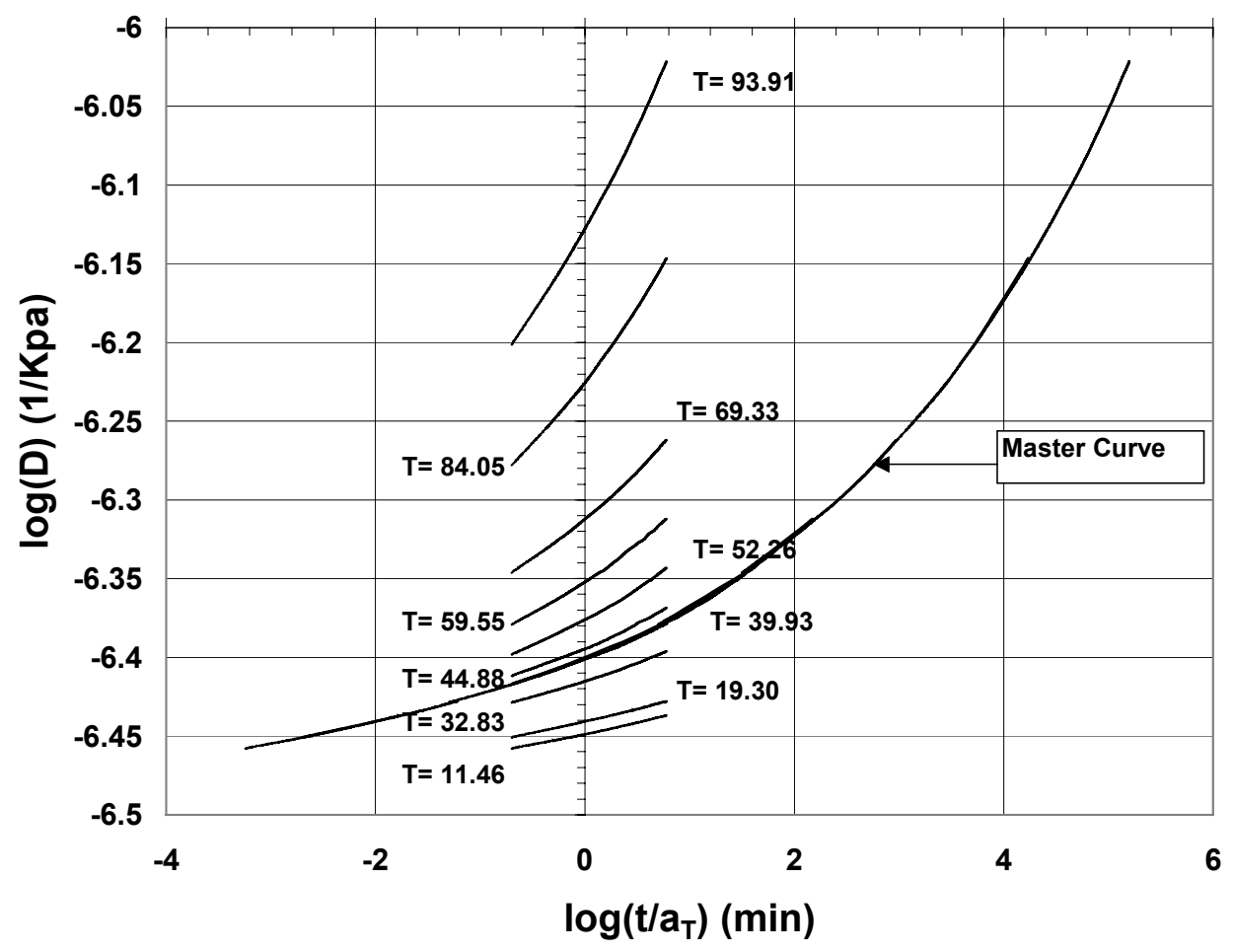

Figure 3.8. TTSP graphs and master curve shifted to $40^{\circ} \mathrm{C}$ (Material E). 


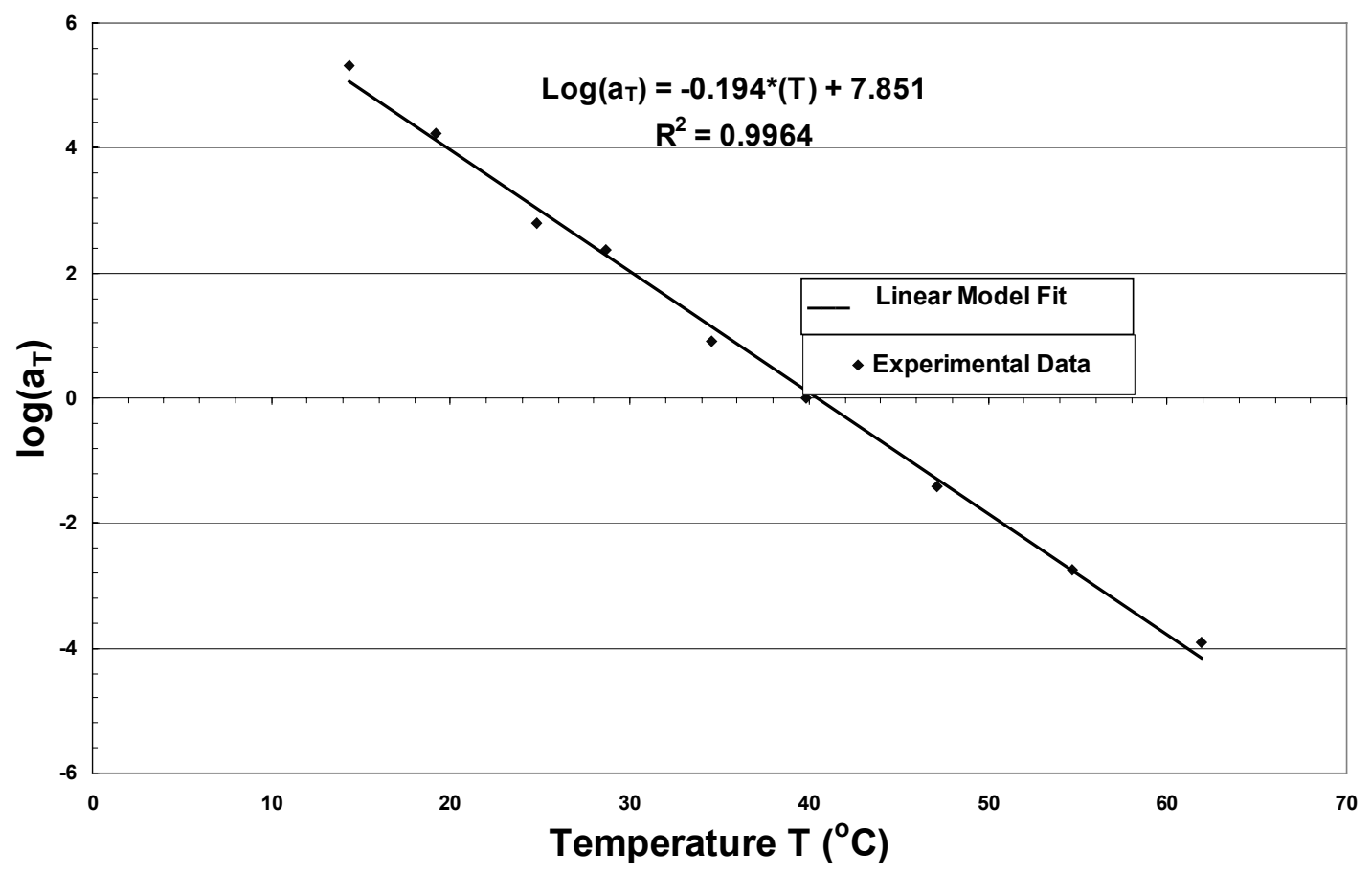

Figure 3.9. Theoretical and experimental values of the TTSP shift factors at $40{ }^{\circ} \mathrm{C}$ (Material A).

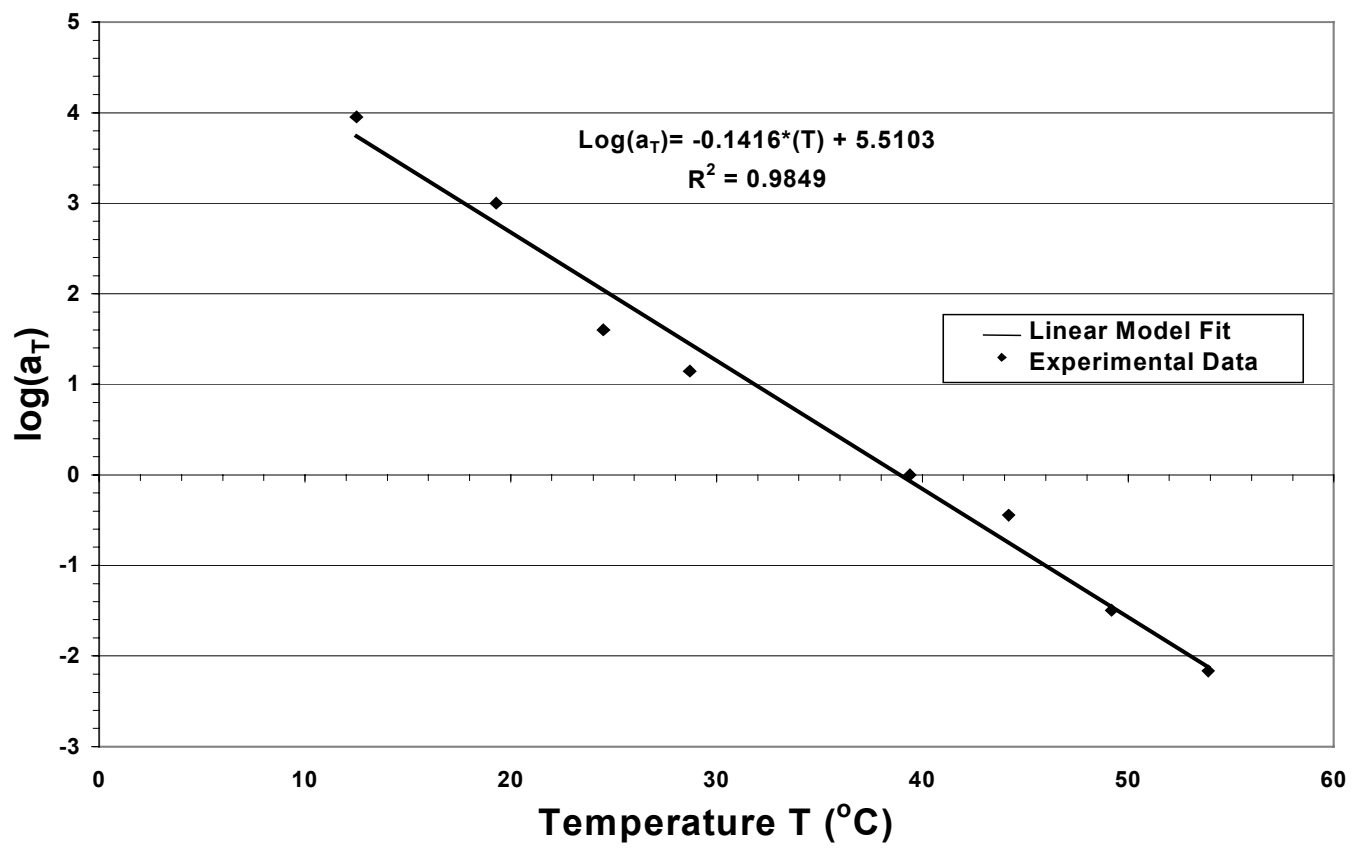

Figure 3.10. Theoretical and experimental values of the TTSP shift factors at $40{ }^{\circ} \mathrm{C}$ (Material B). 


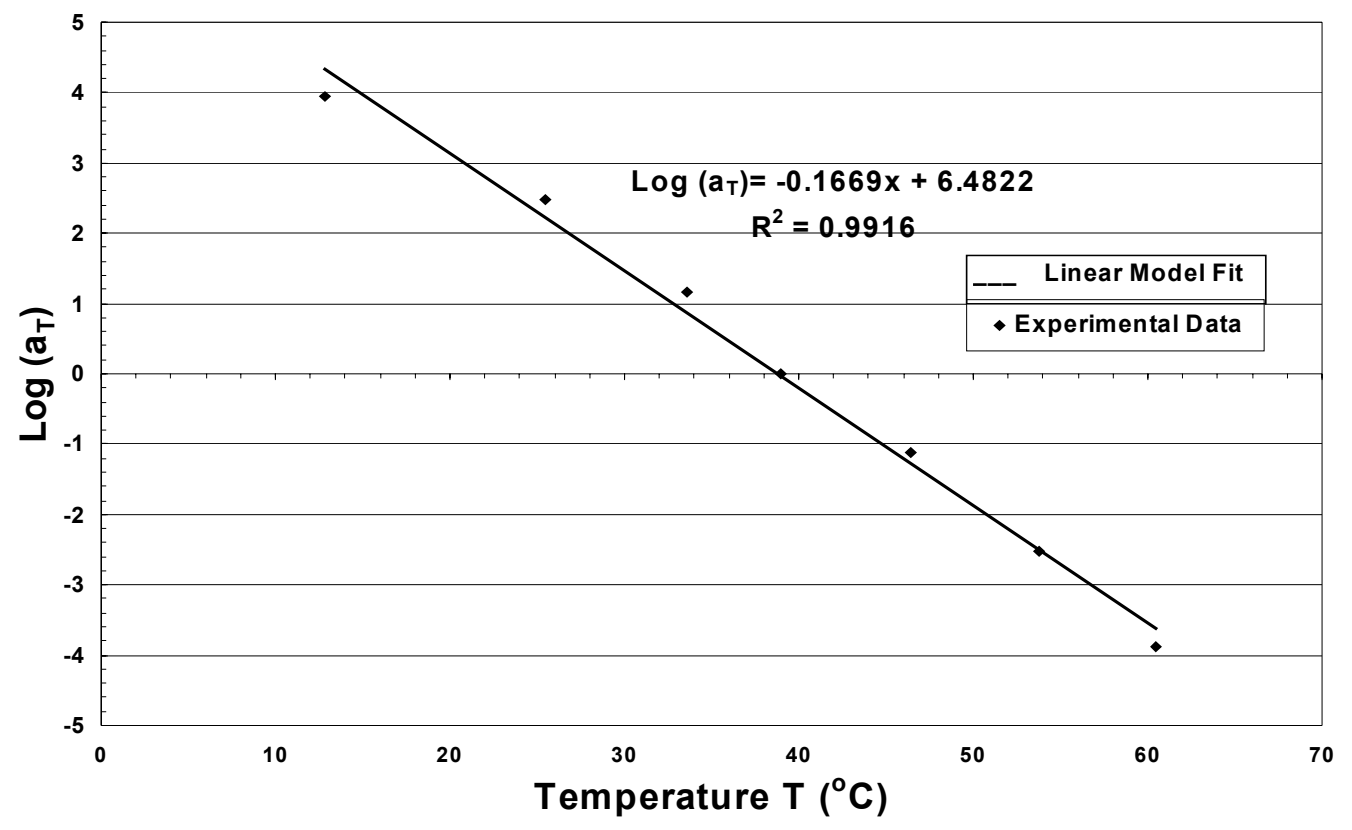

Figure 3.11. Theoretical and experimental values of the TTSP shift factors at $40{ }^{\circ} \mathrm{C}$ (Material $\mathrm{C}$ ).

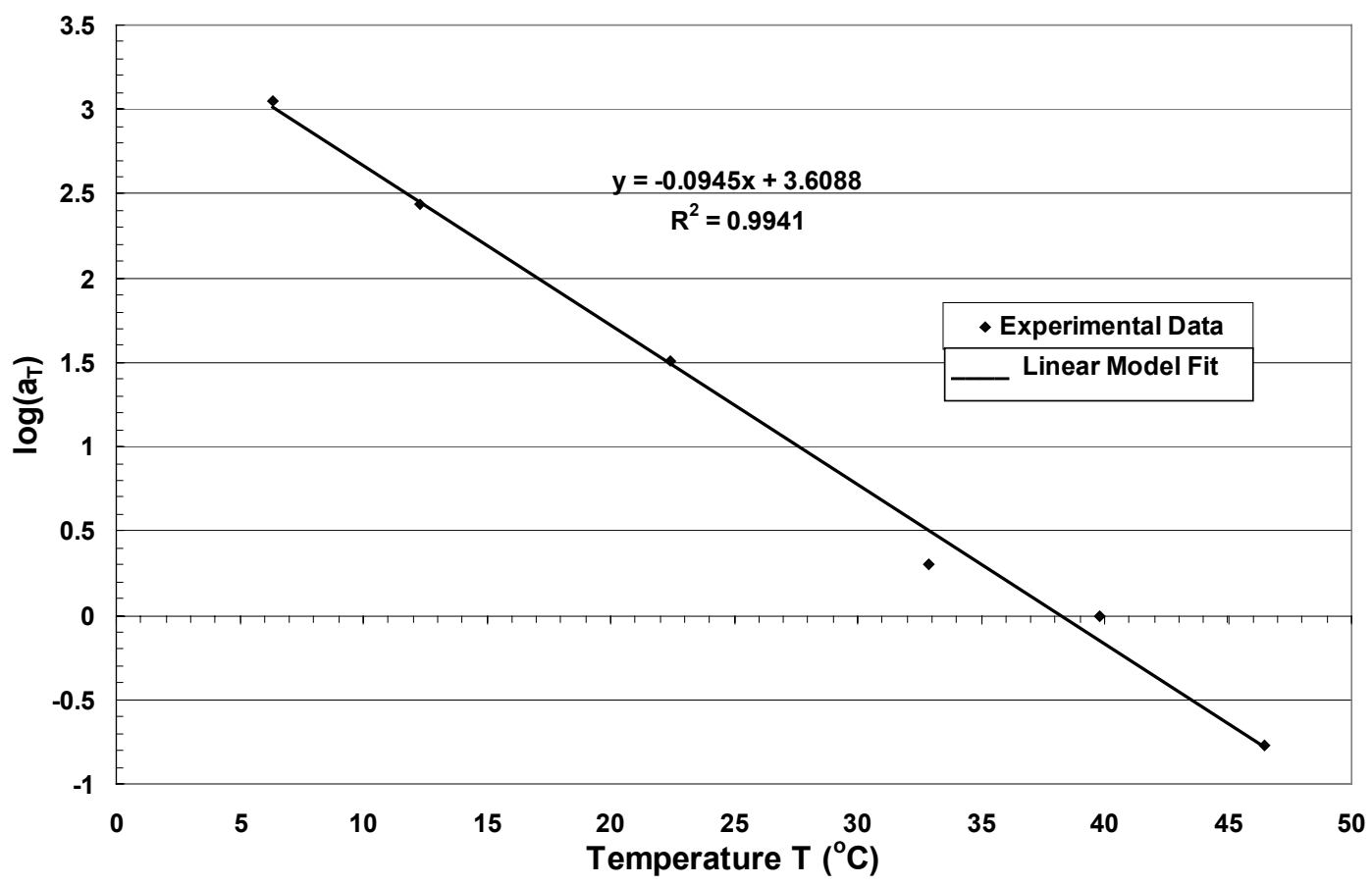

Figure 3.12. Theoretical and experimental values of the TTSP shift factors at $40{ }^{\circ} \mathrm{C}$ (Material D). 


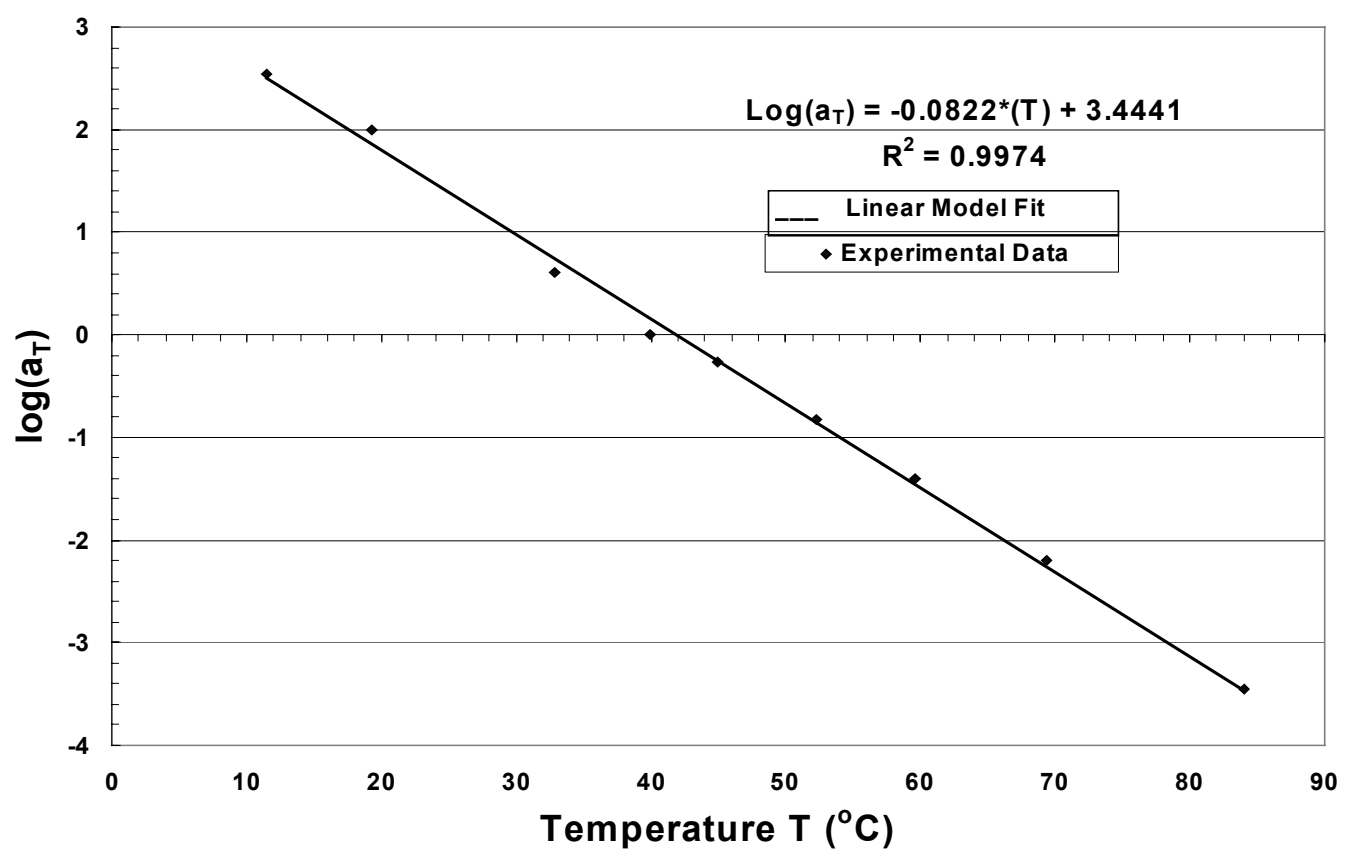

Figure 3.13. Theoretical and experimental values of the TTSP shift factors at $40{ }^{\circ} \mathrm{C}$ (Material E).

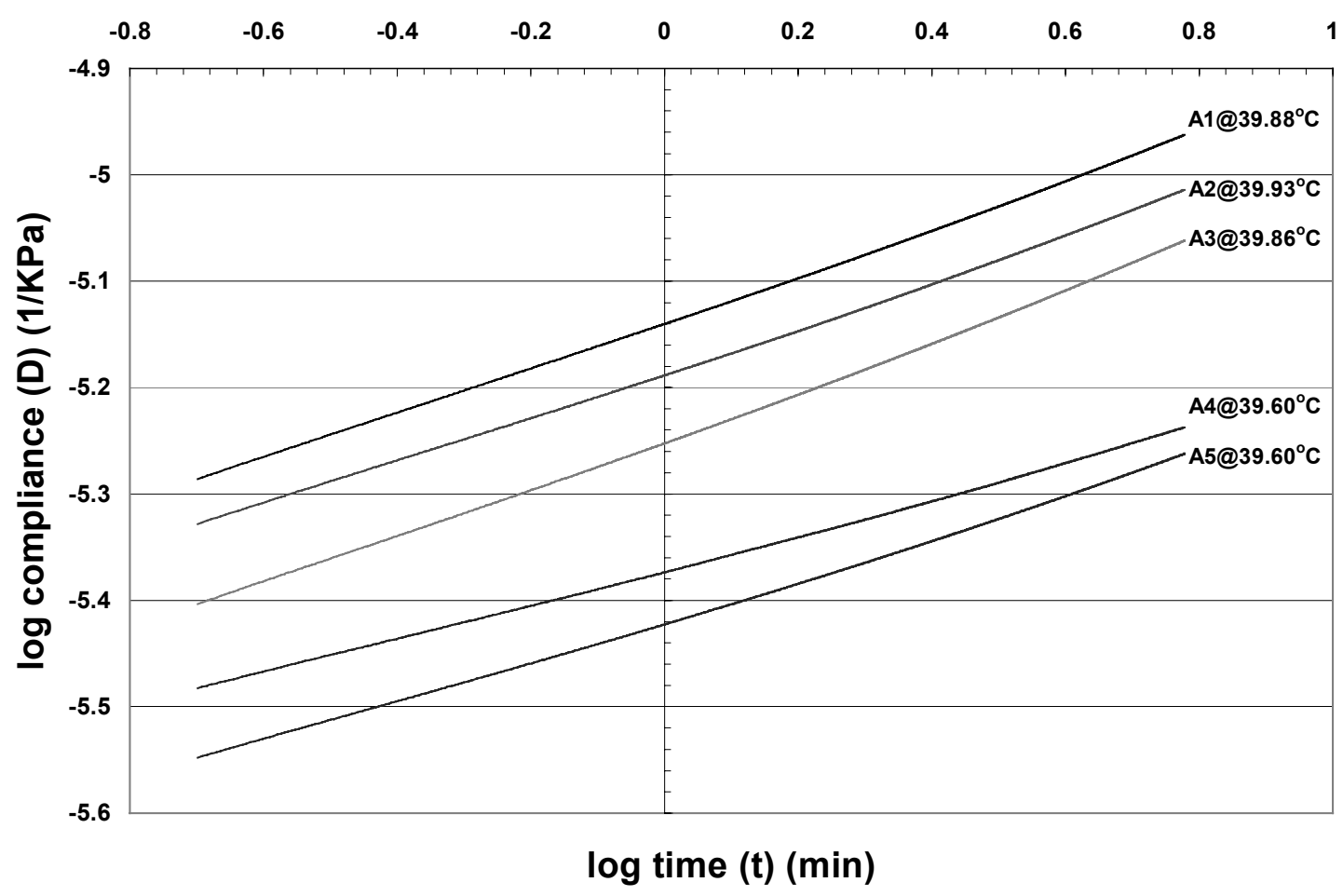

Fig 3.14 Un-shifted momentary curves of 5 specimens 


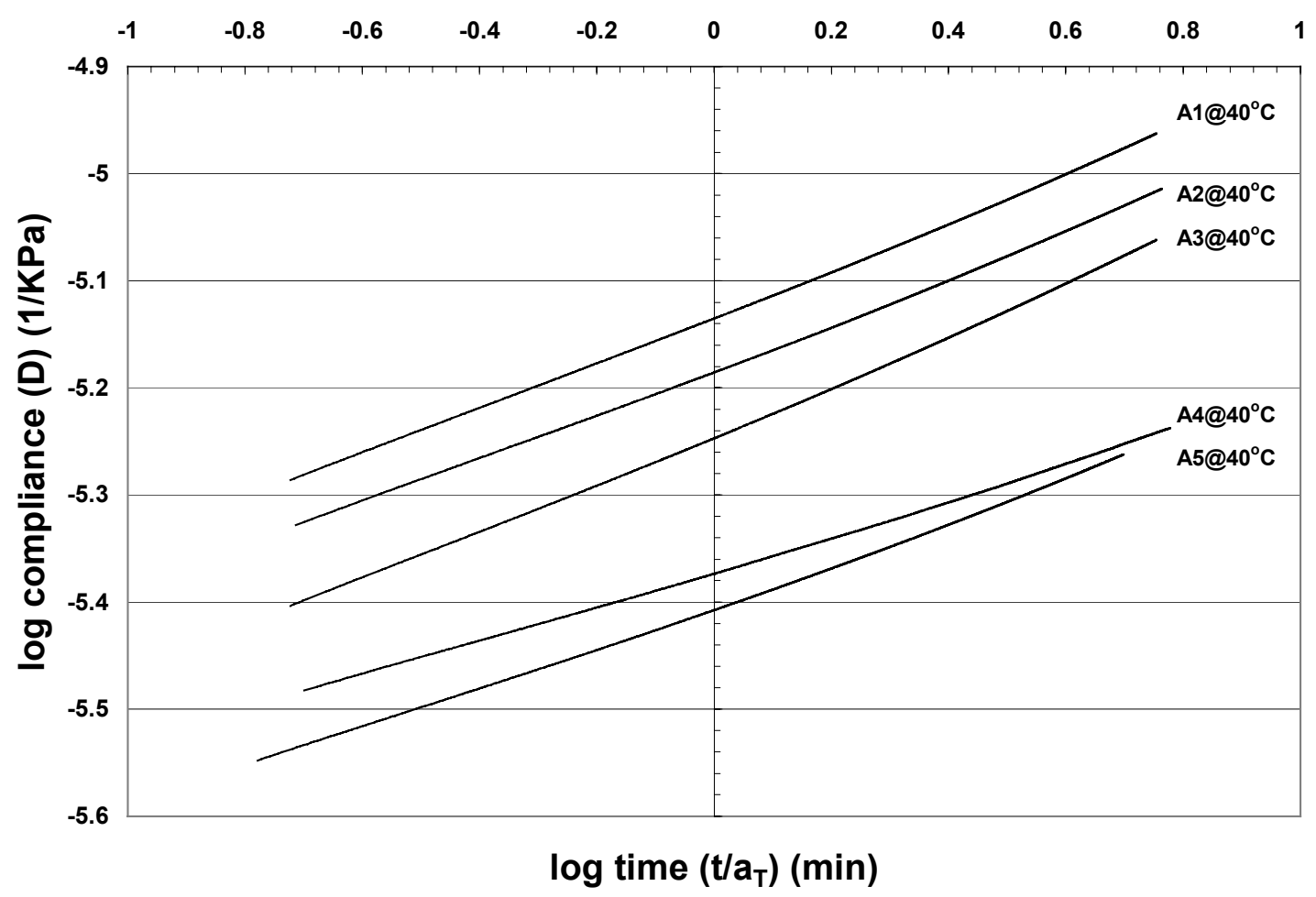

Fig 3.15 Shifted momentary curves of 5 specimens at $40^{\circ} \mathrm{C}$

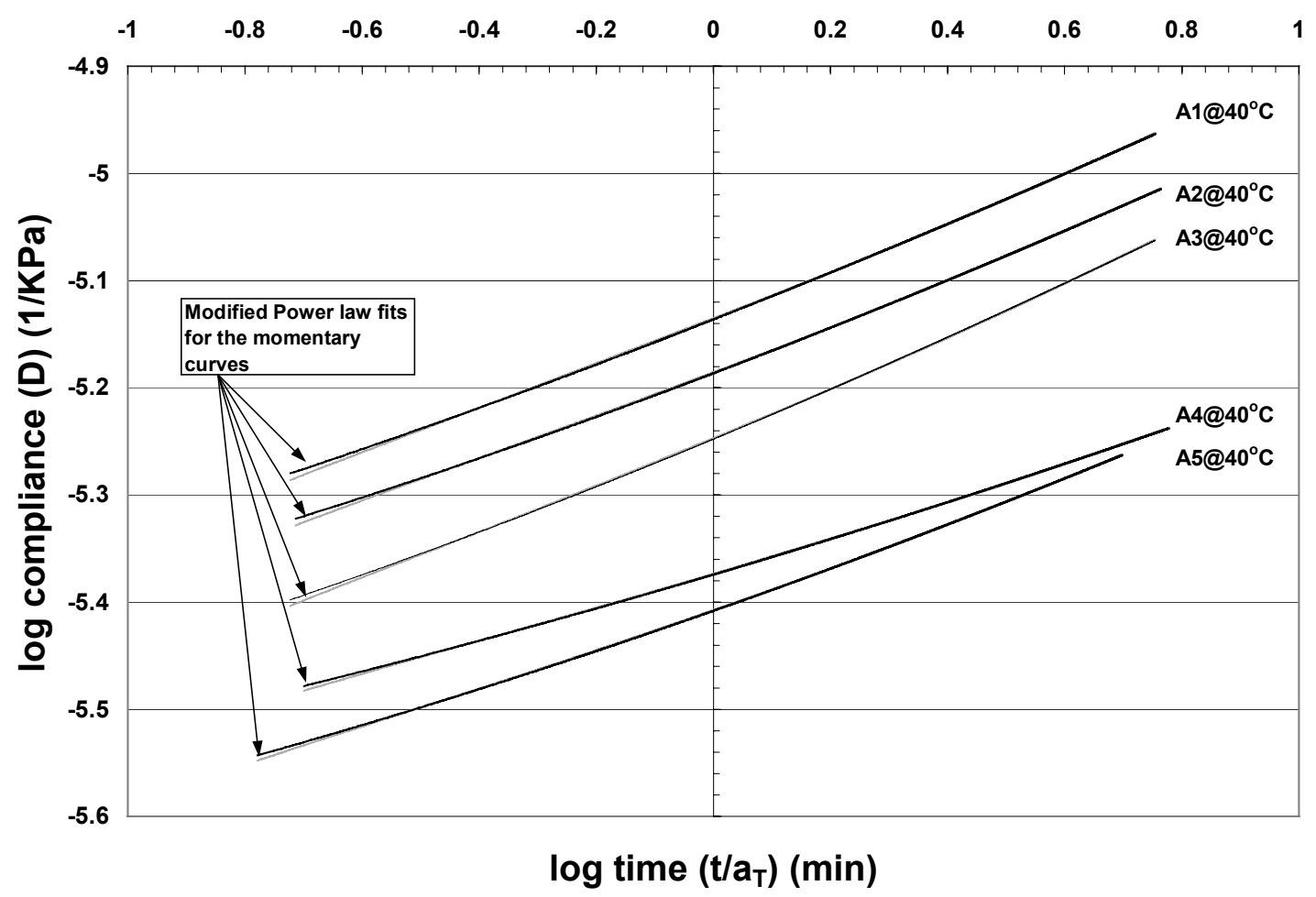

Fig 3.16 Modified power law fit for a specimen A1 


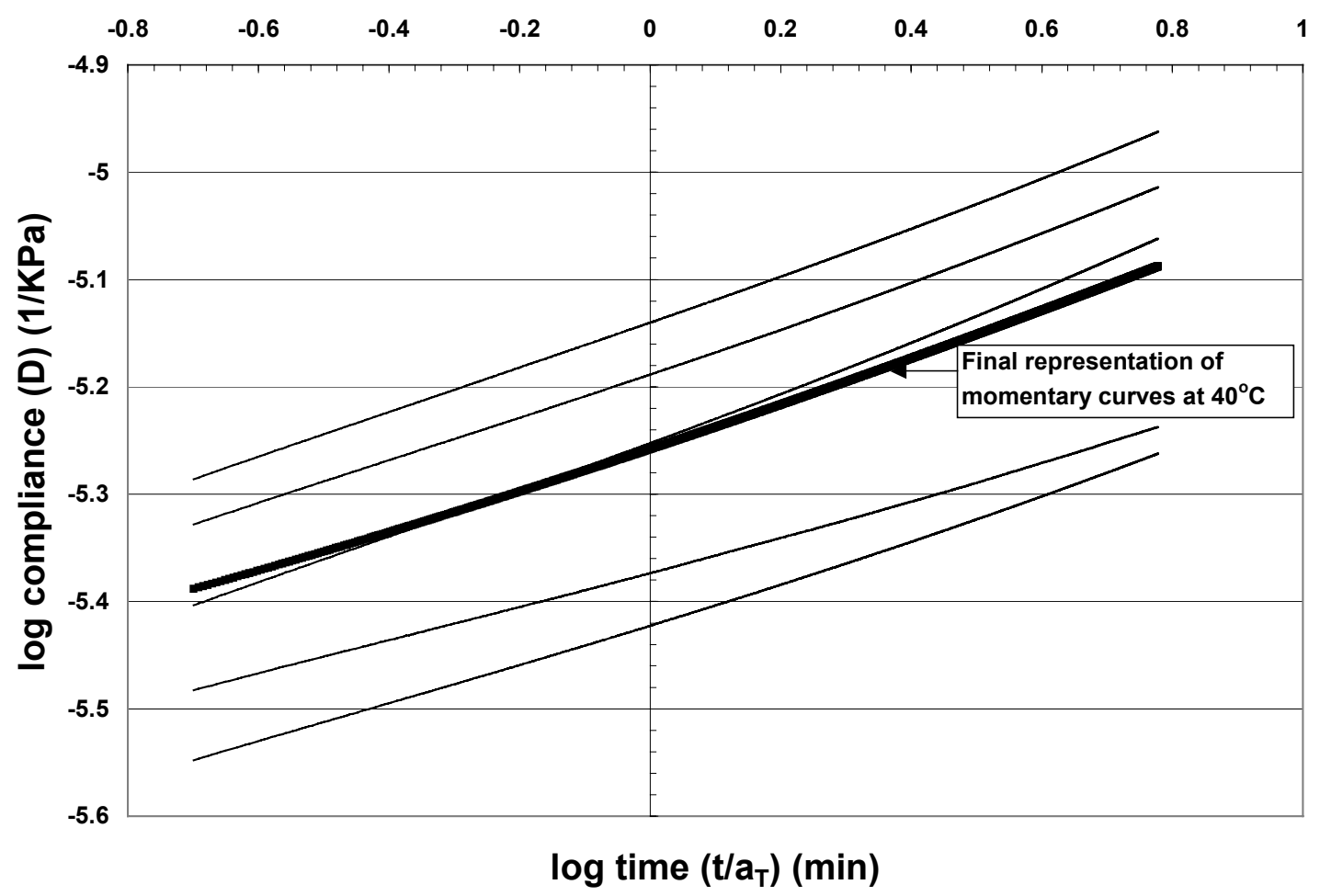

Fig 3.17 Final representation of the momentary curves of 5 specimens at $40^{\circ} \mathrm{C}$ (Material A)

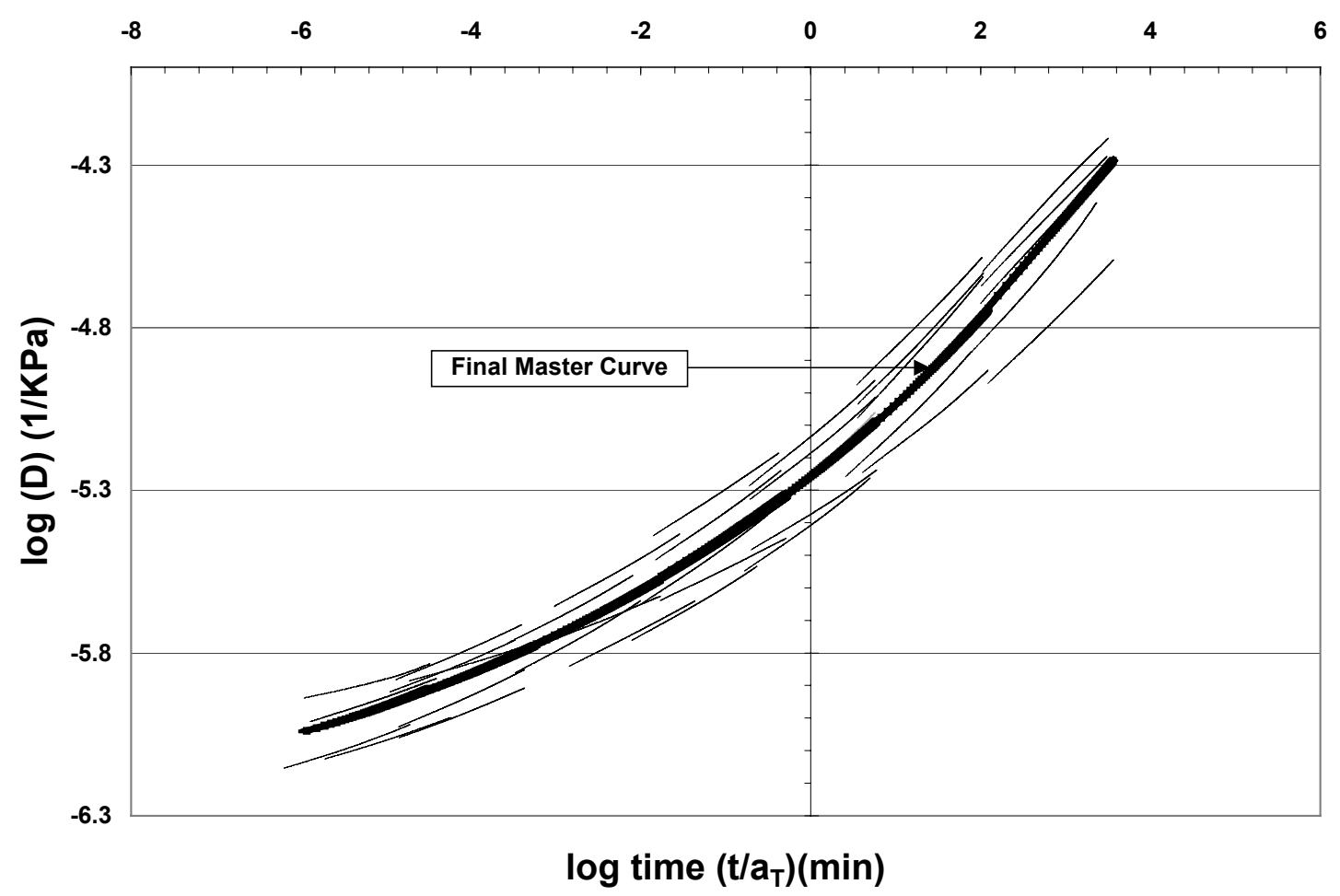

Figure 3.18. Variability of Creep Compliance for material A (at $\left.40^{\circ} \mathrm{C}\right)$ 


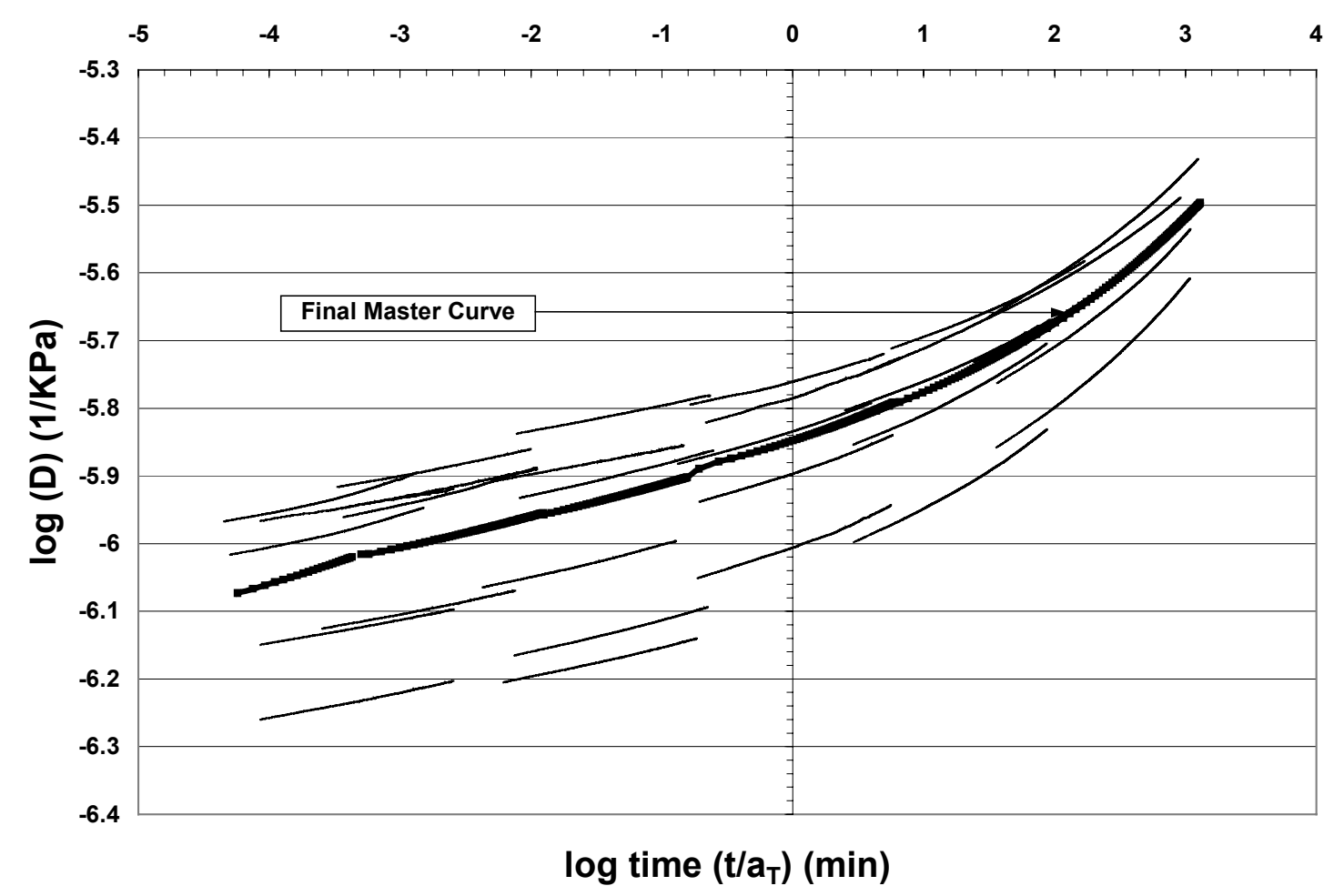

Figure 3.19. Variability of Creep Compliance for material B (at $40^{\circ} \mathrm{C}$ )

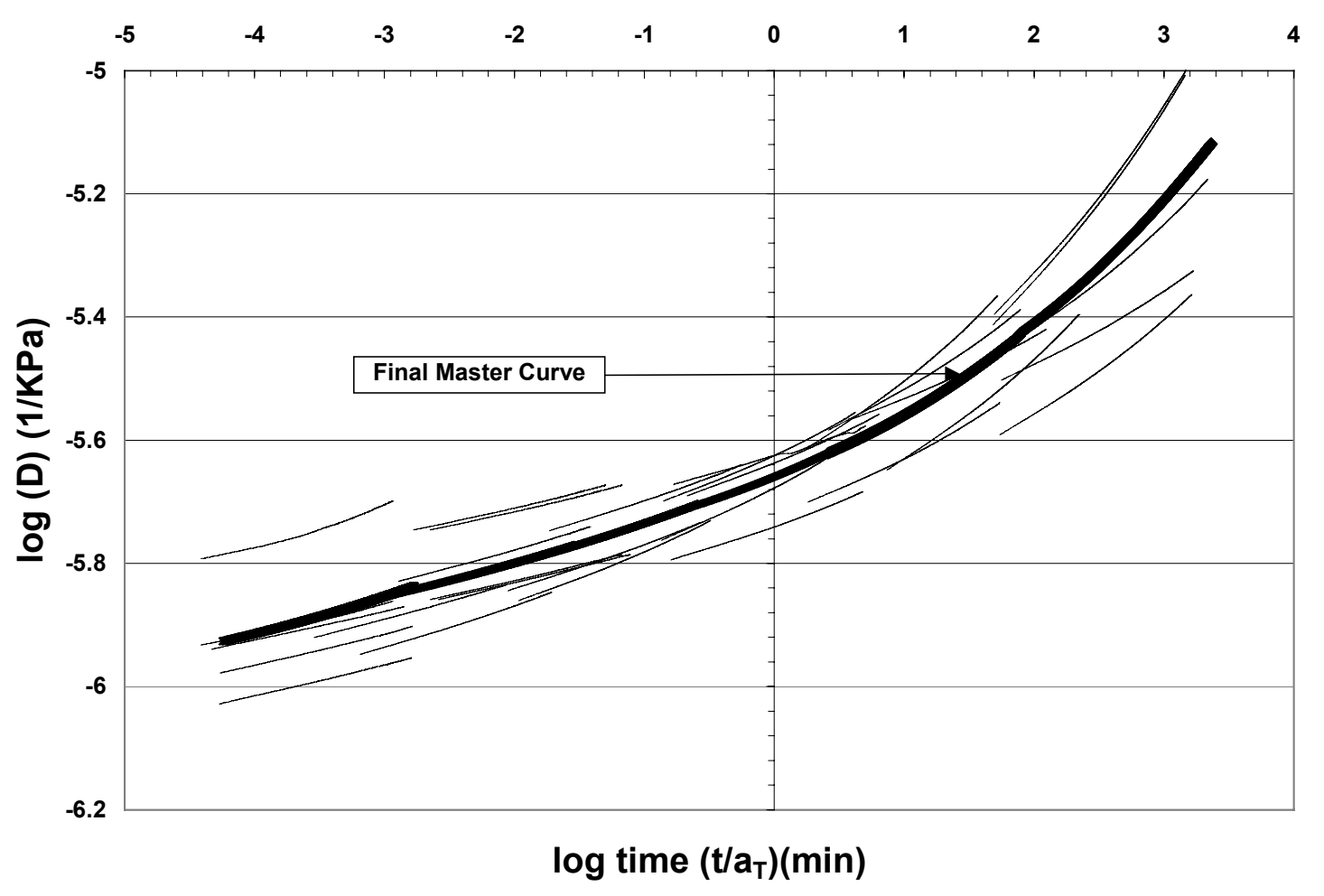

Figure 3.20. Variability of Creep Compliance for material $\mathrm{C}\left(\right.$ at $40^{\circ} \mathrm{C}$ ) 


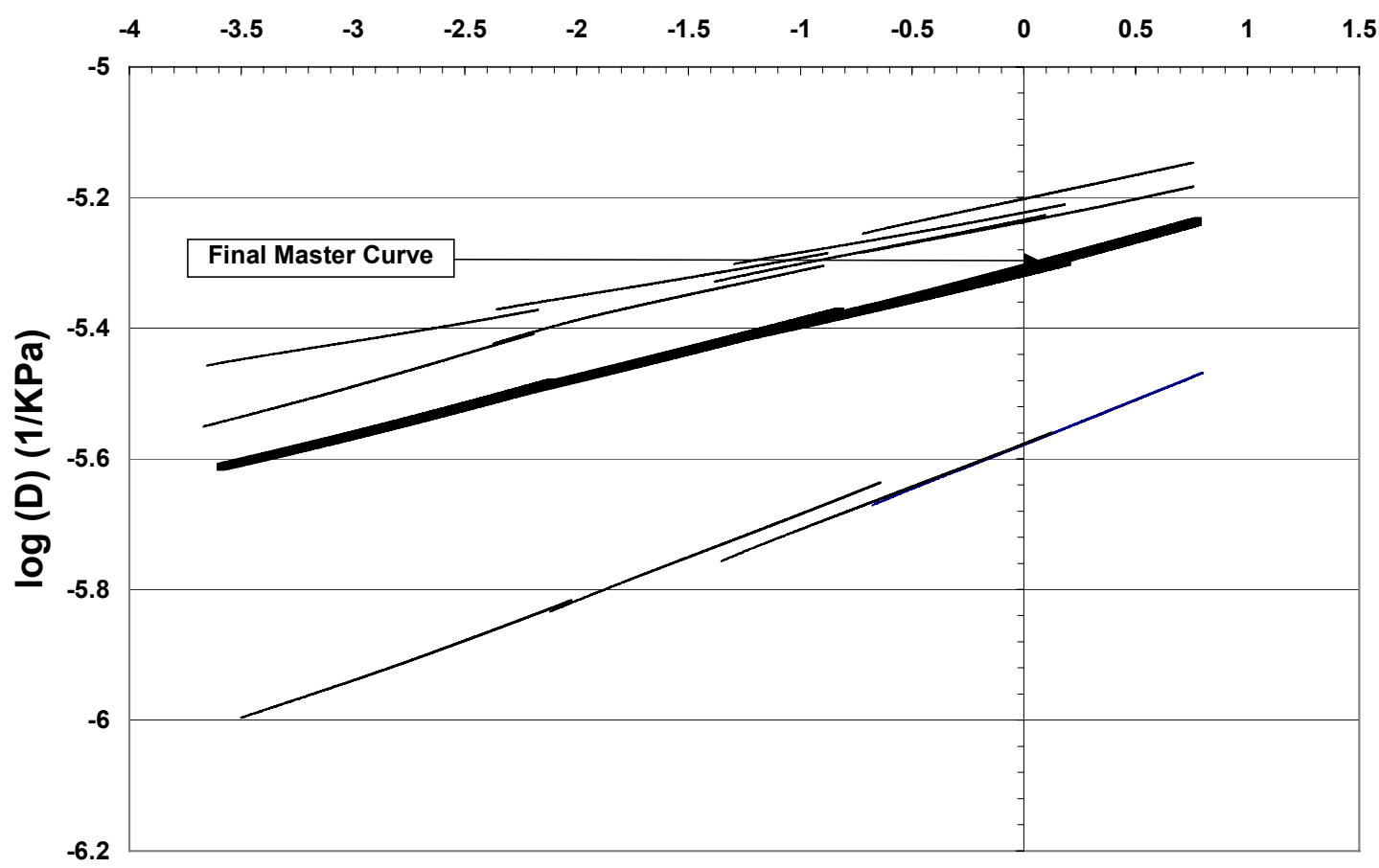

log time $\left(t / a_{T}\right)(\min )$

Figure 3.21. Variability of Creep Compliance for material D (at $\left.40^{\circ} \mathrm{C}\right)$

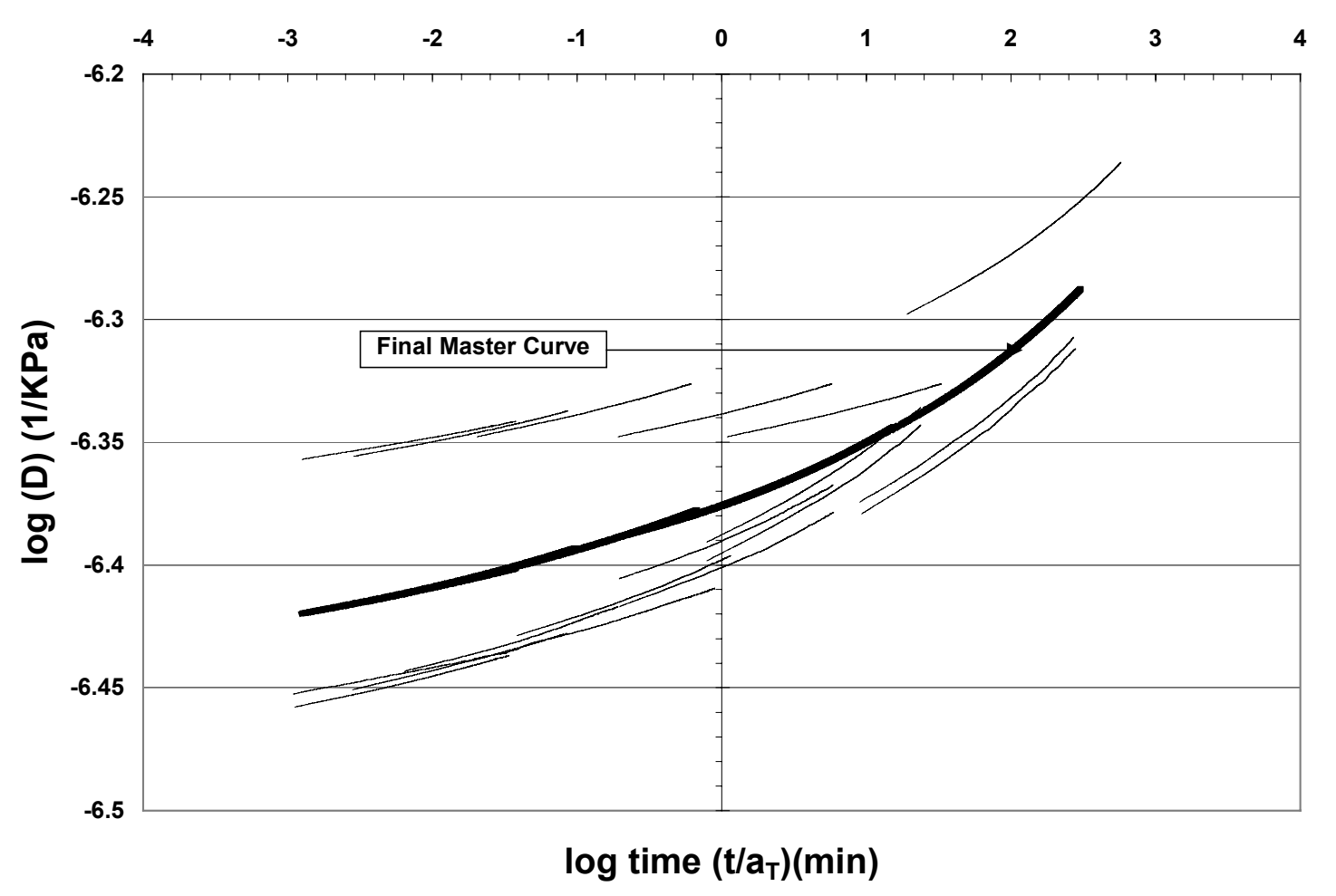

Figure 3.22. Variability of Creep Compliance for material E (at $40^{\circ} \mathrm{C}$ ) 


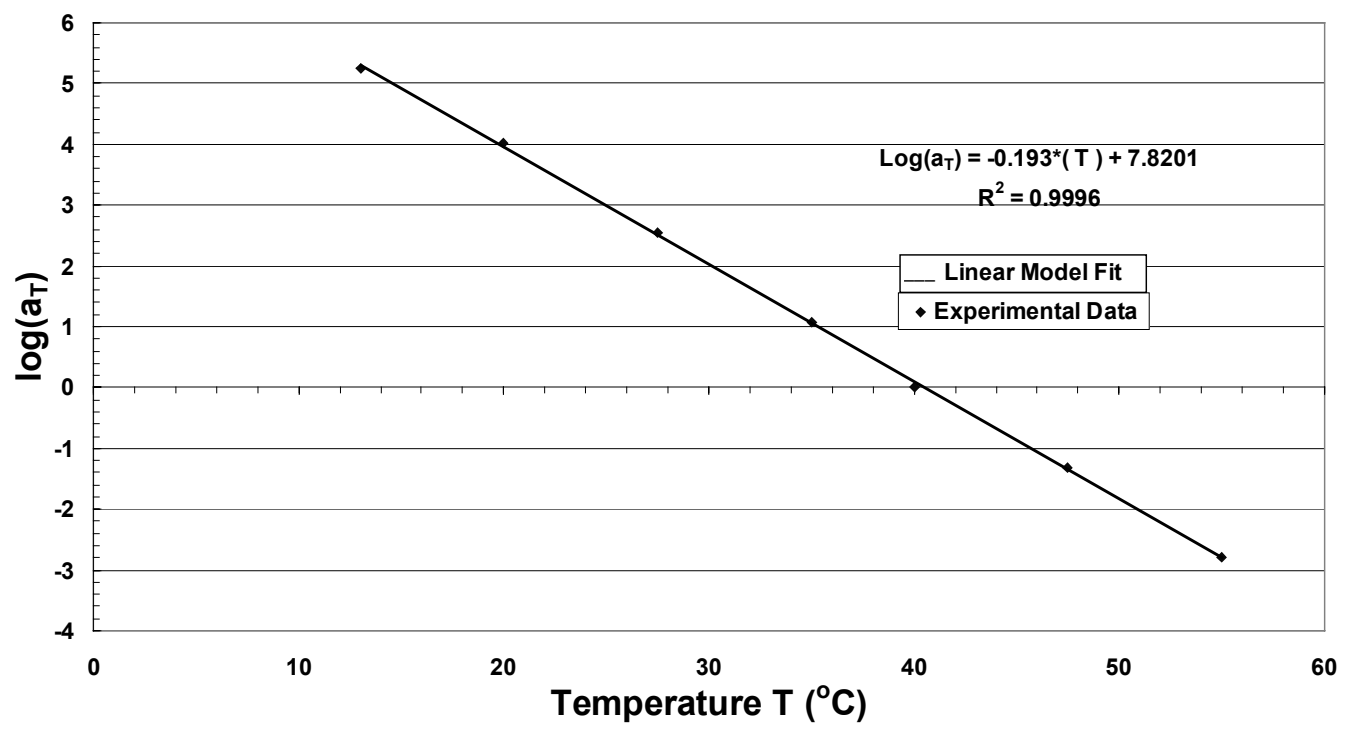

Figure 3.23. Average shift factor plot for material $A\left(T_{\text {ref }}=40^{\circ} \mathrm{C}\right)$

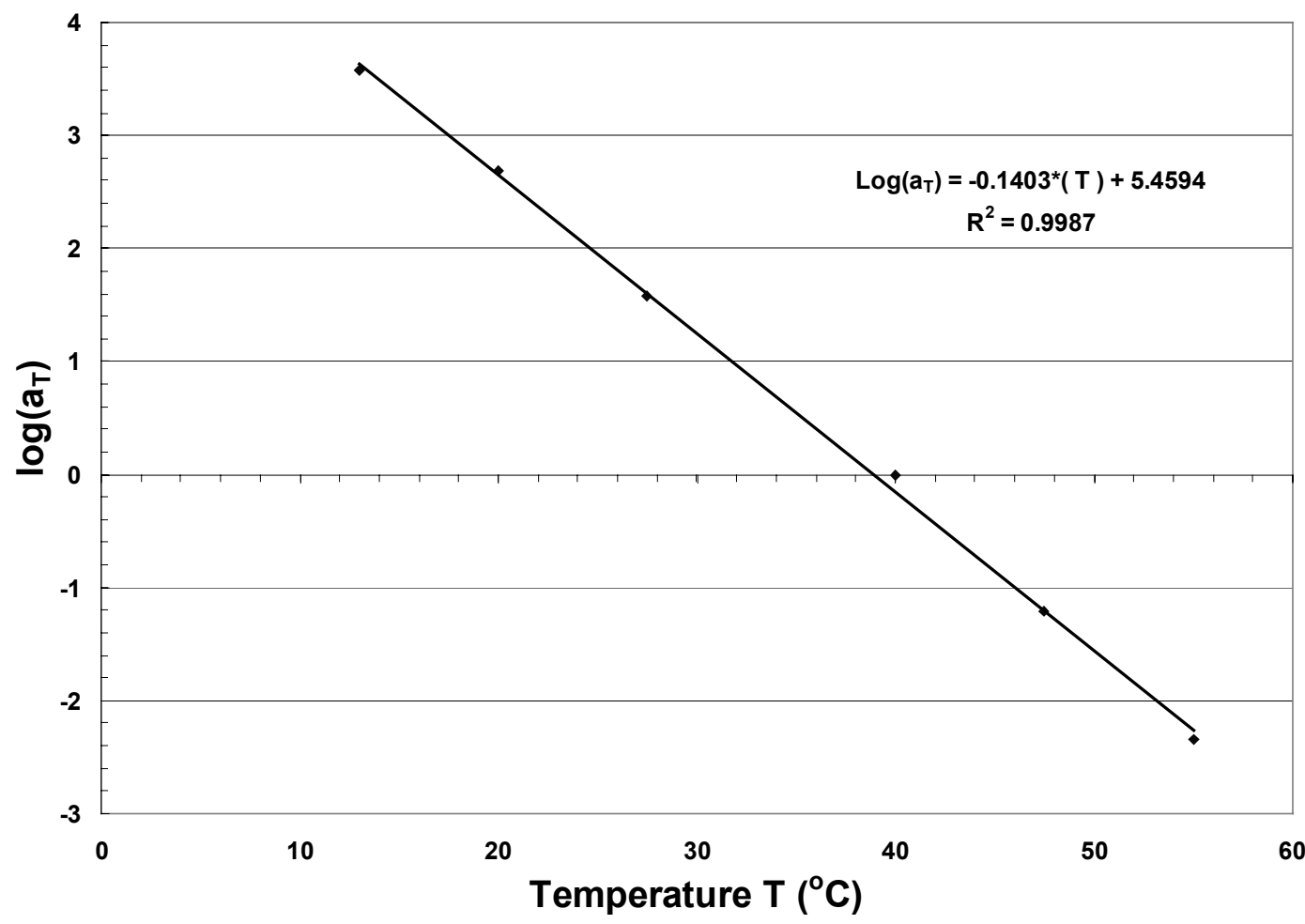

Figure 3.24 Average shift factor plot for material $B\left(T_{\text {ref }}=40^{\circ} \mathrm{C}\right)$ 


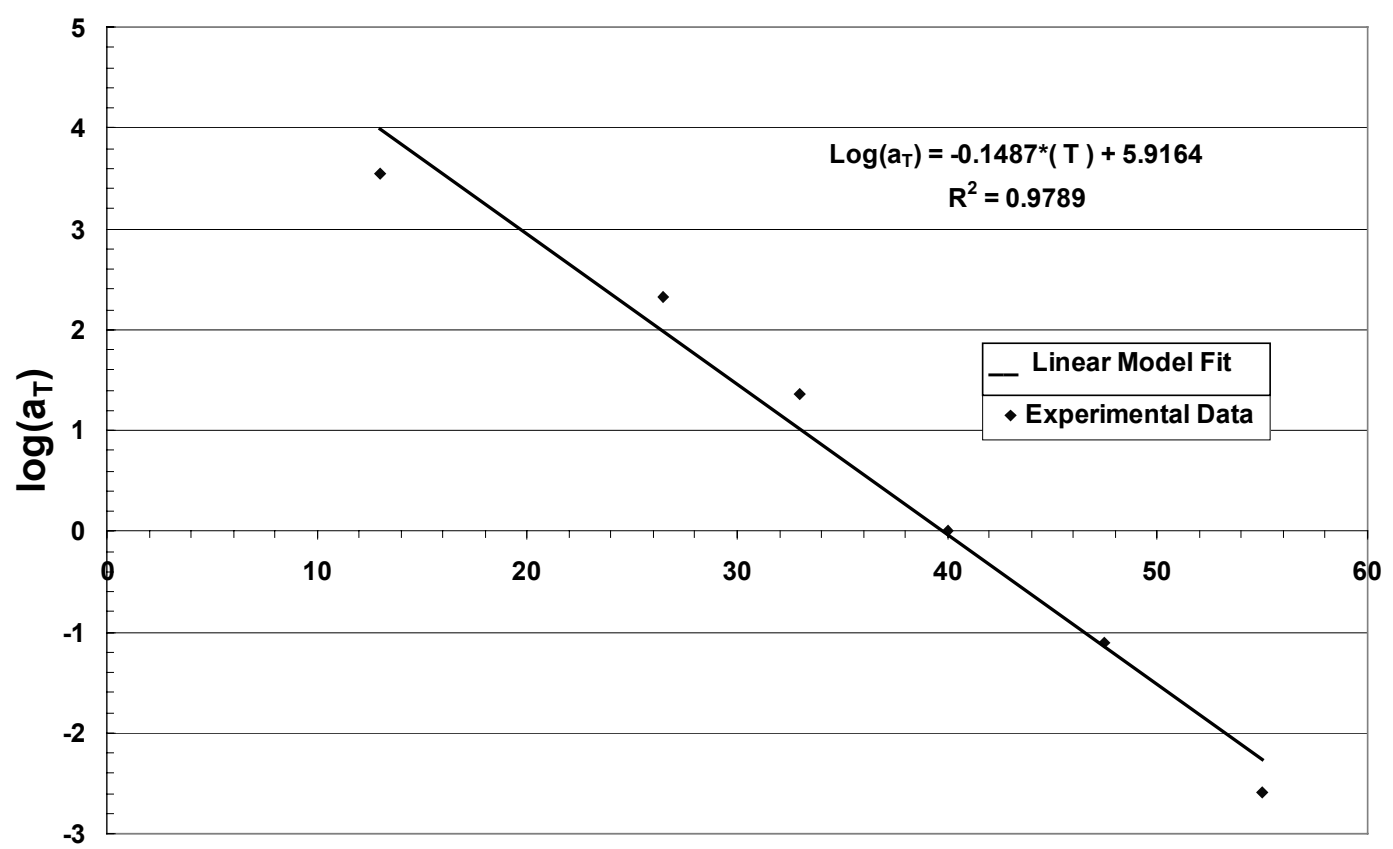

Temperature $\mathrm{T}\left({ }^{\circ} \mathrm{C}\right)$

Figure 3.25. Average shift factor plot for material $C\left(T_{\text {ref }}=40^{\circ} \mathrm{C}\right)$

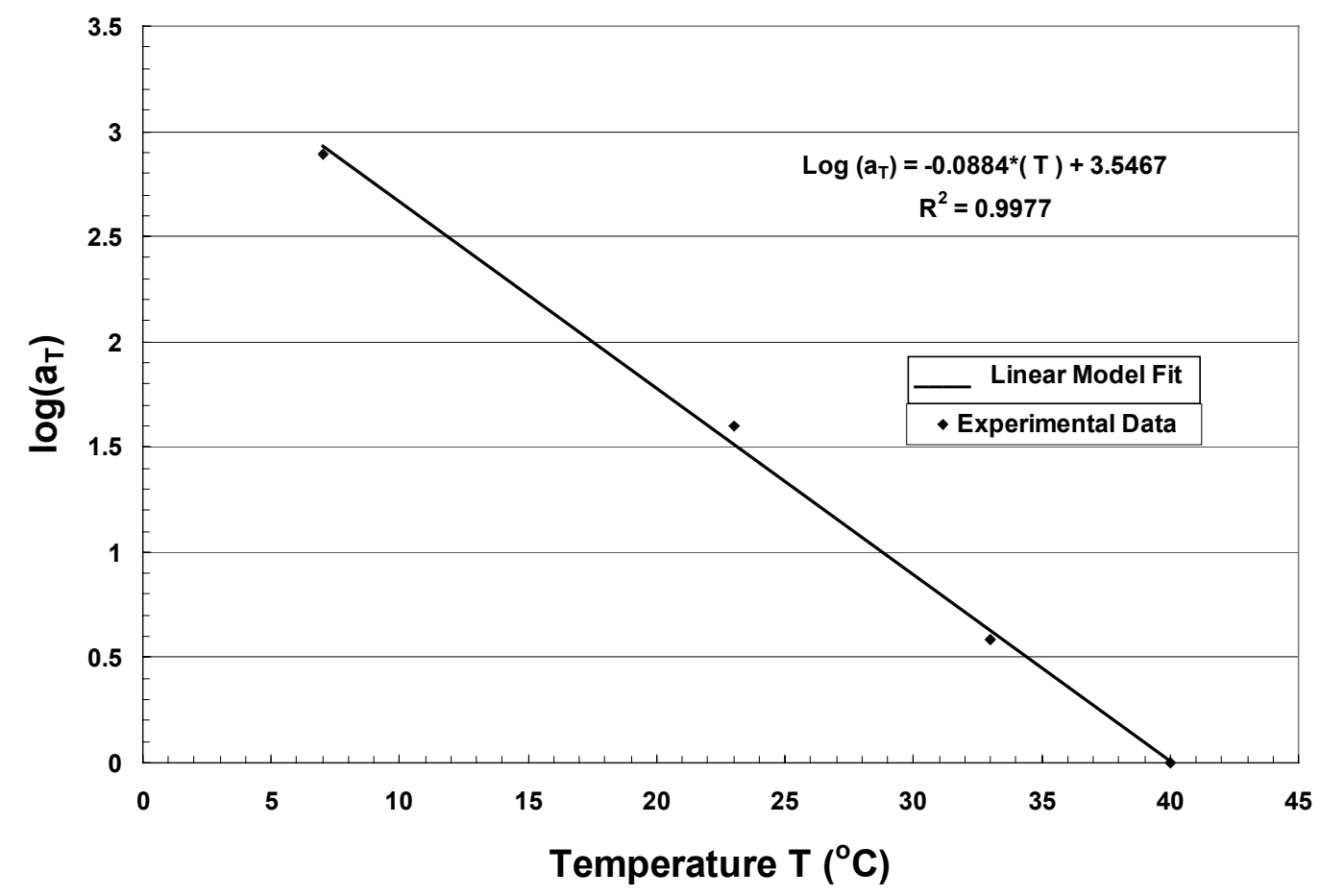

Figure 3.26. Average shift factor plot for material $D\left(T_{\text {ref }}=40^{\circ} \mathrm{C}\right)$ 


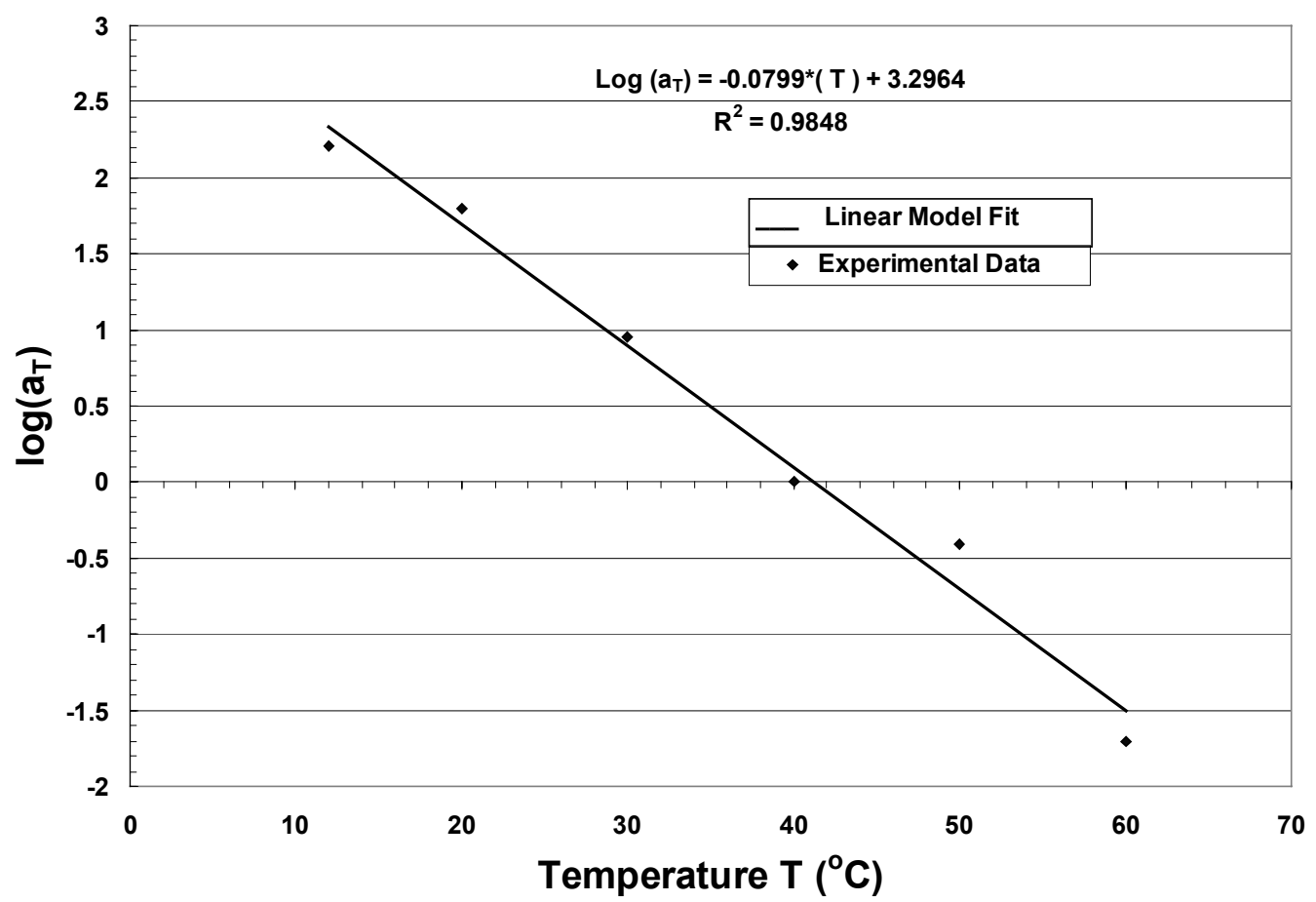

Figure 3.27. Average shift factor plot for material $E\left(T_{\text {ref }}=40^{\circ} \mathrm{C}\right)$

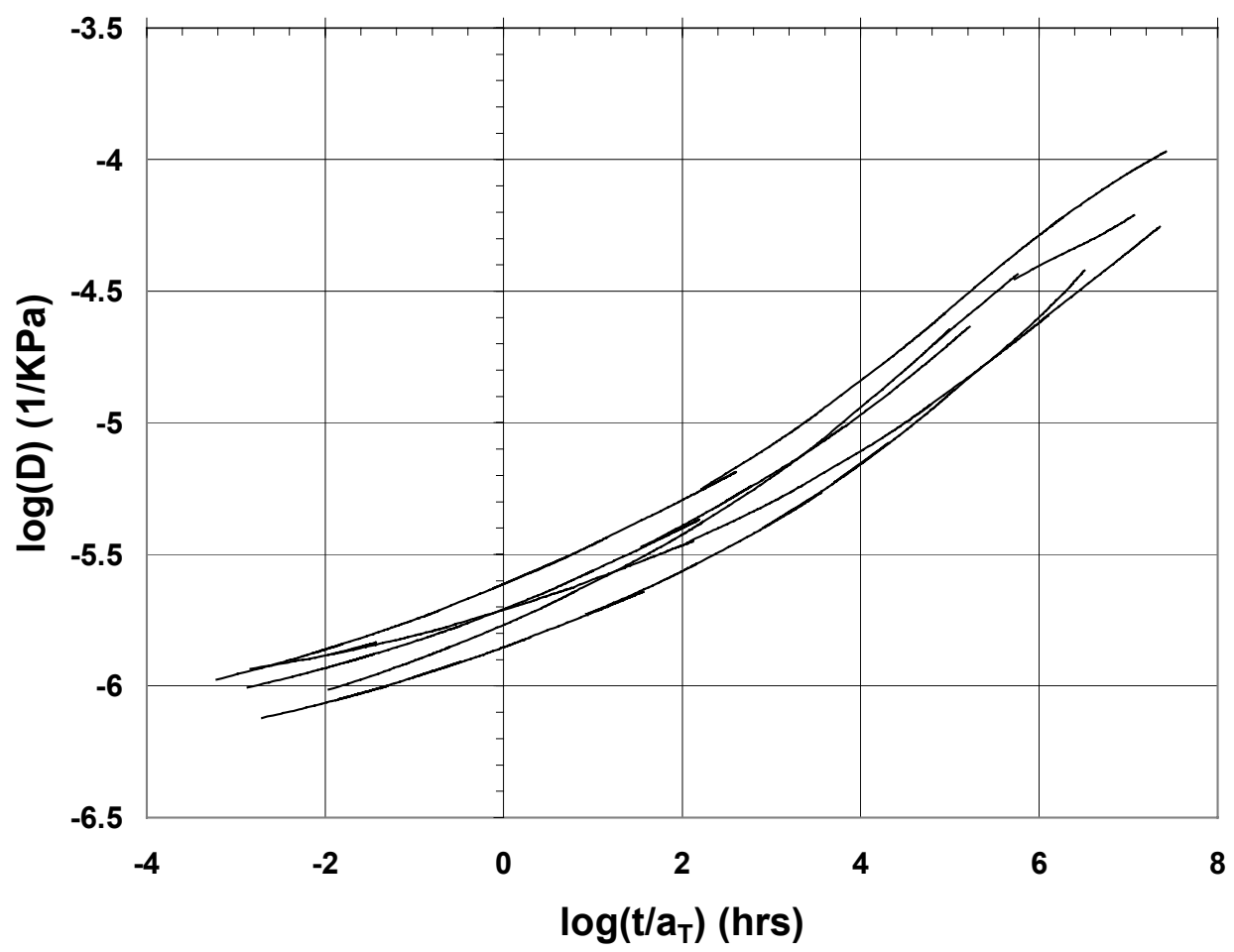

Figure 3.28. Specimen master curves of material A shifted for temperature $\left(t_{\mathrm{e}}=60 \mathrm{~min}\right)$ 


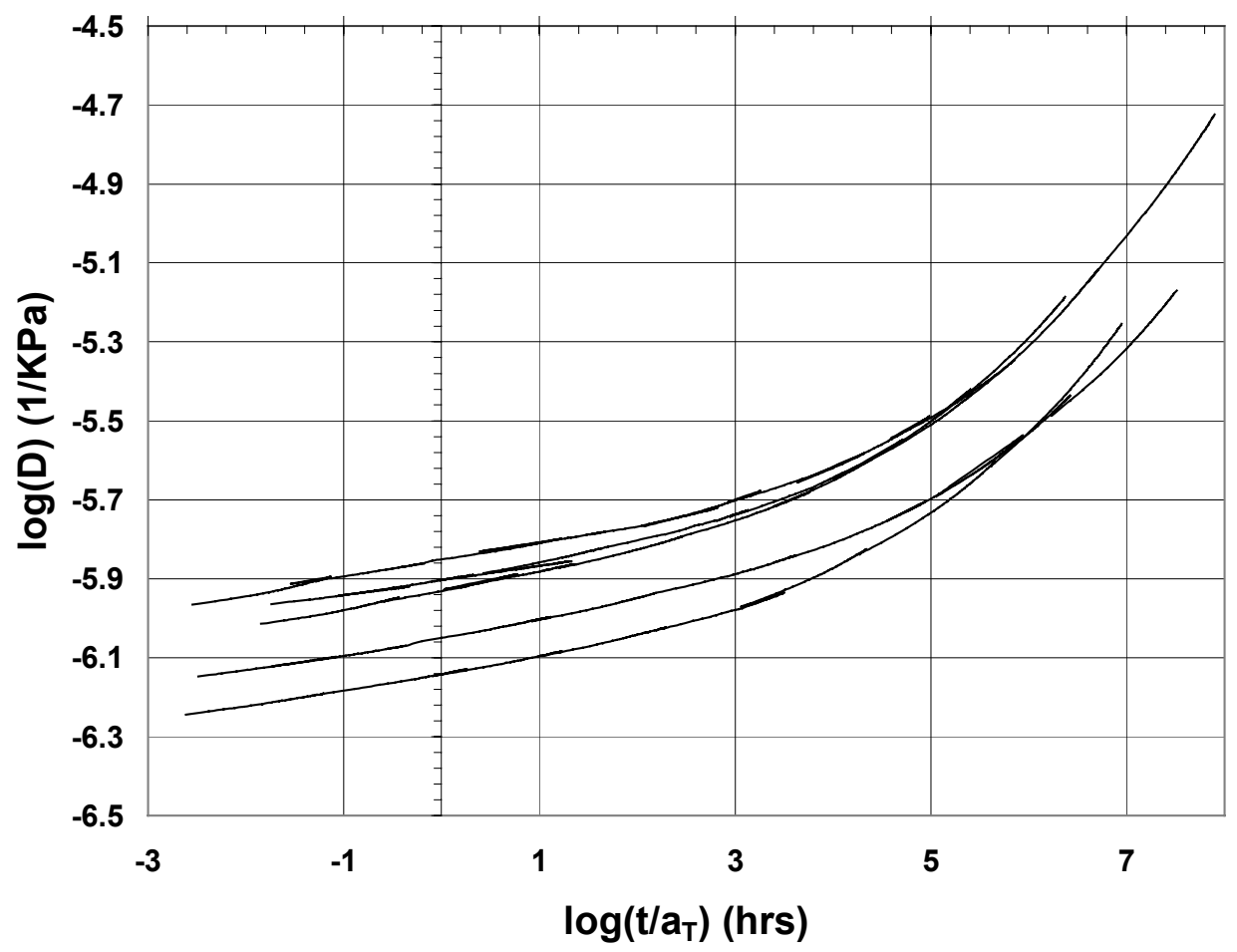

Figure 3.29. Specimen master curves of material B shifted for temperature $\left(t_{\mathrm{e}}=60 \mathrm{~min}\right)$

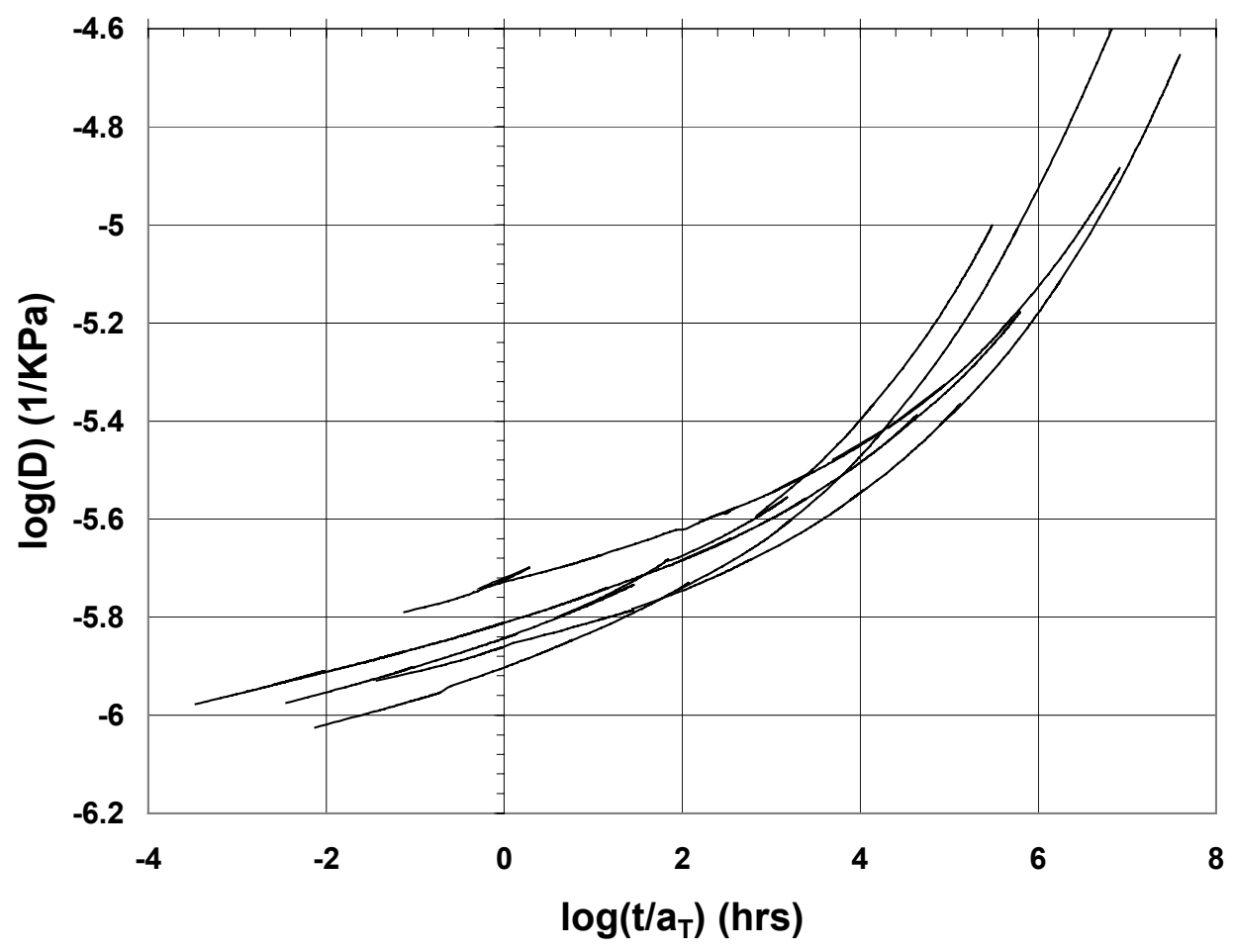

Figure 3.30. Specimen master curves of material $\mathrm{C}$ shifted for temperature $\left(\mathbf{t}_{\mathrm{e}}=\mathbf{6 0} \mathrm{min}\right)$ 


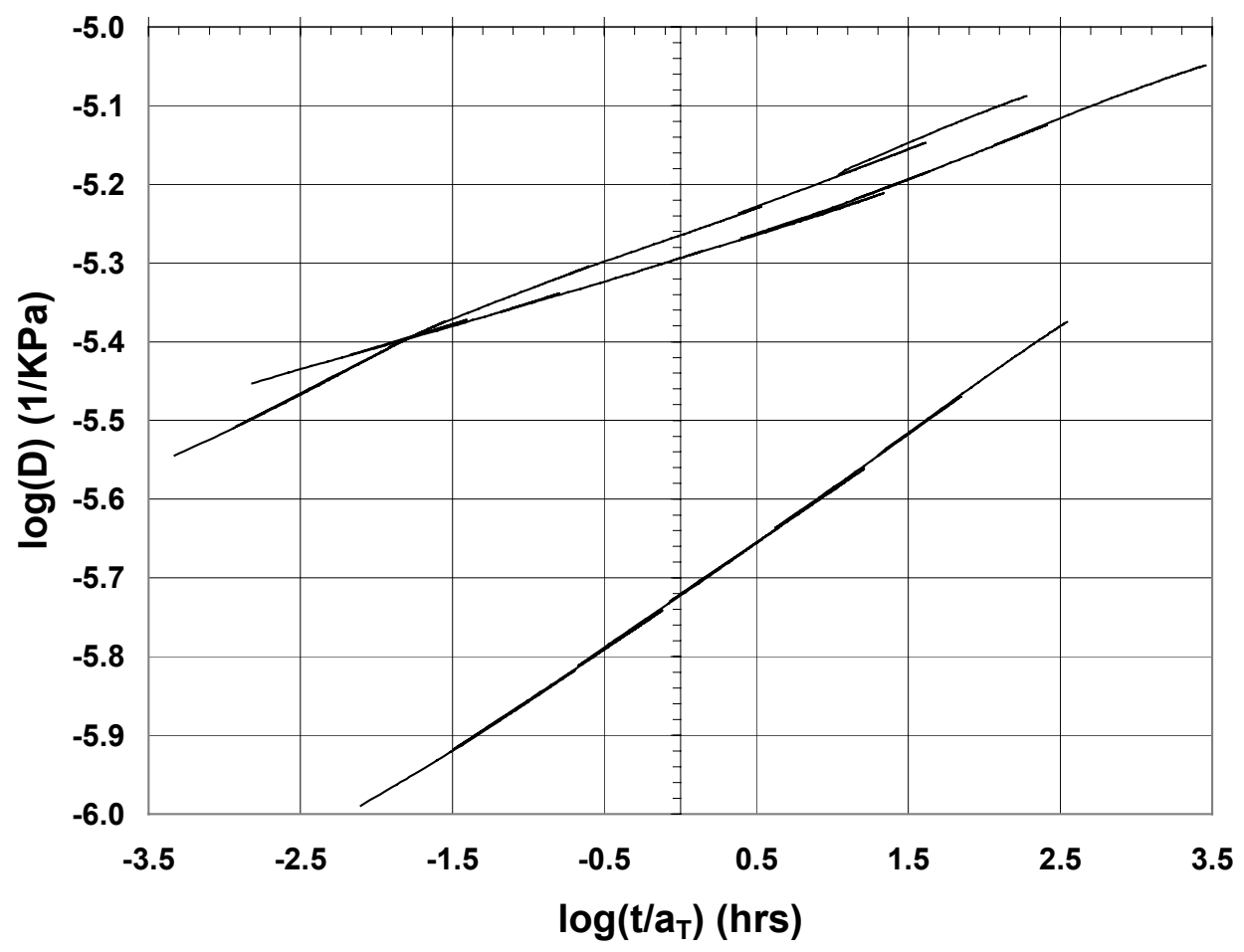

Figure 3.31. Specimen master curves of material $D$ shifted for temperature $\left(t_{e}=60 \mathrm{~min}\right)$

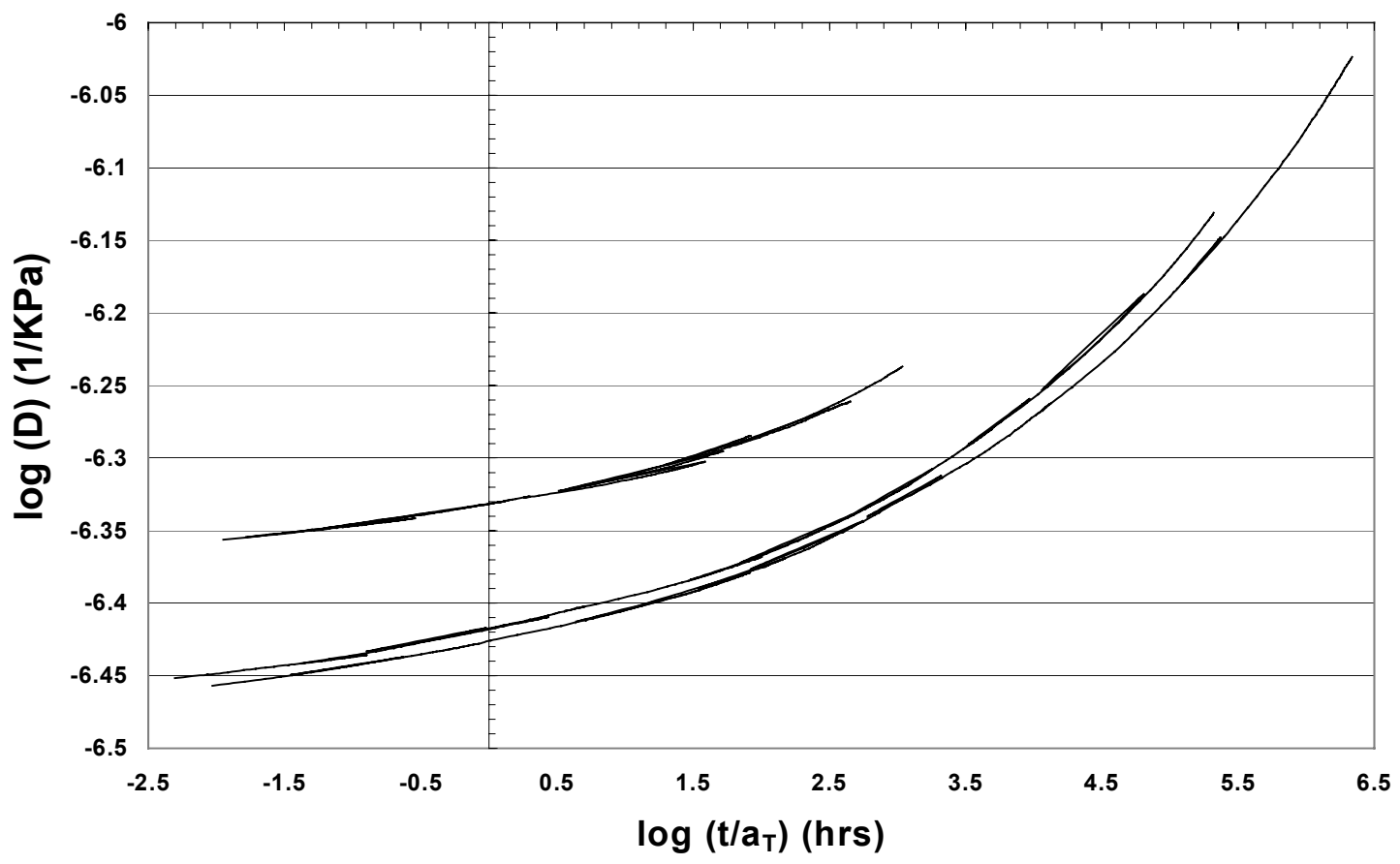

Figure 3.32. Specimen master curves of material $E$ shifted for temperature $\left(t_{e}=60 \mathrm{~min}\right)$ 


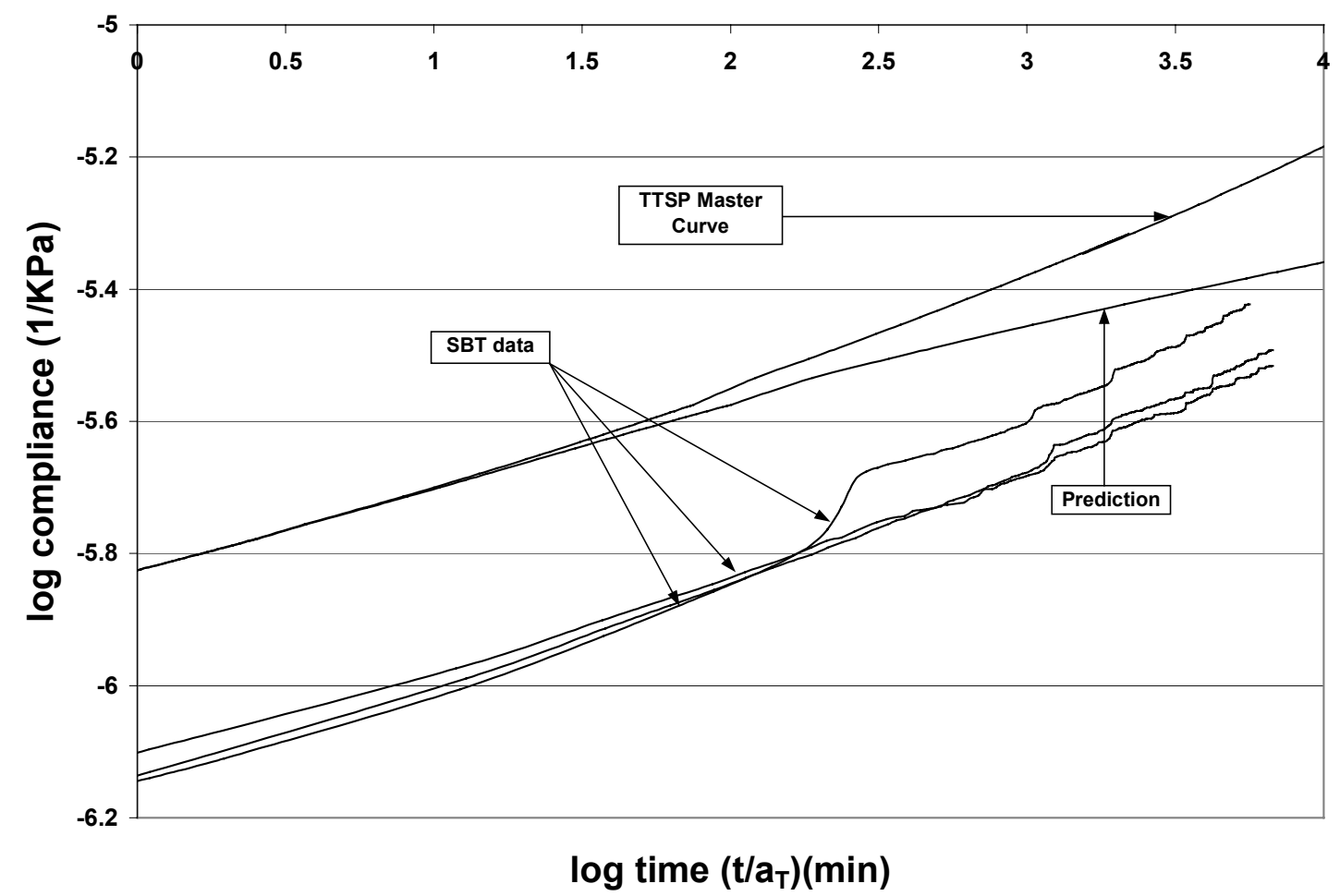

Fig 3.33 Comparison with long-term bending data at $21.1^{\circ} \mathrm{C}$ (Material A)

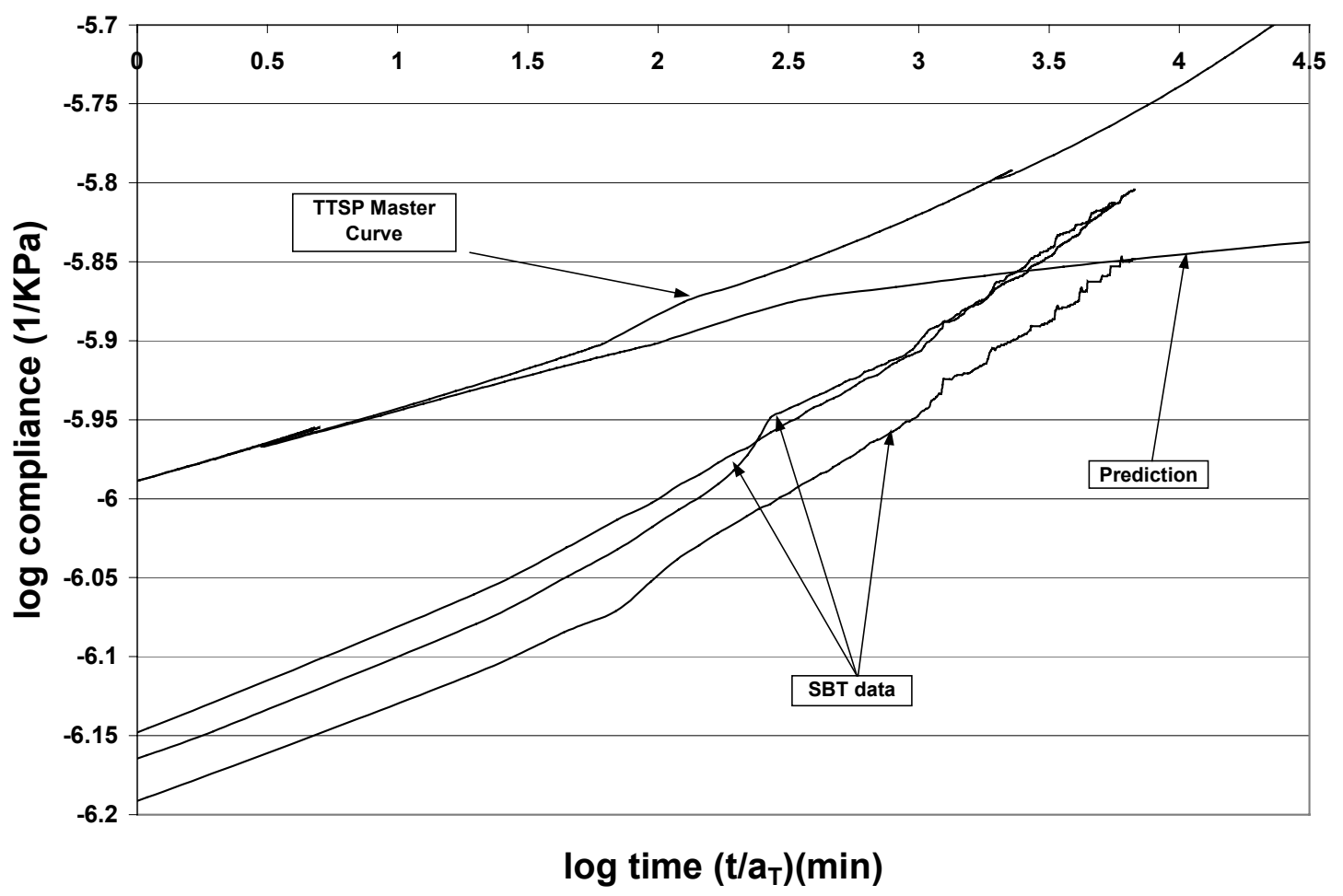

Fig 3.34 Comparison with long-term bending data at $21.1^{\circ} \mathrm{C}$ (Material B) 


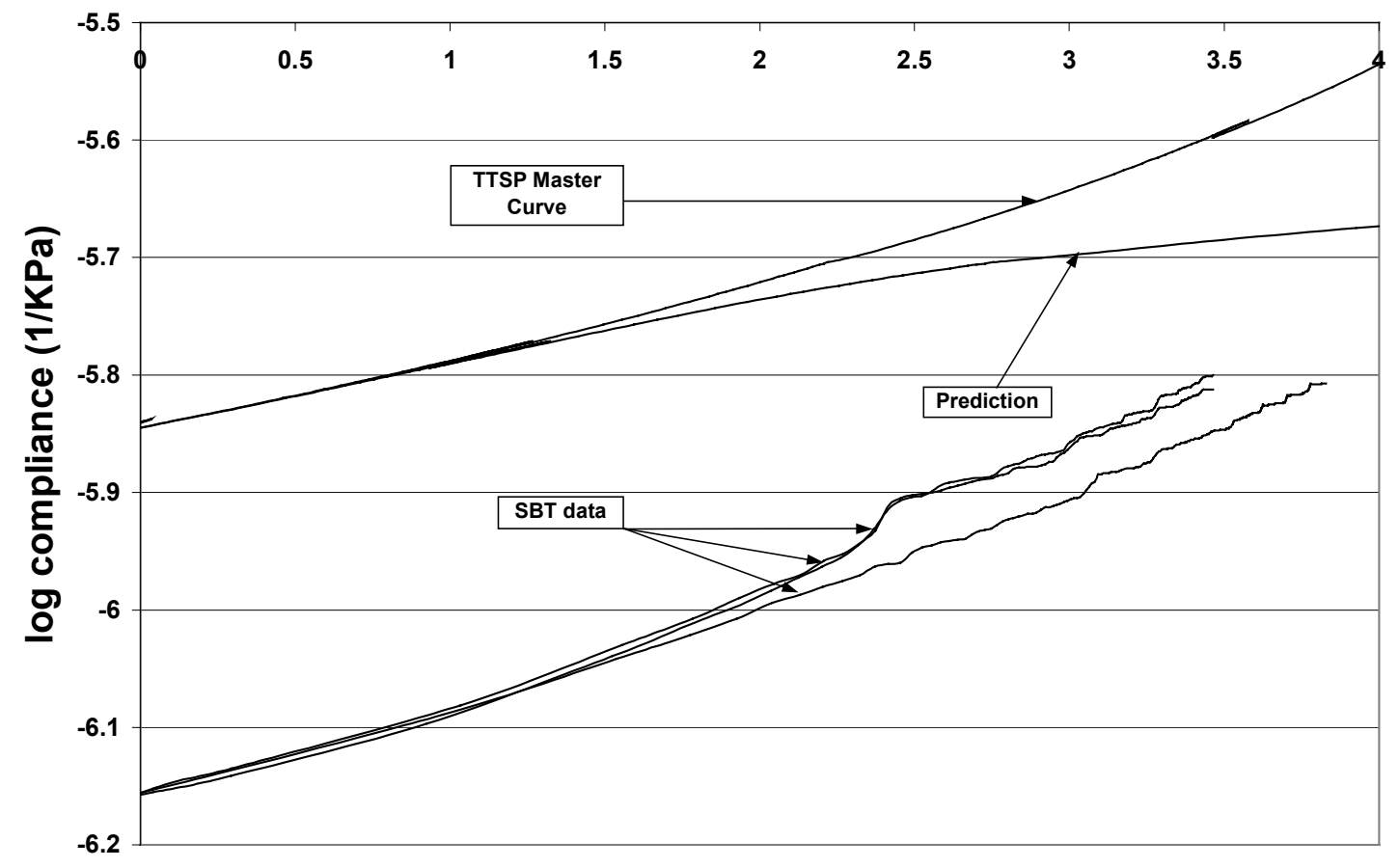

log time $\left(t / a_{T}\right)(\min )$

Fig 3.35 Comparison with long-term bending data at $21.1^{\circ} \mathrm{C}$ (Material $\mathrm{C}$ )

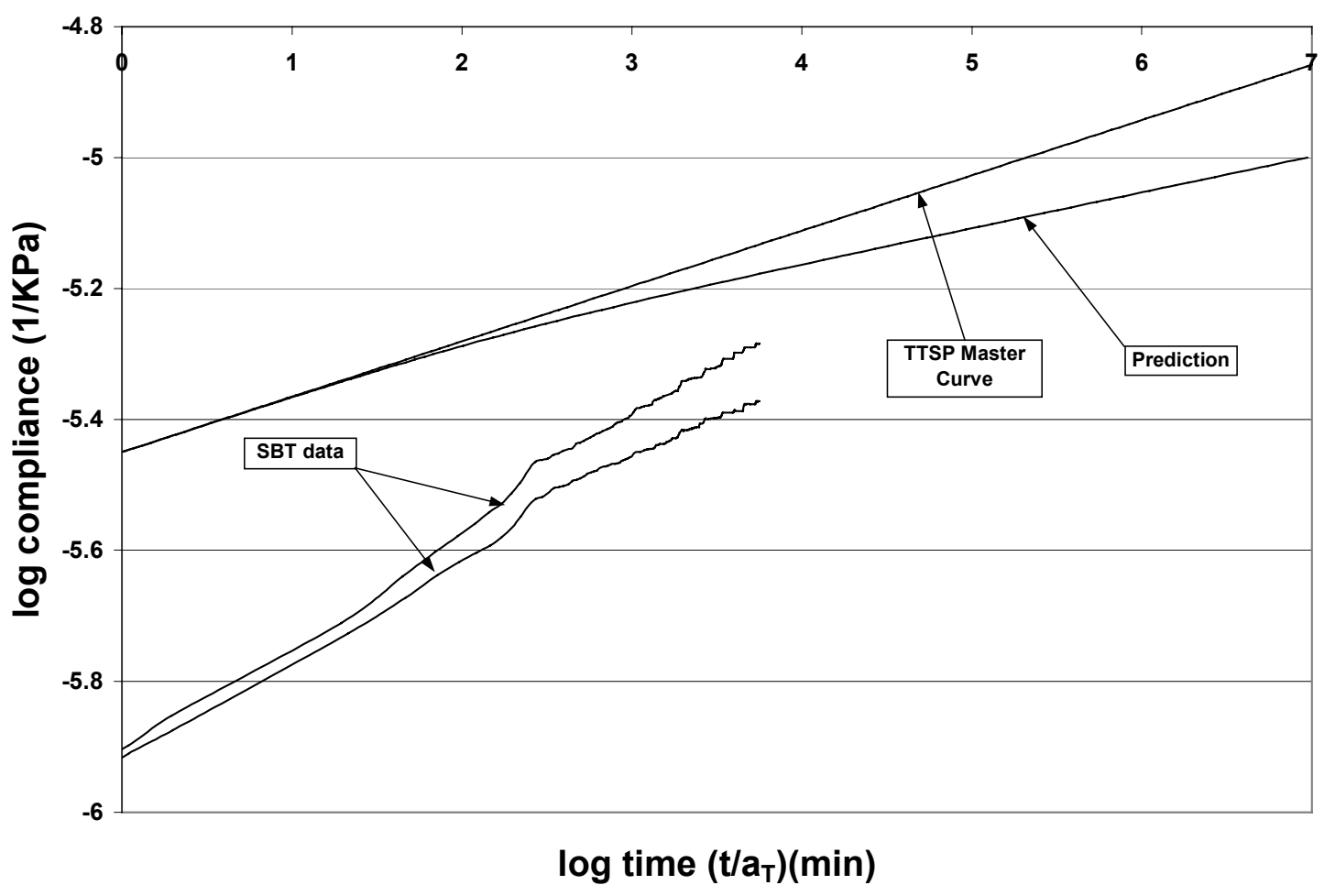

Fig 3.36 Comparison with long-term bending data at $21.1^{\circ} \mathrm{C}$ (Material D) 


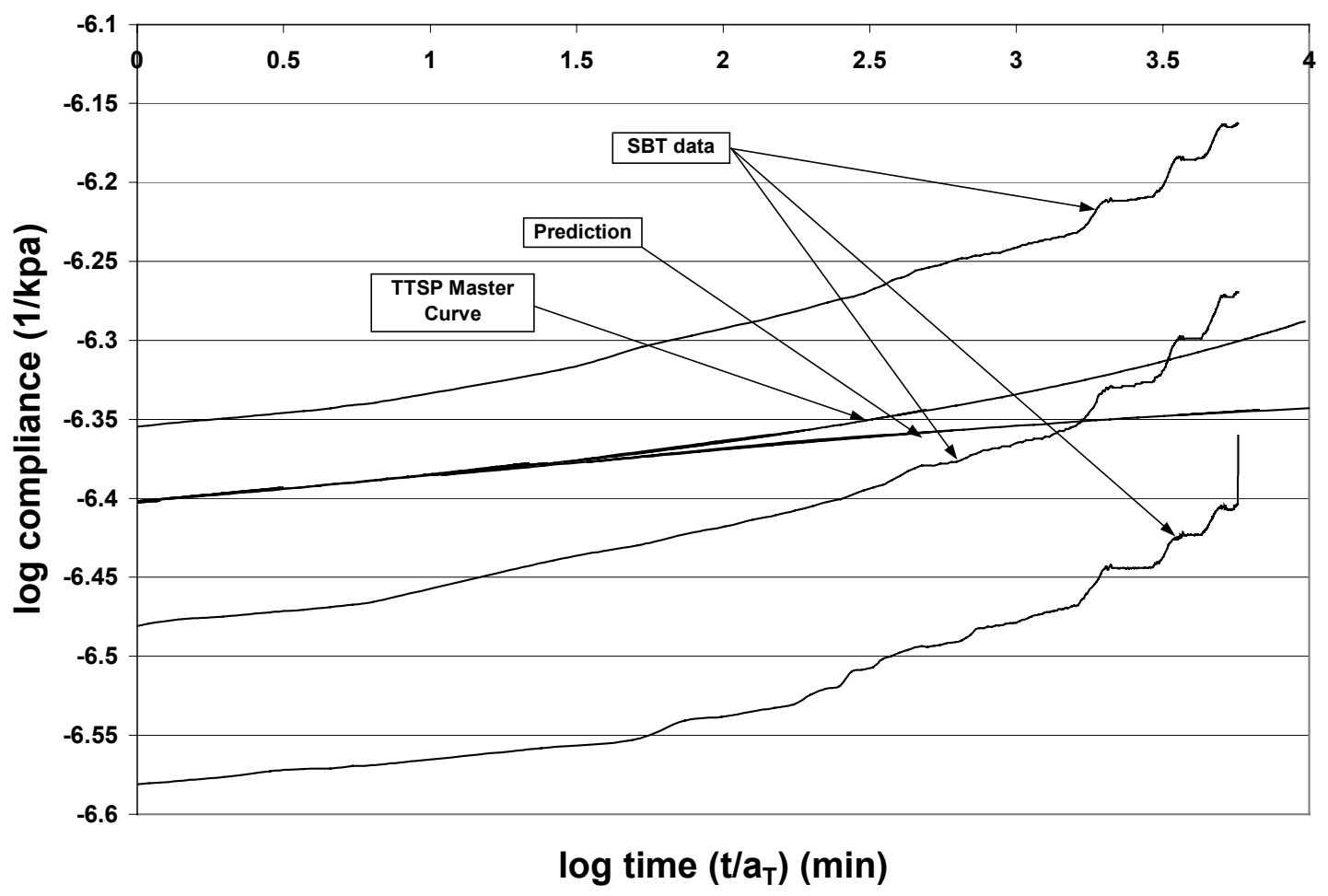

Fig 3.37 Comparison with long-term bending data at $21.1^{\circ} \mathrm{C}$ (Material E)

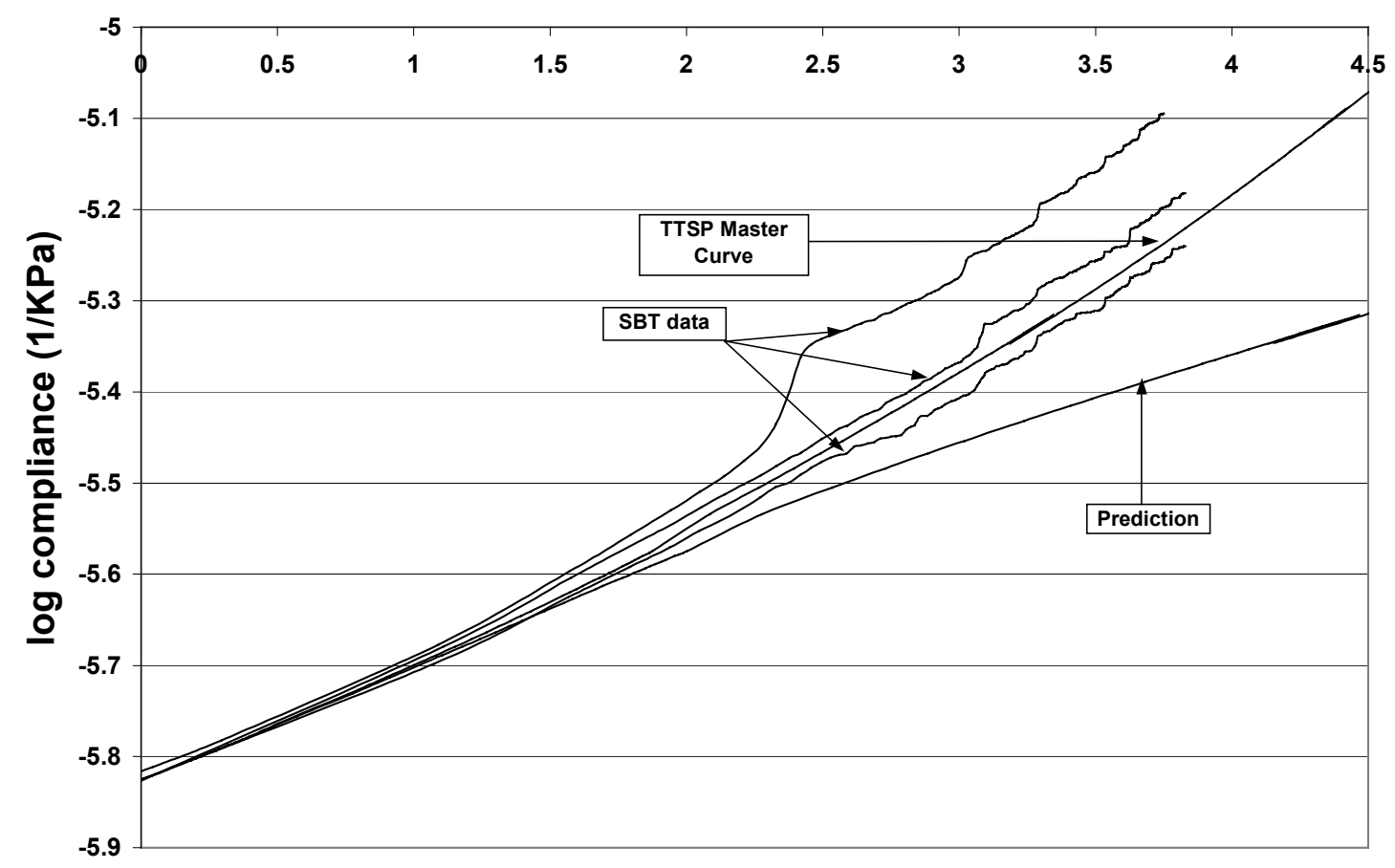

log time $\left(t / a_{T}\right)(\min )$

Fig 3.38 Comparison with long-term bending data at $21.1^{\circ} \mathrm{C}$ after shifting (Material A) 


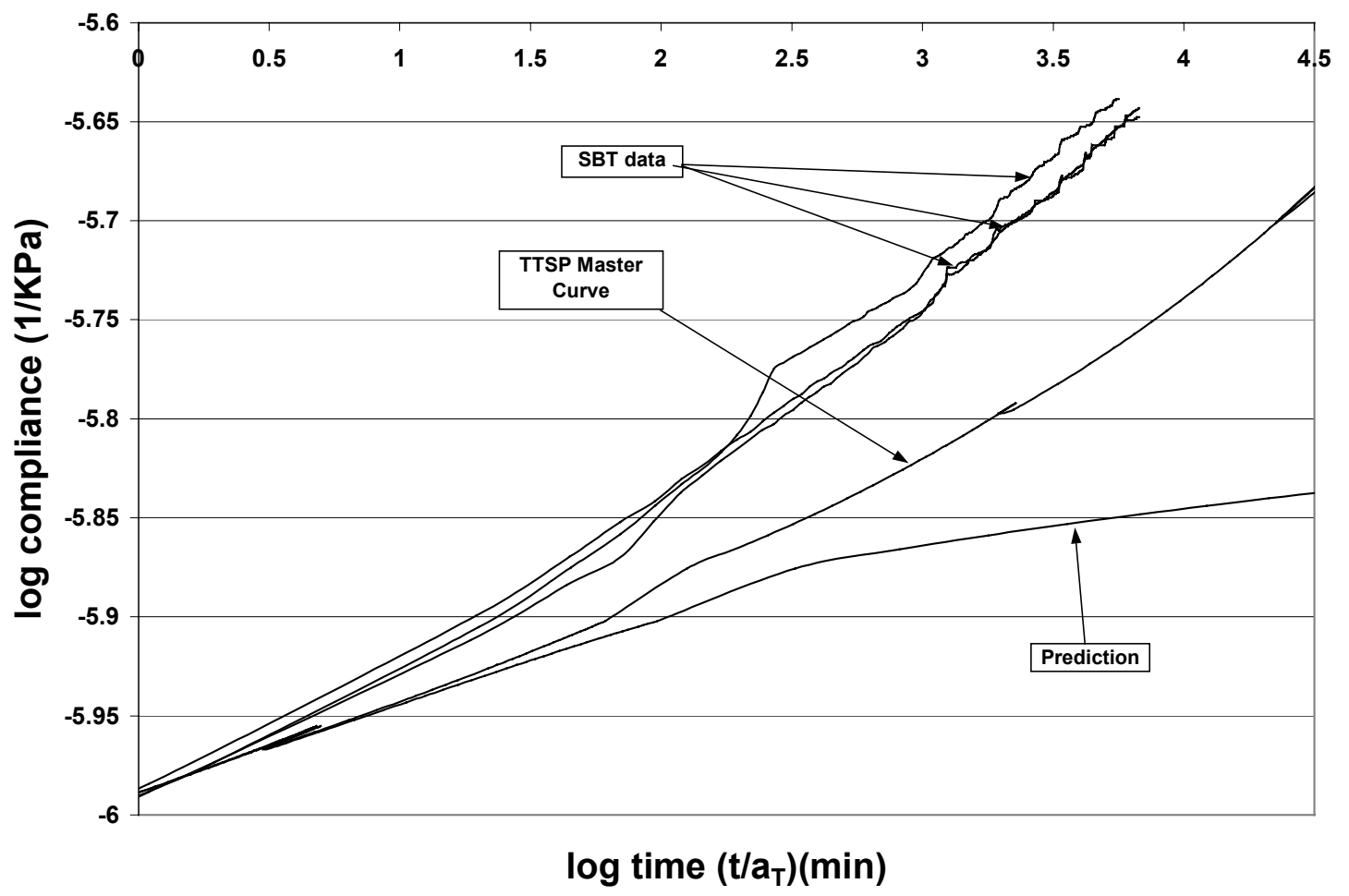

Fig 3.39 Comparison with long-term bending data at $21.1^{\circ} \mathrm{C}$ after shifting (Material B)

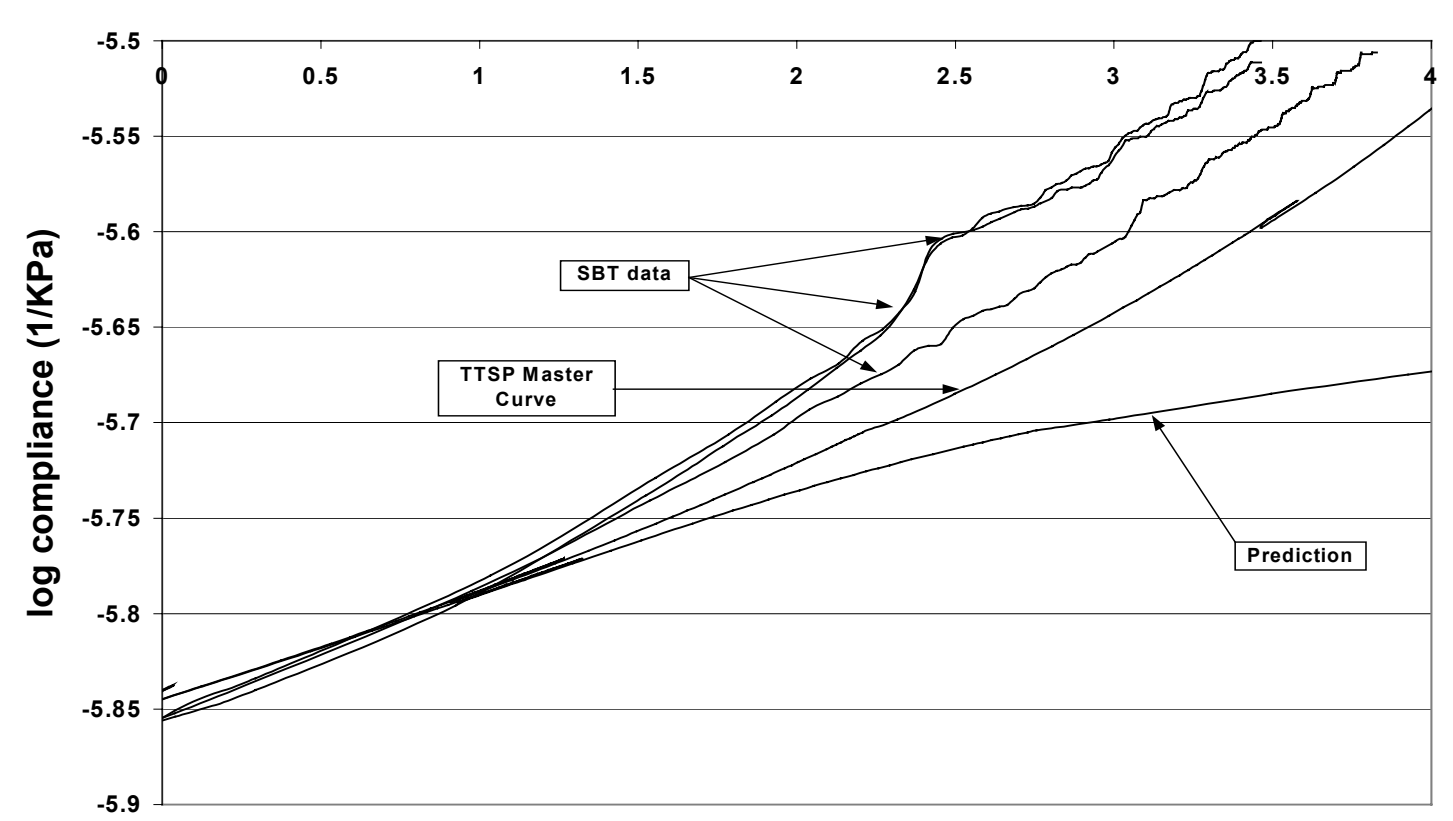

$\log$ time $\left(t / a_{T}\right)(\min )$

Fig 3.40 Comparison with long-term bending data at $21.1^{\circ} \mathrm{C}$ after shifting (Material C) 


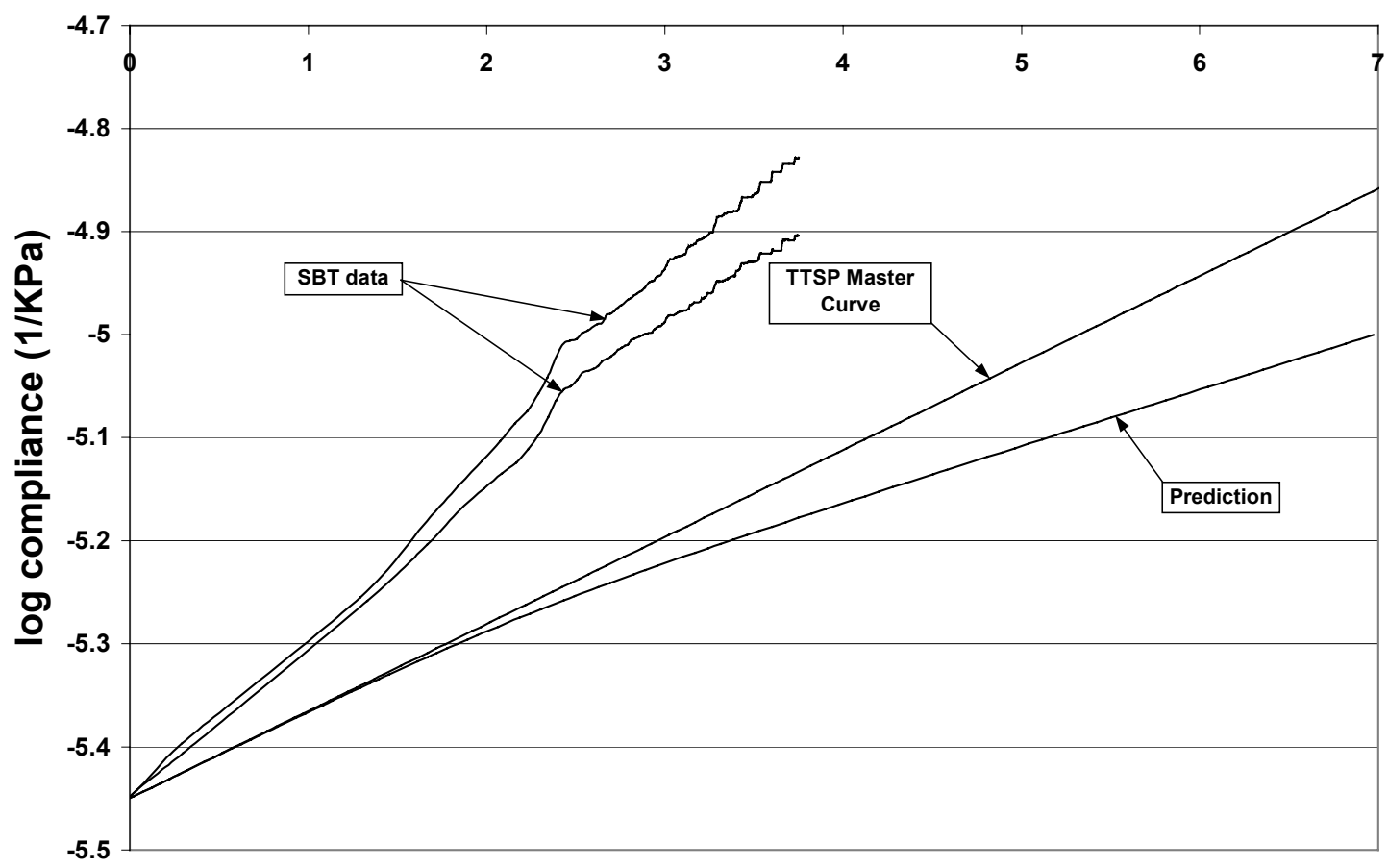

$\log$ time $\left(\mathbf{t} / \mathrm{a}_{\mathrm{T}}\right)(\mathrm{min})$

Fig 3.41 Comparison with long-term bending data at $21.1^{\circ} \mathrm{C}$ after shifting (Material D)

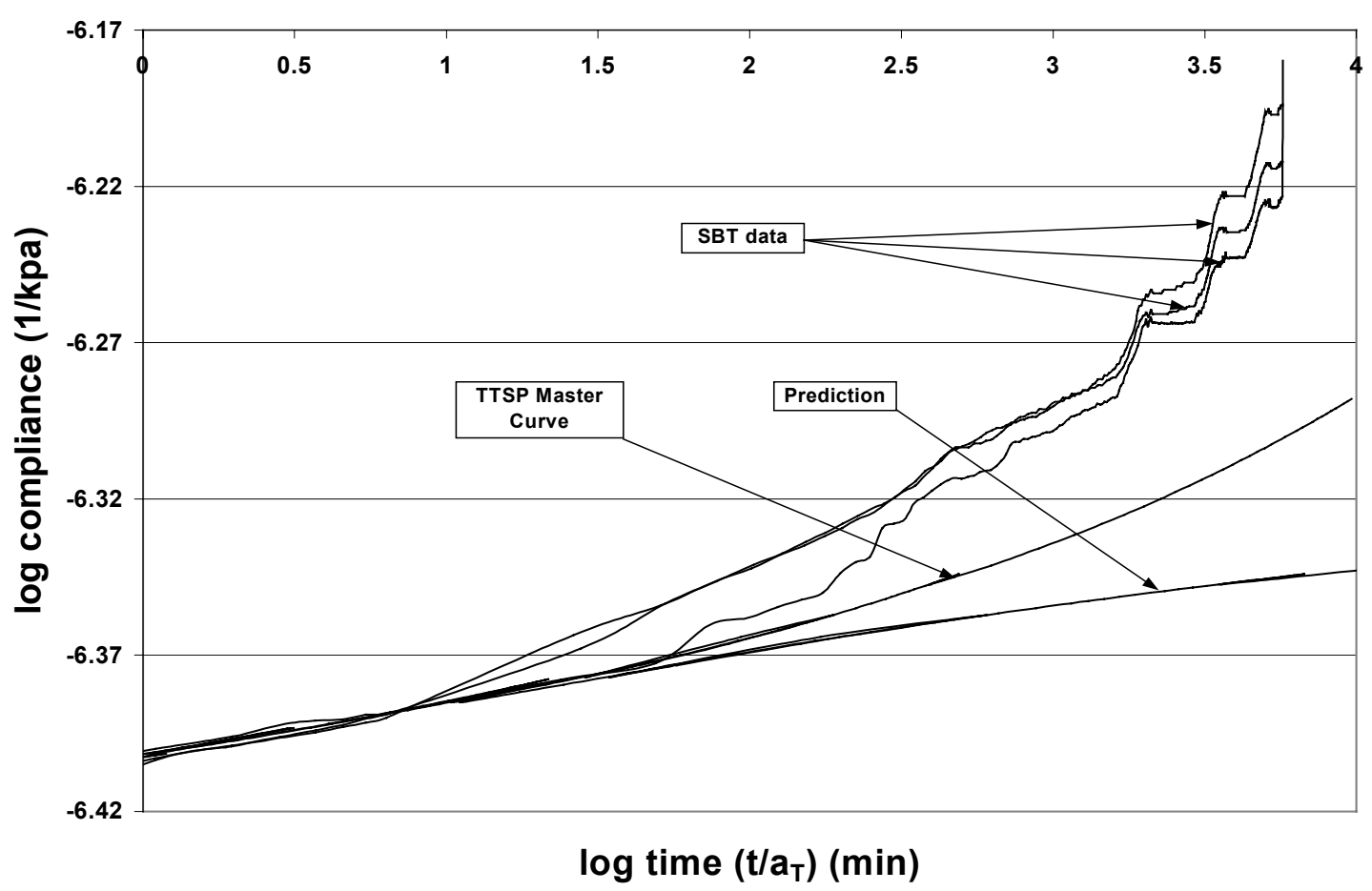

Fig 3.42 Comparison with long-term bending data at $21.1^{\circ} \mathrm{C}$ after shifting (Material E) 


\section{Chapter 4: PREDICTION OF FULL-SCALE RESULTS USING SHORT TERM DATA}

\subsection{INTRODUCTION:}

The main aim of this work is to predict the long-term creep of the liner. Longterm creep data from full-size encased liners are reported in [12]. In order to predict encased liner data, the master curve must be shifted to the age and temperature of encased liners. The master curve was obtained at $\mathrm{T}=40^{\circ} \mathrm{C}$ and age $\mathrm{t}_{\mathrm{e}}=60 \mathrm{~min}$. The age of the encased liners at the onset of full-size testing are given in Table 4.1. For a encased liner, age zero is the time of installation. Then, Effective Time Theory (ETT) [1] was applied on the master curve to predict the long-term compliance of the encased liners.

\subsection{METHODOLOGY AND COMPARISONS}

\subsubsection{SHIFTING FOR TEMPERATURE AND INITIAL AGE}

To shift the master curve obtained using TTSP to any temperature is trivial. The master curve is composed of a number of momentary curves, which are initially shifted to a reference temperature $\mathrm{T}_{\mathrm{R}}=40^{\circ} \mathrm{C}$ to form the master curve at $40^{\circ} \mathrm{C}$. Shifting to the encased-liner test temperature is done by shifting the whole master curve from $40^{\circ} \mathrm{C}$ to $21^{\circ} \mathrm{C}$. The shift factor for doing this is found from the logarithmic plot of temperature (T) vs shift factor $\left(\mathrm{a}_{\mathrm{T}}\right)$, which was discussed in Section 3.2.

The master curve was constructed with momentary curves at reference age $\mathrm{t}_{\mathrm{e}}=$ $60 \mathrm{~min}$. The master curve shifted to the age of the liner at the onset of the full-size test (Table 4.1). The shift factor for doing this is determined from the double logarithmic plot of $\log \left(\mathrm{a}_{\mathrm{e}}\right) \mathrm{vs} \log \left(\mathrm{t}_{\mathrm{e}}\right)$ as discussed in Section 2.2. 
If " $\lambda$ " is the time of the master curve, it is divided by a shift factor, $\mathrm{a}_{\mathrm{T}}$, in order to shift it to the required temperature and then divided by another shift factor, $\mathrm{a}_{\mathrm{e}}$, in order to bring it to the initial age of the liner.

$$
\lambda(\text { real-time }) \rightarrow \frac{\lambda}{a_{T}}(\text { shifted_for_temperature }) \rightarrow \frac{\left(\frac{\lambda}{a_{T}}\right)}{\left(a_{e}\right)}(\text { shifted_for_age })
$$

\subsubsection{PREDICTION}

Once the master curve is shifted for temperature and initial age, it corresponds to the same temperature and initial age of the liner. The master curve shows no physical aging since it is made up of momentary creep curves [13]. But the encased liner data shows physical aging, because it is tested in real time.

Effective Time Theory (ETT) can be used in to predict the long-term creep of the liner from the master curve. According to ETT, the unaged time $\lambda$ in the master curve is related to real time as

$$
\lambda=\frac{t_{e}}{\alpha}\left[\left(1+t / t_{e}\right)^{\alpha}-1\right] \quad \text { for } \quad \mu<1
$$

where, $t_{e}$ is the age of the sample when the test started, $\mu$ is the shift rate, $\alpha=1-\mu$, and $t$ is the time. Inverting Equation (4.2) we can stretch the unaged time $\lambda$ of the master curve into real time

$$
t=t_{e}\left[\left[\frac{\lambda \alpha}{t_{e}}+1\right]^{\frac{1}{\alpha}}-1\right]
$$


In other words, aging has the effect of delaying creep with respect to that on the master curve (Fig. 4.1). Using the method described in Section 4.1.1, the master curves of each specimen are used to predict the long-term creep of the liner (Fig. 4.1 - 4.5).

As a final step, the averaged master curve described in Section 3.2, is used along with the method described in Section 4.1.1 to predict the long-term creep of the liner (Fig. 4.6 - 4.10). The predictions are also compared with the long-term bending data [13]. Predictions made by ETT are good for all materials except material C. It is suspected that material $\mathrm{C}$ yields during testing.

\subsection{SUMMARY}

A summary of our findings is given below:

1. The master curve is first shifted for temperature to the temperature at which the full-size test was done.

2. The master curve is then shifted for age to the initial age of the full-scale sample. This is the time between liner installation and beginning of the full-size test.

3. Effective Time Theory (ETT) is used to predict the long-term creep of the liner from the master curves.

\subsection{CONCLUSIONS}

The following are the conclusions drawn from the prediction done on the polymers.

1. The ETT proves good for the prediction of long-term creep compliance of the full size pipe data for materials A, B, D and E. 
2. The TTSP proves good for the prediction of the long-term creep compliance of the full size data for material C. 


\begin{tabular}{|c|c|c|c|c|c|}
\hline & te & Sample 1 & Sample 2 & Sample 3 & Average $\left(\mathbf{a}_{\mathrm{e}}\right)$ \\
\hline Material A & $\mathbf{7 7 8 3 3}$ & 3.966 & 9.4355 & 8.3528 & 7.252433 \\
\hline Material B & $\mathbf{1 2 9 6 6 6}$ & 15.467 & 17.0336 & 18.714 & 17.07233 \\
\hline Material C & $\mathbf{1 2 9 6 6 6}$ & 10.645 & 11.406 & 31.6148 & 17.8886 \\
\hline Material D & $\mathbf{1 6 8 6 0 0}$ & 7.2643 & 13.346 & 2.198 & 7.6027 \\
\hline Material E & $\mathbf{1 7 6 6 6 6 . 7}$ & 19.2307 & 24.0184 & 27.3585 & 23.53587 \\
\hline
\end{tabular}

Table 4.1. Initial physical age of the full-scale samples and their corresponding shift factor, $\mathbf{a}_{\mathrm{e}}$. 


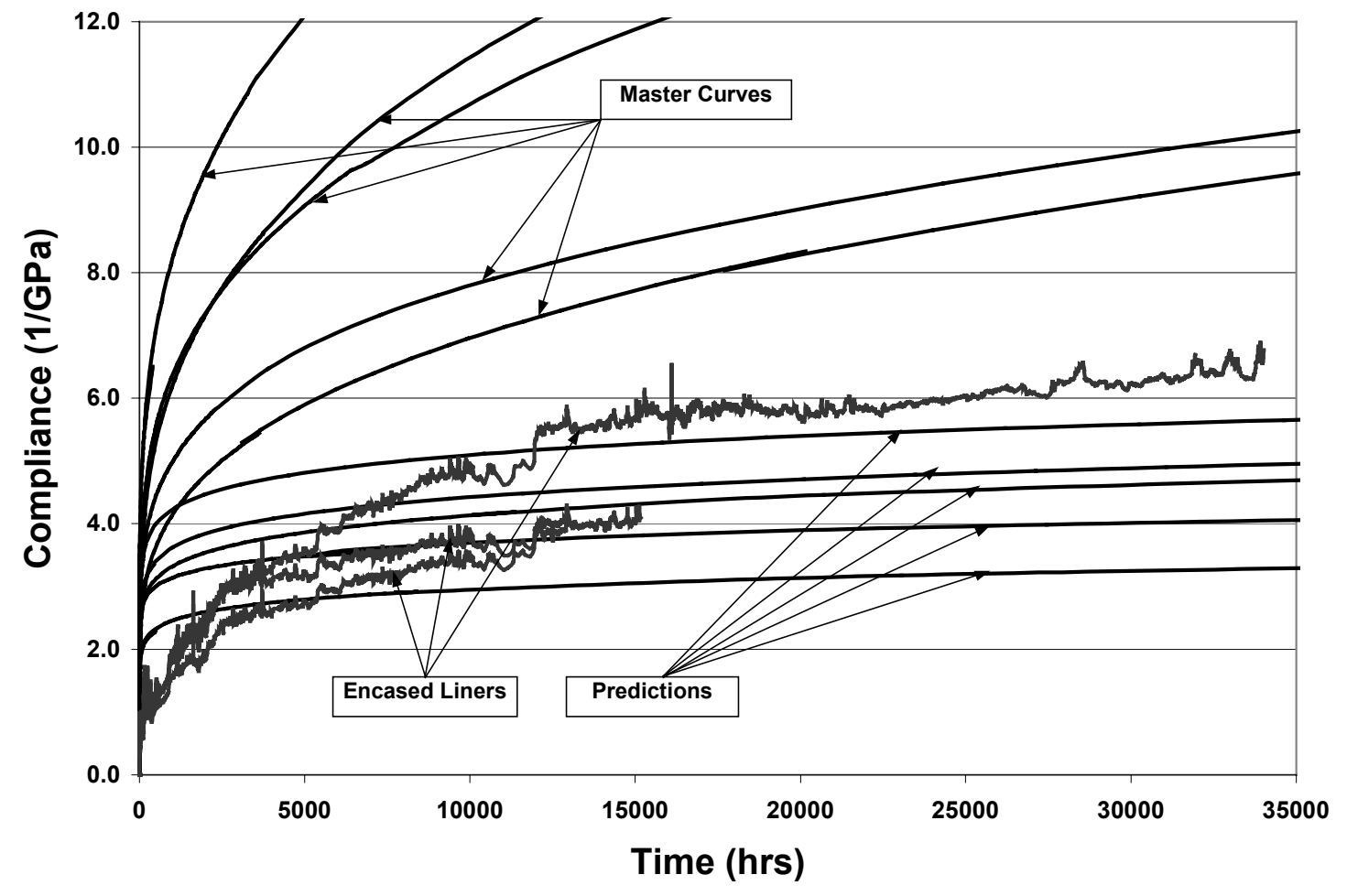

Fig 4.1 Prediction using 5 specimens compared to data of 3 encased liners (Material A)

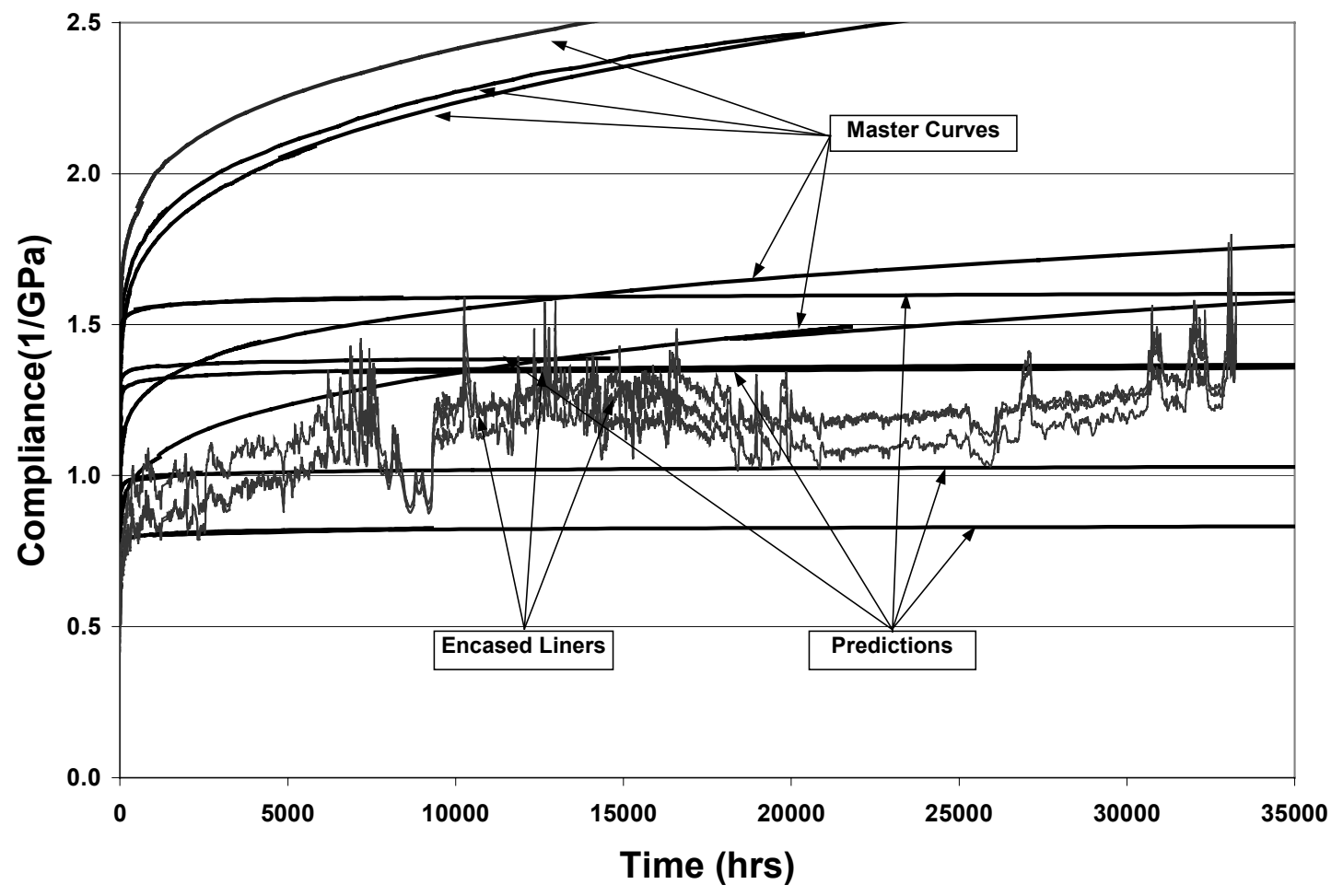

Fig 4.2 Prediction using 5 specimens compared to data of 3 encased liners (Material B) 


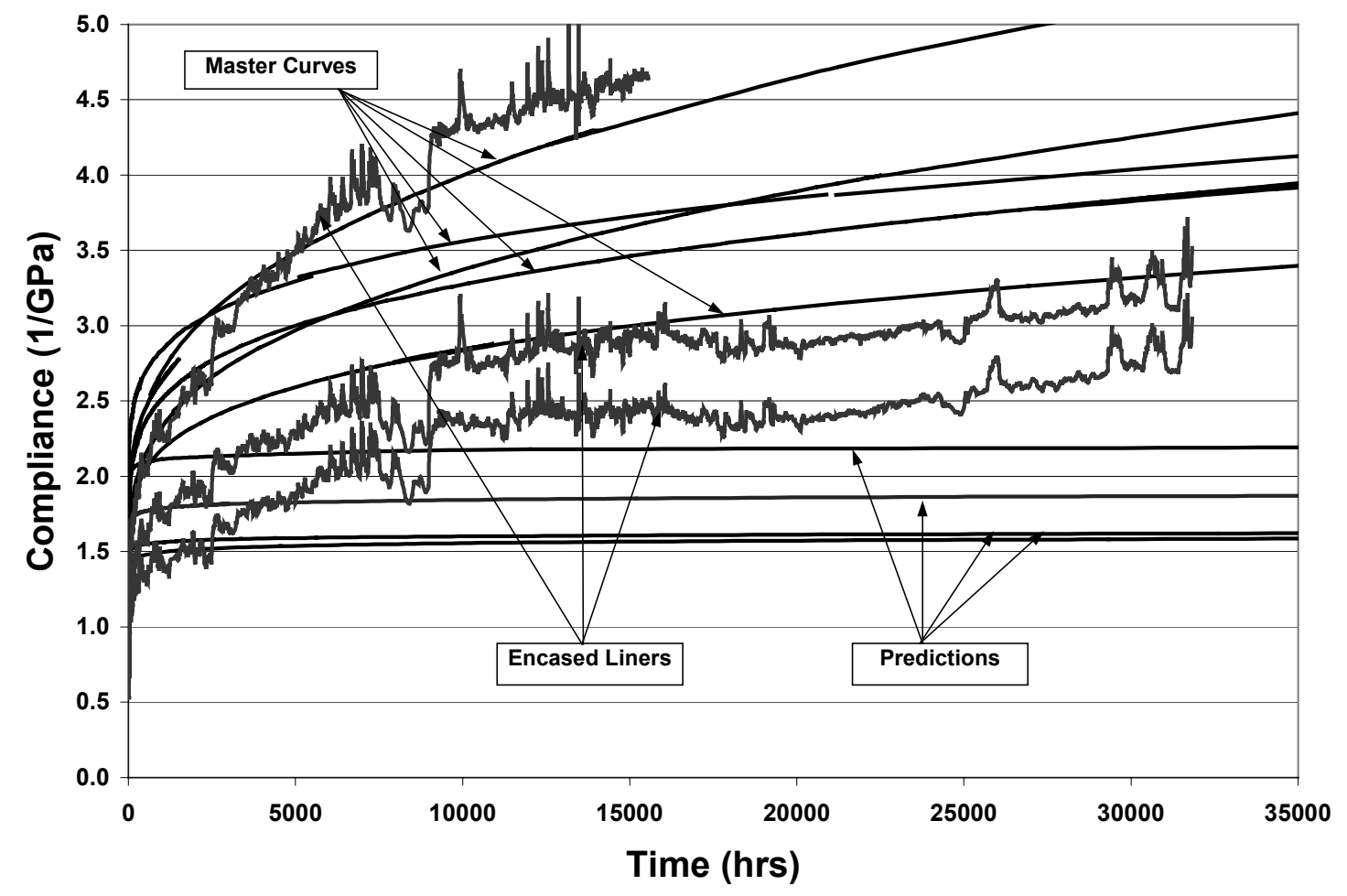

Fig 4.3 Prediction using 5 specimens compared to data of 3 encased liners (Material C)

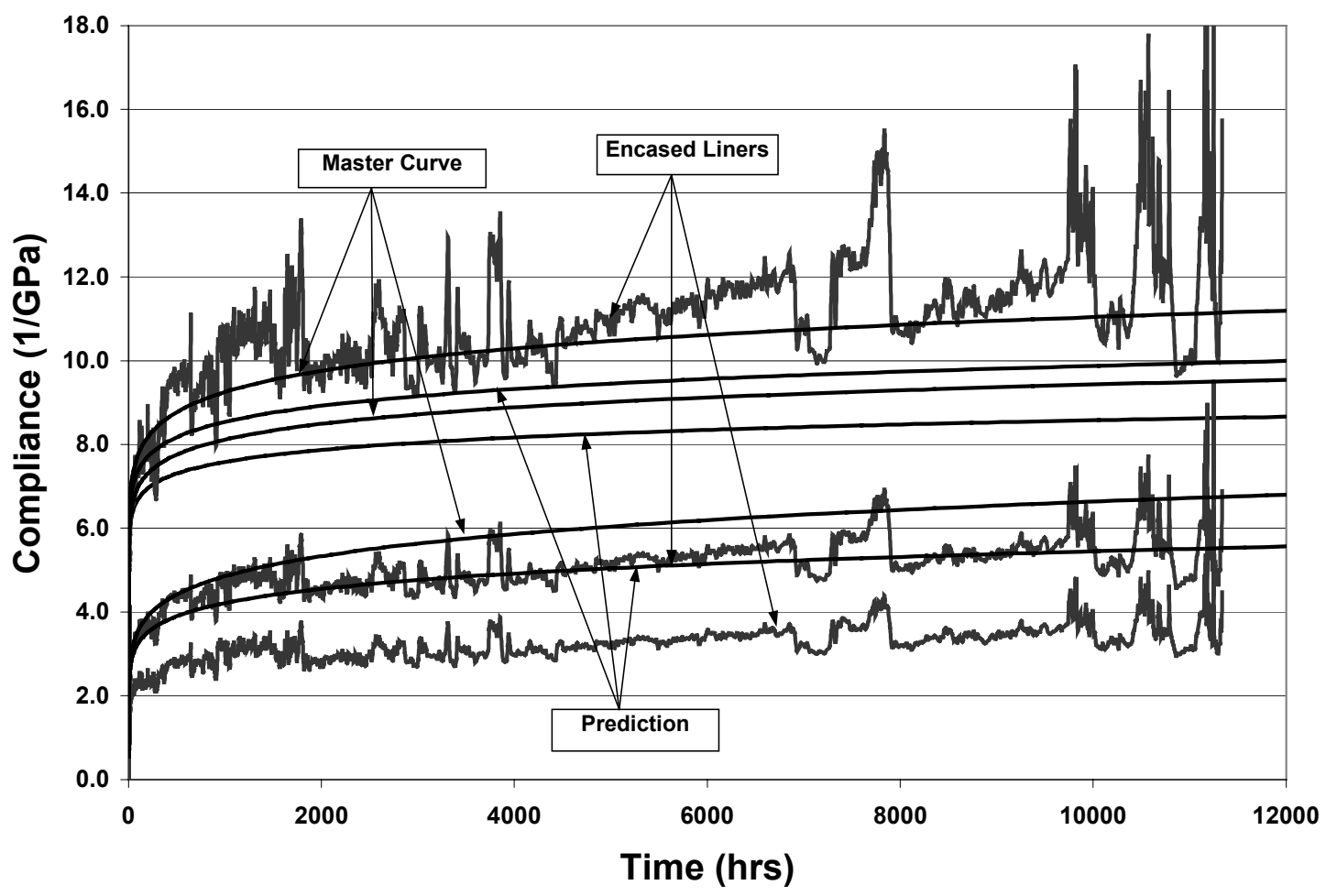

Fig 4.4 Prediction using 3 specimens compared to data of 3 encased liners (Material D) 


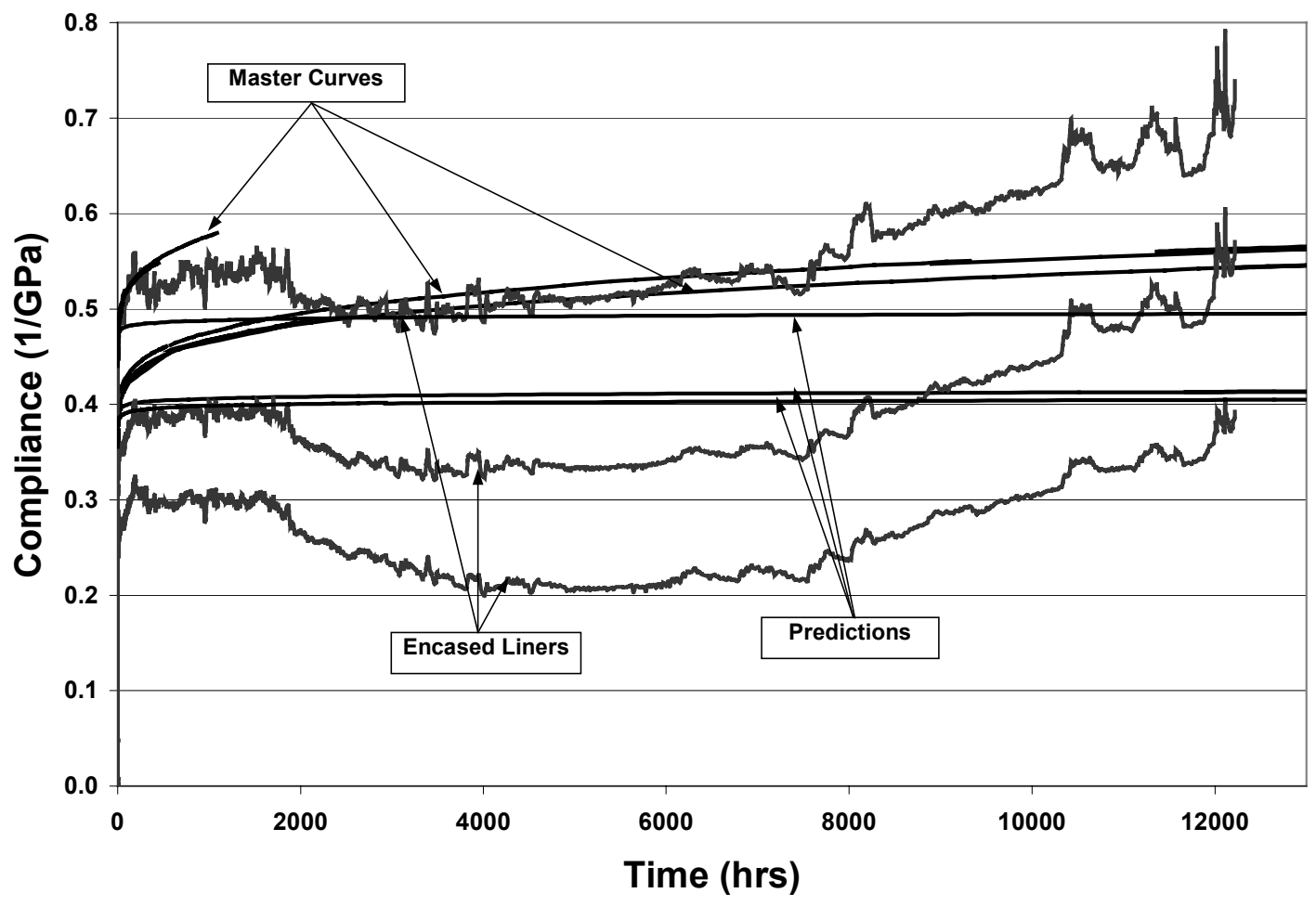

Fig 4.5 Prediction using 3 specimens compared to data of 3 encased liners (Material E)

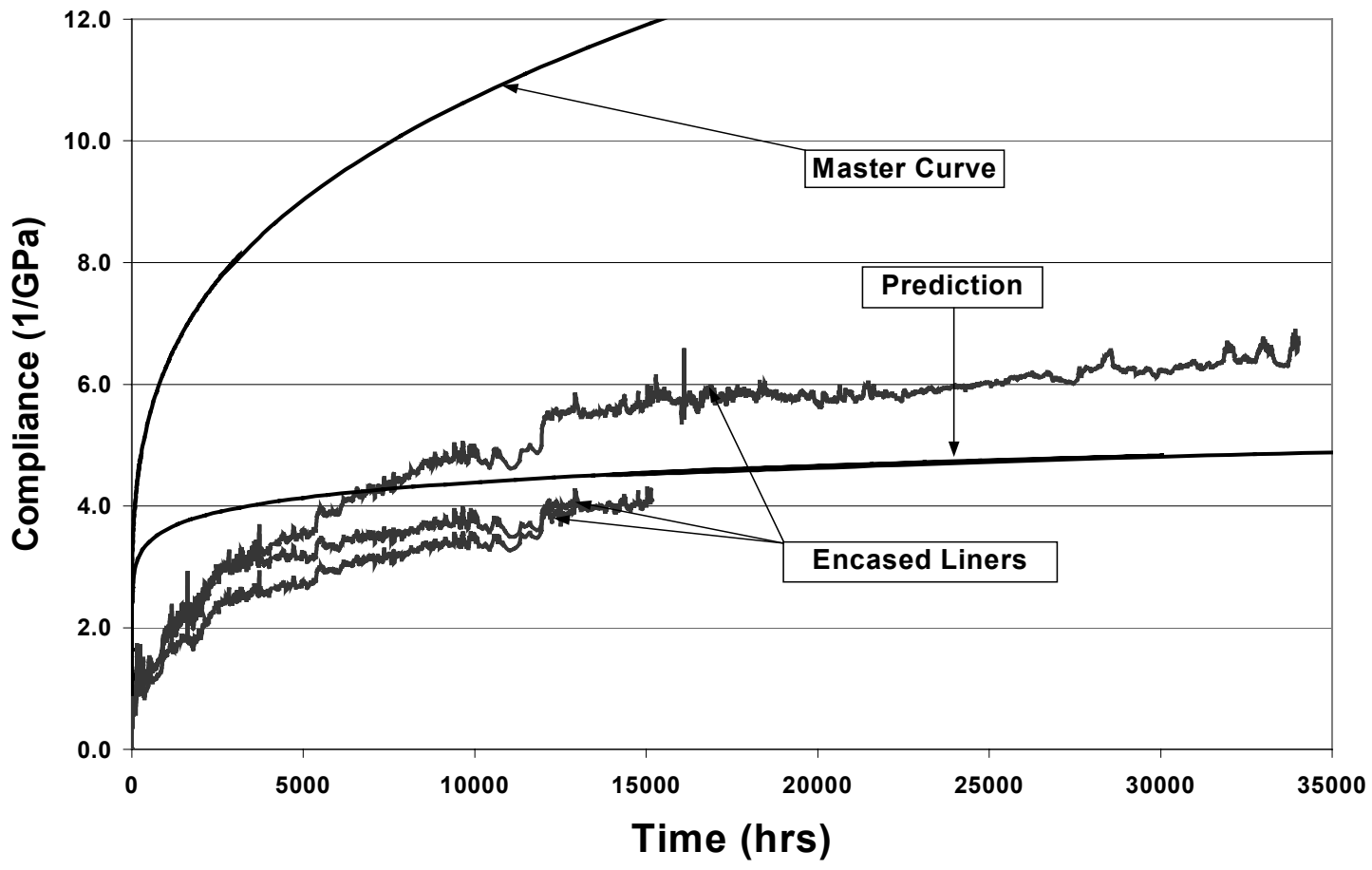

Fig 4.6 Prediction using the average of the 5 specimens compared to encased liner data (Material A) 


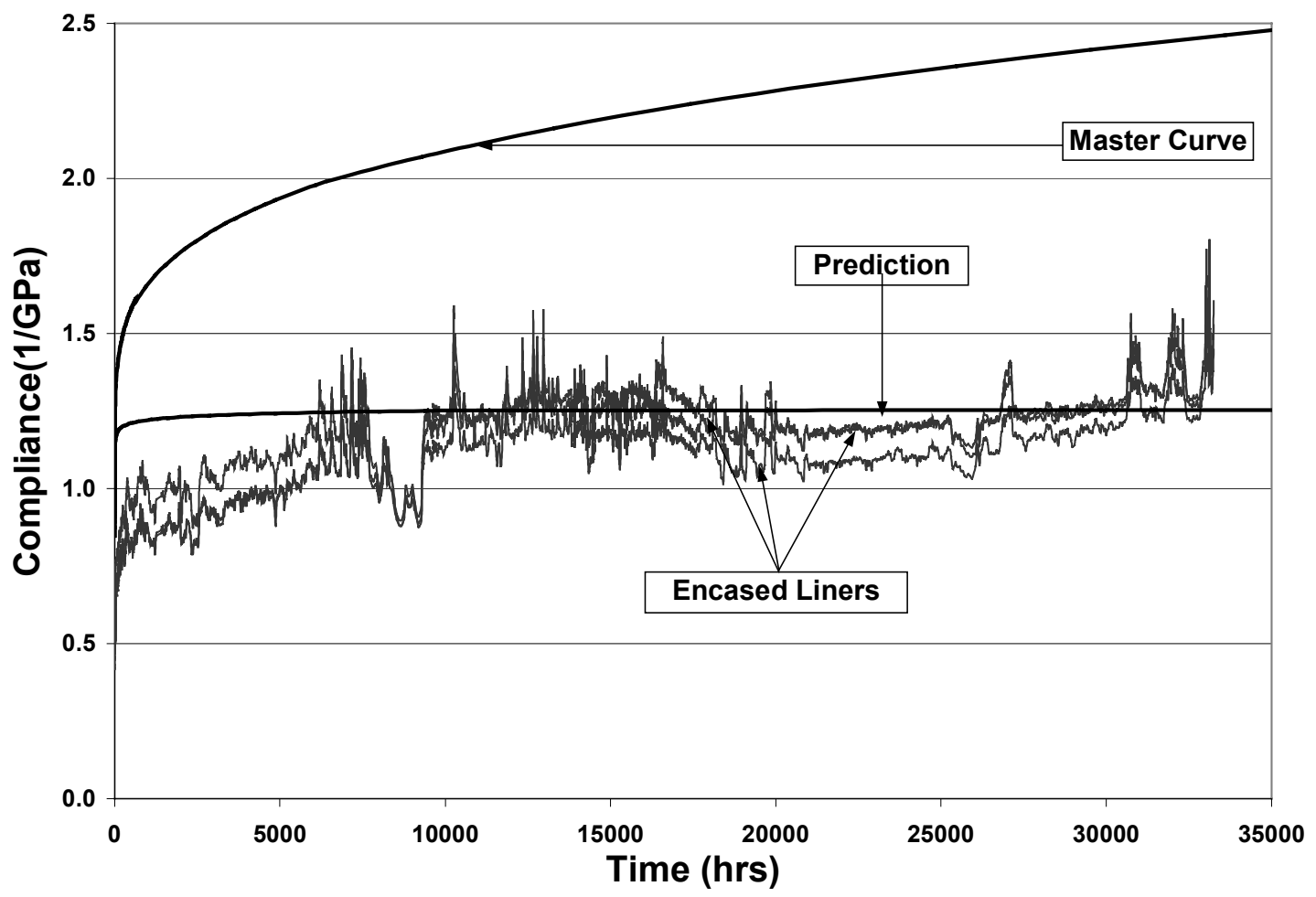

Fig 4.7 Prediction using the average of the 5 specimens compared to encased liner data (Material B)

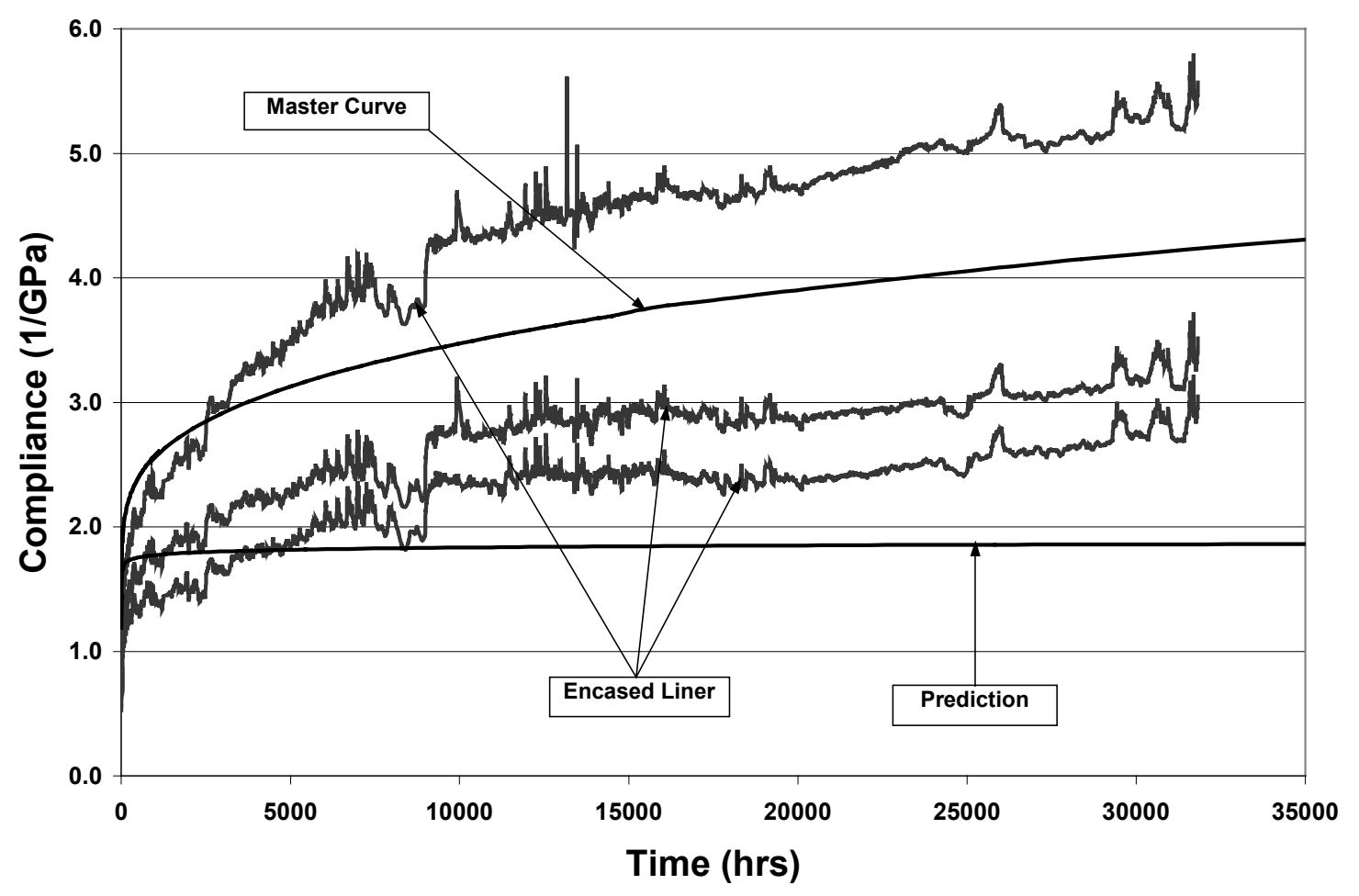

Fig 4.8 Prediction using the average of the 5 specimens compared to encased liner data (Material C) 


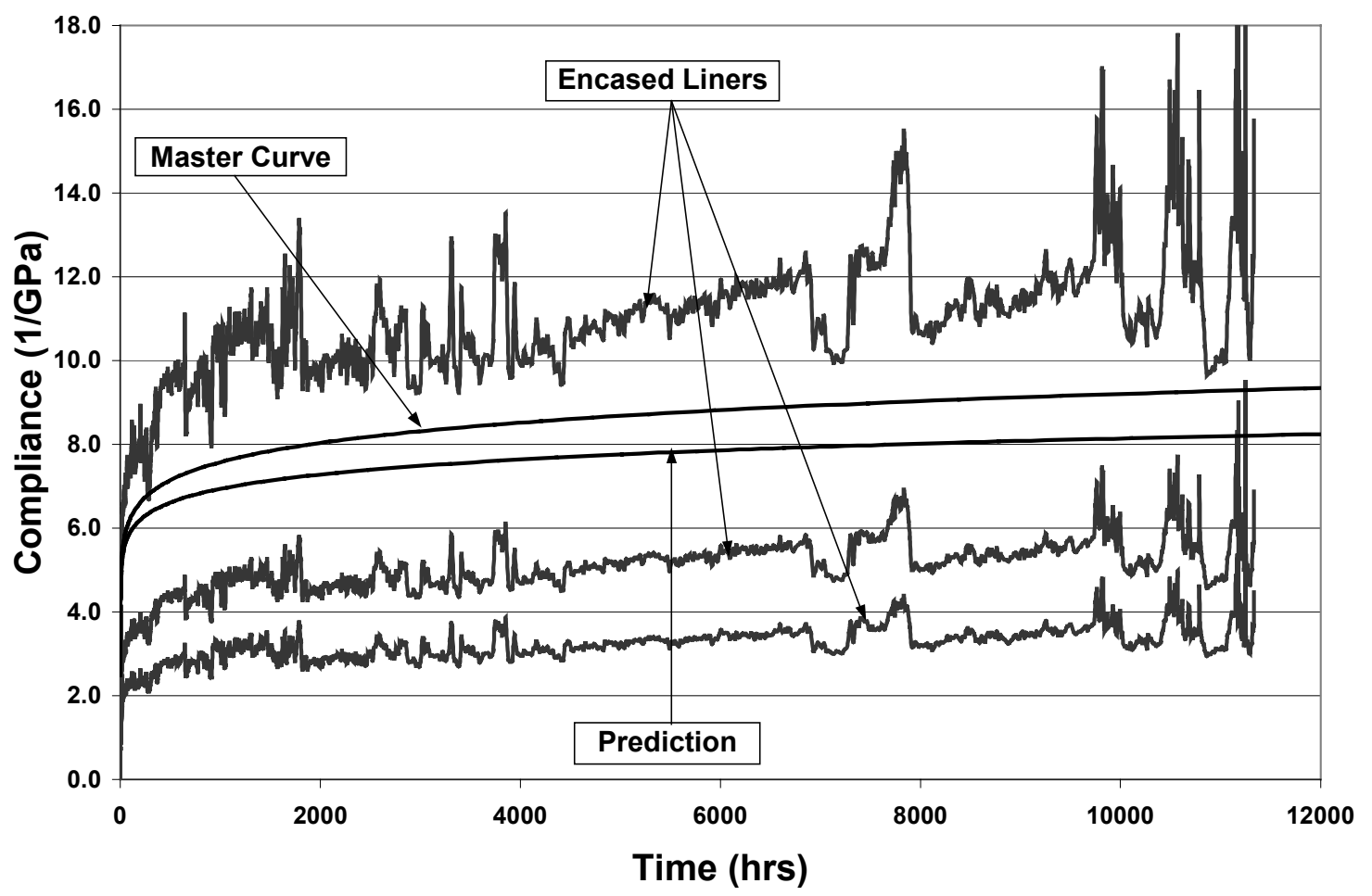

Fig 4.9 Prediction using the average of the 3 specimens compared to encased liner data (Material D)

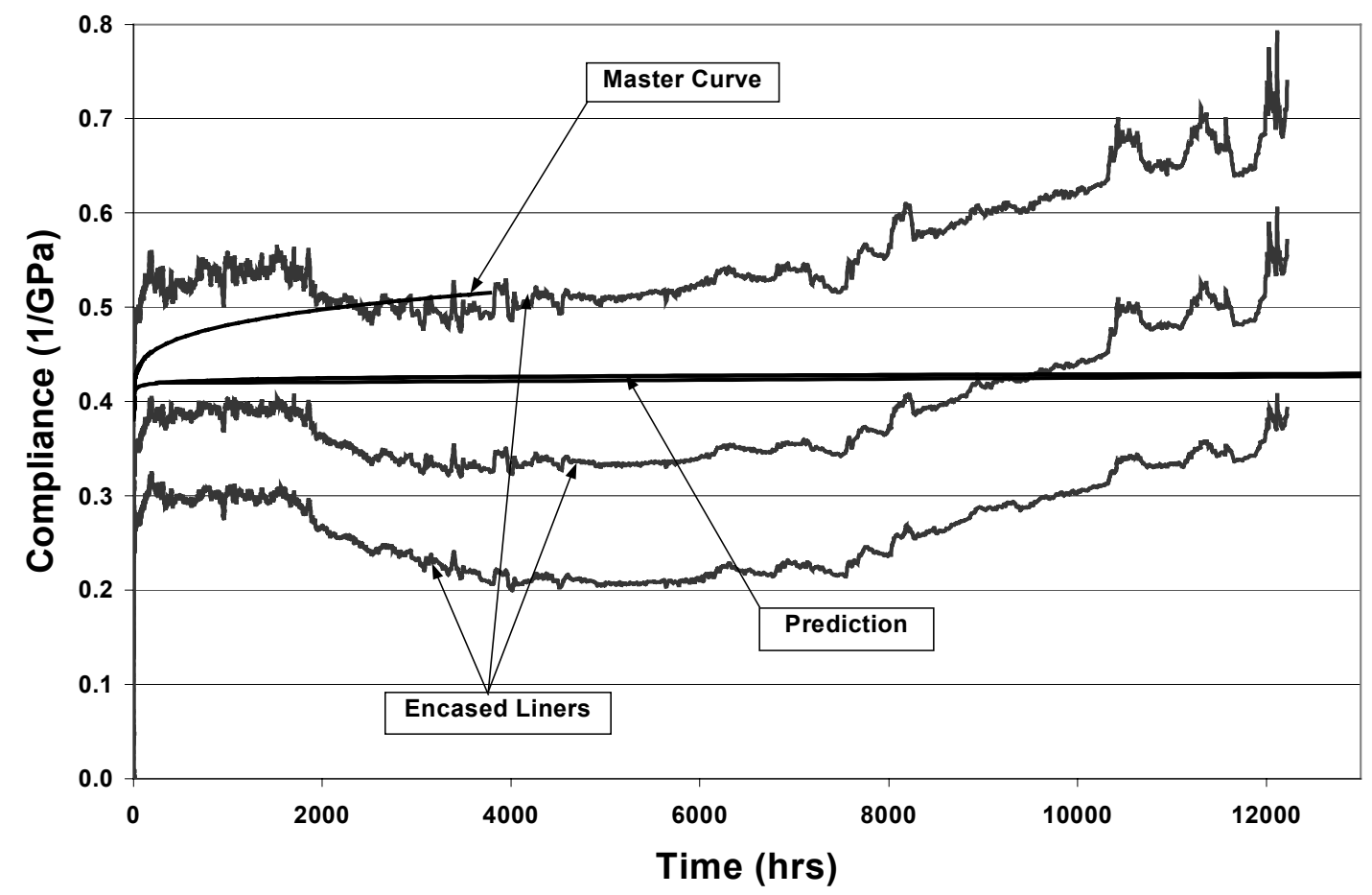

Fig 4.10 Prediction using the average of the 3 specimens compared to encased liner data (Material E) 


\section{CHAPTER 5: FREQUENCY- TEMPERATURE SUPERPOSITION}

"A dynamic mechanical experiment is one in which a polymer is subjected to a sinusoidal strain of infinitesimal amplitude and fixed angular frequency"[15]. The results of a dynamic experiment are obtained in the frequency domain. In a transformation from a frequency-domain to a time-domain or vise versa, the range of time and frequency is between 0 and infinity [14]. It is very difficult to obtain data at very small and very large time and frequency. Thus a wider range for frequency than that of the experimental instrument is desirable. Therefore, similar to the TTSP, Frequency Temperature Superposition (FTSP) is used [17].

\subsection{EXPERIMENTAL PROCEDURE}

All tests were done in a three point bending fixture with the load applied at midspan. The tests were done in a temperature range of $12^{\circ} \mathrm{C}$ to $55^{\circ} \mathrm{C}$. The testing machine, test environmental conditions, and specimen preparation were the same as discussed in chapter 2 (or Section 2.2).

\subsubsection{SPECIMEN TESTING}

Each specimen is tested at different temperature to determine the storage modulus $E^{\prime}(\omega)$ as a function of frequency at specified temperature. The testing method remains the same as described in Section 3.1.1 until the sample reaches an age of $60 \mathrm{~min}$. The complete procedure is given here:

a. The thickness and width of each specimen is measured at both ends and at the mid-span using a micrometer. The values measured are averaged for calculations. All measurements are made in SI units. 
b. The specimen is placed in the three point bending fixture of the DMA. The DMA is attached to a computer, which controlled the operations of the DMA using "PYRIS" software (version 3.80). The height and depth of the specimen are entered along with the initial state of the specimen, i.e., the initial temperature. The width remained constant at $15 \mathrm{~mm}$, as it was the span of the three point bending fixture.

c. After making sure that the specimen is properly seated into the fixture, the furnace is closed and the temperature is set to the annealing temperature. There is a time lag of 3-4 min for the temperature to equilibrate.

d. The specimen is kept at the annealing temperature for 10 min after which the furnace is opened in order to air-quench the specimen at room temperature. The time at which the furnace is opened is considered to be age zero $\left(t_{\mathrm{e}}=0\right)$ of the specimen.

e. After quenching for $10 \mathrm{~min}$, the furnace is closed and the temperature is set to $40^{\circ} \mathrm{C}$. The sample is allowed to stabilize at this temperature for $15 \mathrm{~min}$. Two creep tests, each of 1 min duration are performed. These tests are done in order to mechanically condition the sample (Refer Section 2.3).

f. After $45 \mathrm{~min}$ of aging time, the temperature of the furnace is set to the test temperature.

g. When the age of the specimen reaches $t_{e}=60 \mathrm{~min}$, a dynamic test ranging from 1 $\mathrm{Hz}$ to $10.2 \mathrm{~Hz}$ is performed. The test is done such that it is a snapshot, $t / t_{\mathrm{e}} \leq 10$, in order to keep the curve as a momentary curve. 
The frequency range is chosen as 1-10.2 Hz. A smaller frequency range (ie., smaller than $1 \mathrm{~Hz}$ ) was very time consuming while a higher frequency range was too fast and the data recorded could not be trusted. The elapsed test time reaches the limit of the snapshot $(\mathrm{t}=6 \mathrm{~min})$ at $10.2 \mathrm{~Hz}$ and hence the data collected after $10.2 \mathrm{~Hz}$ is discarded.

The load and the corresponding deflection data for the specimen are automatically recorded and then saved into a file. The dynamic force used is $500 \mathrm{mN}$ while the static load used is $100 \mathrm{mN}$. The deflection is not allowed to exceed $10 \%$ of the support span. A smaller dynamic force did not bend the sample enough to get a valid reading.

Momentary curves at different temperatures are obtained for the same specimen. The test temperature range is from $13^{\circ} \mathrm{C}$ to $55^{\circ} \mathrm{C}$. For highest accuracy, all momentary curves are obtained without removing the specimen from the measuring system. After testing, the specimen is removed from the fixture and a new specimen is tested.

\subsection{EXPERIMENTAL RESULTS AND DATA INTERPRETATION}

The storage modulus $E^{\prime}(\omega)$ is a function of frequency $\omega$. The first step is to perform a Frequency Temperature Superposition (FTSP) similar to a Time-Temperature Superposition (TTSP) as in Section 3.2. A reference frequency $\omega_{\mathrm{R}}$ is chosen and all other momentary curves at different temperatures are shifted horizontally along the frequency axis using a shift factor, $\mathrm{a}_{\mathrm{T}}$, to form a master curve (Fig. 5.1 - 5.5). Material E, being very stiff, cracked under dynamic load and hence no master curve could be obtained (Fig. 5.5). The horizontal shift factor, $\mathrm{a}_{\mathrm{T}}$, was determined by overlapping the curves on an excel spreadsheet. The overlapping was done by choosing the start point of the curve to be shifted and a point on the reference curve having the same storage modulus and then reducing the difference in frequency scale between them. Thus, a master curve over a 
wide range of frequency is obtained. Similar to a TTSP, a single specimen is used to construct a FTSP master curve. Because of material variability the FTSP master curves vary from specimen to specimen (Fig. 5.6 - 5.9). In order to reduce the scatter, each unshifted momentary curve is fit (Fig 5.14) with a power law equation defined as

$$
E^{\prime}(\omega)=E_{1}{ }^{\prime} \omega^{n}
$$

Next, take the average of $E_{1}$ and the average $n$ as representation of the material behavior at that temperature (Fig. 5.15). Repeat this procedure for every temperature. Then, shift the average curves to the reference temperature, thus creating a master curve that represents all the data from multiple specimens, as shown in Fig. 5.16-5.19. The corresponding shift factor plots are shown in Fig. 5.20-5.23. The shifting is done as described earlier.

Using the average shift-factor plots (Fig 5.21-5.24) to shift the raw data for every specimen results in Fig. 5.16-5.19, that show the actual scatter. An alternative procedure could be to fit an equation to the individual specimen master curves shown in Fig. 5.65.9. However, this would require assuming a model equation for the master curve. In addition, there would be no rational way to average the shift factor plots corresponding to that many master curves. In contrast, the procedure proposed in this work results in the thick line in Fig. 5.16-5.19 where the master curve is a direct representation of data without assuming any model equation. Three specimens were tested for samples A, C and D, while four specimens were tested for material B (Fig. 5.6-5.9).

A polynomial equation is used to fit the master curve of material A (Fig. 5.24). The master curves of materials $\mathrm{B}, \mathrm{C}$ and $\mathrm{D}$ are fit using a linear model and three equations for each sample are obtained (Fig. 5.25 - 5.27). 
The master curve is in the frequency domain and hence has to be brought to the time domain. To do this, the interrelation among the moduli has to be known and is defined by Lakes [16] as,

$$
\left.\frac{2}{\pi} E^{\prime \prime}(\omega)\right|_{\omega=1 / \tau} \approx-\left.\frac{d E^{\prime}(\omega)}{d \ln \omega}\right|_{\omega=1 / \tau} \approx-\frac{d E(t)}{d \ln t}
$$

where, $\tau=(1 / \mathrm{t})$ and $\mathrm{E}^{\prime \prime}(\omega)$ is the loss modulus.

Equation 5.3 implies that

$$
\left.E^{\prime}(\omega)\right|_{\omega=1 / \tau} \approx E(t)
$$

For improved accuracy [16], the interrelationship between transient and dynamic properties is given as,

$$
\left.E(t) \approx E^{\prime}(\omega)\right|_{\omega=2 / \pi t}
$$

Using the equation of the master curve and equation 5.5, the relaxation modulus is found as a function of time. The time range of each sample is obtained from the frequency range of the master curve using the following relationship

$$
\omega=\frac{2}{\pi t}
$$

A longer time range is obtained by shifting the FTSP to a smaller reference temperature, $13^{\circ} \mathrm{C}$, using the average shift plots (Fig. 5.20-5.23). It is found that using equation (5.5) is not accurate enough. An alternative would be to follow the method suggested by Janas [6] assuming $v$ to be a constant, which is not, as shown in Section 5.3 and by Progelhof.R.C [7]. Hence we propose the following empirical equation

$$
E(t)=E^{\prime}(\omega)+0.0004 E^{\prime}(0.02 \omega)-0.25 E^{\prime}(5 \omega)+0.35 E^{\prime}(0.2 \omega)
$$


The relaxation modulus thus obtained (Fig. 5.28-5.30) is fit with a power law equation

$$
E(\lambda)=E_{o} *(\lambda)^{-n}
$$

where, " $\mathrm{E}_{\mathrm{o}}$ " is the initial modulus, " $\mathrm{n}$ " is the slope of the relaxation curve plotted on a $\log -\log$ scale and $\lambda$ is the time. The Laplace transformation of the power law gives the compliance, $\mathrm{D}$, in the time domain as

$$
D(\lambda)=\frac{1}{E_{o} \Gamma(1-n) \Gamma(1+n)} t^{n}
$$

where, " $\Gamma$ "gamma for $\mathrm{n}>0$ is defined as [16]

$$
\Gamma(x)=\int_{0}^{\infty} t^{x-1} e^{-\lambda} d t
$$

A comparison is made between the D $(\lambda)$ obtained by using TTSP and FTSP (Fig. 5.31 - 5.33). A chart of the steps followed in the transformation is also shown in Fig.5.34.

Material A was treated separated because E' vs log frequency $(\omega)$ is not a straight line but is fit with a polynomial equation (Fig.5.24). Hence, Eq 5.6 is modified by changing the empirical coefficients and a new equation is proposed as

$$
E(t)=E^{\prime}(\omega)+0.9 E^{\prime}(0.005 \omega)-0.25 E^{\prime}(5 \omega)+0.35 E^{\prime}(0.2 \omega)
$$

The same procedure is followed and comparison is made between the $D(\lambda)$ obtained by using TTSP and FTSP (Fig. 5.35-5.36).

\subsection{POISSON'S RATIO}

Testing of specimens is also done using Rheometric's RMS 800 DMA. Specimens of size $(63.5 \mathrm{~mm} \times 12.7 \mathrm{~mm} \mathrm{X} 1.5 \mathrm{~mm})$ are tested under torsion by varying the 
frequency of the dynamic force. The complex shear modulus $\left(\mathrm{G}^{*}\right)$ is obtained directly from the test (Fig. 5.37)

Specimens having the same age $t_{\mathrm{e}}=60 \mathrm{~min}$ are then tested in bending using a Perkin Elmer DMA 7e, under the same frequency range 0.1-10.2 Hz and temperature. The complex relaxation modulus $\left(E^{*}\right)$ is obtained directly from the bending test (Fig. $5.38)$.

The complex Poisson's ratio as function of frequency, $v^{*}(\omega)$, is obtained by using the following relationship [16]

$$
v^{*}(\omega)=\frac{E^{*}(\omega)}{2 G^{*}(\omega)}-1
$$

Poisson's ratio was found to vary with frequency (Fig. 5.36) and thus the method described by Janas and McCullough [6] could not be used (see section 1.2, Eq.1.12).

\subsection{SUMMARY}

A summary of our testing methodology is given below:

1. The specimen to be tested is cut, measured and placed in the DMA.

2. The specimen is annealed at a temperature $15^{\circ} \mathrm{C}$ above its glass transition temperature $\left(\mathrm{T}_{\mathrm{g}}\right)$ in the DMA for $10 \mathrm{~min}$.

3. The specimen is then air quenched for $10 \mathrm{~min}$ and then enclosed inside the DMA at test temperature.

4. At age $45 \mathrm{~min}$, mechanical conditioning is done.

5. At an age of $60 \mathrm{~min}$, a dynamic test is done at temperatures ranging from $12^{\circ} \mathrm{C}$ to $55^{\circ} \mathrm{C}$.

6. The storage modulus is plotted against the frequency in log scale. 
7. All curves are fitted with a power law. For each temperature, the average parameter E' and n represents the behavior.

8. A curve is chosen as the reference curve and all the other average curves are shifted to the reference curve using a shift factor ' $\mathrm{a}_{\mathrm{T}}$ '. The curve obtained is the master curve.

\subsection{CONCLUSIONS}

The following are the conclusions drawn from the dynamic study:

1. The range of $1-10.2 \mathrm{~Hz}$ is the best. A smaller frequency range (i.e. smaller than $1 \mathrm{~Hz}$ ) was very time consuming while a higher frequency range was too fast and the data recorded could not be trusted.

2. The frequency range of the FTSP master curve determined the time range used to plot the relaxation modulus in time domain. The lowest testing temperature should be used as a reference to obtain the longest time.

3. The plot of storage modulus vs frequency of material A was not linear. All others were linear.

4. Material B, C and D gave good results.

5. Material E cannot be tested in dynamic mode. This is due to cracking damage under dynamic load. Thus an FTSP could not be obtained for material E.

6. A good comparison between FTSP and TTSP in the time domain was found for all materials with a linear storage modulus E' vs log frequency plot. 


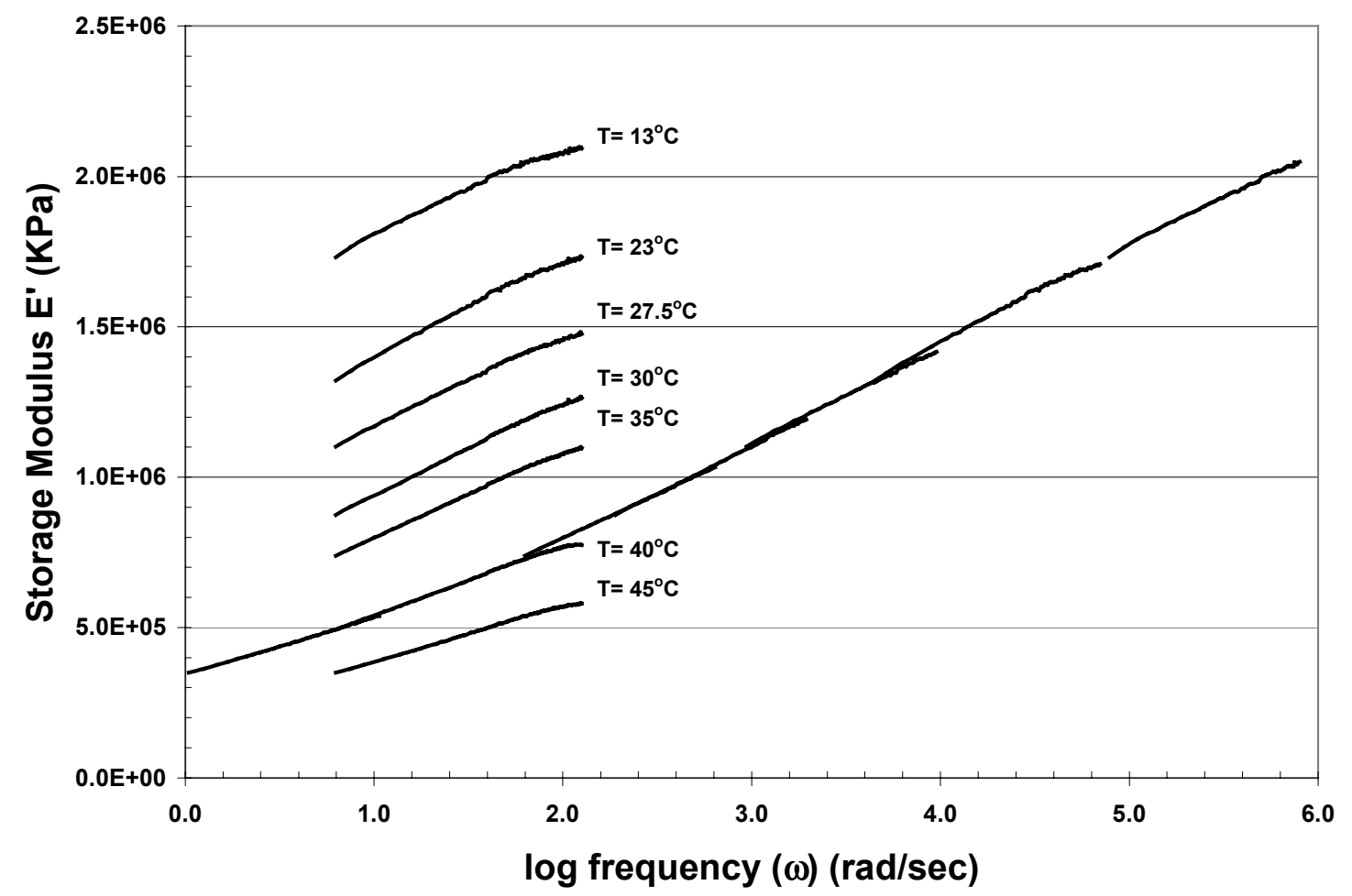

Figure 5.1. FTSP graphs and master at $40^{\circ} \mathrm{C}$ (Material A)

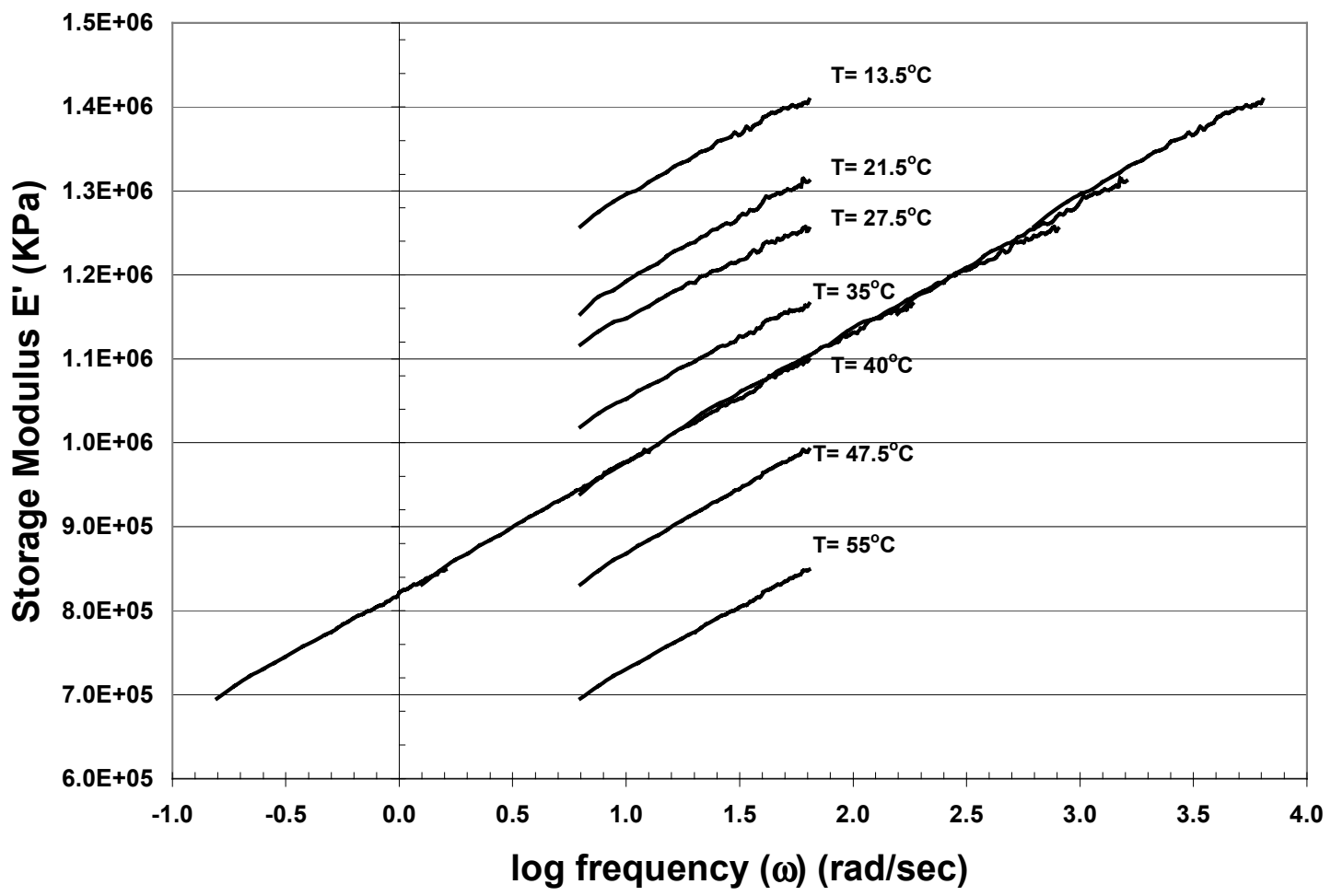

Figure 5.2. FTSP graphs and master curve at $40^{\circ} \mathrm{C}$ (Material B) 


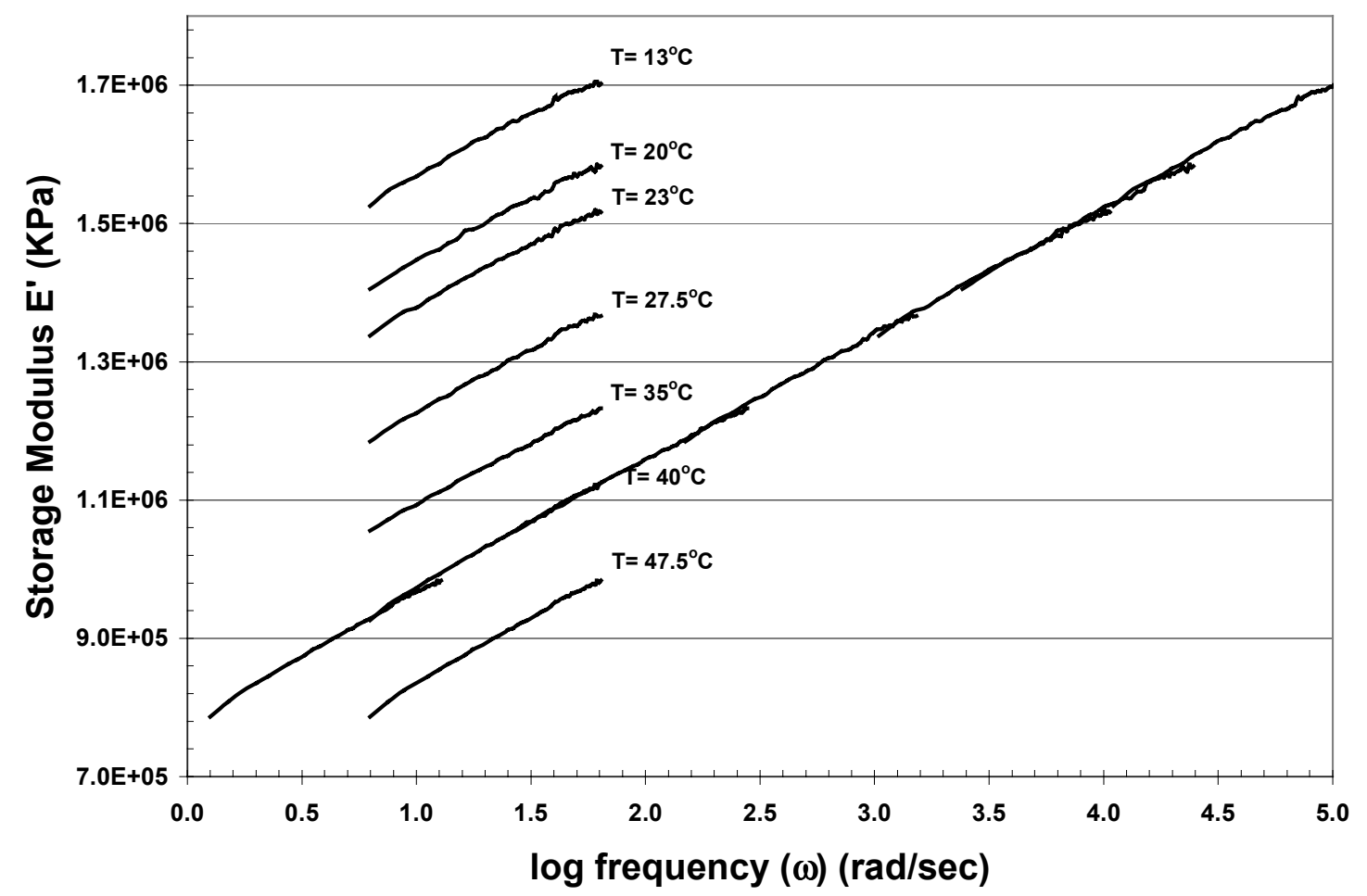

Figure 5.3. FTSP graphs and master curve at $40^{\circ} \mathrm{C}$ (Material C)

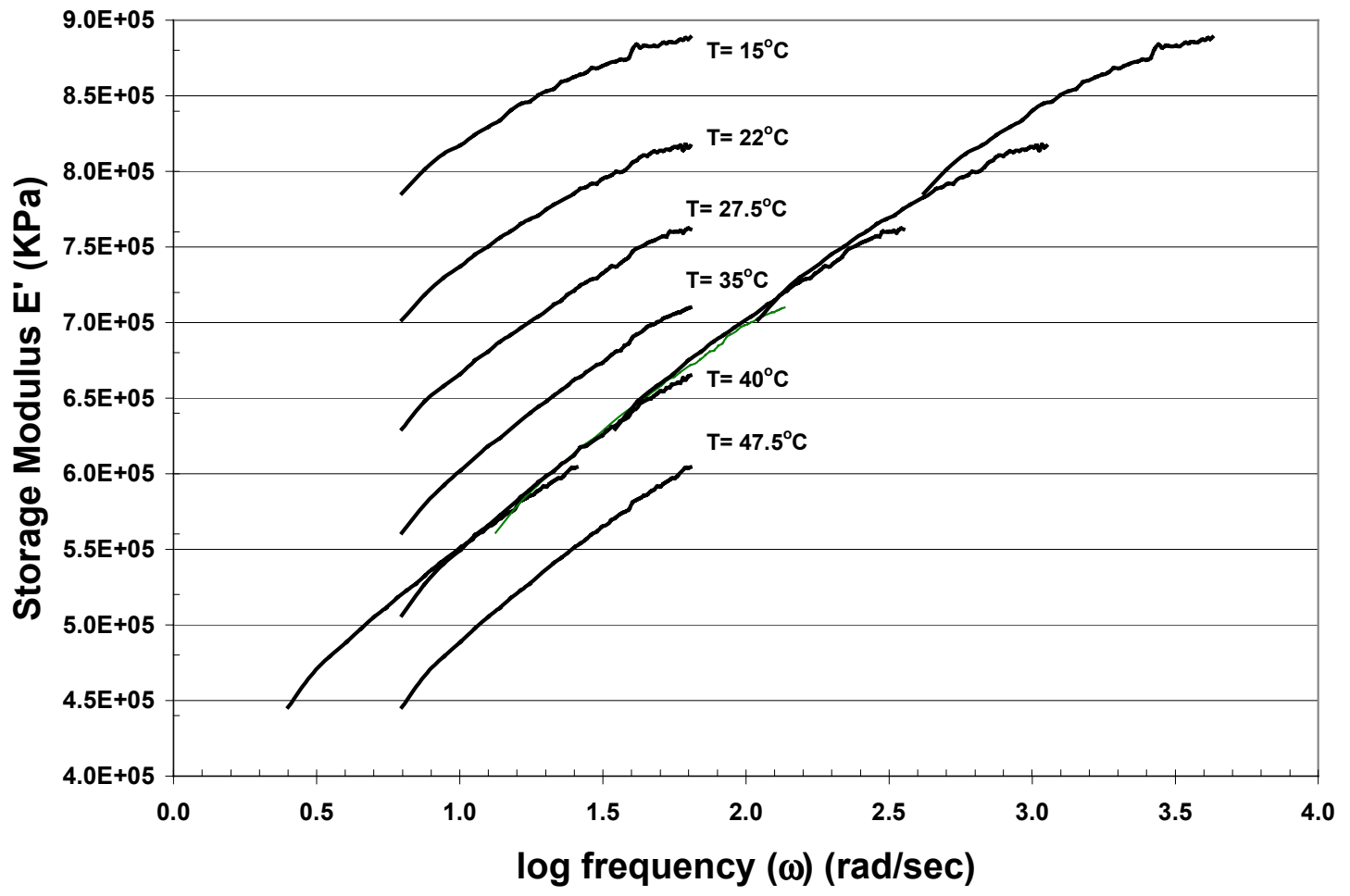

Figure 5.4. FTSP graphs and master curve at $40^{\circ} \mathrm{C}$ (Material D) 


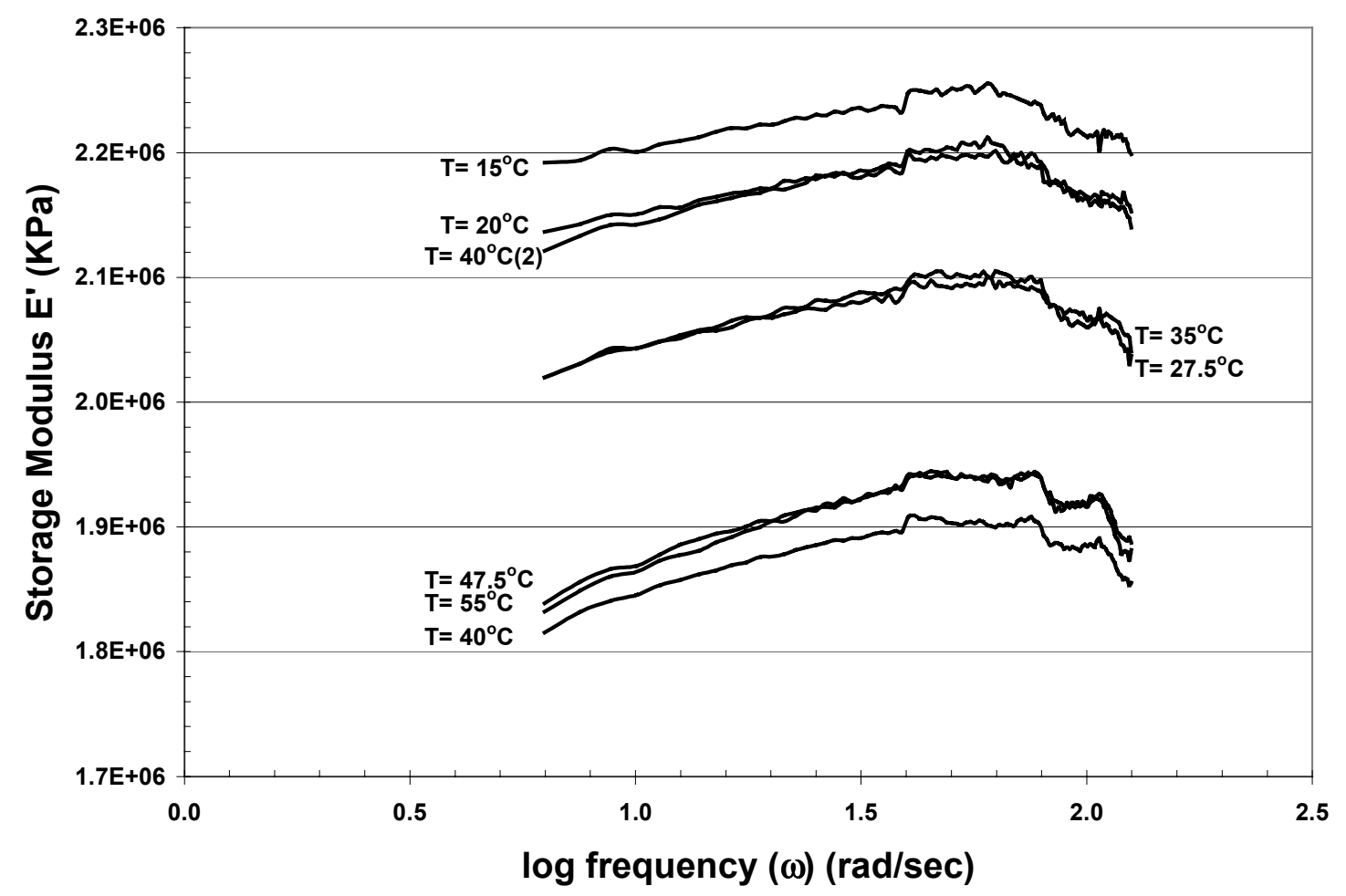

Figure 5.5. Storage Modulus vs log frequency (Material E)

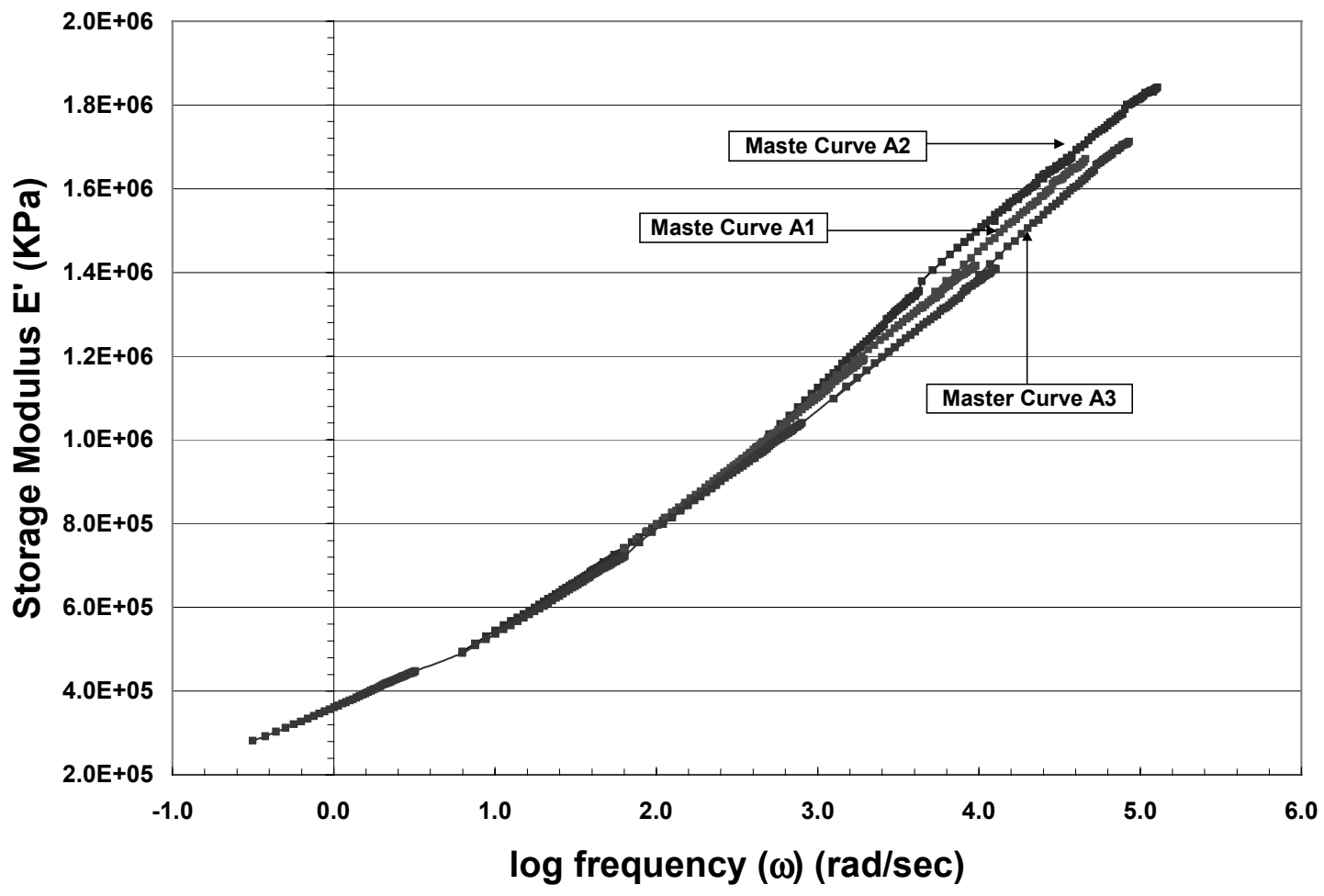

Figure 5.6. Master curves at $40^{\circ} \mathrm{C}$ (Material A) 


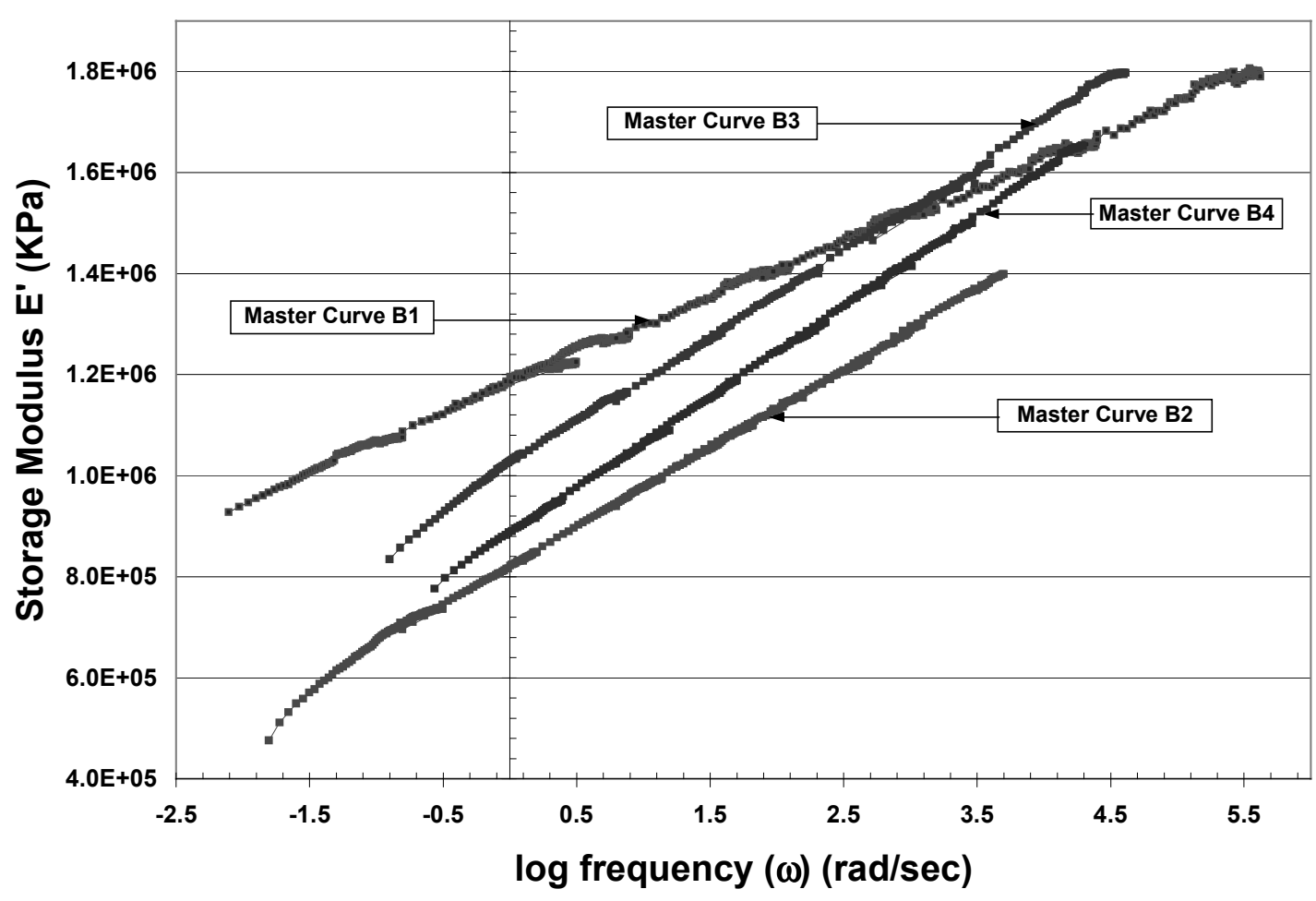

Figure 5.7. Master curves at $40^{\circ} \mathrm{C}$ (Material B)

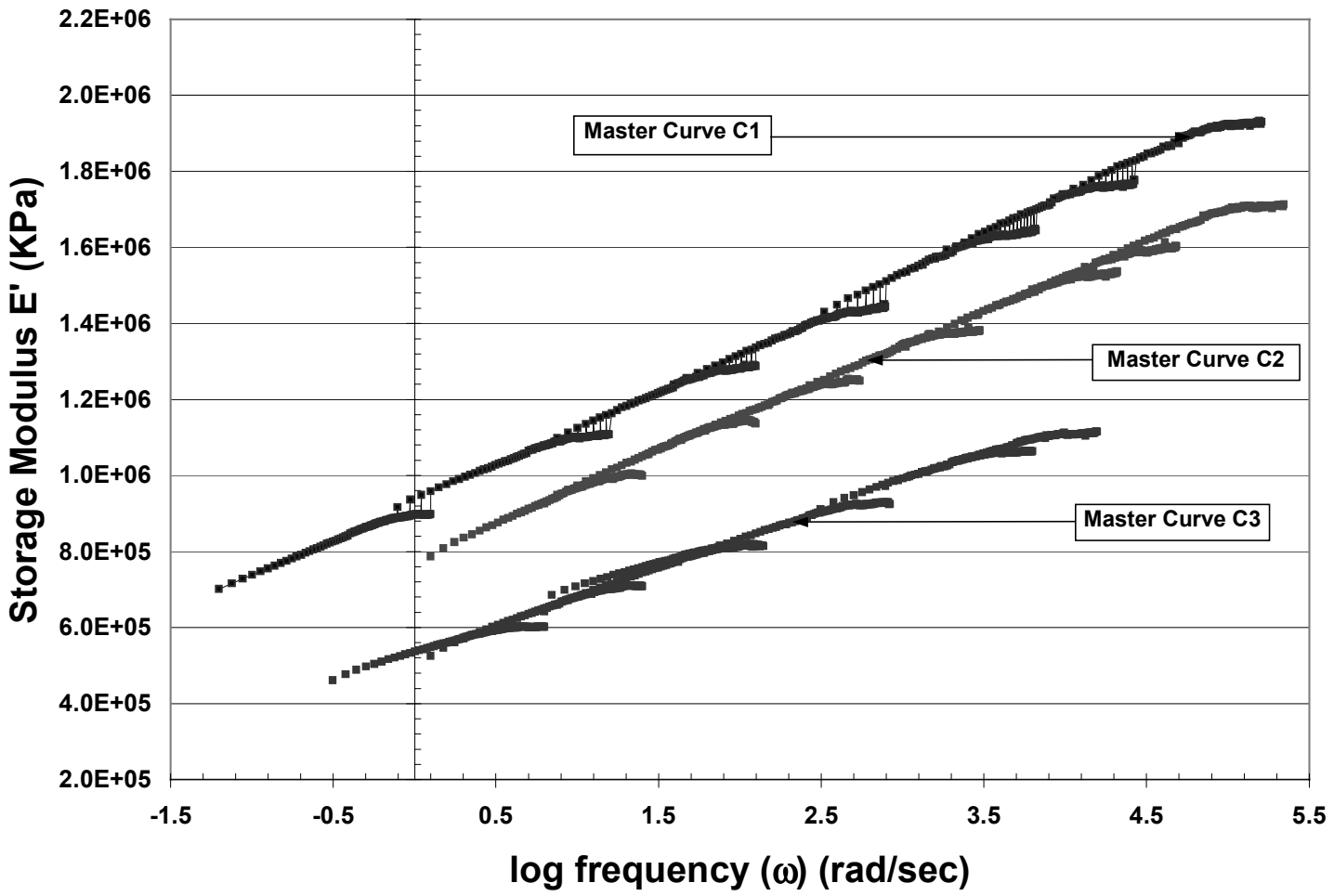

Figure 5.8. Master curves at $40^{\circ} \mathrm{C}$ (Material C) 


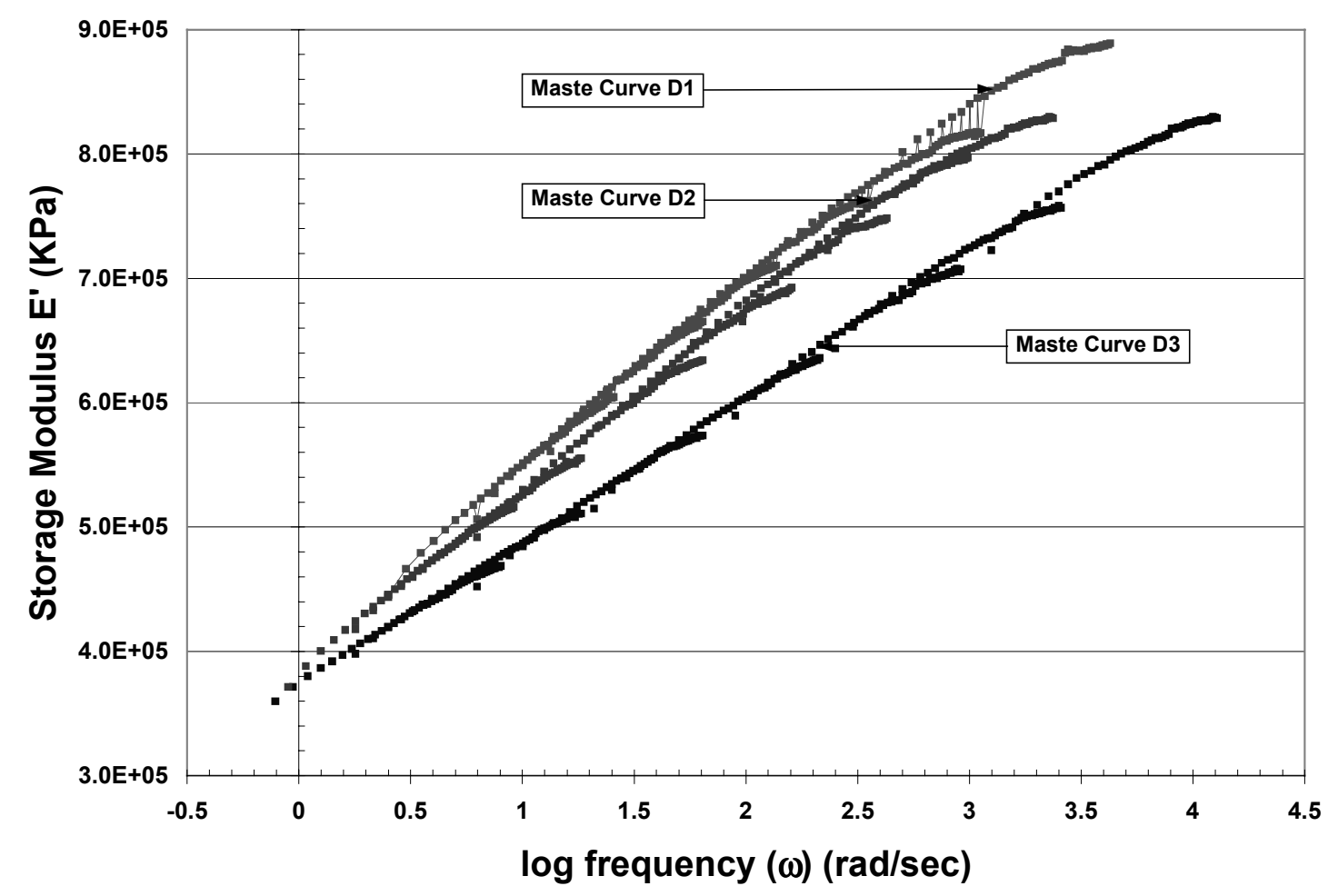

Figure 5.9. Master curves at $40^{\circ} \mathrm{C}$ (Material $\left.\mathrm{D}\right)$

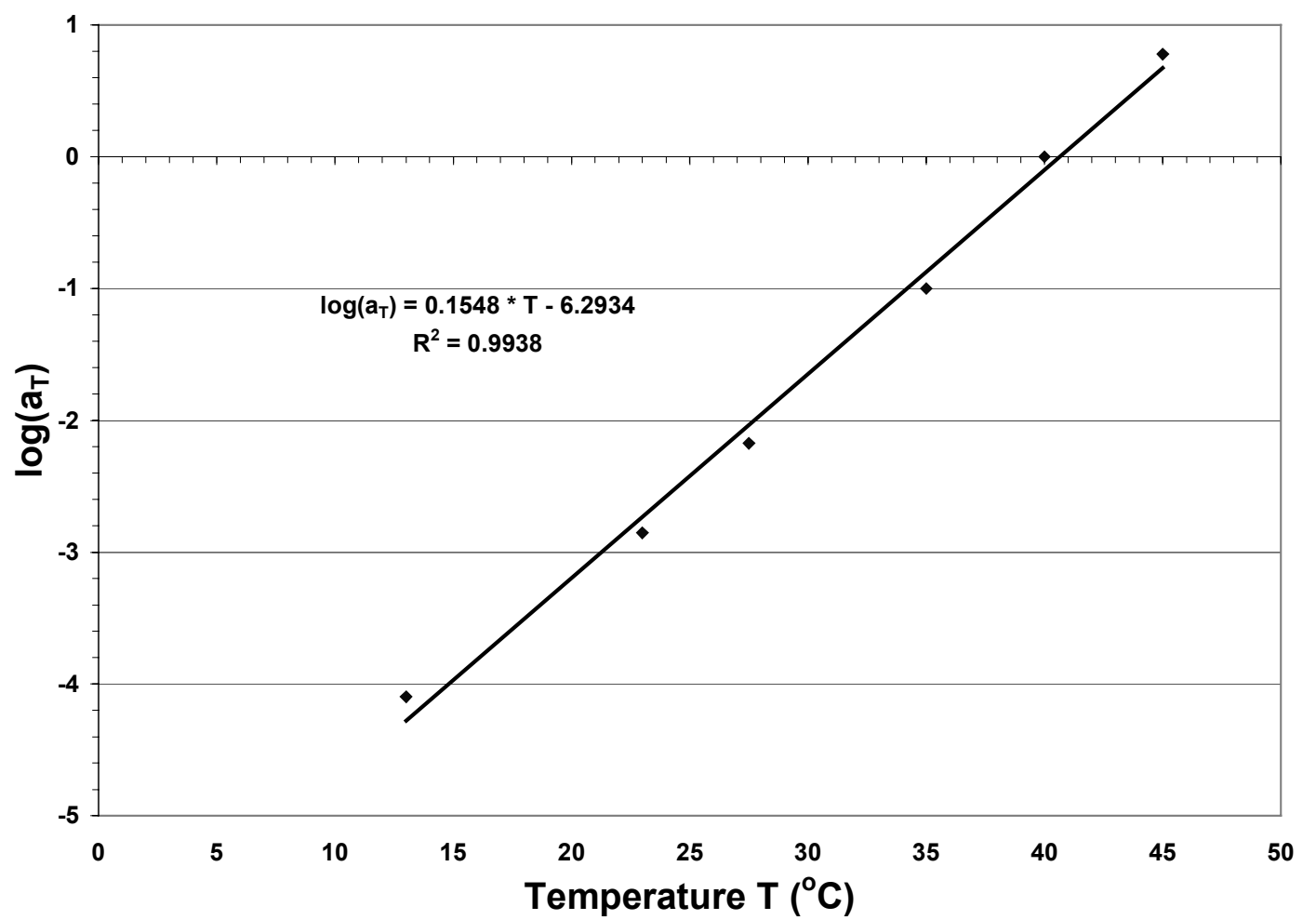

Figure 5.10. Linear fit for shift factor $\left(\mathrm{a}_{\mathrm{T}}\right) \mathrm{Vs}$ Temperature (Material A) 


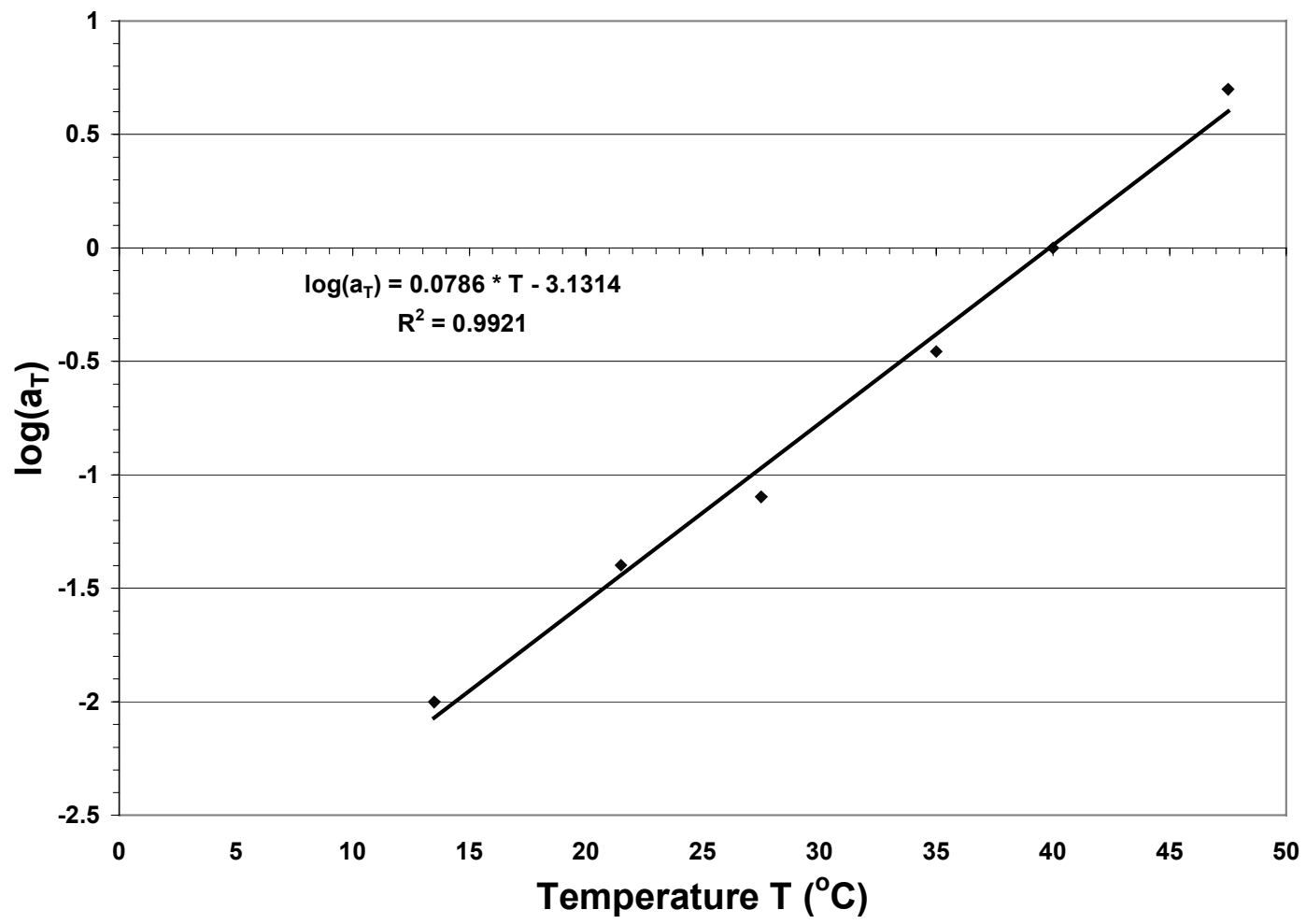

Figure 5.11. Linear fit for shift factor $\left(\mathrm{a}_{\mathrm{T}}\right)$ Vs Temperature (Material B)

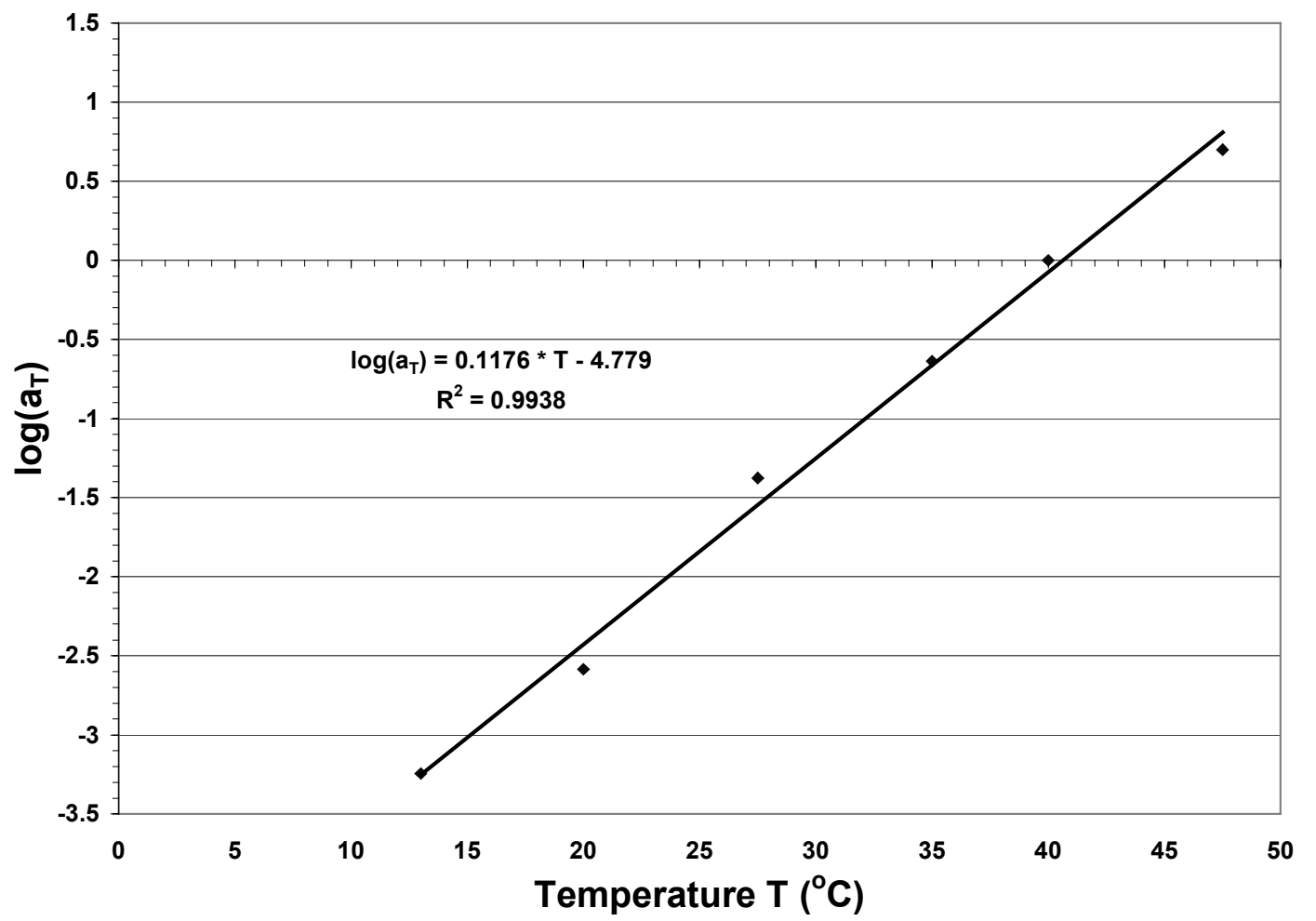

Figure 5.12. Linear fit for shift factor $\left(a_{T}\right)$ Vs Temperature (Material $\left.C\right)$ 


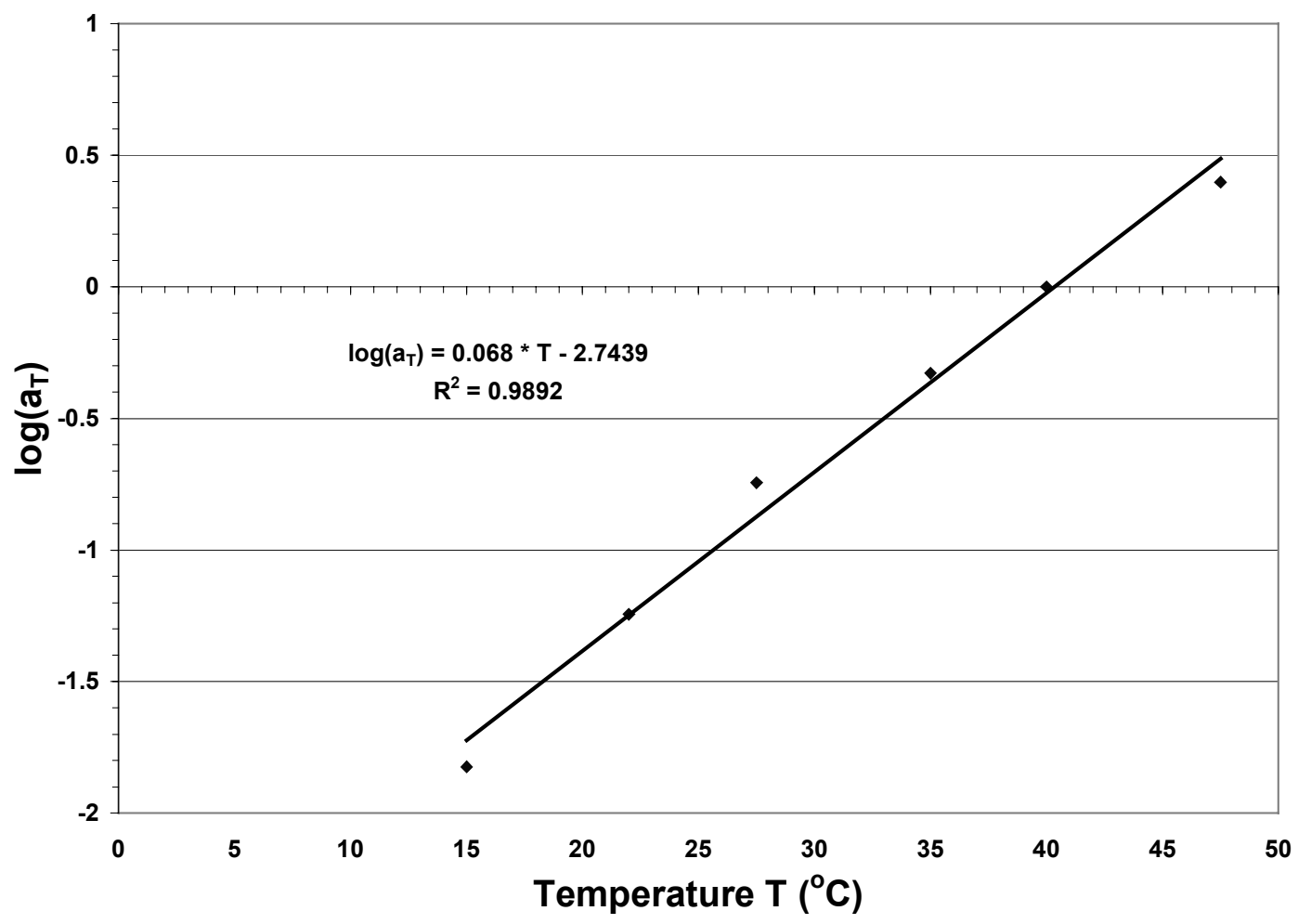

Figure 5.13. Linear fit for shift factor $\left(\mathrm{a}_{T}\right)$ Vs Temperature (Material $\left.D\right)$

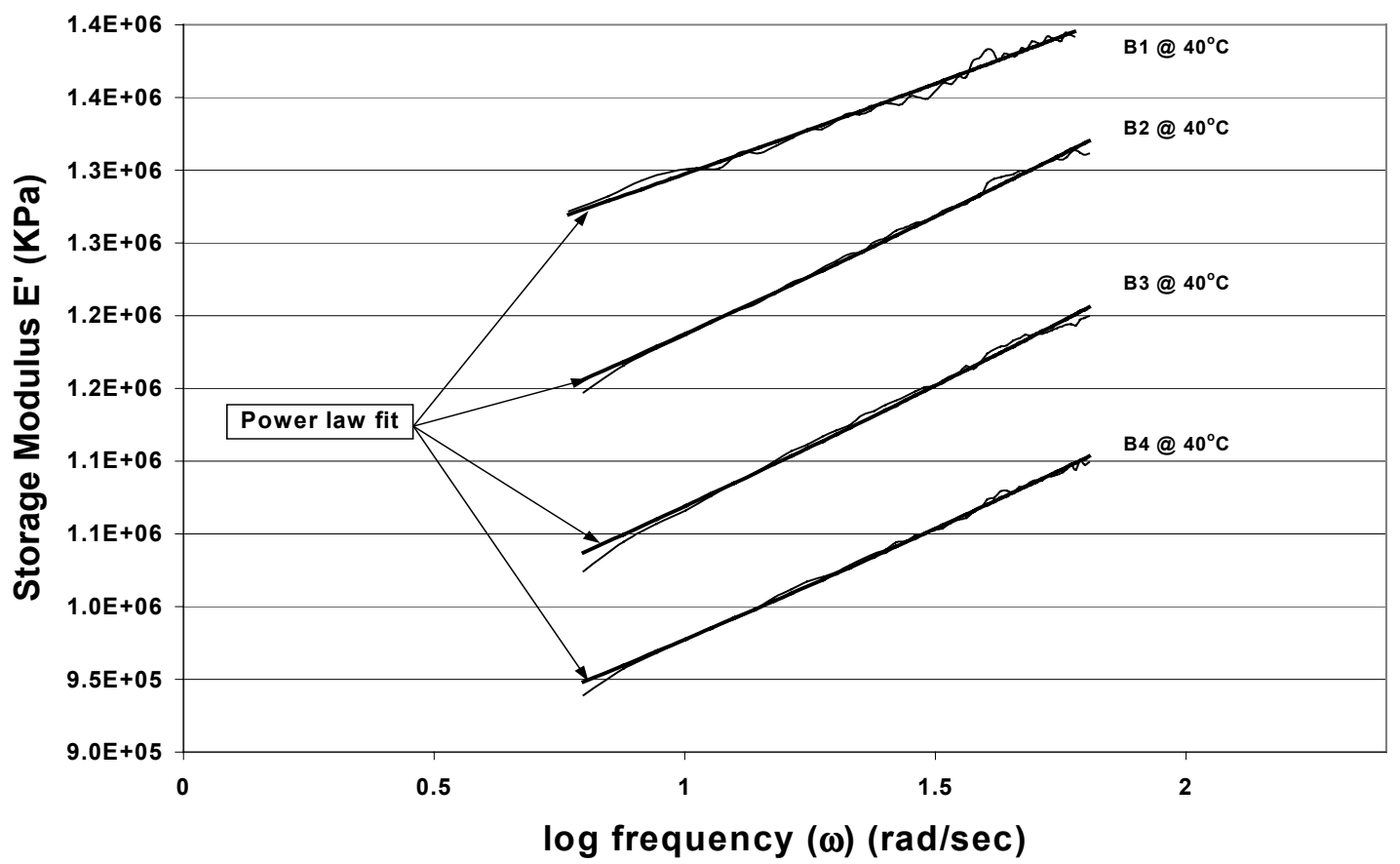

Figure 5.14. Fit for the un-shifted momentary curve at $40^{\circ} \mathrm{C}$ (Material B) 


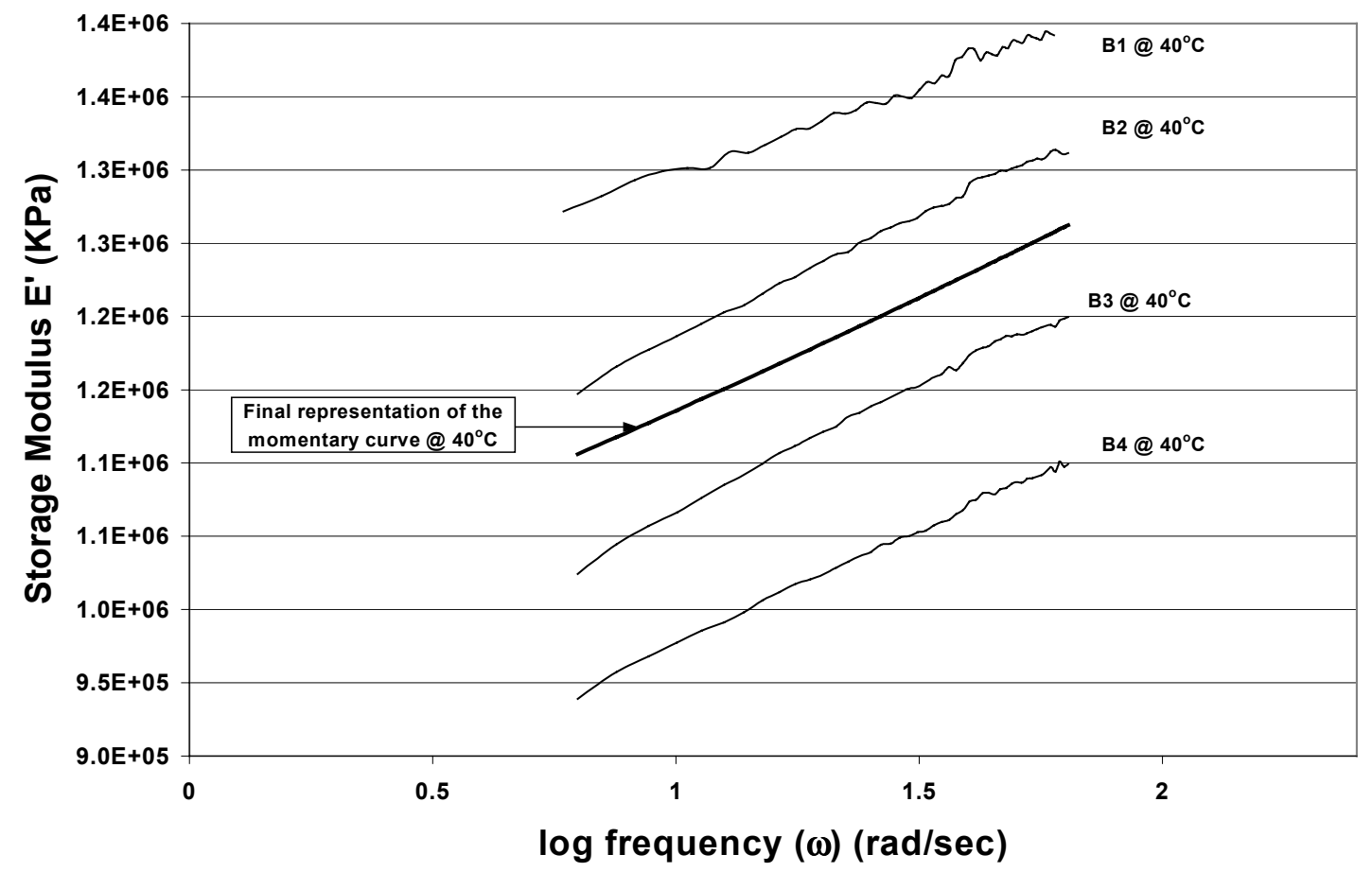

Figure 5.15. Final representation of the shifted momentary curves at $40^{\circ} \mathrm{C}$ (Material B)

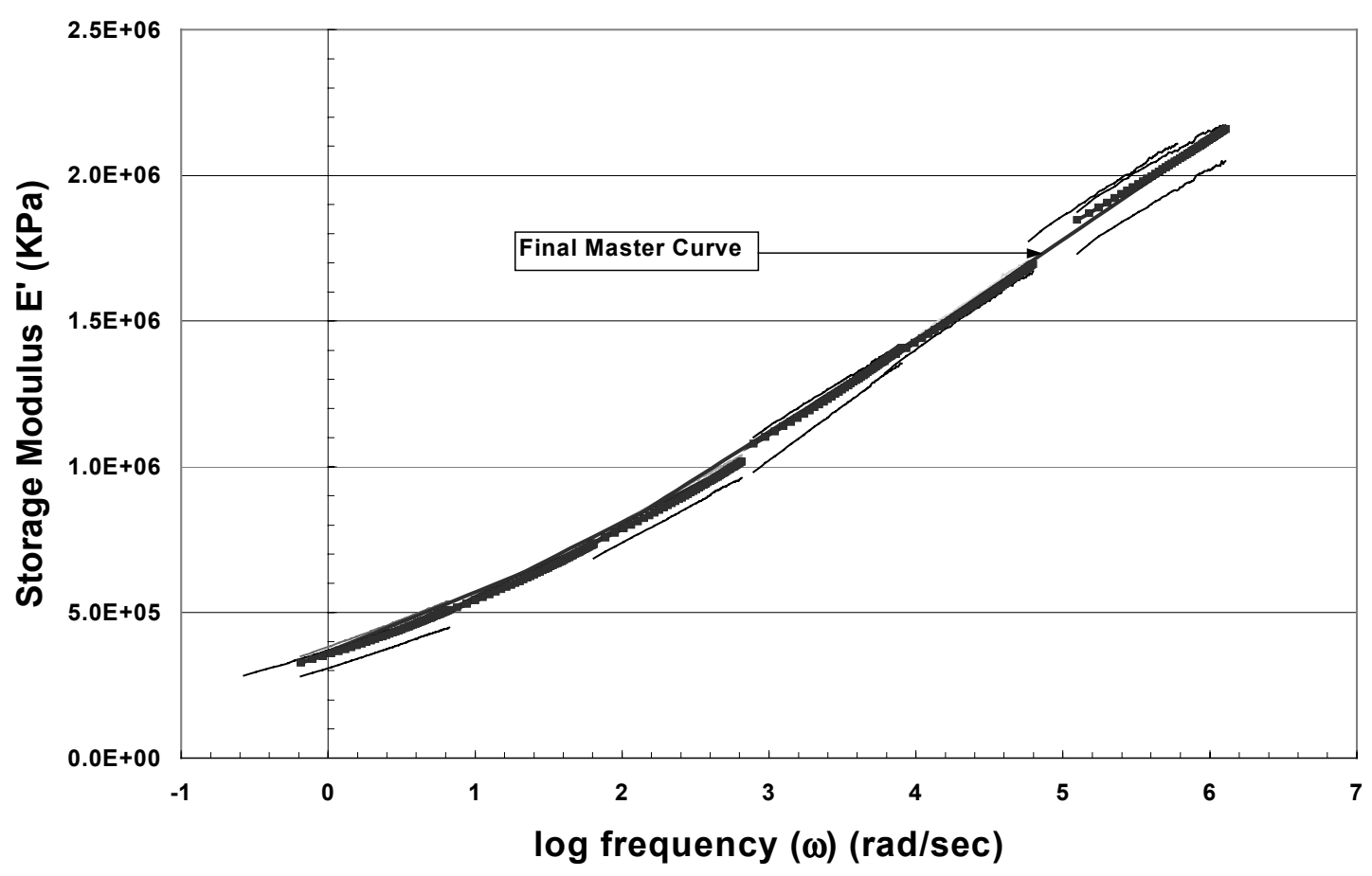

Figure 5.16. Final master curve at $40^{\circ} \mathrm{C}$ (Material A) 


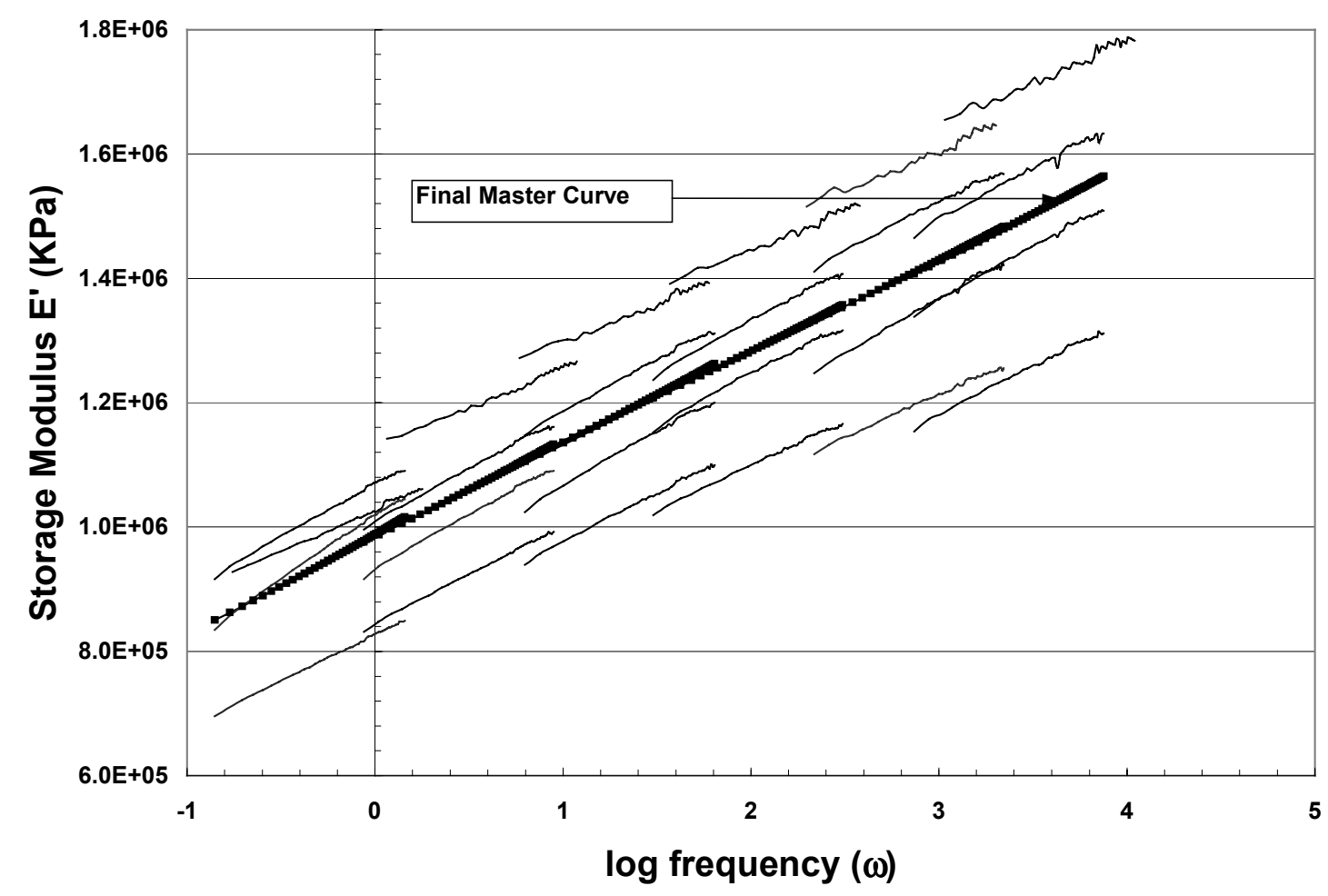

Figure 5.17. Final master curve at $40^{\circ} \mathrm{C}$ (Material B)

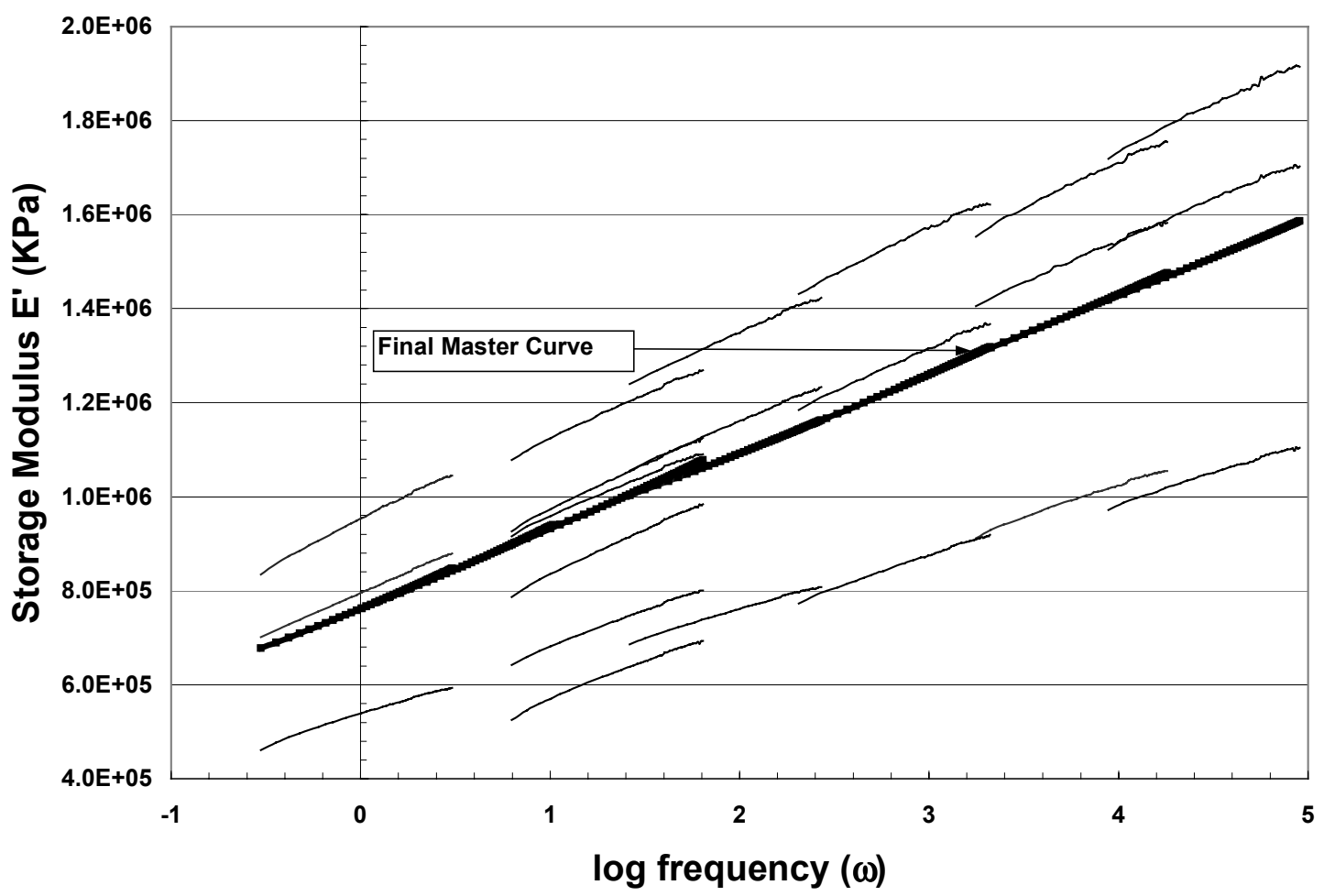

Figure 5.18. Final master curve at $40^{\circ} \mathrm{C}$ (Material C) 


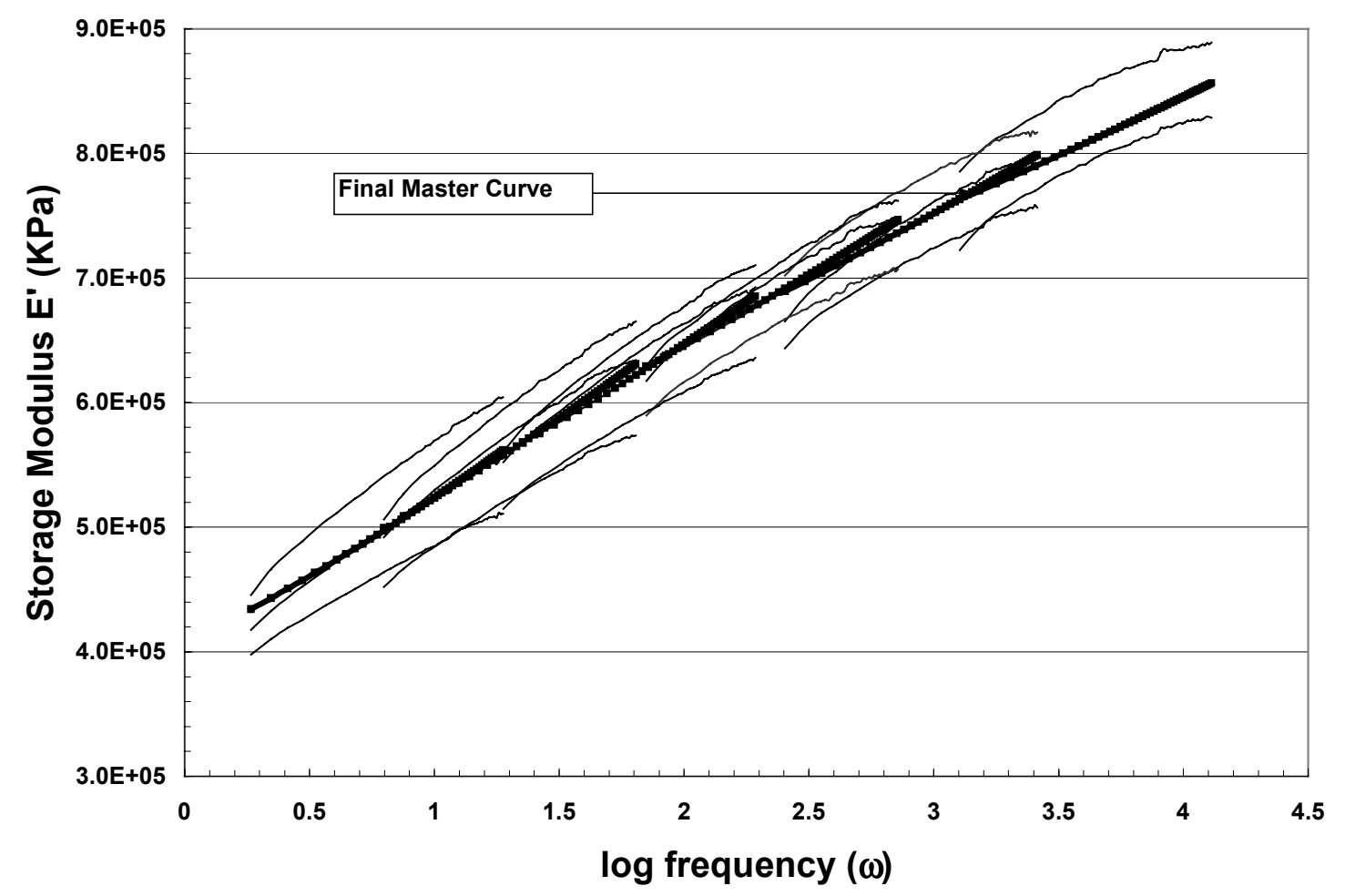

Figure 5.19. Final master curve at $40^{\circ} \mathrm{C}$ (Material D)

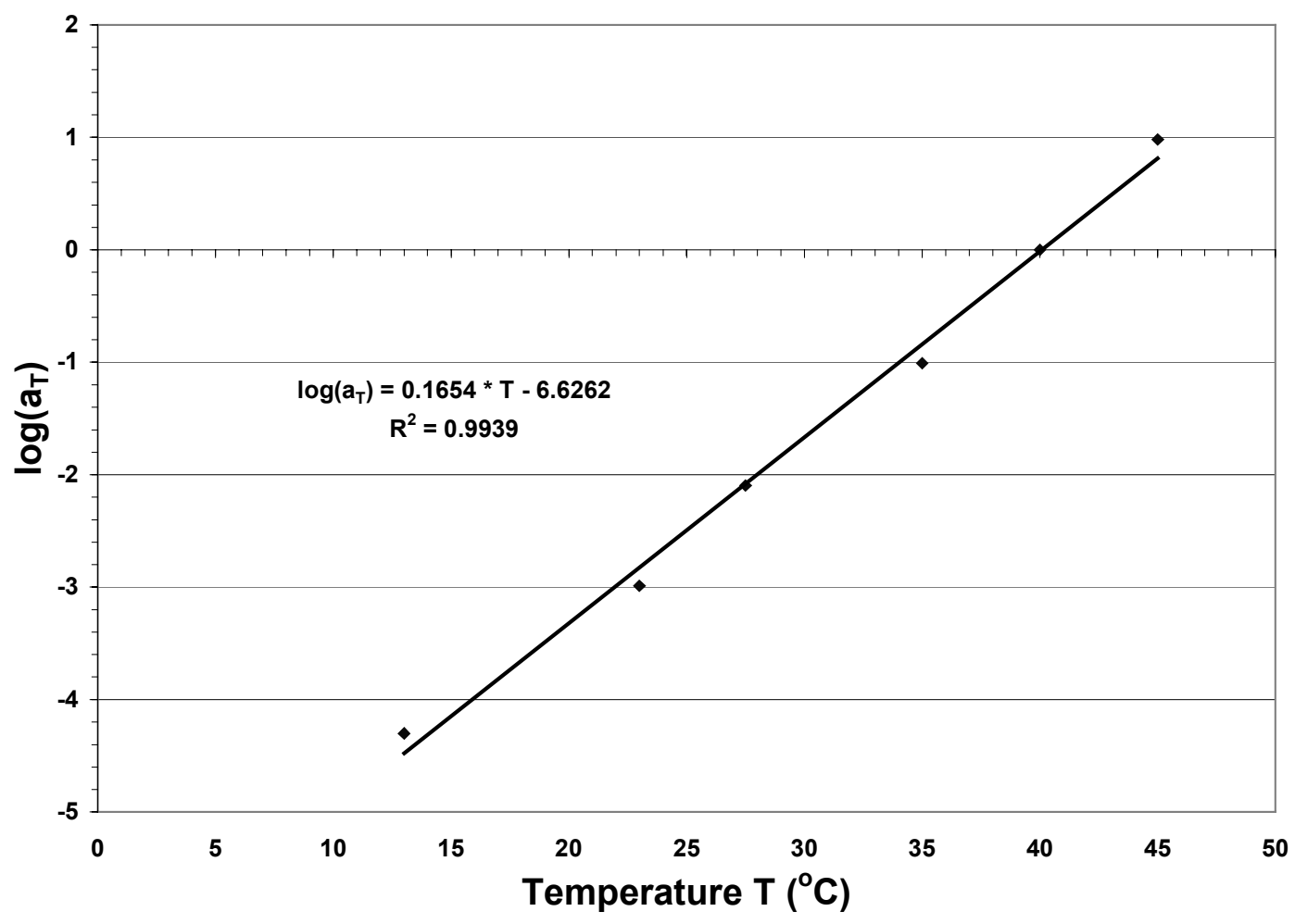

Figure 5.20. Average Shift Factor plot for Material A 


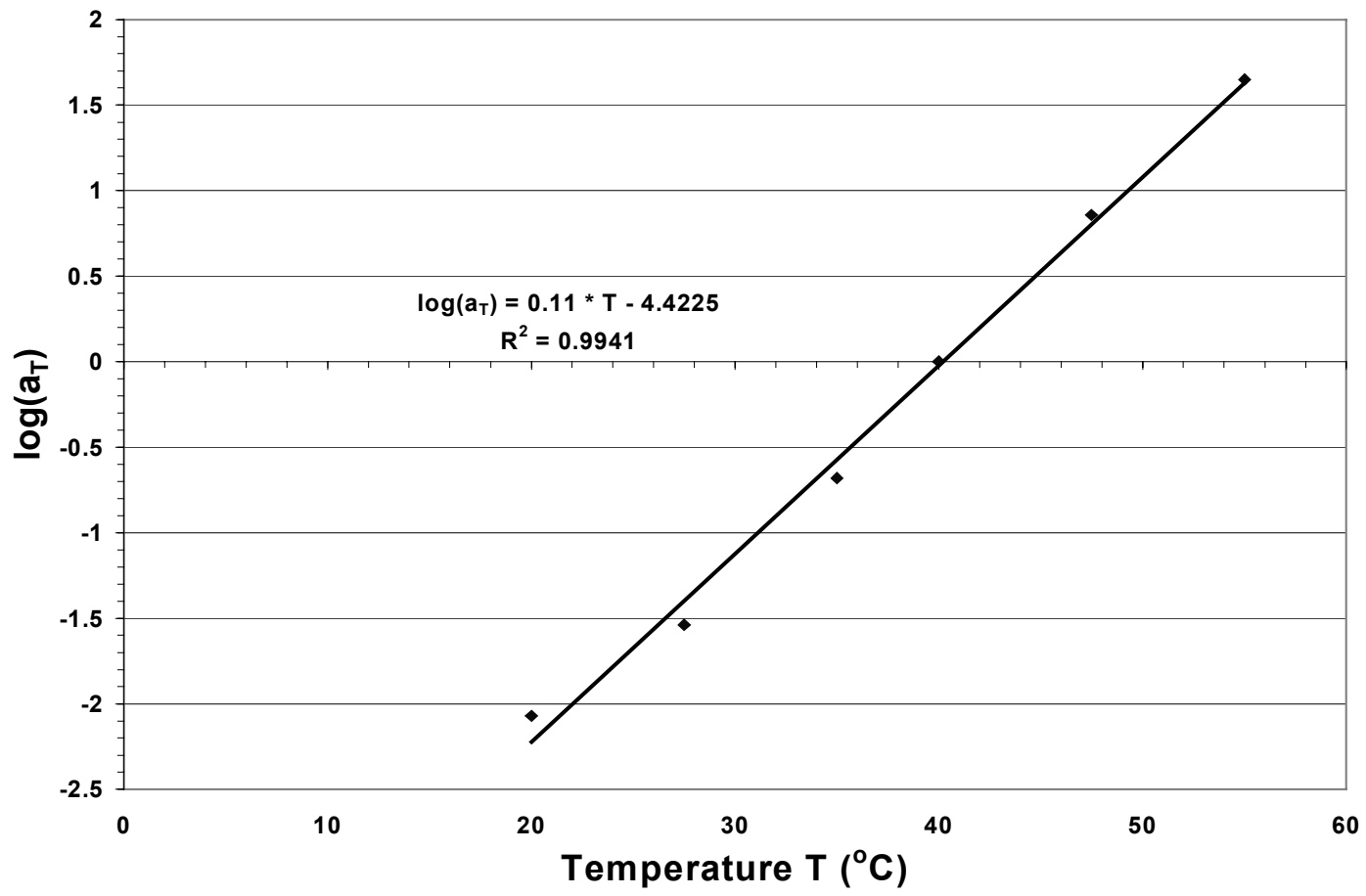

Figure 5.21. Average Shift Factor plot for Material B

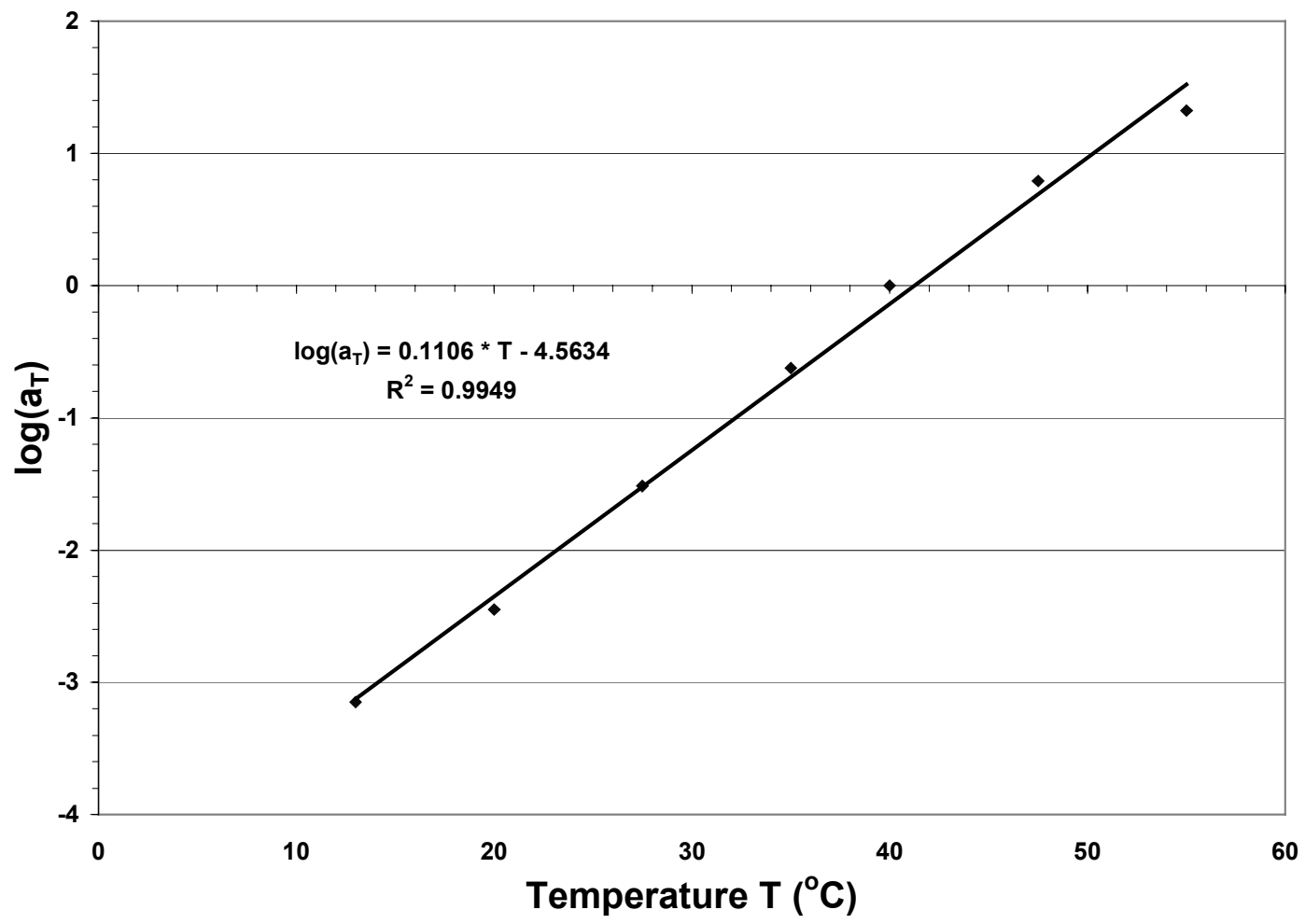

Figure 5.22. Average Shift Factor plot for Material C 


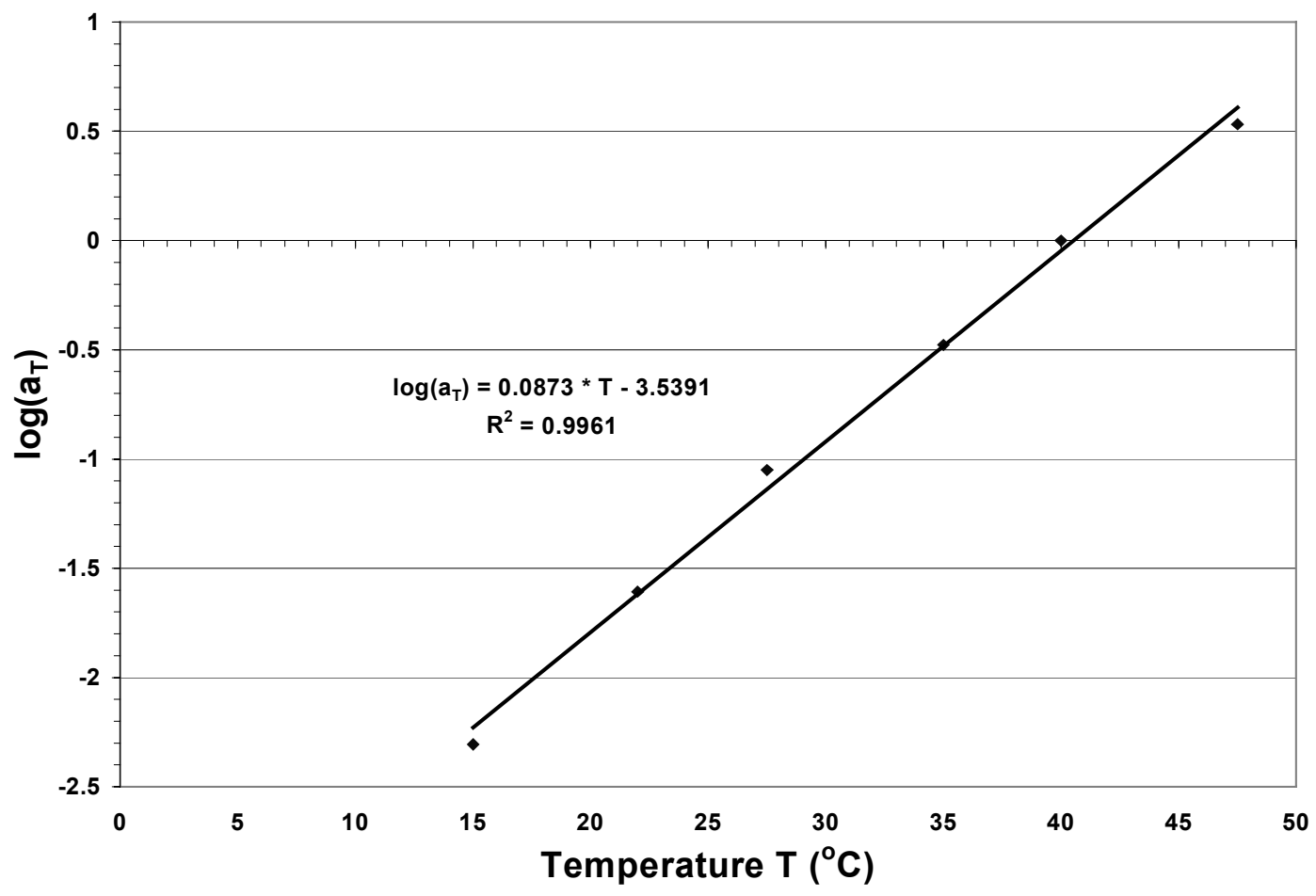

Figure 5.23. Average Shift Factor plot for Material D

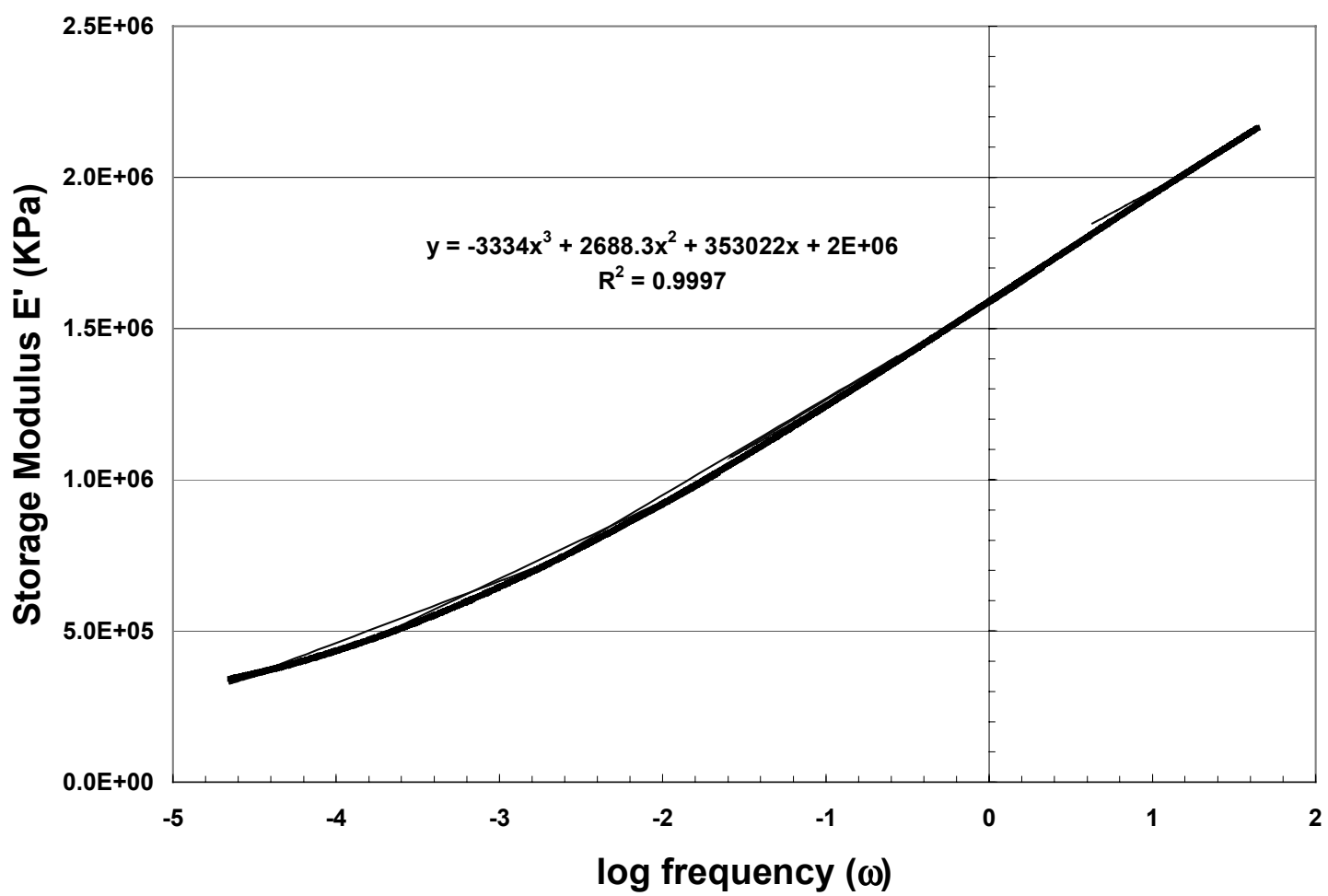

Figure 5.24. Polynomial Fit for the Master Curve at $13^{\circ} \mathrm{C}$ (Material A) 


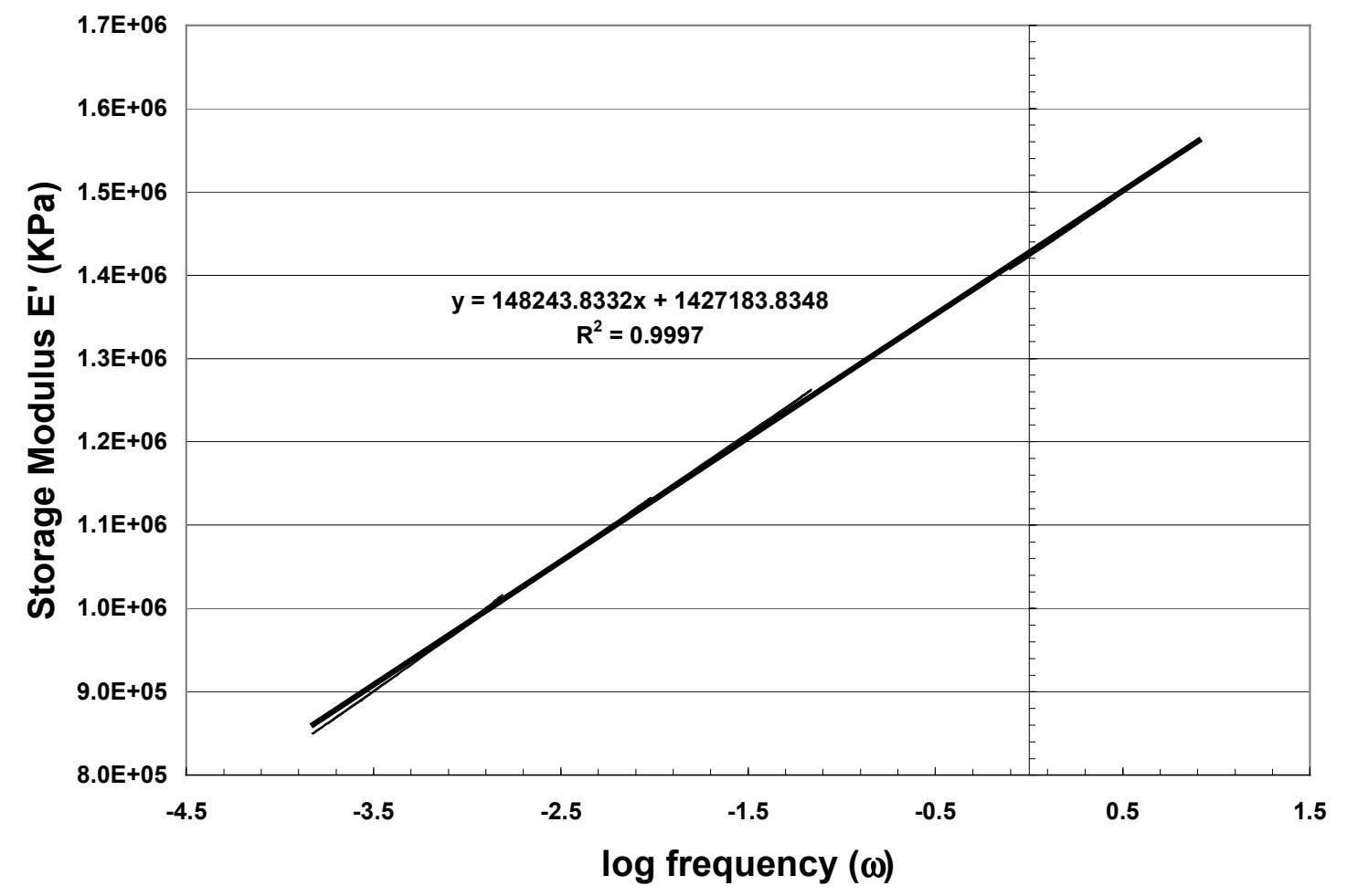

Figure 5.25. Linear Fit for the Master Curve at $13^{\circ} \mathrm{C}$ (Material B)

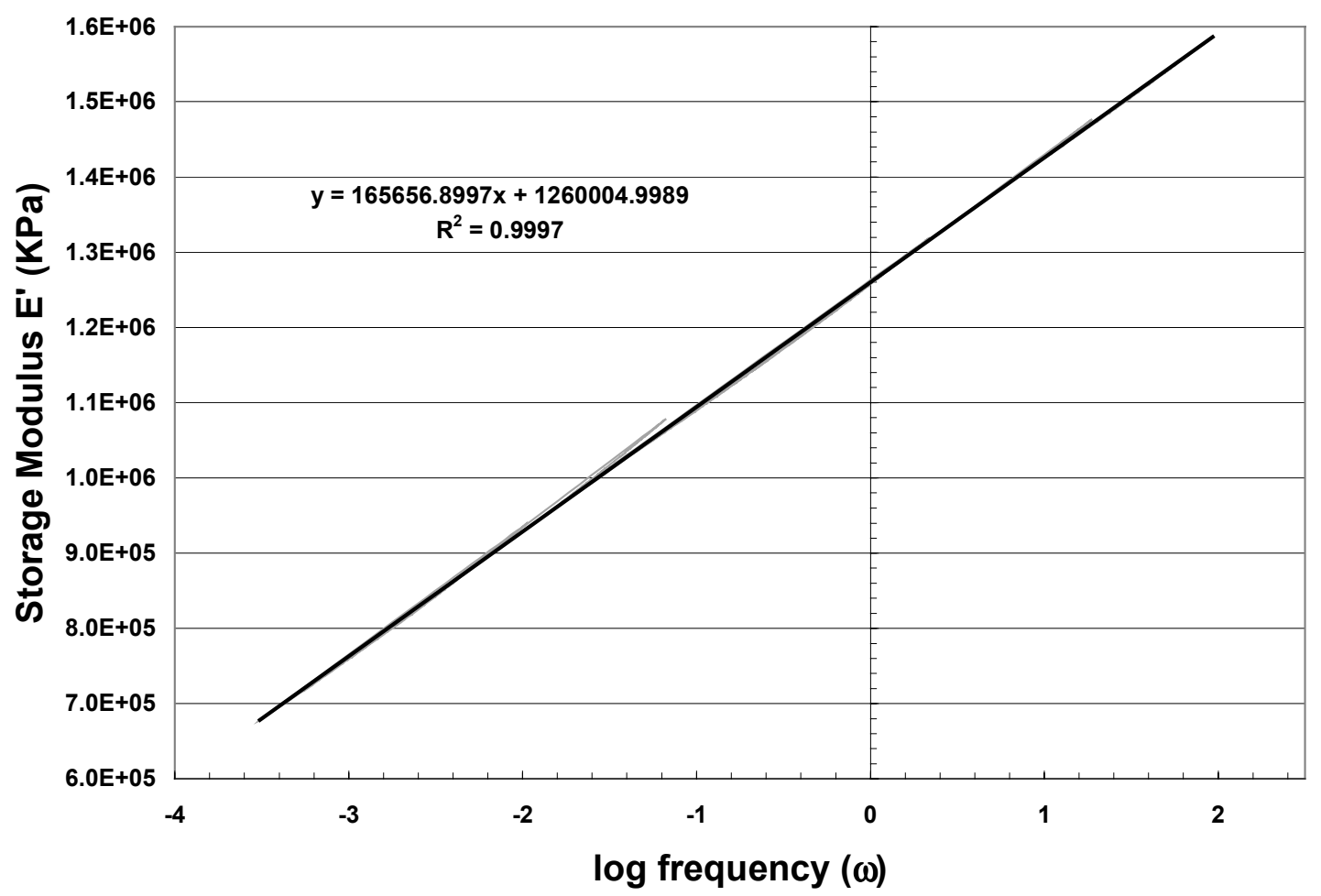

Figure 5.26. Linear Fit for the Master Curve at $13^{\circ} \mathrm{C}$ (Material C) 


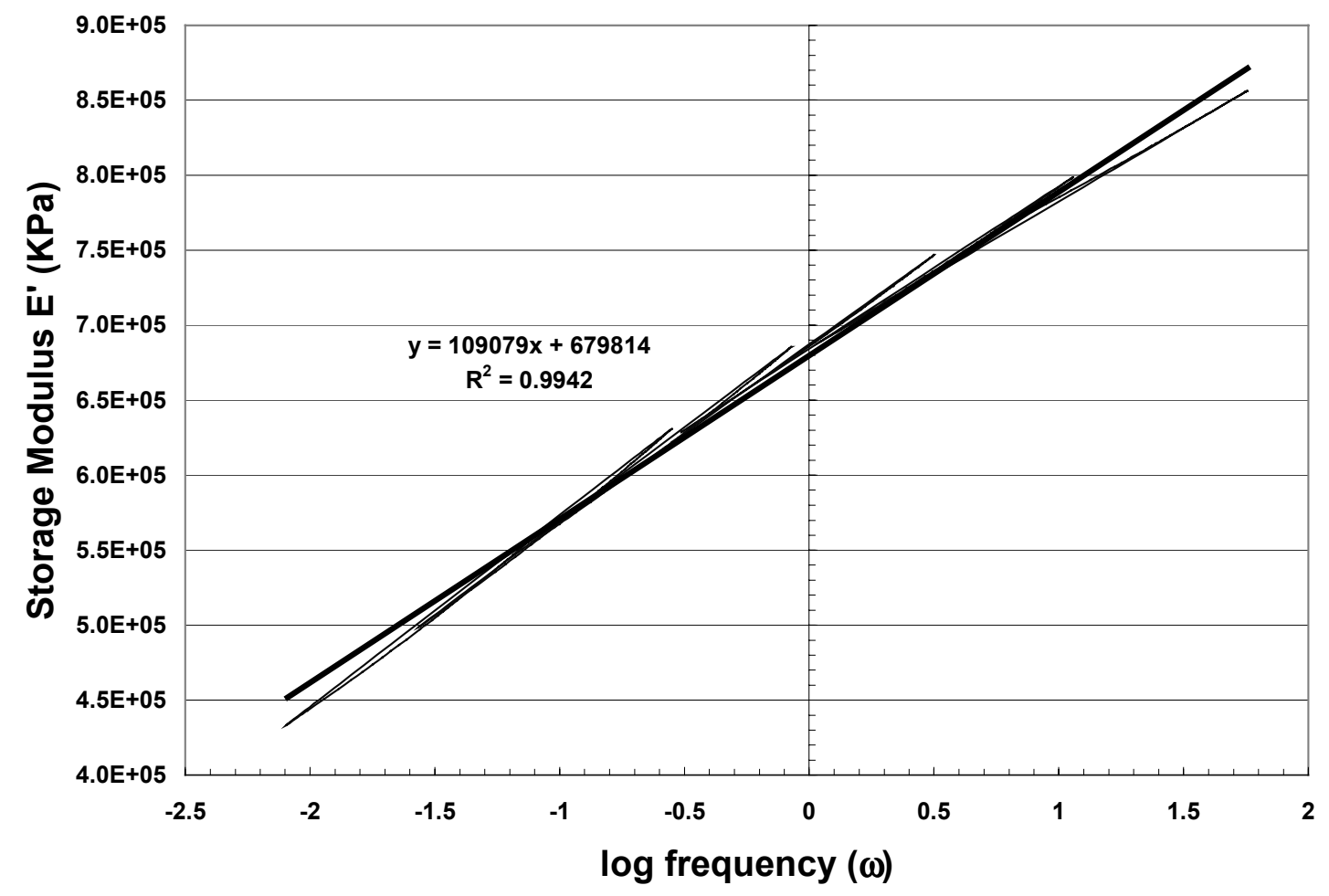

Figure 5.27. Linear Fit for the Master Curve at $13^{\circ} \mathrm{C}$ (Material D)

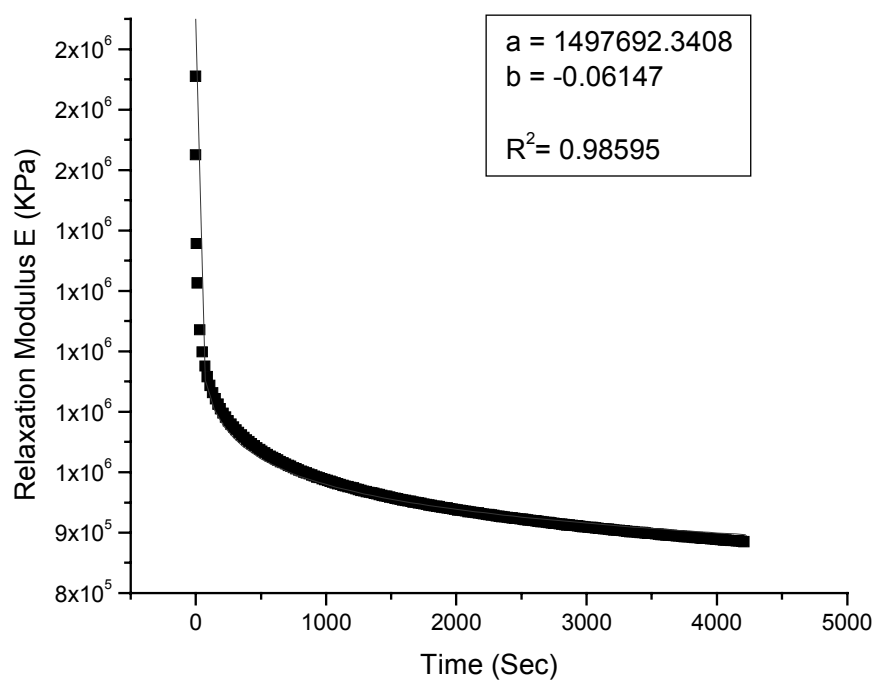

Figure 5.28. Power law fit for Relaxation modulus of Material B 


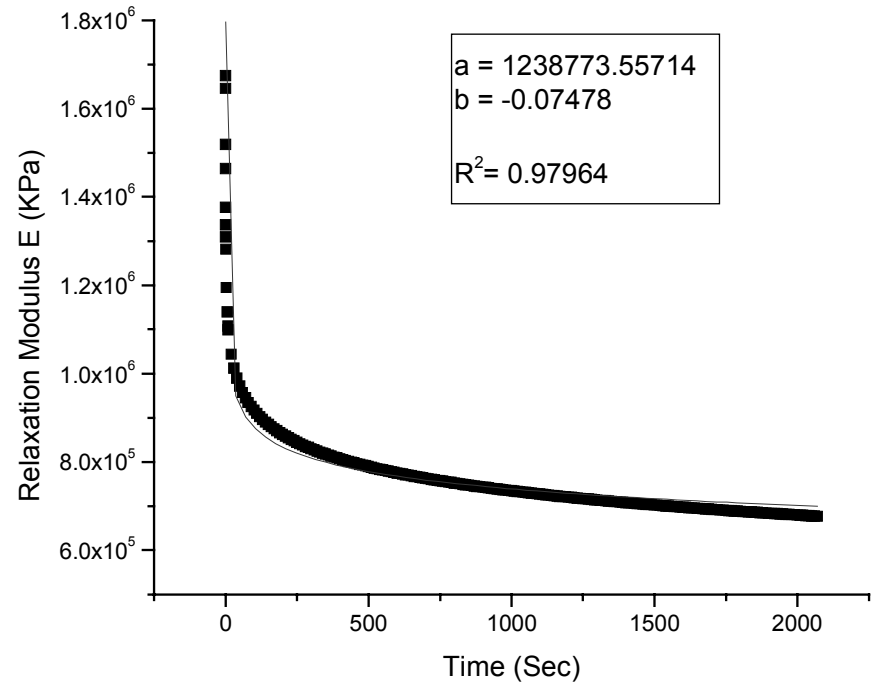

Figure 5.29. Power law fit for Relaxation modulus of Material C

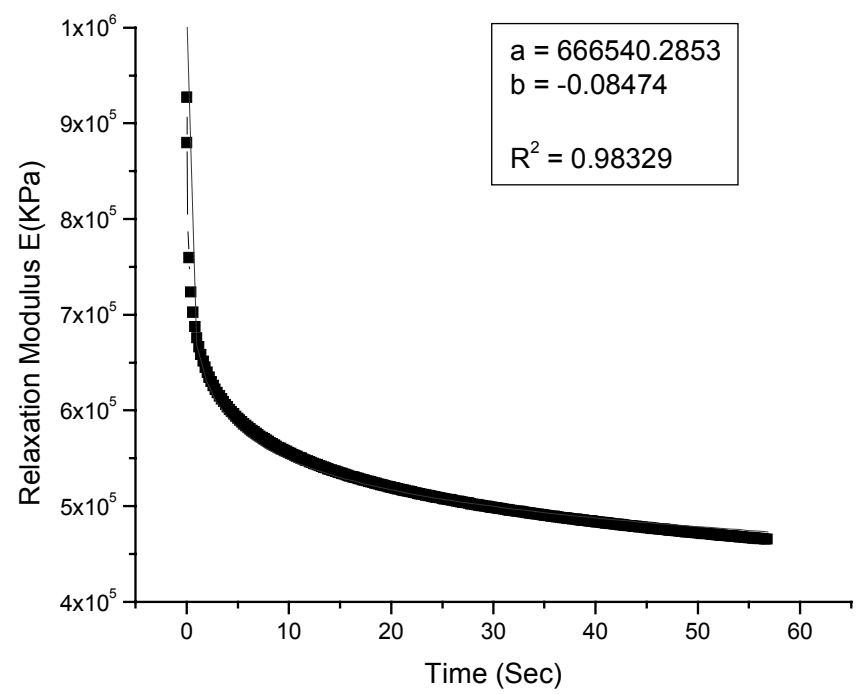

Figure 5.30. Power law fit for Relaxation modulus of Material D 


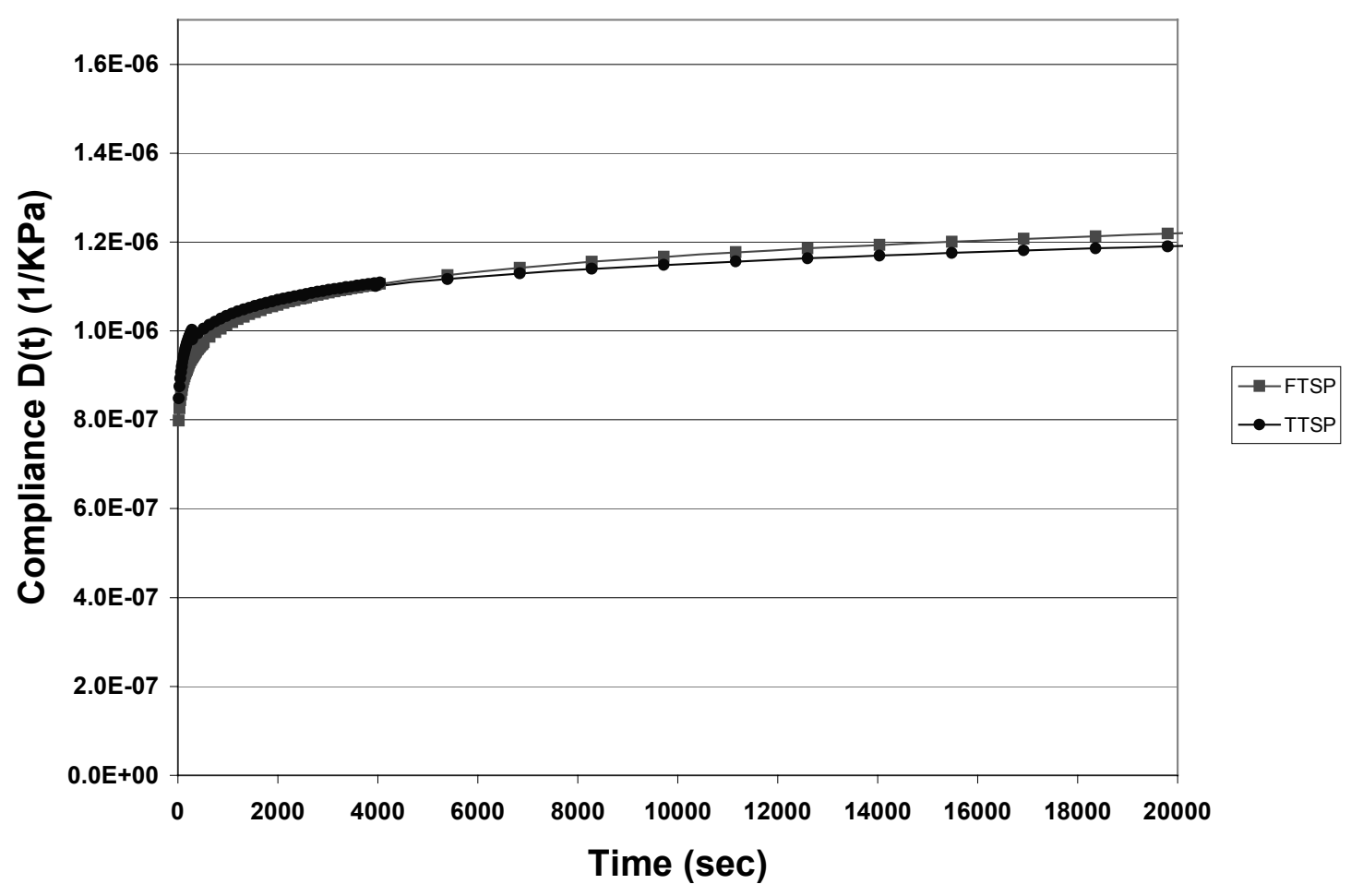

Figure 5.31. Comparison of master curves from TTSP and FTSP at $13^{\circ} \mathrm{C}$ (Material B)

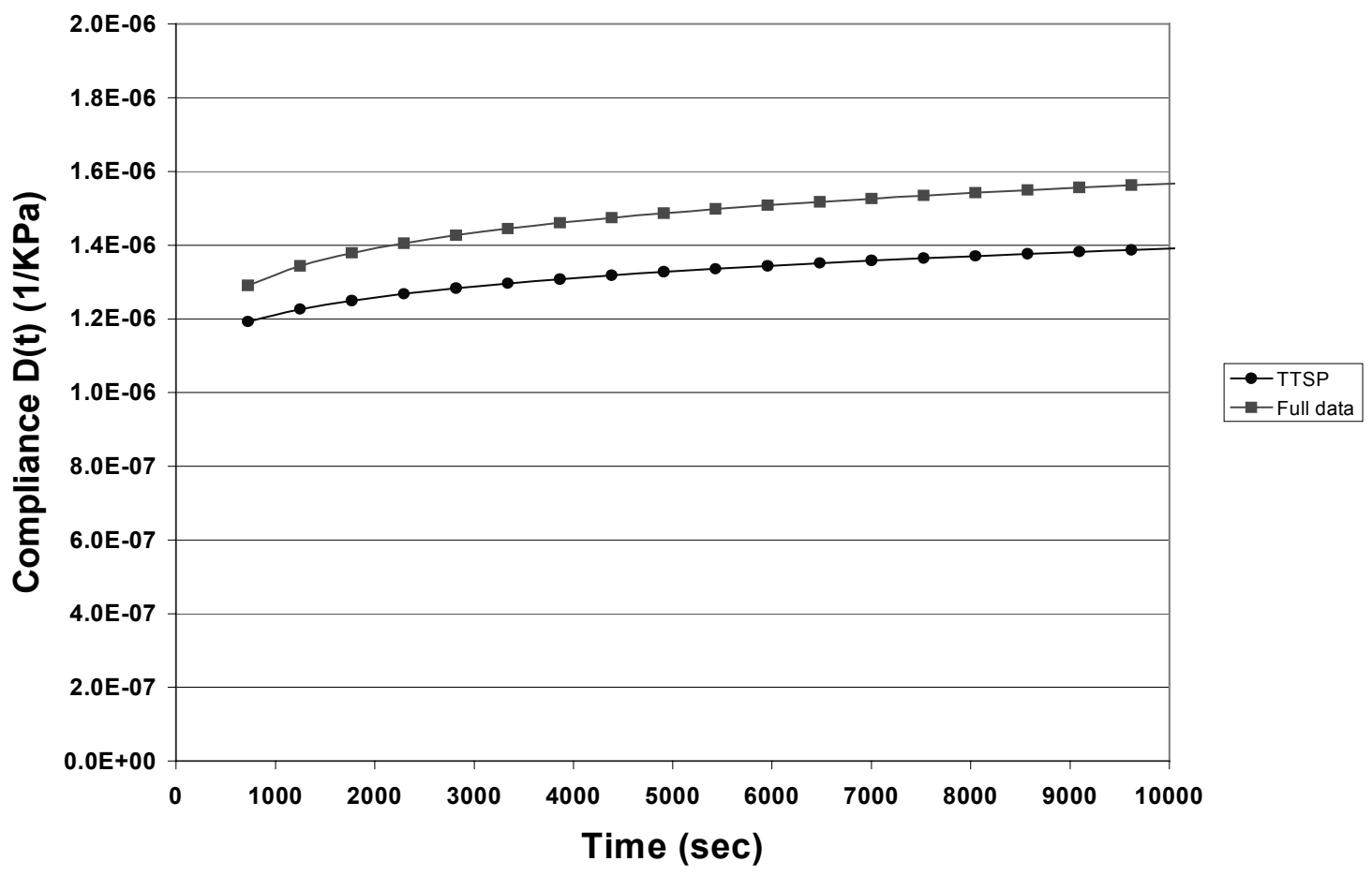

Figure 5.32. Comparison of master curves from TTSP and FTSP at $13^{\circ} \mathrm{C}$ (Material C) 


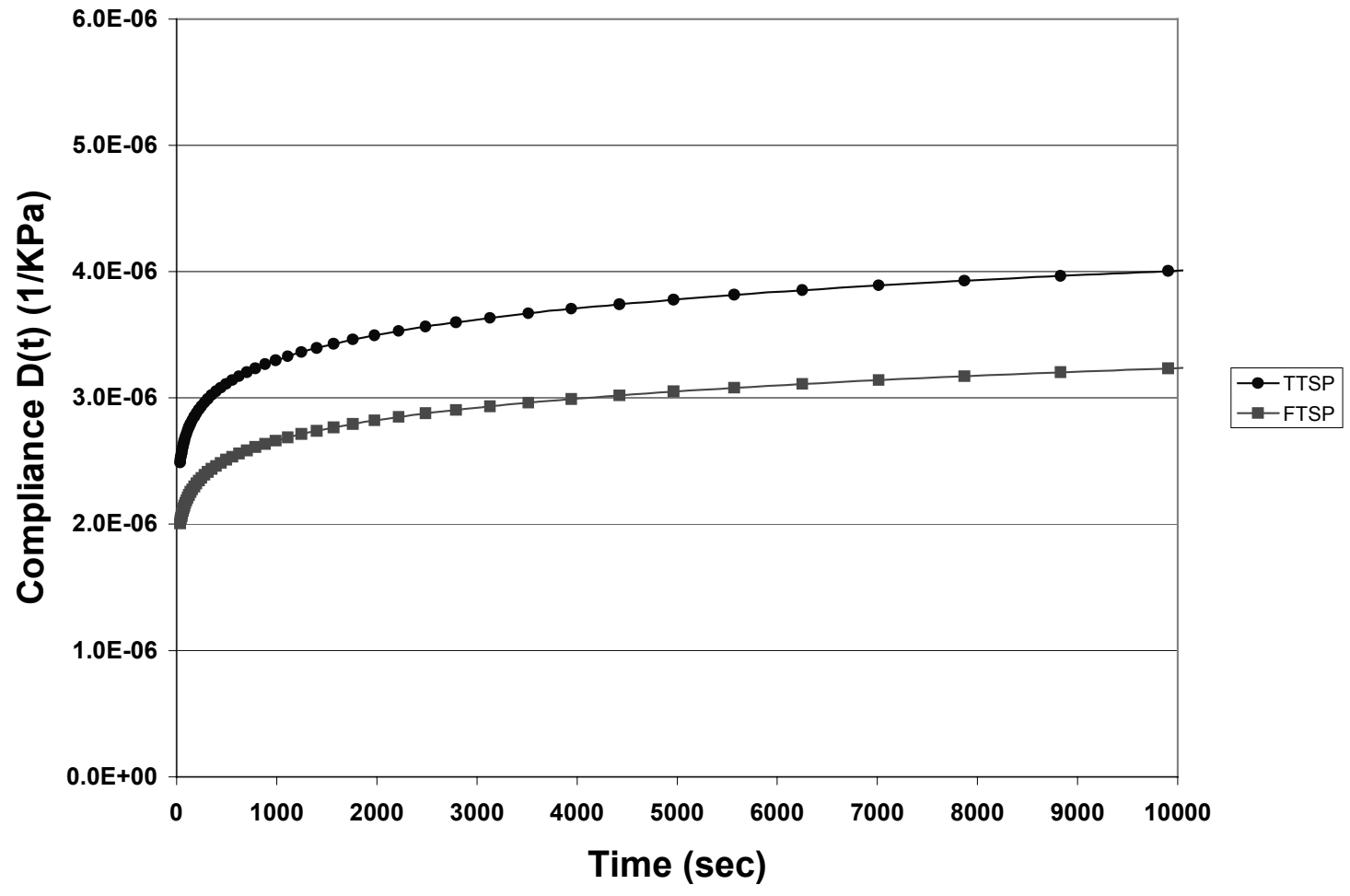

Figure 5.33. Comparison of master curves from TTSP and FTSP at $13^{\circ} \mathrm{C}$ (Material D)
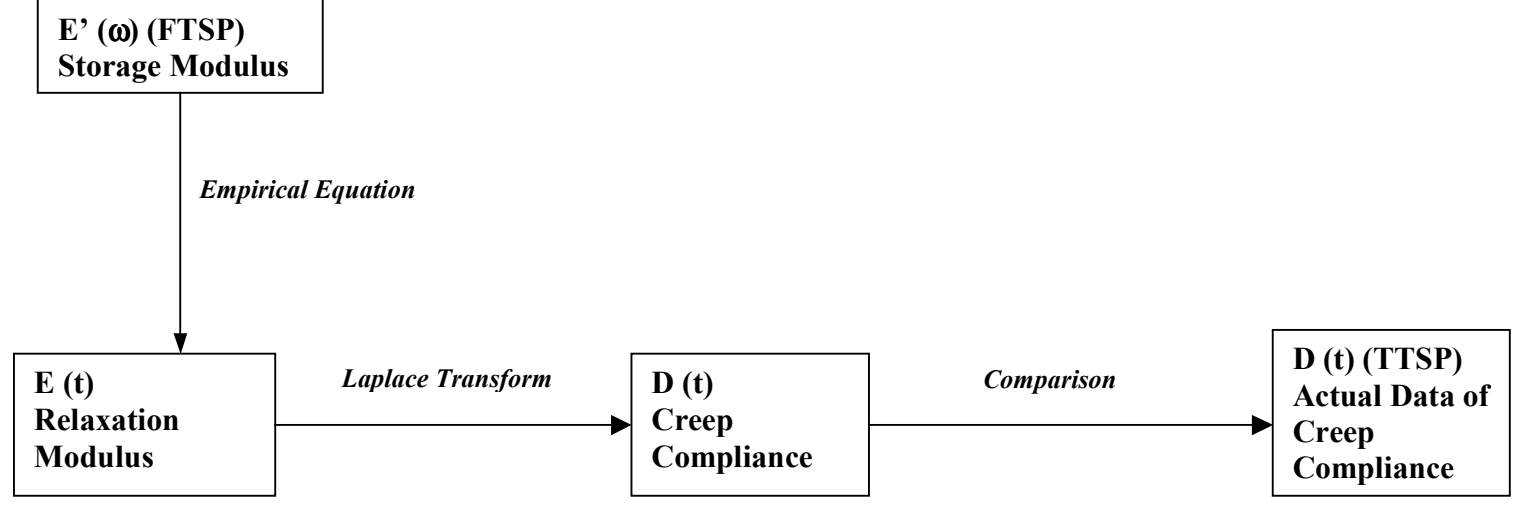

Figure 5.34. Steps in the transformation 


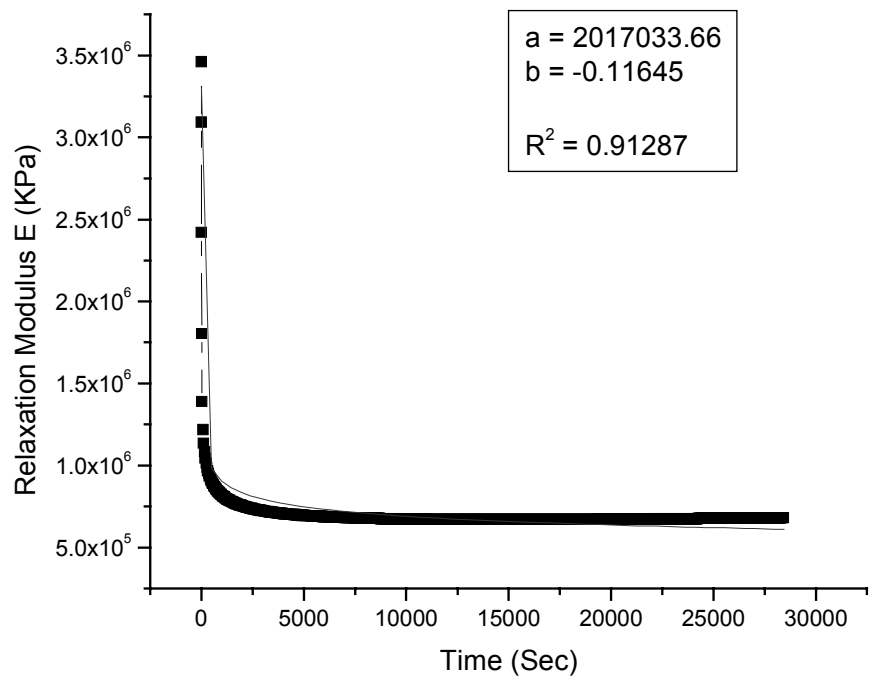

Figure 5.35. Comparison of master curves from TTSP and FTSP at $13^{\circ} \mathrm{C}$ (Material A)

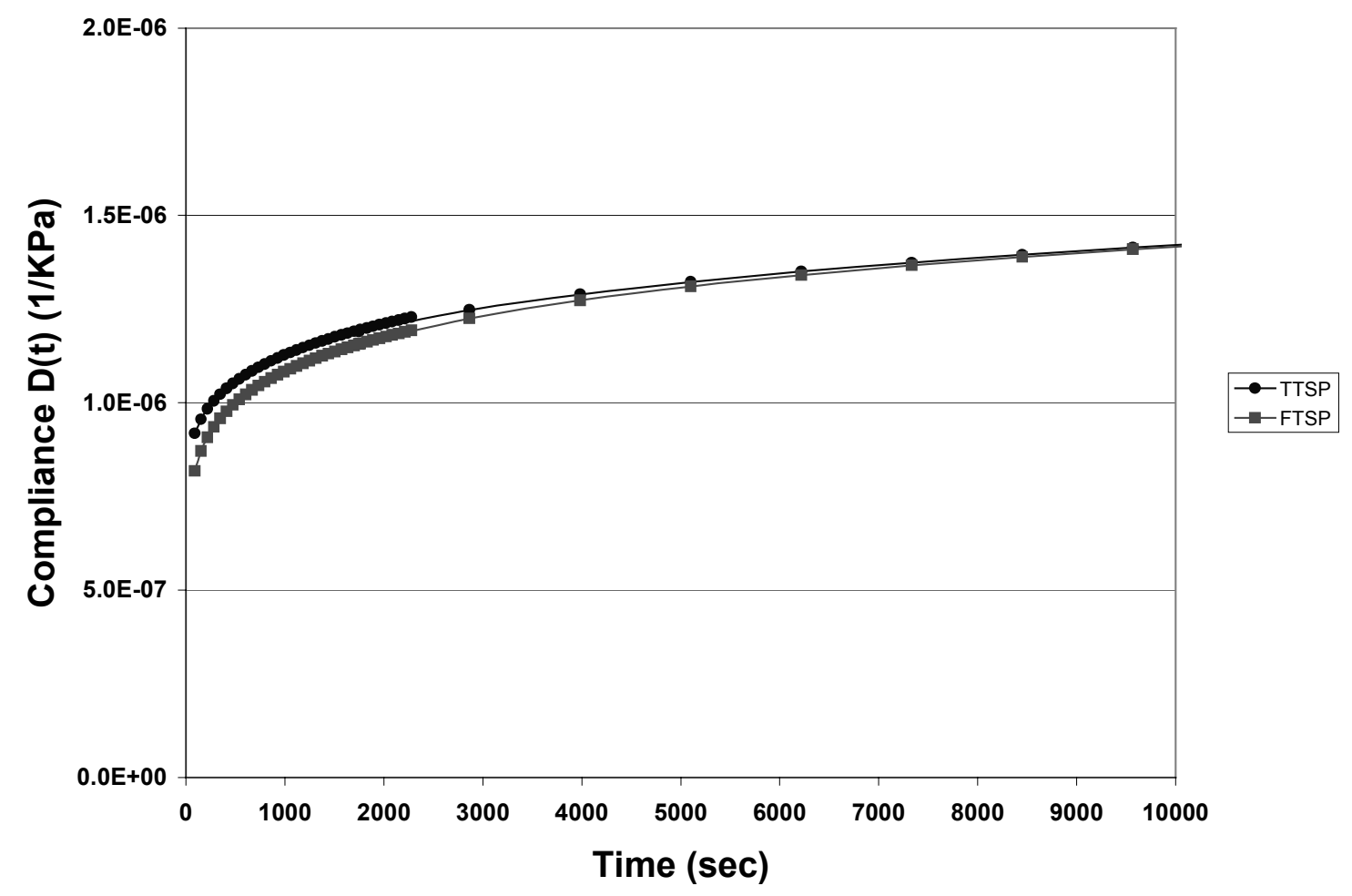

Figure 5.36. Variation of Poisson's ratio with frequency for material A 


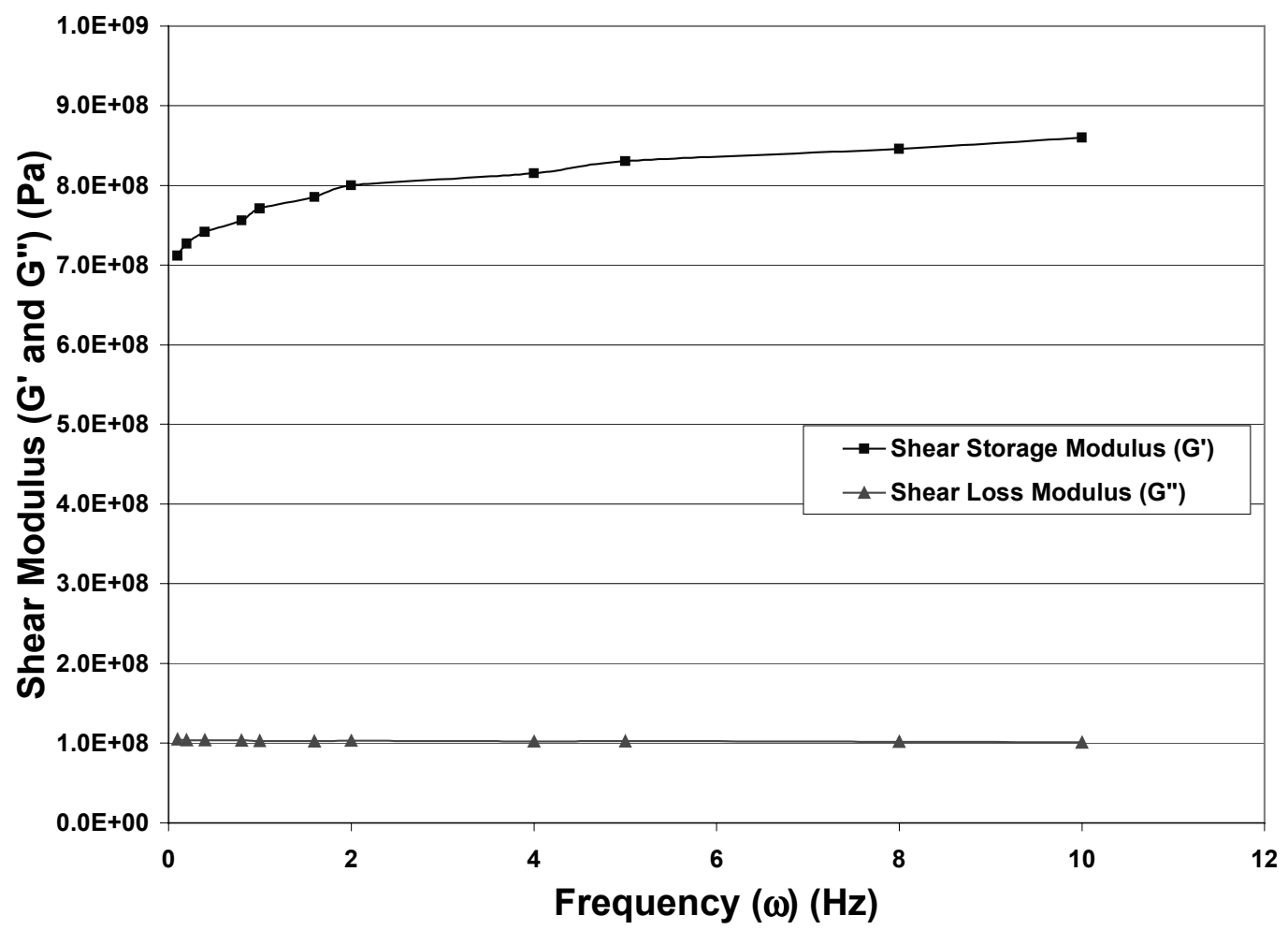

Figure 5.37. Shear Loss and Storage modulus for material A

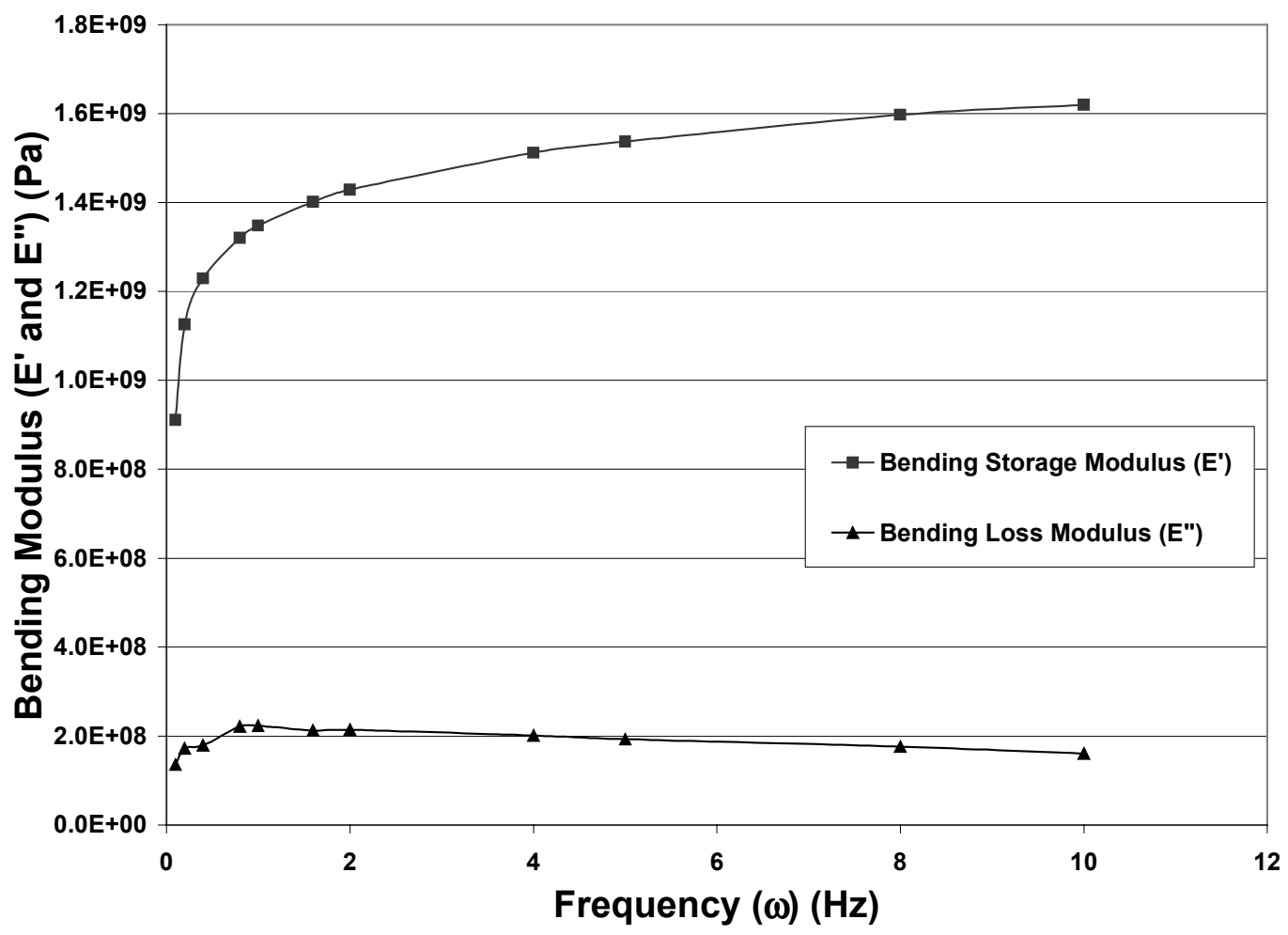

Figure 5.38. Bending Loss and Storage modulus for material A 


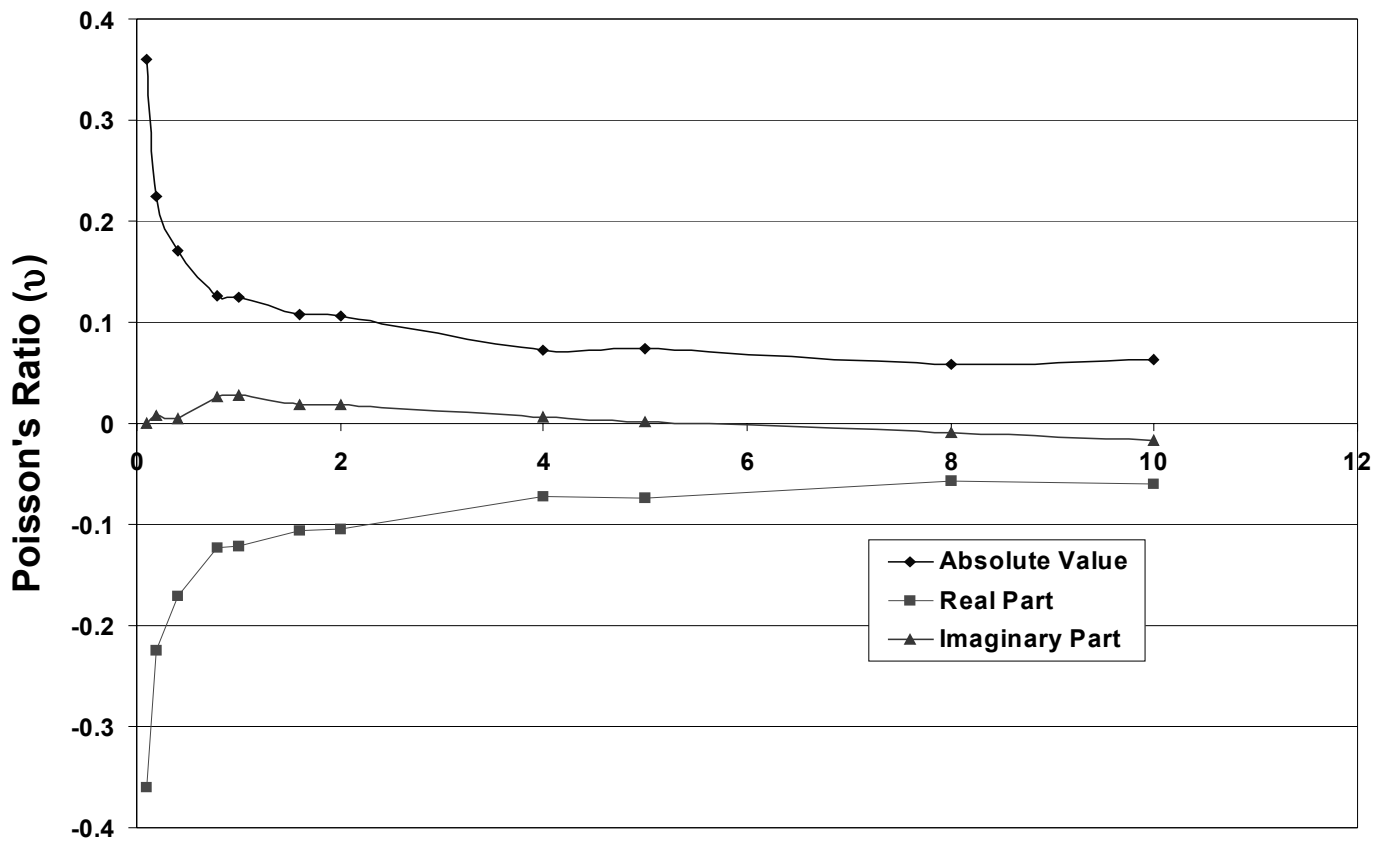

Frequency $(\mathrm{Hz})$

Figure 5.39. Variation of Poisson's ratio with frequency for material A 


\section{Chapter 6 SUMMARY AND RECOMMENDATIONS}

\subsection{SUMMARY}

This study was aimed at developing a short-term test method that could predict the time-dependent creep behavior of commercial polymers used as liners for sewer pipes. The results were supported by results of Static Bending Tests (SBT). The materials were tested using both, static force and dynamic force.

Time Temperature Superposition Principle (TTSP) was used along with Effective Time Theory (ETT) to predict the long-term creep of the liner samples. The prediction by ETT matched the results obtained by testing full-size specimens for all samples except sample C. The TTSP of sample $\mathrm{C}$ matched the results obtained by testing full-size liners. Thus the master curve obtained from TTSP for sample $\mathrm{C}$ was enough to predict the timedependent creep behavior of the polymer. This was due to the full-size testing conditions of material $\mathrm{C}$ which may have yielded during testing.

Dynamic tests using the Dynamic Mechanical Analyzer (DMA) were done. The results were in the frequency domain and hence were transformed into the time domain. The compliance in time domain was then compared to the compliance obtained directly through static tests, i.e., the master curve obtained by using TTSP. Material E cannot be tested in dynamic mode. This is due to cracking damage under dynamic load. Thus an FTSP could not be obtained for material E. A good comparison between FTSP and TTSP in the time domain was found for all materials with a linear storage modulus E' vs log frequency plot. 


\subsection{CONTRIBUTION}

This thesis dealt with developing a standard protocol to obtain the TTSP and FTSP. Details of the testing method, i.e., the annealing, air quenching, conditioning, mechanical conditioning, were done in various ways and ultimately the shortest and easiest method was chosen to do the test. The frequency range for the FTSP was also determined by doing several tests and then choosing the best range.

A new method to average the master curves to form a single master curve, as a representation for the material, was developed.

An empirical equation was proposed in order to transform the storage modulus in the frequency domain to the time domain. A novel comparison between frequencydomain and time-domain data was presented.

\subsection{RECOMMENDATIONS}

Though the results of this study matched the results obtained by testing full-size samples [12] and also the results of SBT [13], there are some areas that could further improve the results.

1. The specimens need to be cut more accurately using finer cutter or other cutting method.

2. Though the polymer samples did not show any change due to moisture, it is recommended to test for moisture along with chemicals found commonly in sewer liner pipes.

3. A better study on the transformation of the data from frequency domain to time domain and vise versa is needed. 


\section{REFERENCES}

1. Struik L. C. E. (1978), Physical Aging In The Amorphous Polymers And Other Materials, Elseveier, Delft, The Netherlands.

2. Beckmann J., McKenna G. B., Landes B. G., Bank D. H. and Bubeck R. A. (1997), "Physical Aging Kinetics Of Syndiotatic Polystyrene As Determined From Creep Behavior", Polymer Engineering and Science, v 37, n 9, p 14591468.

3. Wang J. Z., Parvatareddy H., Chang T., Iyengar N., Dillard D. A. and Reifsnider K. L. (1995), "Physical Aging Behavior Of High-Performance Composites", Composites Science and Technology, v 54, n 4, p 405-415.

4. Dean G. D., Read B. E. and Tomlins P. E. (1990), “ A Model For Long- Term Creep and the effects of Physical Aging In Poly ( butylene terephthalate), Plastics and Rubber Processing and Applications, v13, n1, p37-46.

5. McCrum N. G. (1991), “The Interpretation Of Physical Aging In Creep and DMTA from Sequential Aging Theory", Plastics, Rubber and Composite Processing and Applications, v18, n3, p181-191.

6. Janas V. F. and McCullough R. L. (1987), “ The Effects of Physical Aging on the Viscoelastic Behavior of a Thermoset Polyester" Composite Science and Technology, v 50, p 99-118. 
7. Progelhof R. C and Throne J. L (1993), "Polymer Engineering Principles", Hanser Publishers, Cincinnati.

8. Sullivan J. L. (1990), "Creep and Physical Aging of Composites", Composites Science and Technology, v 39, p 207-232.

9. Bradshaw R. D., Brinson L. C. (1997), "Physical Aging In polymers and Polymer Composites: An Analysis and method for Time-Aging Time Superposition", Polymer Engineering and Science, v 119, n 3, p 233-241.

10. Bradshaw R. D., Brinson L. C. (1999), "Mechanical Response of Linear Viscoelastic Composite Laminates Incorporating Nonisothermal Physical Aging Effects", Composites Science and Technology, v 59, n 9, p 1411-1427.

11. Bradshaw R. D., Brinson L. C. (1999), "Continuous Test Data Method to Determine a reference Curve and Shift Rate for Isothermal Physical Aging", Polymer Engineering and Science, v 39, n 2, p 211-235.

12. Barbero, E. J. and Rangarajan, S. (2002), "Long term testing of Trenchless Pipe Liners ", ASME-IPC, Calgary, Alberta, Canada.

13. Barbero, E. J. and Ford K. J. (2003), “Accelerated Creep Testing Of Trenchless Liners", ASCE-IPC, Baltimore, MD. 
14. Barbero, E. J., Julius, M., and Yao, Z. (2003), “Time and Frequency Viscoelastic Behavior of Commercial Polymers." CCC-2003, Calabria, Italy.

15. Gupta R. K. (2000), Polymer and Composite Rheology, Second Edition, Marcel Dekker, Inc., New York, NY.

16. Lakes R. S (1998), Viscoelastic Solids, CRC press LLC, Boca Raton, FL.

17. Baumgaertel M. and Winter H. H. (1989), “ Determination of Discrete Relaxation and Retardation time spectra from dynamic mechanical data", Rheologica Acta, $v$ 28, n 6, p 511-519.

18. William N. Findley, James S. Lai and Kasif Onaran (1976), Creep and Relaxation Of Nonlinear Viscoelastic Materials, Dover Publications, Inc., New York. 